\author{
UNIVERSIDADE DE SÃO PAULO \\ FACULDADE DE ZOOTECNIA E ENGENHARIA DE ALIMENTOS
}

RAPHAEL EUCLIDES PRESTES SALEM

Desenvolvimento de $\mathrm{ZrO}_{2} / \mathrm{Al}_{2} \mathrm{O}_{3}$ e $\mathrm{ZrO}_{2} / \mathrm{Al}_{2} \mathrm{O}_{3}-\mathrm{NbC}$ usando sinterização convencional e não convencional 
RAPHAEL EUCLIDES PRESTES SALEM

\title{
Desenvolvimento de $\mathrm{ZrO}_{2} / \mathrm{Al}_{2} \mathrm{O}_{3}$ e $\mathrm{ZrO}_{2} / \mathrm{Al}_{2} \mathrm{O}_{3}-\mathrm{NbC}$ usando sinterização convencional e não convencional
}

\author{
Versão corrigida
}

(Versão original encontra-se na unidade que aloja o Programa de Pós-Graduação)

Tese apresentada à Faculdade de Zootecnia e Engenharia de Alimentos da Universidade de São Paulo como parte dos requisitos para a obtenção do título de Doutor em Engenharia e Ciência de Materiais.

Área de concentração: Desenvolvimento, Caracterização e Aplicação de Materiais Voltados à Agroindústria.

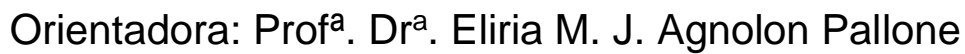

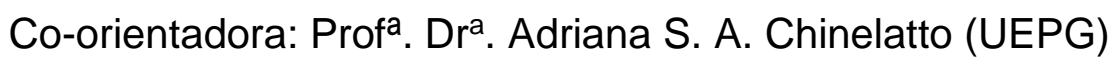


Dados internacionais de Catalogação da Publicação

Serviço de Biblioteca e Informação da Faculdade de Zootecnia e Engenharia de Alimentos da Universidade de São Paulo

Salem, Raphael Euclides Prestes

SS163d Desenvolvimento de $\mathrm{ZrO}_{2} / \mathrm{Al}_{2} \mathrm{O}_{3}$ e $\mathrm{ZrO}_{2} / \mathrm{Al}_{2} \mathrm{O}_{3}-\mathrm{NbC}$

usando sinterização convencional e não convencional

/ Raphael Euclides Prestes Salem ; orientadora

Eliria Maria de Jesus Agnolon Pallone;

coorientadora Adriana Scoton Antonio Chinelatto. -

Pirassununga, 2017.

$159 \mathrm{f}$.

Tese (Doutorado - Programa de Pós-Graduação em Engenharia e Ciência de Materiais) -- Faculdade de Zootecnia e Engenharia de Alimentos, Universidade de São Paulo.

1. zircônia. 2. compósito. 3. sinterização. 4. flash sintering. 5. spark plasma sintering. I.

Maria de Jesus Agnolon Pallone, Eliria, orient. II. Chinelatto, Adriana Scoton Antonio, coorient. III. Título.

"Permitida a cópia total ou parcial deste documento, desde que citada a fonte - o autor" 
RAPHAEL EUCLIDES PRESTES SALEM

\section{Desenvolvimento de $\mathrm{ZrO}_{2} / \mathrm{Al}_{2} \mathrm{O}_{3}$ e $\mathrm{ZrO}_{2} / \mathrm{Al}_{2} \mathrm{O}_{3}-\mathrm{NbC}$ usando sinterização convencional e não convencional}

Banca Examinadora:

Sliria $M^{\mathrm{a}}$ de Jesus Agnolon Pallone - Presidente da Banca Examinadora Professora Doutora - Universidade de São Paulo/FZEA - Orientadora

SefvedrJiu'Zune

Alfredo José Zara

Professor Doutor - Universidade Estadual de Ponta Grossa

Wuecina fd lousa

Dulcina Maria Pinatti Ferreira de Souza

Professora Doutora - Universidade Federal de São Carlos

42

Fernando Gustavo Tonin

Professor Doutor - Universidade de São Paulo/FZEA

Maria Amparo Borrell Tomás

Professora Doutora - Universitat Politècnica de València

Jamia Rombin Souncander

Vânia Trombini Hernandes

Professora Doutora - Universidade Federal do ABC

Pirassununga, 11 de dezembro de 2017. 


\section{DEDICATÓRIA}

Aos meus pais, Cida e Miguel, que me fizeram de uns átomos, moldaram-me o caráter, protegeram-me e não pouparam esforços para me fazer chegar até aqui e adiante;

Ao meu avô Sebastião de Moura Prestes, fonte de espiritualidade e de incentivo;

A Samanta, meu projeto de vida e minha fonte de inspiração. 


\section{VITAE}

- Bacharel em Engenharia de Materiais pela Universidade Estadual de Ponta Grossa (UEPG), 2008;

- Mestre em Engenharia e Ciência de Materiais pela Universidade Estadual de Ponta Grossa (UEPG), 2012. 


\section{AGRADECIMENTOS}

Primeiramente, a Deus, pela saúde e discernimento para encarar esta empreitada, e por não me abandonar, quaisquer que tenham sido as dificuldades;

"Não se perturbe o vosso coração. Credes em Deus, crede também em mim." (Jo, 14:1)

À minha orientadora, Prof ${ }^{a}$. Dra . Eliria Maria de Jesus Agnolon Pallone, pela sua preciosa e competente orientação, pelo incentivo, pela amizade e disponibilidade em todos os momentos, fazendo-me sentir sempre bem-vindo no grupo e sendo um importante exemplo de profissional a se seguir;

Sempre me lembrarei das vezes em que eu estava inseguro e dizia que iria tentar fazer algo, e a Profa. Eliria me disse: "Você não vai tentar. Você vai fazer."

À minha co-orientadora de doutorado e orientadora de mestrado, Prof ${ }^{a}$. Dra . Adriana Scoton Antonio Chinelatto, pela sua preciosa e competente orientação, pela longa amizade e pelos grandes exemplos que sempre levarei comigo;

Sempre me lembrarei das vezes em que após uma longa conversa e algumas discussões inconclusivas, Profá. Adriana e eu falávamos, sem querer, ao mesmo tempo: "Mas vai dar certo!"

Aos meus pais, Aparecida e Miguel, e ao meu irmão Eduardo, pela educação que custou muito suor, pelos exemplos de retidão e profissionalismo, e pelo amor e paciência em todo este período, como por toda a vida;

À minha noiva, Samanta Mizunuma, pelo amor e incentivo incondicionais, pelo companheirismo em todas as inquietudes e pelo exemplo de esforço dado diariamente, que me motiva a buscar ser um companheiro e profissional exemplar;

\section{À Universidade de São Paulo - FZEA:}

- À equipe do Programa de Pós-Graduação em Engenharia e Ciência de Materiais e ao Serviço de Pós-Graduação;

- À Drª . Julieta Adriana Ferreira, pelo apoio constante e auxílio nas análises de DRX;

- Aos técnicos, em especial o Téc. Leonardo Pozzobon, pela realização de análises;

- Ao Laboratório de Caracterização Estrutural (LCE) da Universidade Federal de São Carlos, pela realização da microscopia eletrônica de transmissão;

- Aos membros de minha banca de qualificação, Prof. Dr. João Adriano Rossignolo e Profa ${ }^{\text {. Dr }}$. Vânia Trombini Hernandes (UFABC), por importantes contribuições ao projeto de pesquisa;

- À minha amiga e colega de graduação, mestrado, e agora doutorado, Christiane Lago Ojaimi, pela longa amizade que nutrimos e toda a ajuda que sempre me deu, com boas discussões e reflexões sobre todos os assuntos da pesquisa e do dia-a-dia; 
- À minha contemporânea de estágio (ainda que por pouco tempo) e colega de laboratório, Laís Alecrim, por toda a amizade e apoio inicial na Espanha, além de constante ajuda no trabalho aqui, lá, e até depois de doutorar-se;

- Aos colegas e amigos de laboratório, André, Carol, Chris, Isabela, João Vitor, Kátia e Thauane, pela amizade, momentos de descontração e constante ajuda no laboratório, nas prensagens isostáticas, na flash sintering e em todos os desafios que enfrentamos;

\section{À Universidade Tecnológica Federal do Paraná - Câmpus Londrina, que autorizou e viabilizou a minha licença para capacitação de doutorado:}

- À Diretoria de Pós-Graduação e à Diretoria-Geral do Câmpus Londrina, pelo auxílio documental e administrativo;

- Ao meu professor, Pró-Reitor de Graduação, Prof. Dr. Luís Maurício Resende, pelos aconselhamentos que só podem ser dados por ele;

- Ao Departamento Acadêmico e à Coordenação de Curso de Engenharia de Materiais, onde sou lotado, pela cobertura de minhas aulas e auxílio durante a licença;

\section{À Universidade Estadual de Ponta Grossa - Departamento de Engenharia de Materiais, que me recebeu como ex-aluno e me permitiu realizar parte dos experimentos da minha pesquisa durante o período de doutorado:}

- Ao acadêmico Fábulo Ribeiro Monteiro, meu fiel escudeiro, de refinadas habilidades manuais, contagiante vontade de aprender e exemplo de humildade e competência, pelo fundamental auxílio na preparação e caracterização de amostras e discussão de resultados;

- Aos professores, em especial ao Prof. Dr. Adilson Luiz Chinelatto, pelo auxílio na obtenção das imagens de FEG/MEV;

- Aos funcionários e técnicos, Dirceu, Douglas, Josely e Milton;

- Aos demais alunos de IC que me auxiliaram, Caroline, Charles, Emerson, Jéssica, Rafaella, Barreto e Rodrigo, pelos conhecimentos compartilhados;

- Aos velhos amigos e colegas de pós-graduação Edson, Mazur, Viviane, Josiane, Kairin, Ana, Joéverton, e todos os demais que participaram do meu dia-a-dia acadêmico em Ponta Grossa;

- À equipe do Laboratório Multiusuário (LabMU) por diversas caracterizações;

\section{À Universitat Politècnica de València, Instituto de Tecnología de Materiales (Espanha), por me receber e prover a estrutura para o estágio de doutorado- sanduíche:}

- À minha supervisora, Prof ${ }^{a}$. Drª . María Dolores Salvador, pela recepção na UPV, pela sua atenção, constante apoio e estímulo para extrair mais resultados;

- À minha cossupervisora, Profâa. Drª . Amparo Borrell, por todas as correções, sugestões, seminários, e apoio técnico-científico; 
- Ao Dr. Emilio Rayón Encinas, por los cafecitos e realização dos ensaios de nanoindentação;

- Ao Prof. Dr. Rodrigo Moreno (Universidad Autónoma de Madrid, Espanha), pela cooperação e aconselhamento;

- Aos colegas de grupo, Álvaro, Ánggel, Fran, Julien, Pablo e Prisca, pela amizade, por los arroces y bocadillos en el "Trinquet" e apoio durante o estágio de doutoradosanduíche;

- Ao Centro de Investigación en Nanomateriales y Nanotecnología, Universidad de Oviedo (Espanha), na pessoa do Dr. Carlos Gutiérrez-González, pela realização da sinterização por SPS;

- À Universitat de València (Espanha), pela realização de caracterizações complementares por DRX;

- Aos roomies Arnulf, Fumiko, Lucas, Mai, também a Clément e a Thibault por compartilhar as lavagens de louças e as inquietações inerentes a uma experiência no estrangeiro; A Márcia, Wladimir, Bianca, Joíra, Sergio, Laura e Dominik pela amizade nutrida em encontros e reencontros tão aleatórios;

Aos órgãos de fomento:

- Fundação Araucária / CAPES, que por meio do edital conjunto 13/2014 - Capacitação de Doutorado para Docentes (convênio 810/2014), proveu apoio financeiro para a realização do projeto;

- Fundação Erasmus Mundus, financiada com recursos de União Europeia, que por meio do projeto Euro-Brazilian Windows Plus (EBW+), financiou o meu estágio de doutorado-sanduíche (mobilidade) por seis meses na UPV; E ao setor de cooperação internacional da Universidade do Porto (Portugal), que coordenou o projeto;

- Coordenação de Aperfeiçoamento de Pessoal de Nível Superior - CAPES, que através do PROAP, financiou parte das despesas relativas a eventos científicos;

- Fundação de Amparo à Pesquisa do Estado de São Paulo - FAPESP, que providenciou o fomento necessário à construção do sistema de flash sintering coordenado pelo grupo de pesquisa de que faço parte;

Finalmente, aos queridos amigos de sempre, Bruno, Carlos, Eliane, Erica, Felippe, Izumi, Lorene, Ricardo, Stephanie, Thiago, Wagner, Yoshiko Sensei e meus familiares, que sempre estão presentes nos momentos de espairecer, queixar-se e descontrair.

Foram muitas pessoas e instituições, cada uma contribuindo com um ou mais "tijolinhos", para que este trabalho fosse sendo concretizado. A maior lição é de que não somos nada sozinhos.

Portanto, agradeço a todos os que contribuíram direta e indiretamente para a realização deste projeto acadêmico e de vida. 
"Quem, por direito, não é senhor do seu dizer, não se pode dizer senhor de qualquer direito."

(Cármen Lúcia Antunes Rocha) 


\section{RESUMO}

SALEM, R. E. P. Desenvolvimento de $\mathrm{ZrO}_{2} / \mathrm{Al}_{2} \mathrm{O}_{3}$ e $\mathrm{ZrO}_{2} / \mathrm{Al}_{2} \mathrm{O}_{3}-\mathrm{NbC}$ usando sinterização convencional e não convencional, 2017. 159 f. Tese (Doutorado) Faculdade de Zootecnia e Engenharia de Alimentos, Universidade de São Paulo, Pirassununga, 2017.

Os compósitos cerâmicos de alto desempenho têm sido objeto de frequentes estudos nas últimas décadas, visando à melhora das propriedades mecânicas e ao aumento da sua gama de aplicações em produtos tecnológicos. Este trabalho consistiu em estudar a preparação, a sinterização convencional e não convencional e as propriedades mecânicas e tribológicas resultantes de dois sistemas compósitos: $\mathrm{t}-\mathrm{ZrO}_{2} / \mathrm{Al}_{2} \mathrm{O}_{3}$ e t$\mathrm{ZrO}_{2} / \mathrm{Al}_{2} \mathrm{O}_{3}-\mathrm{NbC}$. No sistema $\mathrm{t}-\mathrm{ZrO}_{2} / \mathrm{Al}_{2} \mathrm{O}_{3}$ foram estudadas as composições de $0,5 \mathrm{e}$ $15 \%$ em volume de $\mathrm{Al}_{2} \mathrm{O}_{3}$ usando pós comerciais. No sistema $\mathrm{t}-\mathrm{ZrO}_{2} / \mathrm{Al}_{2} \mathrm{O}_{3}-\mathrm{NbC}$, foi usado um pó nanocristalino de $\mathrm{Al}_{2} \mathrm{O}_{3}-\mathrm{NbC}$, obtido por moagem reativa de alta energia e adicionado na proporção de $5 \%$ em volume à matriz de $\mathrm{t}^{-\mathrm{ZrO}_{2}}$. Os pós foram prensados uniaxial e isostaticamente e sinterizados em forno convencional e pelas técnicas de flash sintering ( $\mathrm{FS})\left(\mathrm{t}-\mathrm{ZrO}_{2} / \mathrm{Al}_{2} \mathrm{O}_{3}\right)$ e spark plasma sintering (SPS) $\left(\mathrm{t}-\mathrm{ZrO}_{2} / \mathrm{Al}_{2} \mathrm{O}_{3}-\mathrm{NbC}\right)$. Os compósitos $\mathrm{t}-\mathrm{ZrO}_{2} / \mathrm{Al}_{2} \mathrm{O}_{3}$ sinterizados convencionalmente e $\mathrm{t}-\mathrm{ZrO}_{2} / \mathrm{Al}_{2} \mathrm{O}_{3}-\mathrm{NbC}$ sinterizados convencionalmente e por SPS foram caracterizados por medidas de densidade aparente, dilatometria, microscopia eletrônica de varredura (MEV), e medidas de propriedades mecânicas: dureza, módulo de Young e tenacidade à fratura. Os compósitos $\mathrm{t}-\mathrm{ZrO}_{2} / \mathrm{Al}_{2} \mathrm{O}_{3}$ sinterizados por $\mathrm{FS}$ foram caracterizados por medidas de densidade aparente, dilatometria in situ e MEV. Os nanocompósitos de $\mathrm{t}-\mathrm{ZrO}_{2} / \mathrm{Al}_{2} \mathrm{O}_{3}$ $\mathrm{NbC}$ foram também caracterizados quanto à resistência ao desgaste pelo método esfera-no-disco, utilizando esferas de $\mathrm{Al}_{2} \mathrm{O}_{3}$ e WC-6\%Co como contramateriais. Os resultados mostraram que a moagem reativa de alta energia foi completa e efetiva na obtenção de pós nanométricos de $\mathrm{Al}_{2} \mathrm{O}_{3}-\mathrm{NbC}$, com tamanhos de cristalito de $9,1 \mathrm{~nm}$ para $\mathrm{Al}_{2} \mathrm{O}_{3}$ e 9,7 nm para o $\mathrm{NbC}$. A desaglomeração posterior à moagem de alta energia foi eficaz na redução do tamanho de aglomerados. Os compósitos $\mathrm{t}-\mathrm{ZrO}_{2} / \mathrm{Al}_{2} \mathrm{O}_{3}$ e t$\mathrm{ZrO} / \mathrm{Al}_{2} \mathrm{O}_{3}-\mathrm{NbC}$ sinterizados convencionalmente e $\mathrm{ZrO}_{2} / \mathrm{Al}_{2} \mathrm{O}_{3}-\mathrm{NbC}$ sinterizados por SPS mostraram alta densificação (>97\% DT e boas propriedades mecânicas. Os nanocompósitos de $\mathrm{t}-\mathrm{ZrO}_{2} / \mathrm{Al}_{2} \mathrm{O}_{3}$ sinterizados por $\mathrm{FS}$ apresentaram uma densificação ultrarrápida $(<1 \mathrm{~min})$ com retração linear superior às amostras sinterizadas em forno convencional, ocorrente a temperaturas inferiores a $1000^{\circ} \mathrm{C}$, com densidades relativas superiores a $90 \%$ DT em algumas composições. Os nanocompósitos de $\mathrm{t}-\mathrm{ZrO}_{2} / \mathrm{Al}_{2} \mathrm{O}_{3}$ $\mathrm{NbC}$ apresentaram propriedades competitivas entre os compósitos sinterizados convencionalmente e por SPS, com dureza e tenacidade à fratura superiores às da t$\mathrm{ZrO}_{2}$ monolítica. A resistência ao desgaste desses nanocompósitos sinterizados convencionalmente, no entanto, foi notadamente superior à dos sinterizados por SPS. A oxidação do $\mathrm{NbC}$ nos compósitos sinterizados convencionalmente influiu negativamente nas propriedades, levando à sugestão de uma "janela" de temperaturas em que a sinterização do nanocompósito de $\mathrm{t}-\mathrm{ZrO}_{2} / \mathrm{Al}_{2} \mathrm{O}_{3}-\mathrm{NbC}$ seja interessante sem a degradação das propriedades mecânicas. Os resultados permitiram concluir que os materiais estudados apresentam potencial para aplicações industriais que requerem cerâmicas de alto desempenho mecânico e de resistência ao desgaste.

Palavras-chave: $\mathrm{t}-\mathrm{ZrO}_{2} / \mathrm{Al}_{2} \mathrm{O}_{3}-\mathrm{NbC}, \mathrm{t}-\mathrm{ZrO}_{2} / \mathrm{Al}_{2} \mathrm{O}_{3}$, flash sintering, spark plasma sintering. 


\begin{abstract}
SALEM, R. E. P. Development of $\mathrm{ZrO}_{2} / \mathrm{Al}_{2} \mathrm{O}_{3}$ and $\mathrm{ZrO}_{2} / \mathrm{Al}_{2} \mathrm{O}_{3}-\mathrm{NbC}$ using conventional and non-conventional sintering, 2017. $159 \mathrm{pp}$. Doctoral Thesis, Faculdade de Zootecnia e Engenharia de Alimentos, Universidade de São Paulo, Pirassununga, 2017.

High performance ceramic composites have been the subject of frequent studies in recent decades, aiming at improving mechanical properties and increasing their range of applications in technological products. This work consisted in studying the preparation, the conventional and non-conventional sintering and the mechanical properties resulting from two $\mathrm{t}-\mathrm{ZrO} 2$ matrix composites: the $\mathrm{t}-\mathrm{ZrO}_{2} / \mathrm{Al}_{2} \mathrm{O}_{3}$ system and the $\mathrm{t}-\mathrm{ZrO}_{2} / \mathrm{Al}_{2} \mathrm{O}_{3}-\mathrm{NbC}$ system. In the $\mathrm{t}-\mathrm{ZrO}_{2} / \mathrm{Al}_{2} \mathrm{O}_{3}$ system, the compositions of 0,5 and $15 \%$ by volume of $\mathrm{Al}_{2} \mathrm{O}_{3}$ using commercial powders were studied, while in the t$\mathrm{ZrO}_{2} / \mathrm{Al}_{2} \mathrm{O}_{3}-\mathrm{NbC}$ system, an $\mathrm{Al}_{2} \mathrm{O}_{3}-\mathrm{NbC}$ nanocrystalline powder obtained by high energy reactive milling, deagglomerated, leached in $\mathrm{HCl}$ and added in the proportion of $5 \%$ by volume to the $\mathrm{t}-\mathrm{ZrO}_{2}$ matrix. The obtained powders were uniaxially and isostatically pressed and sintered in conventional furnace and using flash sintering (t$\mathrm{ZrO}_{2} / \mathrm{Al}_{2} \mathrm{O}_{3}$ ) and spark plasma sintering (SPS) (t-ZrO$\left./ \mathrm{Zl}_{2} \mathrm{O}_{3}-\mathrm{NbC}\right)$. Conventionally sintered $\mathrm{t}-\mathrm{ZrO}_{2} / \mathrm{Al}_{2} \mathrm{O}_{3}$ and conventionally sintered $\mathrm{t}-\mathrm{ZrO}_{2} / \mathrm{Al}_{2} \mathrm{O}_{3}-\mathrm{NbC}$ composites were characterized by measurements of apparent density, dilatometry, SEM, and mechanical properties: hardness, Young's modulus and fracture toughness. The t$\mathrm{ZrO}_{2} / \mathrm{Al}_{2} \mathrm{O}_{3}$ composites sintered by FS were characterized by measurements of apparent density, in situ dilatometry and $\mathrm{SEM}$. $\mathrm{t}-\mathrm{ZrO}_{2} / \mathrm{Al}_{2} \mathrm{O}_{3}-\mathrm{NbC}$ nanocomposites were also characterized for wear strength by the ball-in-disc method, using $\mathrm{Al}_{2} \mathrm{O}_{3}$ and WC- $6 \%$ Co beads as countermaterials. The results showed that the high energy reactive milling was complete and effective in obtaining nanometric powders of $\mathrm{Al}_{2} \mathrm{O}_{3}$ $\mathrm{NbC}$, with crystallite sizes equal to 9.1 and $9.7 \mathrm{~nm}$, for $\mathrm{Al}_{2} \mathrm{O}_{3}$ and $\mathrm{NbC}$, respectively. The deagglomeration after high energy reactive milling was effective in reducing the size of agglomerates. Conventionally sintered $\mathrm{t}-\mathrm{ZrO}_{2} / \mathrm{Al}_{2} \mathrm{O}_{3}$ and $\mathrm{t}-\mathrm{ZrO}_{2} / \mathrm{Al}_{2} \mathrm{O}_{3}-\mathrm{NbC}$ composites and SPS-sintered $\mathrm{t}-\mathrm{ZrO}_{2} / \mathrm{Al}_{2} \mathrm{O}_{3}-\mathrm{NbC}$ showed high densification (> 97\% TD), good dispersion of the inclusions in the matrix and good mechanical properties. The $\mathrm{t}-\mathrm{ZrO}_{2} / \mathrm{Al}_{2} \mathrm{O}_{3}$ nanocomposites sintered by FS presented an ultrafast densification $(<1 \mathrm{~min})$ with linear shrinkage superior to the sintered samples in conventional furnace, occurring at temperatures lower than $1000^{\circ} \mathrm{C}$, with relative densities higher than $90 \%$ TD in some compositions. The $t-\mathrm{ZrO}_{2} / \mathrm{Al}_{2} \mathrm{O}_{3}-\mathrm{NbC}$ nanocomposites presented competitive properties between conventionally sintered and SPS-sintered composites with higher hardness and fracture toughness than monolithic $\mathrm{t}-\mathrm{ZrO}_{2}$. The wear resistance of these conventionally sintered nanocomposites, however, was markedly higher than those of SPS-sintered ones. The oxidation of $\mathrm{NbC}$ in the composites sintered conventionally influenced negatively the properties, leading to the suggestion of a "window" of temperatures in which the sintering of the t$\mathrm{ZrO}_{2} / \mathrm{Al}_{2} \mathrm{O}_{3}-\mathrm{NbC}$ nanocomposite is interesting without the degradation of the mechanical properties. The results allowed concluding that the studied materials present potential for industrial applications that require high mechanical performance and wear resistance ceramics.
\end{abstract} sintering.

Keywords: zirconia, composite, sintering, flash sintering, spark plasma 


\title{
RESUMEN
}

\author{
SALEM, R. E. P. Desarrollo de $\mathrm{ZrO}_{2} / \mathrm{Al}_{2} \mathrm{O}_{3}$ e $\mathrm{ZrO}_{2} / \mathrm{Al}_{2} \mathrm{O}_{3}-\mathrm{NbC}$ usando \\ sinterización convencional y no convencional, 2017. 159 pp. Tesis Doctoral, \\ Faculdade de Zootecnia e Engenharia de Alimentos, Universidade de São Paulo, \\ Pirassununga, 2017.
}

Los composites cerámicos de alto rendimiento han sido objeto de frecuentes estudios en las últimas décadas, buscando la mejora de las propiedades mecánicas y el aumento de su gama de aplicaciones en productos tecnológicos. Este trabajo consistió en estudiar la preparación, la sinterización convencional y no convencional y las propiedades mecánicas resultantes de dos sistemas compuestos con matriz de $\mathrm{t}^{-} \mathrm{ZrO}_{2}$ : el sistema t$\mathrm{ZrO}_{2} / \mathrm{Al}_{2} \mathrm{O}_{3}$ y el sistema $\mathrm{t}-\mathrm{ZrO}_{2} / \mathrm{Al}_{2} \mathrm{O}_{3}-\mathrm{NbC}$. En el sistema $\mathrm{t}-\mathrm{ZrO}_{2} / \mathrm{Al}_{2} \mathrm{O}_{3}$ se estudiaron las composiciones de 0,5 y $15 \%$ en volumen de $\mathrm{Al}_{2} \mathrm{O}_{3}$ usando polvos comerciales, mientras que en el sistema $\mathrm{t}-\mathrm{ZrO}_{2} / \mathrm{Al}_{2} \mathrm{O}_{3}-\mathrm{NbC}$, se utilizó un polvo nanocristalino de $\mathrm{Al}_{2} \mathrm{O}_{3}-\mathrm{NbC}$, obtenido por molienda reactiva de alta energía, desaglomerado, lixiviado en $\mathrm{HCl}$ y agregado en la proporción del $5 \%$ en volumen a la matriz de $\mathrm{t}-\mathrm{ZrO}_{2}$. Los polvos obtenidos fueron prensados uniaxial e isostáticamente y sinterizados en un horno convencional y por las técnicas de flash sintering (FS) $\left(\mathrm{t}-\mathrm{ZrO}_{2} / \mathrm{Al}_{2} \mathrm{O}_{3}\right)$ y spark plasma sintering (SPS) $\left(\mathrm{t}-\mathrm{ZrO}_{2} / \mathrm{Al}_{2} \mathrm{O}_{3}-\mathrm{NbC}\right)$. Los composites $\mathrm{t}-\mathrm{ZrO}_{2} / \mathrm{Al}_{2} \mathrm{O}_{3}$ sinterizados convencionalmente y $\mathrm{t}-\mathrm{ZrO}_{2} / \mathrm{Al}_{2} \mathrm{O}_{3}-\mathrm{NbC}$ sinterizados convencionalmente y por SPS fueron caracterizados por medidas de densidad aparente, dilatometría, MEB, y medidas de propiedades mecánicas: dureza, módulo de Young y tenacidad a la fractura. Los composites $\mathrm{t}-\mathrm{ZrO}_{2} / \mathrm{Al}_{2} \mathrm{O}_{3}$ sinterizados por $\mathrm{FS}$ se caracterizaron por medidas de densidad aparente, dilatometría in situ y MEB. Los nanocompuestos de $\mathrm{t}-\mathrm{ZrO}_{2} / \mathrm{Al}_{2} \mathrm{O}_{3}-\mathrm{NbC}$ también se caracterizaron en la resistencia al desgaste por el método esfera-en-disco, utilizando esferas de $\mathrm{Al}_{2} \mathrm{O}_{3}$ y WC-6\% Co como contramateriales. Los resultados mostraron que la molienda reactiva de alta energía fue completa y efectiva en la obtención de polvos nanométricos de $\mathrm{Al}_{2} \mathrm{O}_{3}-\mathrm{NbC}$, con tamaños de cristalito igual a 9,1 y $9,7 \mathrm{~nm}$, para $\mathrm{Al}_{2} \mathrm{O}_{3}$ y $\mathrm{NbC}$, respectivamente. La desagregación posterior a la molienda reactiva de alta energía fue eficaz en la reducción del tamaño de aglomerados. Los composites t$\mathrm{ZrO}_{2} / \mathrm{Al}_{2} \mathrm{O}_{3}$ y $\mathrm{t}-\mathrm{ZrO}_{2} / \mathrm{Al}_{2} \mathrm{O}_{3}-\mathrm{NbC}$ sinterizados convencionalmente y $\mathrm{t}-\mathrm{ZrO}_{2} / \mathrm{Al}_{2} \mathrm{O}_{3}-\mathrm{NbC}$ sinterizados por SPS mostraron alta densificación (>97\% DT), buena dispersión de las inclusiones en la matriz y buenas propiedades mecánicas. Los nanocomposites de t$\mathrm{ZrO}_{2} / \mathrm{Al}_{2} \mathrm{O}_{3}$ sinterizados por FS presentaron una densificación ultrarrápida (<1 min) con retracción lineal superior a las muestras sinterizadas en horno convencional, ocurrente a temperaturas inferiores a $1000^{\circ} \mathrm{C}$, con densidades relativas superiores al $90 \%$ DT en algunas composiciones. Los nanocompuestos de $\mathrm{t}-\mathrm{ZrO}_{2} / \mathrm{Al}_{2} \mathrm{O}_{3}-\mathrm{NbC}$ presentaron propiedades competitivas entre los compuestos sinterizados convencionalmente y por SPS, con dureza y tenacidad a la fractura superiores a las de la $\mathrm{t}-\mathrm{ZrO}_{2}$ monolítica. La resistencia al desgaste de estos nanocompuestos sinterizados convencionalmente, sin embargo, fue notablemente superior a la de los sinterizados por SPS. La oxidación del $\mathrm{NbC}$ en los compuestos sinterizados convencionalmente influyó negativamente en las propiedades, llevando a la sugerencia de una "ventana" de temperaturas en que la sinterización del nanocompuesto de $\mathrm{t}-\mathrm{ZrO}_{2} / \mathrm{Al}_{2} \mathrm{O}_{3}-\mathrm{NbC}$ sea interesante sin la degradación de las propiedades mecánicas. Los resultados permitieron concluir que los materiales estudiados presentan potencial para aplicaciones industriales que requieren cerámicas de alto desempeño mecánico y de resistencia al desgaste.

Palabras-clave: circona, composite, sinterización, flash sintering, spark plasma sintering. 


\section{PUBLICAÇÕES}

1. SALEM, R. E. P.; MONTEIRO, F. R.; GUTIÉRREZ-GONZÁLEZ, C. F.; BORRELL, A.; SALVADOR, M. D.; CHINELATTO, A. S. A.; CHINELATTO, A. L.; FERREIRA, J. A.; PALLONE, E. M. J. A. Effect of $\mathrm{Al}_{2} \mathrm{O}_{3}-\mathrm{NbC}$ incorporation on the mechanical properties of $3 \mathrm{Y}-\mathrm{TZP} / \mathrm{Al}_{2} \mathrm{O}_{3}-\mathrm{NbC}$ nanocomposites obtained by conventional and spark plasma sintering. Ceramics International, v. 44, n. 2, pp. 2504-2509, 2018.

2. SALEM, R. E. P.; MONTEIRO, F. R.; CHINELATTO, A. S. A.; CHINELATTO, A. L.; MOYA, M. D. S.; TOMÁS, A. B.; PALLONE, E. M. J. A. Wear study of $3 \mathrm{Y}-\mathrm{TZP} / 5$ vol\% $\mathrm{Al}_{2} \mathrm{O}_{3}-\mathrm{NbC}$ nanocomposites sintered by conventional and spark plasma sintering techniques. In: XVI Brazil MRS Meeting, 2017, Gramado. Proceedings of the XVI Brazil MRS Meeting, 2017.

3. SALEM, R. E. P.; MONTEIRO, F. R.; CHINELATTO, A. S. A.; CHINELATTO, A. L.; BORRELL, A.; SALVADOR, M. D.; PALLONE, E. M. J. A. Mechanical characterization of $\mathrm{Y}-\mathrm{TZP} / \mathrm{Al}_{2} \mathrm{O}_{3}-\mathrm{NbC}$ nanocomposites sintered by different techniques. In: 15th Conference \& Exhibition of the European Ceramic Society, 2017, Budapest. Book of Abstracts of the 15th Conference \& Exhibition of the European Ceramic Society, v. 1. p. 267, 2017.

4. SALEM, R. E. P.; MONTEIRO, F. R.; CHINELATTO, A. S. A.; CHINELATTO, A. L.; PALLONE, E. M. J. A. Síntese e processamento de nanocompósitos de $\mathrm{ZrO}_{2} / \mathrm{Al}_{2} \mathrm{O}_{3}-\mathrm{NbC}$ usando sinterização convencional. In: 60 Congresso Brasileiro de Cerâmica, 2016, Águas de Lindoia. Anais do 60 Congresso Brasileiro de Cerâmica, 2016.

5. SALEM, R. E. P.; MONTEIRO, F. R.; DONATO, R. B.; CHINELATTO, A. S. A.; CHINELATTO, A. L.; PALLONE, E. M. J. A. Produção e sinterização de compósitos de zircônia tetragonal reforçada com alumina em diferentes proporções volumétricas por rota coloidal. In: 59 Congresso Brasileiro de Cerâmica, 2015, Barra dos Coqueiros. Anais do 59 Congresso Brasileiro de Cerâmica, 2015.

6. SALEM, R. E. P.; DONATO, R. B.; MONTEIRO, F. R.; CHINELATTO, A. S. A.; CHINELATTO, A. L.; PALLONE, E. M. J. A. Sinterização de compósitos alumina-zircônia produzidos por diferentes métodos. In: XXI Congresso Brasileiro de Engenharia e Ciência dos Materiais, 2014, Cuiabá. Anais do XXI CBECIMat, 2014. 


\section{LISTA DE FIGURAS}

Figura 1 - Fases polimórficas da zircônia: (a) cúbica; (b) tetragonal; (c) monoclínica.

Figura 2 - Diagrama de fases do sistema $\mathrm{ZrO}_{2}-\mathrm{Y}_{2} \mathrm{O}_{3}$, na porção rica em $\mathrm{ZrO}_{2}$.

Figura 3 - Esquema da classificação dos materiais nanoestruturados de acordo com sua composição química e dimensionalidade dos cristalitos. .30

Figura 4 - Formas de impacto com pouco e muito material em um moinho do tipo "Spex".

Figura 5 - Representação esquemática da variação da temperatura com o tempo durante 0 processo de moagem de alta energia quando ocorre a reação de combustão. .33

Figura 6 - (a) Variação do tamanho de cristalito e (b) Variação da área superficial especifica, com o tempo de moagem, para o sistema $\mathrm{Al}_{2} \mathrm{O}_{3}-\mathrm{NbC}$ submetido a moagem de alta energia. .35

Figura 7 - (a) Sinterização via fase líquida; (b) Sinterização no estado sólido. 40

Figura 8 - Representação esquemática das duas possíveis formas pelas quais um conjunto de partículas pode reduzir sua energia: Densificação seguida de crescimento de grão e coalescimento das partículas.

Figura 9 - Representação esquemática dos seis distintos mecanismos que podem contribuir para a sinterização de uma massa consolidada de partículas cristalinas.. 43 Figura 10 - Modelos idealizados para os três estágios da sinterização: (a) Estágio inicial; (b) Final do estágio inicial; (c) Estágio intermediário; (d) Estágio final. . 45 Figura 11 - Exemplos de microestruturas reais (seções planares) para (a) estágio inicial; (b) estágio intermediário; (c) estágio final da sinterização..... .46 Figura 12 - Esquematização dos mecanismos básicos de formação de pescoço nos contatos das partículas na SPS.

Figura 13 - Representação esquemática de um aparato de SPS. .50

Figura 14 - Representação esquemática do fluxo de corrente em um sistema de SPS: (a) pó e molde condutores; (b) pó condutor, molde isolante; (c) pó nãocondutor, molde condutor.

Figura 15 - Exemplo do comportamento da dissipação de potência elétrica (linha cheia) em comparação com a previsão calculada por elementos finitos (linha 
pontilhada) em uma amostra de zircônia estabilizada com 3\% mol de ítria sinterizada por flash sintering com um campo de $100 \mathrm{~V} / \mathrm{cm}$

Figura 16 - Curvas de sinterização com variação de campo elétrico para 3Y-TZP...57 Figura 17 - Contato entre duas superfícies: (a) duas superfícies rugosas em contato; (b) áreas de contato correspondentes.

Figura 18 - Desenvolvimento do volume de desgaste com o tempo a uma determinada força normal aplicada; a inclinação da curva (dividida pela força normal aplicada) representa a taxa de desgaste específica.

Figura 19 - Representação esquemática das diferentes interações entre partículas abrasivas deslizantes e a superfície dos materiais.

Figura 20 - Exemplo de estágios no desgaste por delaminação: (a) deformação plástica nas asperezas locais; (b) formação de trincas no maciço; (c) propagação de trincas paralelas à superfície; (d) delaminação da camada trincada. .65 Figura 21 - Fluxograma resumido das etapas realizadas no desenvolvimento do trabalho: (a) sistema $\mathrm{t}-\mathrm{ZrO}_{2} / \mathrm{Al}_{2} \mathrm{O}_{3}$; (b) sistema $\mathrm{t}-\mathrm{ZrO}_{2} / \mathrm{Al}_{2} \mathrm{O}_{3}-\mathrm{NbC}$ 73

Figura 22 - Esquematização do forno adaptado para flash sintering. .81

Figura 23 - Configuração de amostra em cadinho de alumina com proteção de grafite para simular atmosfera redutora na sinterização em forno convencional. .84 Figura 24 - Curvas de retração versus temperatura da $\mathrm{t}-\mathrm{ZrO}_{2}$ e dos compósitos t$\mathrm{ZrO}_{2} / \mathrm{Al}_{2} \mathrm{O}_{3}$ obtidas por dilatometria. 90

Figura 25 - Curvas da taxa de retração linear versus temperatura dos compósitos t$\mathrm{ZrO} / \mathrm{Al}_{2} \mathrm{O}_{3}$ obtidas por dilatometria. 91

Figura 26 - Micrografias obtidas por MEV dos compósitos $\mathrm{t}-\mathrm{ZrO}_{2} / \mathrm{Al}_{2} \mathrm{O}_{3}$ sinterizados.

Figura 27 - Micrografias obtidas por MEV dos compósitos $\mathrm{t}-\mathrm{ZrO}_{2} / \mathrm{Al}_{2} \mathrm{O}_{3}$ sinterizados a $1350^{\circ} \mathrm{C}$ : .95

Figura 28 - Curvas de retração linear versus temperatura dos materiais sinterizados por flash sintering e por sinterização convencional: (a) $\mathrm{t}-\mathrm{ZrO}_{2}$; (b) $\mathrm{t}-\mathrm{ZrO}_{2} / 5 \%$ vol $\mathrm{Al}_{2} \mathrm{O}_{3} ;$; $\mathrm{c}-\mathrm{ZrO}_{2} / 15 \%$ vol $\mathrm{Al}_{2} \mathrm{O}_{3}$. 100

Figura 29 - Micrografias de MEV das superfícies de fratura das amostras de $\mathrm{t}-\mathrm{ZrO}_{2}$ sinterizadas por flash sintering: (a) Campo de $150 \mathrm{~V} / \mathrm{cm}, \mathrm{AC}, 1000 \mathrm{~Hz}$; (b) Campo de $200 \mathrm{~V} / \mathrm{cm}, \mathrm{AC}, 1000 \mathrm{~Hz}$; (c) Campo de $150 \mathrm{~V} / \mathrm{cm}$, DC; (d) Campo de $200 \mathrm{~V} / \mathrm{cm}$, DC. 
Figura 30 - Micrografias de MEV das superfícies de fratura das amostras de t$\mathrm{ZrO}_{2} / 5 \%$ vol $\mathrm{Al}_{2} \mathrm{O}_{3}$ sinterizadas por flash sintering: (a) Campo de $150 \mathrm{~V} / \mathrm{cm}, \mathrm{AC}, 1000$ Hz; (b) Campo de 200 V/cm, AC, 1000 Hz; (c) Campo de 150 V/cm, DC; (d) Campo de $200 \mathrm{~V} / \mathrm{cm}$, DC. 106

Figura 31 - Micrografias de MEV das superfícies de fratura das amostras de t$\mathrm{ZrO}_{2} / 15 \%$ vol $\mathrm{Al}_{2} \mathrm{O}_{3}$ sinterizadas por flash sintering: (a) Campo de $150 \mathrm{~V} / \mathrm{cm}, \mathrm{AC}$, $1000 \mathrm{~Hz}$; (b) Campo de 200 V/cm, AC, $1000 \mathrm{~Hz}$; (c) Campo de 150 V/cm, DC; (d) Campo de $200 \mathrm{~V} / \mathrm{cm}$, DC

Figura 32 - Micrografia de MEV da fronteira entre duas regiões com distintos tamanhos de grão na superfície de fratura da $\mathrm{t}-\mathrm{ZrO}_{2}$ sinterizada por flash sintering com campo elétrico de $200 \mathrm{~V} / \mathrm{cm}$ e corrente contínua (DC). 108

Figura 33 - Micrografia de MEV de região com formação de eutético no compósito t$\mathrm{ZrO}_{2} / 15 \%$ vol $\mathrm{Al}_{2} \mathrm{O}_{3}$ sinterizado por flash sintering com campo elétrico de $200 \mathrm{~V} / \mathrm{cm}$ e corrente alternada. 109

Figura 34 - Micrografia de MEV de região com formação de eutético no compósito t$\mathrm{ZrO}_{2} / 15 \%$ vol $\mathrm{Al}_{2} \mathrm{O}_{3}$ sinterizado por flash sintering com campo elétrico de $200 \mathrm{~V} / \mathrm{cm}$ e corrente alternada: (a) obtida com elétrons secundários; (b) obtida com elétrons retroespalhados; (c) ampliação da região de eutético.

Figura 35 - Difratogramas de raios $\mathrm{X}$ da mistura de pós $\mathrm{Al}+\mathrm{C}+\mathrm{Nb}_{2} \mathrm{O}_{5}+\mathrm{Al}_{2} \mathrm{O}_{3}$ antes e após a moagem em moinho de alta energia tipo "Spex" por $330 \mathrm{~min}$. 112 Figura 36 - Curvas de distribuição acumulada de tamanho de partículas do pó de $\mathrm{Al}_{2} \mathrm{O}_{3}-\mathrm{NbC}$ : (a) antes da moagem em moinho planetário; (b) depois da moagem em moinho planetário.

Figura 37 - Micrografia obtida por MET dos pós de $\mathrm{Al}_{2} \mathrm{O}_{3}-\mathrm{NbC}$ : (a) campo escuro; (b) campo claro.

Figura 38 - Análise de TG/DSC do pó de $\mathrm{Al}_{2} \mathrm{O}_{3}-\mathrm{NbC}$ sintetizado por moagem de alta energia em atmosfera de ar sintético. 115

Figura 39 - Curvas de retração linear e taxa de retração linear versus temperatura do nanocompósito $\mathrm{t}-\mathrm{ZrO}_{2} / \mathrm{Al}_{2} \mathrm{O}_{3}-\mathrm{NbC}$ sinterizado convencionalmente, obtidas pelo ensaio de dilatometria em fluxo de ar sintético.

Figura 40 - Micrografias obtidas por MEV das superfícies de fratura dos nanocompósitos $\mathrm{t}-\mathrm{ZrO}_{2} / \mathrm{Al}_{2} \mathrm{O}_{3}-\mathrm{NbC}$ sinterizados convencionalmente a: (a) $1400^{\circ} \mathrm{C} / 2 \mathrm{~h}$; (b) $1450^{\circ} \mathrm{C} / 2 \mathrm{~h}$; (c) $1500^{\circ} \mathrm{C} / 2 \mathrm{~h}$ 
Figura 41 - Micrografia da superfície polida do nanocompósito t- $\mathrm{ZrO}_{2} / \mathrm{Al}_{2} \mathrm{O}_{3}-\mathrm{NbC}$ sinterizado convencionalmente a $1400^{\circ} \mathrm{C} / 2 \mathrm{~h}$ : (a) com menor aumento; (b) com maior aumento.

Figura 42 - Micrografias obtidas por MEV da superfície de fratura do nanocompósito $\mathrm{t}-\mathrm{ZrO}_{2} / \mathrm{Al}_{2} \mathrm{O}_{3}-\mathrm{NbC}$ sinterizado em forno convencional a $1600^{\circ} \mathrm{C} / 2 \mathrm{~h}$ : (a) nanopartículas de nova fase formada; (b) eclosão de provável fase líquida. 124 Figura 43 - Micrografias de MEV da região vicinal a uma trinca macroscópica formada espontaneamente no nanocompósito de $\mathrm{t}-\mathrm{ZrO}_{2} / \mathrm{Al}_{2} \mathrm{O}_{3}-\mathrm{NbC}$ sinterizado convencionalmente a $1600^{\circ} \mathrm{C}$ : (a) imagem de elétrons secundários; (b) imagem de elétrons retroespalhados.

Figura 44 - Diagrama de equilíbrio do sistema $\mathrm{Al}_{2} \mathrm{O}_{3}-\mathrm{Nb}_{2} \mathrm{O}_{5}$, sendo $\mathrm{AN}$ : $\mathrm{AINbO} 4$, $\mathrm{AN}_{11}: \mathrm{AlNb}_{11} \mathrm{O}_{29}$ e $\mathrm{AN}_{49}: \mathrm{AlNb}_{49} \mathrm{O}_{124}$. 126

Figura 45 - Velocidade e deslocamento do pistão versus temperatura durante a sinterização por SPS dos nanocompósitos de $\mathrm{t}-\mathrm{ZrO}_{2} / \mathrm{Al}_{2} \mathrm{O}_{3}-\mathrm{NbC}$ 128 Figura 46 - Micrografias das superfícies de fratura dos nanocompósitos t- $\mathrm{ZrO}_{2} / \mathrm{Al}_{2} \mathrm{O}_{3}-$ $\mathrm{NbC}$ sinterizados por SPS a: (a) $1300^{\circ} \mathrm{C}$; (b) $1350^{\circ} \mathrm{C}$; (c) $1400^{\circ} \mathrm{C}$ 130 Figura 47 - Micrografias das superfícies de fratura dos nanocompósitos de t$\mathrm{ZrO}_{2} / \mathrm{Al}_{2} \mathrm{O}_{3}-\mathrm{NbC}$ sinterizados a $1400^{\circ} \mathrm{C}$ : (a) convencionalmente; (b) por SPS 131 Figura 48 - Coeficiente de fricção dos nanocompósitos $\mathrm{t}-\mathrm{ZrO}_{2} / \mathrm{Al}_{2} \mathrm{O}_{3}-\mathrm{NbC}$ ensaiados com esferas de $\mathrm{Al}_{2} \mathrm{O}_{3}$ e de WC-6\%Co e carga de $15 \mathrm{~N}$. 132 Figura 49 - Micrografias de MEV das superfícies de desgaste dos nanocompósitos de $\mathrm{t}-\mathrm{ZrO}_{2} / \mathrm{Al}_{2} \mathrm{O}_{3}-\mathrm{NbC}$ sinterizados por SPS a: (a) $1300^{\circ} \mathrm{C}$; (b) $1350^{\circ} \mathrm{C}$; (d) $1400^{\circ} \mathrm{C}$, ensaiados com esferas de $\mathrm{Al}_{2} \mathrm{O}_{3}$ e carga de $15 \mathrm{~N}$

Figura 50 - Micrografias de MEV das superfícies de desgaste dos nanocompósitos de $\mathrm{t}-\mathrm{ZrO}_{2} / \mathrm{Al}_{2} \mathrm{O}_{3}-\mathrm{NbC}$ sinterizados convencionalmente a: (a) $1400^{\circ} \mathrm{C}$; (b) $1450^{\circ} \mathrm{C}$; (d) $1500^{\circ} \mathrm{C}$, ensaiados com esferas de $\mathrm{Al}_{2} \mathrm{O}_{3}$ e carga de $15 \mathrm{~N}$ 136 Figura 51 - Micrografias de MEV das superfícies de desgaste dos nanocompósitos de t-ZrO$/ \mathrm{Al}_{2} \mathrm{O}_{3}-\mathrm{NbC}$ sinterizados por SPS a: (a) $1300^{\circ} \mathrm{C}$; (b) $1350^{\circ} \mathrm{C}$; (d) $1400^{\circ} \mathrm{C}$, ensaiados com esferas de WC-6\%Co e carga de $15 \mathrm{~N}$.

Figura 52 - Micrografias de MEV das superfícies de desgaste dos nanocompósitos de $\mathrm{t}-\mathrm{ZrO}_{2} / \mathrm{Al}_{2} \mathrm{O}_{3}-\mathrm{NbC}$ sinterizados convencionalmente a: (a) $1400^{\circ} \mathrm{C}$; (b) $1450^{\circ} \mathrm{C}$; (d) $1500^{\circ} \mathrm{C}$, ensaiados com esferas de WC-6\%Co e carga de $15 \mathrm{~N}$. 


\section{LISTA DE TABELAS}

Tabela 1 - Comparação entre materiais convencionais e nanométricos em termos de fração volumétrica de contorno de grão. 28

Tabela 2 - Valores de densidades dos compósitos sinterizados em diferentes temperaturas.

Tabela 3 - Valores de Módulos de Young da t- $\mathrm{ZrO}_{2}$ e dos compósitos $\mathrm{t}-\mathrm{ZrO}_{2} / \mathrm{Al}_{2} \mathrm{O}_{3}$ com $5 \%$ e $15 \%$ em volume de $\mathrm{Al}_{2} \mathrm{O}_{3}$.

Tabela 4 - Valores de microdureza e tenacidade à fratura da $\mathrm{t}-\mathrm{ZrO}_{2}$ e da $\mathrm{t}-\mathrm{ZrO}_{2} / \mathrm{Al}_{2} \mathrm{O}_{3}$ com $5 \%$ e $15 \%$ em volume de $\mathrm{Al}_{2} \mathrm{O}_{3}$ .96

Tabela 5 - Temperaturas de início da retração linear durante a sinterização por flash sintering e tempo de espera para a $\mathrm{t}-\mathrm{ZrO}_{2}, \mathrm{t}-\mathrm{ZrO}_{2} / 5 \%$ vol $\mathrm{Al}_{2} \mathrm{O}_{3}$ e $\mathrm{t}-\mathrm{ZrO}_{2} / 15 \%$ vol $\mathrm{Al}_{2} \mathrm{O}_{3}$. 103

Tabela 6 - Valores de densidade das amostras sinterizadas por flash sintering. ....104 Tabela 7 - Tamanho de cristalito e fração volumétrica de cada fase calculada pelo método de Rietveld com base no difratograma de raios $X$ do produto de moagem.

Tabela 8 - Valores de densidade relativas (\%DT) e propriedades mecânicas dos nanocompósitos $\mathrm{t}-\mathrm{ZrO}_{2} / \mathrm{Al}_{2} \mathrm{O}_{3}-\mathrm{NbC}$ sinterizados convencionalmente.

Tabela 9 - Valores de densidade aparente (\%DT) e propriedades mecânicas dos nanocompósitos $\mathrm{t}-\mathrm{ZrO}_{2} / \mathrm{Al}_{2} \mathrm{O}_{3}-\mathrm{NbC}$ sinterizados por SPS.

Tabela 10 - Taxas de desgaste dos nanocompósitos $\mathrm{t}-\mathrm{ZrO}_{2} / \mathrm{Al}_{2} \mathrm{O}_{3}-\mathrm{NbC}$ ensaiados com esferas de $\mathrm{Al}_{2} \mathrm{O}_{3}$ e de WC-6\%Co e carga de $15 \mathrm{~N}$.

Tabela 11 - Confirmação dos regimes de desgaste dos nanocompósitos de t$\mathrm{ZrO}_{2} / \mathrm{Al}_{2} \mathrm{O}_{3}-\mathrm{NbC}$ ensaiados com esferas de $\mathrm{Al}_{2} \mathrm{O}_{3}$ e de WC-6\%Co, utilizando carga de $15 \mathrm{~N}$. 


\section{LISTA DE QUADROS}

Quadro 1 - Mecanismos de transporte de matéria na sinterização.

Quadro 2 - Reagentes utilizados para produção do pó precursor de $\mathrm{Al}_{2} \mathrm{O}_{3}-\mathrm{NbC}$ em

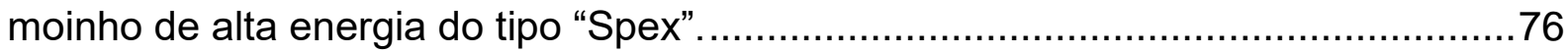

Quadro 3 - Condições de sinterização para flash sintering. .......................................82 


\section{LISTA DE ABREVIATURAS E SIGLAS}

$\begin{array}{ll}\mathrm{Al}_{2} \mathrm{O}_{3} & \text { Alumina } \\ \mathrm{DRX} & \text { Difração de raios X } \\ \mathrm{DSC} & \text { Calorimetria exploratória diferencial } \\ \mathrm{DT} & \text { Densidade teórica } \\ \mathrm{EDS} & \text { Espectroscopia por dispersão de elétrons } \\ \mathrm{FAST} & \text { Field-assisted sintering technique } \\ \mathrm{FS} & \text { Flash sintering } \\ \mathrm{FTIR} & \text { Infravermelho de transformada de Fourier } \\ \mathrm{HCl} & \text { Ácido clorídrico } \\ \mathrm{IR} & \text { Infravermelho } \\ \mathrm{MET} & \text { Microscopia eletrônica de transmissão } \\ \mathrm{MEV} & \text { Microscopia eletrônica de varredura } \\ \mathrm{NbC} & \text { Carbeto de nióbio } \\ \mathrm{PABA} & \text { Ácido para-aminobenzoico } \\ \mathrm{SPS} & \text { Spark plasma sintering } \\ \mathrm{TG}_{\mathrm{t}} & \text { Termogravimetria } \\ \mathrm{ZrO} & \text { Zircônia tetragonal } \\ \mathrm{t}-\mathrm{ZrO} & \end{array}$




\section{SUMÁRIO}



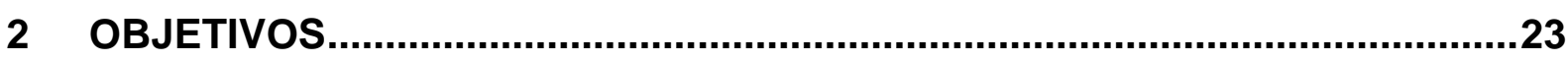

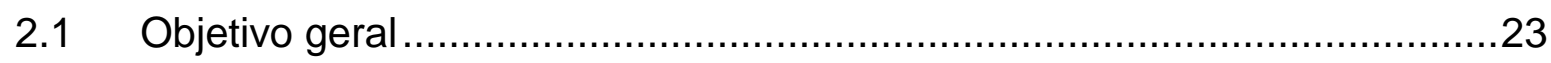

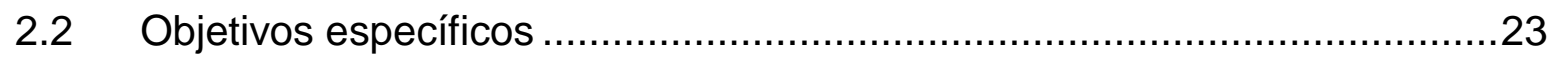

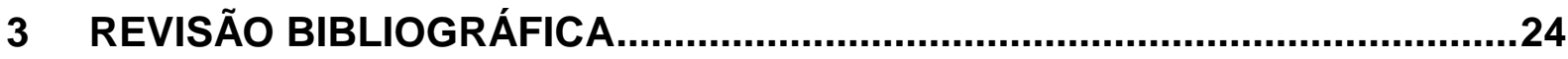

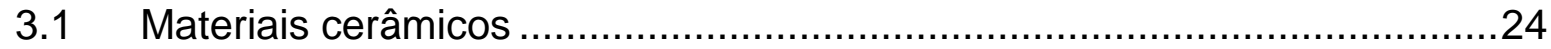

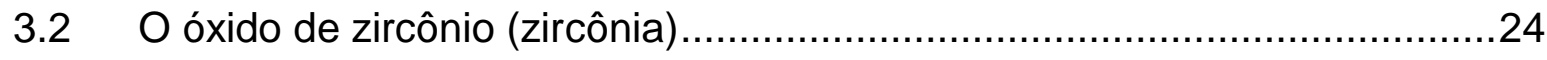

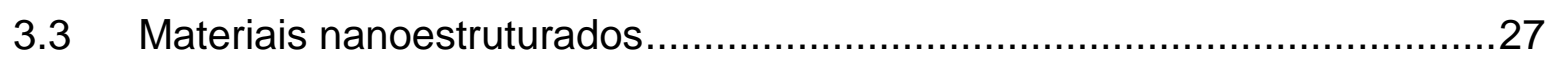

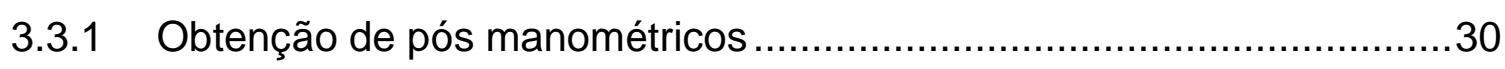

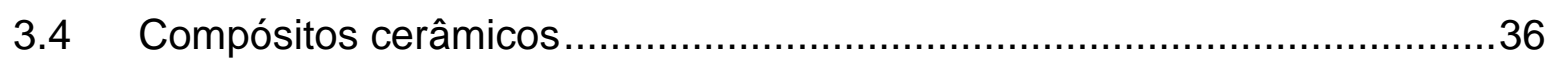

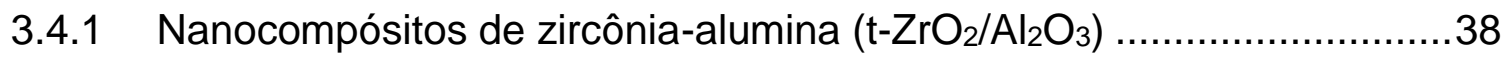



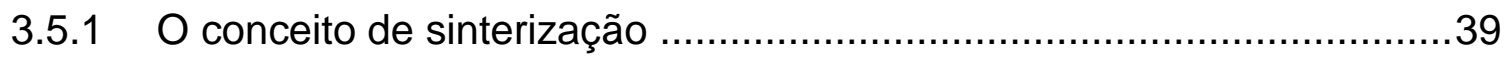

3.5.2 A "força motriz" da sinterização .......................................................40

3.5.3 A sinterização no estado sólido ...................................................... 41

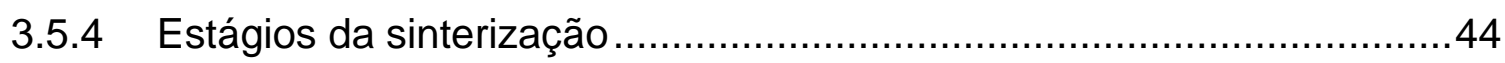

3.5.5 Utilização de atmosfera ou vácuo na sinterização convencional ............46

3.5.6 Métodos não convencionais de sinterização .....................................47

3.6 Caracterização das propriedades mecânicas de materiais cerâmicos........58

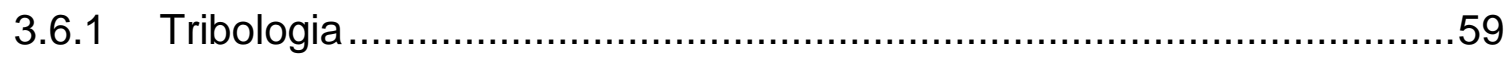

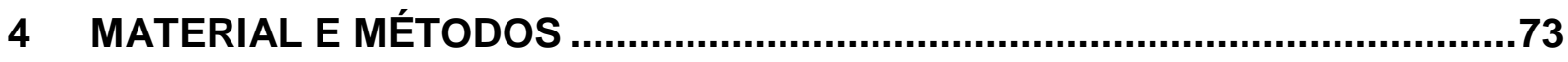

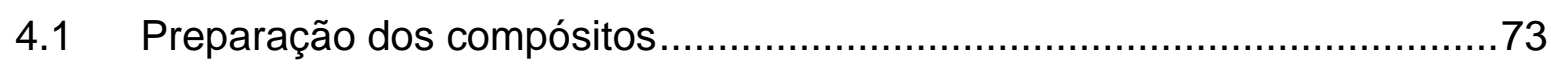

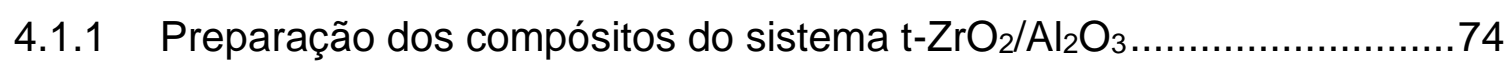

4.1.2 Preparação dos pós compósitos do sistema $\mathrm{t}-\mathrm{ZrO}_{2} / \mathrm{Al}_{2} \mathrm{O}_{3}-\mathrm{NbC} \ldots \ldots \ldots \ldots . . .75$

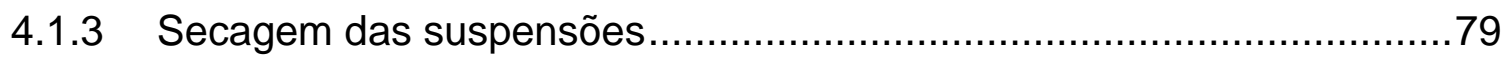

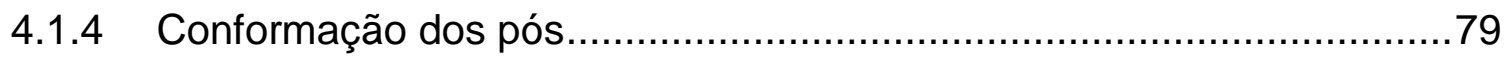

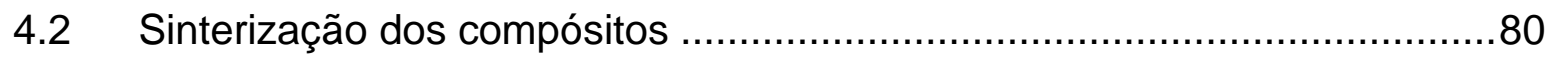





4.3 Caracterização dos compósitos sinterizados dos sistemas $\mathrm{t}-\mathrm{ZrO}_{2} / \mathrm{Al}_{2} \mathrm{O}_{3}$ e t-

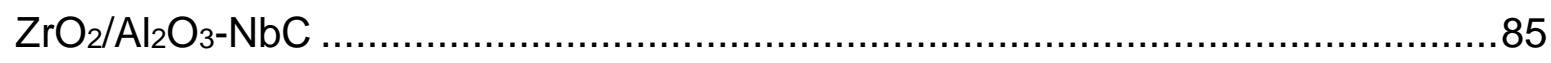

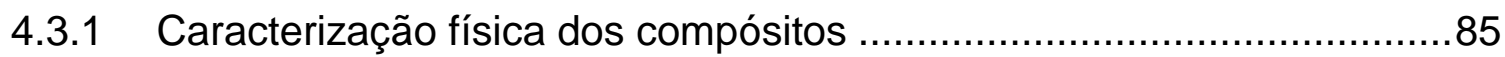




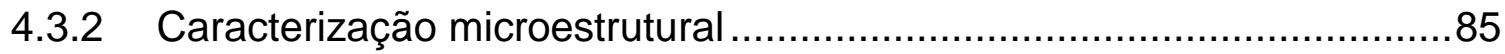

4.3.3 Caracterização das propriedades mecânicas dos compósitos ...............86

5 RESULTADOS E DISCUSSÃO

5.1 Caracterização da $\mathrm{t}-\mathrm{ZrO}_{2}$ e dos compósitos de $\mathrm{t}-\mathrm{ZrO}_{2} / \mathrm{Al}_{2} \mathrm{O}_{3} \ldots \ldots \ldots \ldots \ldots \ldots \ldots . . . . . . . . . .90$

5.1.1 Sinterização convencional ...........................................................90

5.1.2 Sinterização pela técnica de flash sintering ..........................................99

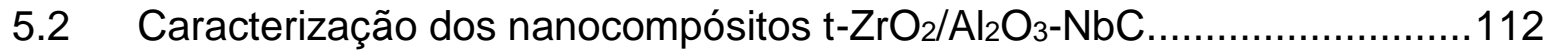

5.2.1 Caracterização do pó de $\mathrm{Al}_{2} \mathrm{O}_{3}-\mathrm{NbC}$ sintetizado por moagem reativa de alta energia

5.2.2 Caracterização dos nanocompósitos de $\mathrm{t}-\mathrm{ZrO}_{2} / \mathrm{Al}_{2} \mathrm{O}_{3}-\mathrm{NbC}$ sinterizados convencionalmente

5.2.3 Caracterização dos nanocompósitos de $\mathrm{t}-\mathrm{ZrO}_{2} / \mathrm{Al}_{2} \mathrm{O}_{3}-\mathrm{NbC}$ sinterizados por SPS.

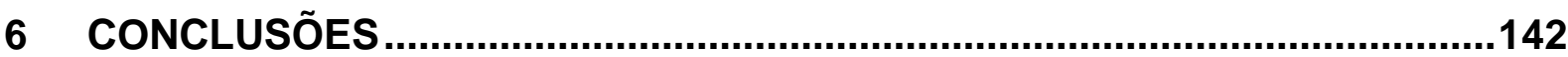

7 SUGESTÕES PARA TRABALHOS FUTUROS …….......................................

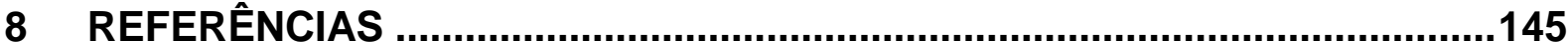




\section{INTRODUÇÃO}

A zircônia $\left(\mathrm{ZrO}_{2}\right)$ e a alumina $\left(\mathrm{Al}_{2} \mathrm{O}_{3}\right)$ são dois dos principais materiais cerâmicos representantes da categoria de cerâmicas avançadas. Quando estabilizada na sua fase tetragonal, a $\mathrm{ZrO}_{2}$ destaca-se pela sua alta tenacidade à fratura, resistência à flexão e inércia química. $A \mathrm{Al}_{2} \mathrm{O}_{3}$, por sua vez, possui um elevado módulo de elasticidade, portanto elevada rigidez, alta dureza e resistência ao desgaste, além de possuir excelente refratariedade. Nos últimos anos, com o advento da nanotecnologia e as crescentes pesquisas neste ramo, muito tem se investigado a respeito das propriedades diferenciadas que materiais cerâmicos nanoestruturados apresentam, por possuir uma característica microestrutural considerada nanométrica $(<100 \mathrm{~nm})$. Esta área promissora da pesquisa em materiais traz à tona diversos desafios, especialmente no tocante à obtenção de uma boa combinação de processamento economicamente viável com a efetiva melhoria de propriedades. Dentre os materiais nanoestruturados figuram os nanocompósitos de matriz cerâmica.

Os carbetos metálicos, materiais majoritariamente sintéticos, também têm se mostrado excelentes materiais quando se trata de inércia química e resistência a altas temperaturas, além de alta dureza e resistência à abrasão. Dentre eles, o carbeto de nióbio $(\mathrm{NbC})$ se compara aos outros carbetos de metais de transição, que são utilizados no reforço de ligas metálicas de alta dureza. Além disso, é importante destacar que o Brasil é o produtor majoritário de nióbio em sua forma bruta no mundo, contando com mais de $95 \%$ dos minérios que contêm esse metal. No entanto, são relativamente escassas as pesquisas científicas que envolvem o nióbio e seus compostos processados e suas aplicações tecnológicas no Brasil. O NbC, entre outros, tem sido reportado como excelente opção no design composicional e microestrutural de novos materiais de alto desempenho mecânico.

O processo de fabricação de um nanocompósito cerâmico envolve desde a seleção rigorosa das matérias-primas até um processo controlado de sinterização, passando pela preparação dos pós que compõem a mistura, sua conformação e eventuais tratamentos subsequentes. Dentre diversos métodos de síntese de materiais, a moagem reativa de alta energia pode ser uma importante etapa do processo de fabricação de um novo material, permitindo a obtenção de materiais 
nanocristalinos com composições e propriedades ajustadas conforme a necessidade e a especificidade do sistema. Este processo tem como vantagem um baixo custo, porém ofuscado pela dificuldade de obter materiais com alta pureza e pela aglomeração das partículas durante o processo. Isto se deve à alta taxa de transferência de energia que nele ocorre, levando a temperaturas elevadas durante a reação dentro do jarro de moagem. Portanto, apesar de vantajosa, a moagem de alta energia requer processos de purificação e desaglomeração após a síntese.

A sinterização de materiais cerâmicos nanoestruturados, que consolida os corpos conformados a partir dos pós em um sólido coerente com fortes ligações entre as partículas, requer temperaturas relativamente altas. Para manter uma microestrutura refinada e as consequentes propriedades inerentes a um material nanoestruturado, visa-se diminuir o quanto possível a temperatura em que 0 processo de sinterização se completa com alta densificação e fino tamanho de grão. Para tanto, métodos não convencionais como spark plasma sintering (SPS) e flash sintering (FS) têm despontado como soluções para a sinterização de materiais de forma ultrarrápida e com alto desempenho. Nestes métodos, o princípio de transferência de calor ocorre de forma diferente da sinterização convencional, promovendo uma ligação eficiente e rápida das partículas do material conformado, geralmente em tempo mais curto e com maior eficiência de processo. No entanto, esses métodos possuem limitações de forma e tamanho dos materiais sinterizados, bem como alto custo e baixa produtividade.

Diante do exposto, neste trabalho foram produzidos, sinterizados (convencional e não convencionalmente) e caracterizados física, microestrutural e mecanicamente nanocompósitos de matriz de $\mathrm{t}-\mathrm{ZrO}_{2}$. Os sistemas estudados foram: $\mathrm{t}-\mathrm{ZrO} \mathrm{rO}_{2} \mathrm{t}-\mathrm{ZrO}_{2} / \mathrm{Al}_{2} \mathrm{O}_{3}$, com $5 \%$ e $15 \%$ em volume de $\mathrm{Al}_{2} \mathrm{O}_{3}$, sinterizados em forno convencional e por flash sintering; e $\mathrm{t}-\mathrm{ZrO}_{2} / \mathrm{Al}_{2} \mathrm{O}_{3}-\mathrm{NbC}$, com $5 \%$ em volume de $\mathrm{Al}_{2} \mathrm{O}_{3}-$ $\mathrm{NbC}$, sinterizado em forno convencional e por spark plasma sintering. Buscou-se obter materiais com microestrutura refinada e de alto desempenho mecânico e tribológico, visando a aplicações onde se requer alta resistência mecânica (dureza e tenacidade à fratura) em conjunto com resistência ao desgaste. 


\section{OBJETIVOS}

\subsection{Objetivo geral}

O objetivo deste trabalho foi produzir e caracterizar nanocompósitos de matriz de $\mathrm{t}-\mathrm{ZrO}_{2}$ (estabilizada com $3 \%$ mol de $\mathrm{Y}_{2} \mathrm{O}_{3}$ ) com adição de $\mathrm{Al}_{2} \mathrm{O}_{3}$ e de nanopartículas de um pó de $\mathrm{Al}_{2} \mathrm{O}_{3}-\mathrm{NbC}$. Nos compósitos $\mathrm{t}-\mathrm{ZrO}_{2} / \mathrm{Al}_{2} \mathrm{O}_{3}$, as proporções utilizadas foram de 5 e $15 \%$ em volume de $\mathrm{Al}_{2} \mathrm{O}_{3}$, e nos compósitos $\mathrm{t}-\mathrm{ZrO}_{2} / \mathrm{Al}_{2} \mathrm{O}_{3}$ $\mathrm{NbC}$, foi de $5 \%$ em volume de $\mathrm{Al}_{2} \mathrm{O}_{3}-\mathrm{NbC}$. A sinterização foi estudada por diferentes métodos: sinterização convencional, Spark Plasma Sintering (SPS) e Flash Sintering (FS).

\subsection{Objetivos específicos}

Dentre os objetivos específicos deste trabalho estão:

- Produção dos pós nanométricos de $\mathrm{Al}_{2} \mathrm{O}_{3}-\mathrm{NbC}$, usando moagem reativa de alta energia em moinho agitador do tipo "Spex";

- Sinterização de $\mathrm{t}-\mathrm{ZrO}_{2}, \mathrm{t}-\mathrm{ZrO}_{2} / \mathrm{Al}_{2} \mathrm{O}_{3}$ e $\mathrm{t}-\mathrm{ZrO}_{2} / \mathrm{Al}_{2} \mathrm{O}_{3}-\mathrm{NbC}$ por:

- Sinterização convencional;

- Sinterização não convencional de $\mathrm{t}-\mathrm{ZrO}_{2} / \mathrm{Al}_{2} \mathrm{O}_{3}-\mathrm{NbC}$ por SPS;

- Sinterização não convencional de $\mathrm{t}-\mathrm{ZrO}_{2}$ e $\mathrm{t}-\mathrm{ZrO}_{2} / \mathrm{Al}_{2} \mathrm{O}_{3}$ por $\mathrm{FS}$;

- Caracterização física, mecânica, microestrutural e de resistência ao desgaste dos materiais desenvolvidos. 


\section{REVISÃo BIBLIOGRÁFICA}

\subsection{Materiais cerâmicos}

A definição mais aceita de uma cerâmica é dada por Kingery e colaboradores (1976): “A cerâmica é um sólido inorgânico, não-metálico". No entanto, dada a variedade de acepções geradas por esta definição, em vista dos diversos tipos de materiais desenvolvidos com o passar dos anos, tornou-se impossível definir qualquer tipo de material pelas suas propriedades específicas. Por exemplo, conforme argumentos de Boch e Nièpce (2007), não se pode dizer que todas as cerâmicas são frágeis, pois algumas podem ser deformadas superplasticamente, chegando a ser menos frágeis que alguns metais. Também, não se pode dizer que todas as cerâmicas são isolantes, a menos que se estabeleça um valor para o gap da banda onde um material não é um semicondutor. Da mesma forma, não se pode considerar todas as cerâmicas más condutoras térmicas, pois o diamante, que é considerado estruturalmente como uma cerâmica, possui a condutividade térmica mais alta do que qualquer outro material conhecido.

Do ponto de vista da engenharia de materiais, ao serem definidos os materiais cerâmicos, não se consideram apenas a composição química, a estrutura e a propriedade dos sólidos, mas também seu método de preparação. De acordo com Boch e Nièpce (2007), seria apropriado dividir em duas cada uma das três categorias de materiais - metálicos, poliméricos e cerâmicos - em subcategorias, como a de materiais naturais e a de materiais sintéticos.

\subsection{O óxido de zircônio (zircônia)}

O óxido de zircônio, ou zircônia $\left(\mathrm{ZrO}_{2}\right)$, é uma das matérias-primas cerâmicas de maior importância tecnológica devido às boas propriedades dentre os materiais cerâmicos e a enorme gama de aplicações que possui. Na natureza, a zircônia é principalmente derivada de duas fontes: o zircão $\left(\mathrm{ZrO}_{2} \mathrm{SiO}_{2}\right)$ e a badeleíta $\left(\mathrm{ZrO}_{2}\right.$ monoclínica impura). O zircão é encontrado como depósito secundário, por exemplo, na Austrália, Índia, África do Sul e Estados Unidos. É frequentemente misturado em 
uma areia com outros minerais, como o rutilo e a monazita (fonte de terras raras). A badeleíta, por sua vez, é encontrada em depósitos menores, e usualmente contém impurezas como sílica, óxido de ferro e titânia. Fontes deste mineral são exploradas comercialmente no Brasil e na África do Sul (LEE, 1994). Desde o final da década de 1970, quando houve um aumento significativo nas pesquisas envolvendo zircônia, especialmente na Europa, Japão e EUA, muitas técnicas de síntese foram desenvolvidas e/ou adaptadas para se obter zircônia de alta pureza e de escala nanométrica e submicrométrica, como reações na fase vapor, precipitação hidrotérmica e técnicas sol-gel, entre outras (SŌMIYA, YAMAMOTO, YANAGIDA, 1988).

A zircônia possui uma estrutura do tipo fluorita cúbica, do tipo $A B_{2}$, onde o cátion $\left(\mathrm{Zr}^{4+}\right)$ é grande o suficiente para estabelecer uma coordenação octaédrica. $\mathrm{A}$ estrutura é baseada no empacotamento CFC dos cátions com todos os interstícios tetraédricos preenchidos por ânions. Apesar disto, na realidade existem três polimorfos cristalinos deste composto: são as fases cúbica, tetragonal e monoclínica, diferenciada pela simetria cristalina e pelos espaçamentos interatômicos, mas não pela coordenação dos íons formadores da estrutura (CHIANG, BIRNIE III, KINGERY, 1997). A zircônia é um óxido com temperatura de fusão extremamente alta (em torno de $2880^{\circ} \mathrm{C}$ ), que solidifica na fase cúbica, depois se transforma na fase tetragonal (em torno de $2370^{\circ} \mathrm{C}$ ) e, finalmente, abaixo de cerca de $1170^{\circ} \mathrm{C}$, torna-se monoclínica (BOCH, NIÈPCE, 2007). A Figura 1 mostra os polimorfos da zircônia. As transformações polimórficas ocorrentes na zircônia são do tipo deslocativas, que ocorrem por simples deslocamentos atômicos. As transformações deslocativas requerem menos energia que transformações reconstrutivas, que por sua vez ocorrem por quebra e rearranjo de ligações, como acontece, por exemplo, com a transformação da alumina de transição $\mathrm{\gamma}-\mathrm{Al}_{2} \mathrm{O}_{3}$ para o seu polimorfo mais estável, $\alpha$ $\mathrm{Al}_{2} \mathrm{O}_{3}$ (CHIANG, BIRNIE III, KINGERY, 1997). 
Figura 1 - Fases polimórficas da zircônia: (a) cúbica; (b) tetragonal; (c) monoclínica.



(a) Cúbica

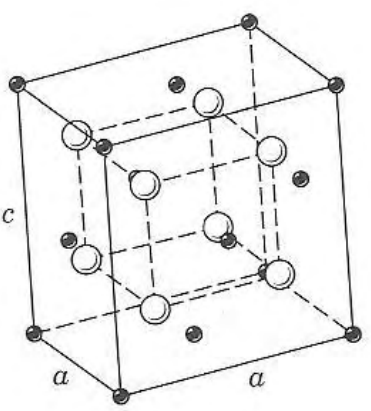

(b) Tetragonal

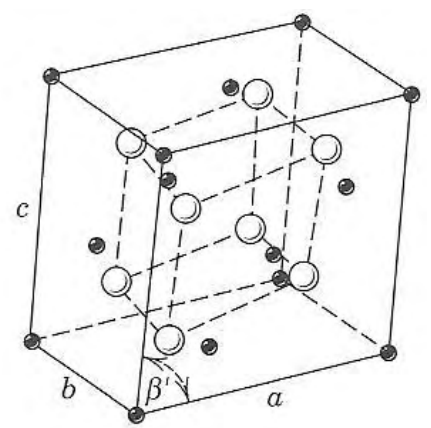

(c) Monoclínica

Fonte: Adaptado de CHIANG, Y. M.; BIRNIE III, D.; KINGERY, W. D. Physical Ceramics: Principles for Ceramic Science and Engineering (The MIT Series in Materials Science and Engineering). New York: John Wiley and Sons, 1997.

A última transição de fase da zircônia no sentido do resfriamento, ou seja, da fase tetragonal para a fase monoclínica, é acompanhada por variações dimensionais consideráveis (aumento de volume em torno de 4\%), que excede o limite de tensão máximo do material, resultando em sua fragmentação. Isto inviabiliza o uso tecnológico da zircônia pura, uma vez que as temperaturas de sinterização são muito mais altas do que a temperatura dessa transformação de fase, que ocorre inevitavelmente durante o resfriamento. Portanto, para se produzir peças de zircônia, é necessário combiná-la com óxidos conhecidos como "estabilizadores", ( $\mathrm{M}_{\times} \mathrm{O}_{\mathrm{y}}=$ principalmente $\mathrm{CaO}, \mathrm{MgO}, \mathrm{Y}_{2} \mathrm{O}_{3}$, e alguns óxidos de terras raras). Desta forma, o diagrama de fases $\mathrm{ZrO}_{2}-\mathrm{M}_{\mathbf{x}} \mathrm{O}_{\mathrm{y}}$ é modificado de forma favorável, o que ajuda a preservar uma zircônia "estabilizada" (seja no estado estável ou metaestável), livre de transições na faixa de temperatura em que é processada e utilizada $(\mathrm{BOCH}$, NIÈPCE, 2007).

A dopagem da zircônia com pequenas quantidades de $\mathrm{Y}_{2} \mathrm{O}_{3}$ resulta na estabilização da fase tetragonal (que possui maior tenacidade à fratura) e, com quantidades relativamente maiores, estabiliza-se a fase cúbica (que possui alta condutividade iônica) à temperatura ambiente. A estabilização da fase tetragonal à temperatura ambiente pode resultar nas seguintes formas comuns da zircônia:

- Zircônia parcialmente estabilizada (PSZ - partially stabilized zirconia), que consiste de uma matriz de uma cerâmica frágil e uma dispersão de precipitados tetragonais, os quais podem estar na sua forma pura ou dopados com $\mathrm{Ca}^{2+}$ (Ca-PSZ) ou $\mathrm{Mg}^{2+}$ (Mg-PSZ); 
- Policristais tetragonais de zircônia (TZP - tetragonal zirconia polycrystals), que consistem de uma matriz de $\mathrm{ZrO}_{2}$ estabilizada, que foi estabilizada na forma tetragonal pela adição de dopantes, tais como $\mathrm{Ce}^{4+}(\mathrm{Ce}-$ TZP) e $\mathrm{Y}^{3+}(\mathrm{Y}-\mathrm{TZP})$.

A zircônia totalmente estabilizada (FSZ - fully stabilized zirconia) refere-se ao material que foi completamente estabilizado na sua forma cúbica (SCHAKELFORD, DOREMUS, 2008).

A Figura 2 mostra um exemplo das modificações proporcionadas pela estabilização no caso do sistema $\mathrm{ZrO}_{2}-\mathrm{Y}_{2} \mathrm{O}_{3}$, material utilizado neste trabalho, com $3 \%$ em mol de $\mathrm{Y}_{2} \mathrm{O}_{3}$, através do seu diagrama de fases parcial, na porção rica em $\mathrm{ZrO}_{2}$.

Figura 2 - Diagrama de fases do sistema $\mathrm{ZrO}_{2}-\mathrm{Y}_{2} \mathrm{O}_{3}$, na porção rica em $\mathrm{ZrO}_{2}$.

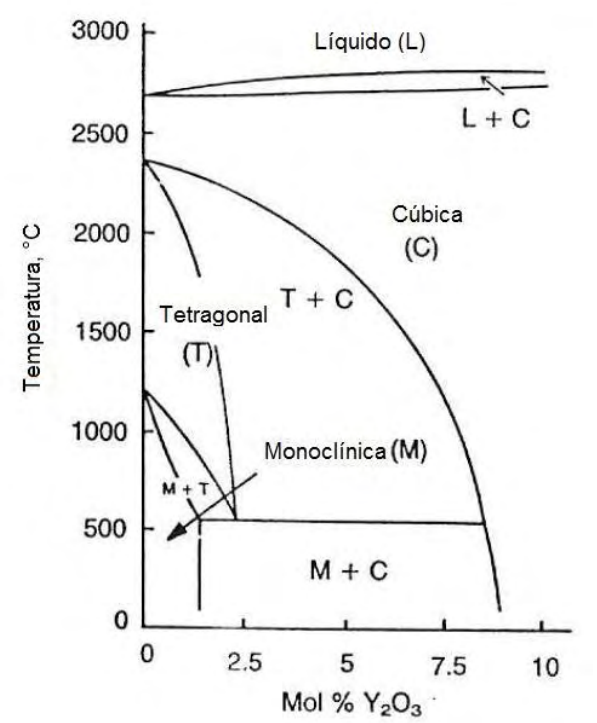

Fonte: Adaptado de SCOTT, H. G. Phase relationships in the zirconia-yttria system. Journal of Materials Science, v. 10, n. 9, pp. 1527-1535, 2006.

\subsection{Materiais nanoestruturados}

Materiais com microestruturas ultrafinas que possuem um tamanho médio de grão ou de fase na ordem nanométrica são classificados como materiais nanoestruturados. Com o avanço nessa área da tecnologia, o significado do termo se modificou, passando a considerar-se como um material nanoestruturado qualquer material contendo grãos, camadas ou filamentos menores que $100 \mathrm{~nm}$, ou camadas 
ou filamentos nessa dimensão (NALWA, 2002). Materiais com tamanho de grão ou partes constituintes acima de $100 \mathrm{~nm}$, mas abaixo de $1 \mu \mathrm{m}$ são normalmente chamados de submicrométricos.

O interesse nesse tipo de materiais foi estimulado pelo fato de que, devido ao pequeno tamanho das suas partes constituintes (partícula, grão ou fase), e a alta razão entre superfície e volume, as propriedades mecânicas, elétricas, ópticas e magnéticas desses materiais costumam tornar-se diferenciadas (NALWA, 2002; HAMPDEN-SMITH, KLEMPERER, BRINKER, 1992).

As propriedades dos materiais nanoestruturados dependem dos seguintes aspectos microestruturais: (1) o tamanho e a distribuição de tamanho de grão finos (< 100 nm); (2) a composição química das fases constituintes; (3) a presença de interfaces, mais especificamente, contornos de grãos, interfaces heterofásicas, ou superfície livre; e (4) interações entre os domínios constituintes. A presença e a interação dessas quatro propriedades normalmente são decisivas para as propriedades desses materiais (NALWA, 2002).

No caso dos materiais cerâmicos, a obtenção de uma microestrutura constituída de grãos uniformes, sejam eles nanométricos ou submicrométricos, resulta em aumento da resistência mecânica, da tenacidade à fratura e da resistência à abrasão, o que possibilita melhor acabamento superficial e ocorrência de até superplasticidade (BECHER et al., 1998; KIM et al., 2001; CHINELATTO, 2002; HIRAGA, 2007; SÁNCHEZ-GONZÁLEZ et al., 2011; MILAK et al., 2015).

A Tabela 1 apresenta uma comparação entre a porcentagem volumétrica de contorno de grão entre materiais nanocristalinos e materiais com tamanho de grão convencional. Pela tabela, pode-se verificar que a porcentagem volumétrica de contorno de grão para um material nanocristalino com tamanho de grão de $20 \mathrm{~nm}$ é 100 vezes maior do que o material com tamanho de grão convencional.

Tabela 1 - Comparação entre materiais convencionais e nanométricos em termos de fração volumétrica de contorno de grão.

\begin{tabular}{l|c|c|c|c|c}
\hline & $\begin{array}{c}\text { Materiais } \\
\text { convencionais }\end{array}$ & \multicolumn{4}{|c}{ Materiais nanométricos } \\
\hline Tamanho de grão $(\mathrm{nm})$ & 2000 & 20 & 10 & 4 & 2 \\
\hline Espessura do contorno de grão $(\mathrm{nm})$ & 0,6 & 0,6 & 0,6 & 0,6 & 0,6 \\
\hline Grãos em 2x2x2 $\mu \mathrm{m}$ & 1 & $10^{6}$ & $0,8 \times 10^{7}$ & $1,3 \times 10^{8}$ & $10^{9}$ \\
\hline $\begin{array}{l}\text { Fração volumétrica de contorno de } \\
\text { grão }\end{array}$ & 0,09 & 9,0 & 18,0 & 42,6 & 80,5 \\
\hline
\end{tabular}

Fonte: Adaptado de WEN, S.; YAN, D. Grain boundary in some nano-materials. Ceramics International, v. 21, pp. 301-303, 1995. 
Essa grande diferença na fração volumétrica de contornos de grão é uma das características mais importantes dos materiais nanocristalinos, e que causa uma melhoria muito significativa nas propriedades, sobretudo nas mecânicas (NALWA, 2002).

Estudos pioneiros de Frenkel (1945) e Herring (1950) indicam que a taxa de densificação é inversamente proporcional ao tamanho de partícula. Baseado nisso, quando uma partícula decresce em tamanho da ordem de micrômetros para nanômetros, pode-se esperar uma grande diminuição no tempo de sinterização, a uma determinada temperatura. Dessa maneira, partículas nanométricas podem oferecer vantagens consideráveis na fabricação de cerâmicas, especialmente porque as temperaturas e tempos de sinterização requeridos podem inibir um crescimento de grão indesejado, o que é muito importante para melhorar as propriedades do material. Isso vem sendo comprovado de forma consistente ao longo dos anos, em trabalhos envolvendo diversos sistemas cerâmicos (ZENG et al., 1998; PRASAD et al., 2010; CHAIM et al., 2012; RYU et al., 2012).

Segundo Gleiter (1995; 2000), os materiais nanoestruturados podem ser divididos em três categorias:

- Materiais e/ou dispositivos com dimensões reduzidas e/ou dimensionalidade na forma de partículas de tamanho nanométrico, fios finos ou filmes finos;

- Materiais e/ou dispositivos nos quais a nanoestrutura (microestrutura em escala nanométrica) é limitada a uma região de superfície fina (de escala nanométrica) de um material maciço (bulk);

- Materiais maciços, com uma microestrutura de escala nanométrica, nos quais a composição química, o arranjo atômico e/ou o tamanho dos blocos constituintes formando o sólido variam em uma escala de comprimento de alguns nanômetros através do maciço.

Essas três categorias, dependendo da composição química dos cristalitos, podem ser agrupadas em quatro famílias (GLEITER, 2000):

- 1a família: os cristalitos e as regiões interfaciais têm a mesma composição química;

- $2^{\text {a }}$ família: consiste de cristalitos com diferentes composições químicas (representado na Figura 3 com diferentes hachuras);

- $3^{a}$ família: consiste na variação de composição que ocorre principalmente entre os cristalitos e as regiões interfaciais; 
- 4a família: é constituída por cristalitos de tamanho nanométrico (sejam em camadas, bastonetes ou cristalitos equiaxiais) dispersos em uma matriz de composição química diferente.

$\mathrm{Na}$ Figura 3 é mostrado um esquema da classificação dos materiais nanoestruturados.

Figura 3 - Esquema da classificação dos materiais nanoestruturados de acordo com sua composição química e dimensionalidade dos cristalitos.



Fonte: Adaptado de GLEITER, H. Nanostructured Materials: State of art and Perspectives. NanoStructured Materials. v. 6, p. 3-14, 1995.

\subsubsection{Obtenção de pós manométricos}

Uma das formas estudadas para a obtenção de materiais nanoestruturados é a moagem de alta energia. Esse processo de moagem foi usado neste trabalho. Os processos de moagem de alta energia (high energy milling) são conhecidos pela expressão inglesa "mechanical alloying", que pode englobar os seguintes processos:

$\rightarrow \quad$ Elaboração mecânica de ligas por meio da mistura de pós elementares;

$\rightarrow \quad$ Moagem convencional, envolvendo a cominuição e a amorfização puramente mecânica de uma substância pura ou composta;

$\rightarrow \quad$ Moagem com reação, envolvendo a cominuição e a amorfização mecanoquímica de misturas reativas. 
O que caracteriza os processos de moagem de alta energia é a alta taxa de transferência de energia devida à alta relação de bolas/material, à elevada quantidade de impacto com forças compressivas no sistema bolas/jarro de moagem/material, e aos longos tempos de processamento inerentes a esta técnica. (TAKACS, 1993; MATTEAZZI, LE CAER, 1991).

Para a obtenção de carbetos e outros materiais avançados com pequeno tamanho de partícula, a moagem de alta energia tem destacado como uma técnica acessível e versátil (BOTTA Fon, W. J. et al., 2001; PALLONE et al., 2003; 2007; TROMBINI et al., 2011).

Em relação à moagem com reação, esta consiste na mistura e moagem de pós reagentes em moinho de alta energia, que farão parte de uma reação química durante a moagem, produzindo um ou mais compostos com partículas de tamanho nanométrico. Este tipo de processo tem sido descrito na literatura de forma mais específica como "mecanossíntese" ou "síntese mecanoquímica" (SURYANARAYANA, 2001).

Como exemplo, McCormick e colaboradores (1989) demonstraram que o CuO podia ser reduzido a $\mathrm{Cu}$ metálico por meio da moagem de alta energia, à temperatura ambiente, utilizando um metal mais reativo, como $\mathrm{Ca}$. A maior parte das reações de síntese mecanoquímica estudadas é de reações de deslocamento do tipo (Equação 1):

$$
\mathrm{MO}+\mathrm{R} \rightarrow \mathrm{M}+\mathrm{RO}
$$

Onde um óxido metálico $(\mathrm{MO})$ é reduzido por um metal mais reativo (redutor, $\mathrm{R})$, ao metal puro $\mathrm{M}$.

A produção de misturas e compostos até em escala nanocristalina se deve às características diferenciais da moagem reativa de alta energia, as quais proporcionam uma mistura em nível atômico seguida por um considerável trabalho mecânico dos materiais constituintes (MATTEAZZI, LE CAER, 1992).

Os moinhos comumente utilizados na moagem de alta energia e nos seus processos derivados são de bolas, sendo principalmente do tipo vibratório, de atrito e planetário. Cada um desses tipos possui configurações distintas que se adaptam conforme a necessidade e o tipo de material e processo que nele será realizado. $O$ 
moinho utilizado nesta pesquisa para a mecanossíntese do pó $\mathrm{Al}_{2} \mathrm{O}_{3}-\mathrm{NbC}$ é do tipo moinho agitador (shakermill) conhecido pelo nome do fabricante Spex. O moinho tipo Spex consiste de uma biela em cuja extremidade se prende o copo com as bolas de moagem. A biela sacode o copo vigorosamente milhares de vezes por minuto, e este deslocamento é acompanhado de movimentos laterais e cíclicos da biela. A cada ciclo, as bolas se chocam entre si e com as paredes do copo, o que acarreta não só moagem, mas também mistura. Nesse tipo de moinho, podem ser variados a atmosfera e o meio de suspensão, que podem interferir no produto final; o tamanho, quantidade e material dos meios de moagem, que variam quanto à sua dureza e densidade; e, finalmente, a relação mássica bola/material, que é a relação de carga do moinho.

Um dos fatores mais importantes para se obter uma reação adequada é a seleção rigorosa da relação de carga do moinho. Se a quantidade de pó é excessiva, poderá ocorrer a sua compactação, enquanto uma quantidade pequena de pó favorecerá a fratura das partículas primárias. A Figura 4 mostra um esquema das duas formas de impacto descritas.

Figura 4 - Formas de impacto com pouco e muito material em um moinho do tipo "Spex".

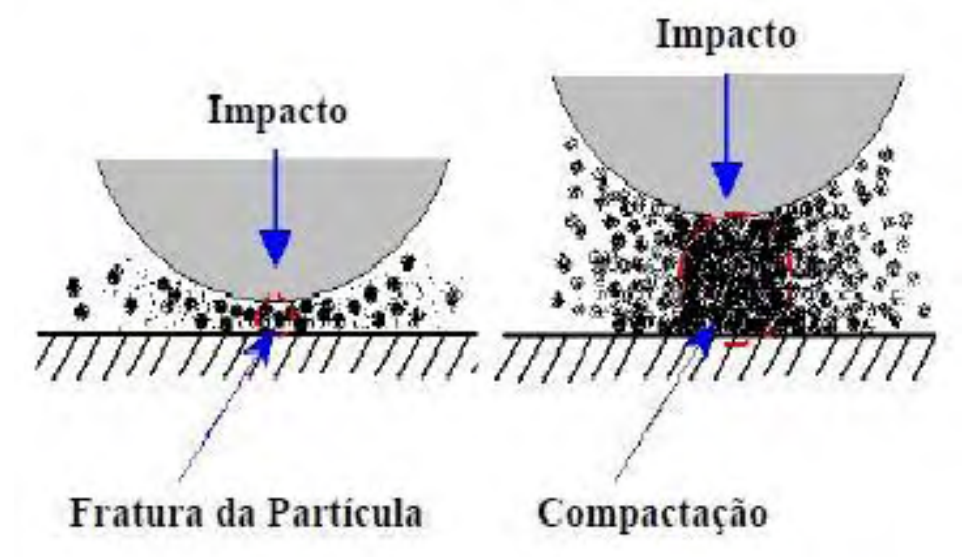

Fonte: Adaptado de MAYO, M. J. Processing of nanocrystalline ceramics from ultrafine particles. International Materials Reviews, v. 41, n. 3, pp. 85-115, 1996.

Apesar de uma grande quantidade de sistemas poderem ser processados por moagem de alta energia, com reação entre os compostos envolvidos, a ocorrência dessas reações à temperatura ambiente é limitada por questões cinéticas. Uma propriedade característica de todas as reações no estado sólido é que elas envolvem a formação de fase(s) de produto(s) nas interfaces dos reagentes. A 
continuação do crescimento da fase de produto envolve a difusão de átomos das fases reagentes através da fase do produto, o que constitui uma camada de barreira evitando a continuidade da reação. Desta forma, essas reações requerem elevadas temperaturas para ocorrer a taxas razoáveis (SURYANARAYANA, 2001).

Dependendo das condições de moagem, existem dois tipos completamente diferentes de reações possíveis (SCHAFFER, McCORMICK, 1990; TAKACS, 1992):

- A reação que pode se estender a um volume muito pequeno durante cada colisão, resultando em uma transformação gradual;

- A reação de combustão auto-propagante que pode ser iniciada, se a entalpia for suficientemente alta.

O segundo tipo de reações requer um tempo crítico de moagem para dar início à reação de combustão. Com controle da temperatura do jarro durante o processo (SCHAFFER, McCORMICK, 1992), observa-se que, depois de certo tempo, a temperatura aumenta abruptamente, sugerindo que ocorreu uma ignição, que é seguida por uma lenta diminuição na temperatura. A Figura 5 mostra esquematicamente essa variação da temperatura com o tempo, durante o processo de moagem.

Figura 5 - Representação esquemática da variação da temperatura com o tempo durante o processo de moagem de alta energia quando ocorre a reação de combustão.

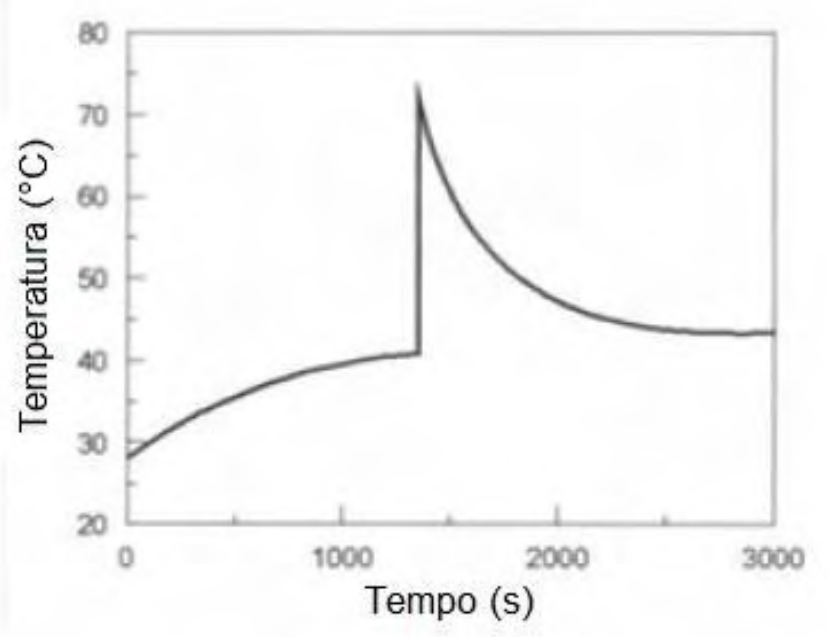

Fonte: Adaptado de BOTTA, W. J.; TOMASI, R.; PALLONE, E. M. J. A.; YAVARI, A. R. Nanostructured composites obtained by reactive milling. Scripta Materialia, v. 44, pp. 1735-1740, 2001.

Botta e colaboradores (2001) afirmam que, no caso da moagem reativa entre sólidos em um moinho de alta energia, quando a reação é suficientemente 
exotérmica e dependente da sua temperatura adiabática, a moagem pode levar a reações autossustentadas do tipo síntese autopropagante de alta temperatura (selfpropagating high temperature synthesis - SHS). Estas reações do tipo SHS também podem ser denominadas "reações auto-sustentadas induzidas mecanicamente". A propagação de uma reação deste tipo requer uma temperatura adiabática mínima de cerca de $1800 \mathrm{~K}$, e essa temperatura mínima é reduzida a aproximadamente $1300 \mathrm{~K}$ durante a moagem.

Isto se explica pelo fato de que são criadas superfícies de fratura a partir da cominuição de partículas proporcionada pelas colisões das partículas entre si, entre as partículas e o jarro de moagem, e entre as partículas e as bolas. $\mathrm{O}$ aumento da superfície de contato entre os reagentes aumenta as taxas de difusão e ocorre devido ao aumento da densidade de defeitos e à redução do tamanho de partícula até uma escala nanométrica.

No caso da reação que forma o pó $\mathrm{Al}_{2} \mathrm{O}_{3}-\mathrm{NbC}$ utilizado como reforço neste trabalho, com a finalidade de se produzirem compósitos $\mathrm{t}-\mathrm{ZrO}_{2} / \mathrm{Al}_{2} \mathrm{O}_{3}-\mathrm{NbC}$, a reação em questão pode ser descrita pela Equação 2:

$$
\mathrm{Nb}_{2} \mathrm{O}_{5}+10 / 3 \mathrm{Al}+2 \mathrm{C} \rightarrow 5 / 3 \mathrm{Al}_{2} \mathrm{O}_{3}+2 \mathrm{NbC}
$$

Pallone e colaboradores (2003) mostraram que esta reação possui uma temperatura adiabática de $2950^{\circ} \mathrm{C}$ para o tempo de reação de 190 minutos, sendo esta temperatura reduzida à medida que se utiliza um pó diluente $\left(\mathrm{Al}_{2} \mathrm{O}_{3}\right)$, até um certo limite. Esse diluente tem como objetivo reduzir o efeito das altas temperaturas, que provocam forte aglomeração dos pós. A Figura 6 mostra o efeito do tempo de moagem no tamanho de cristalito e na área superficial específica na obtenção de pós de $\mathrm{Al}_{2} \mathrm{O}_{3}-\mathrm{NbC}$ usando moagem de alta energia (PALLONE et al., 2003). 
Figura 6 - (a) Variação do tamanho de cristalito e (b) Variação da área superficial especifica, com o tempo de moagem, para o sistema $\mathrm{Al}_{2} \mathrm{O}_{3}-\mathrm{NbC}$ submetido a moagem de alta energia.
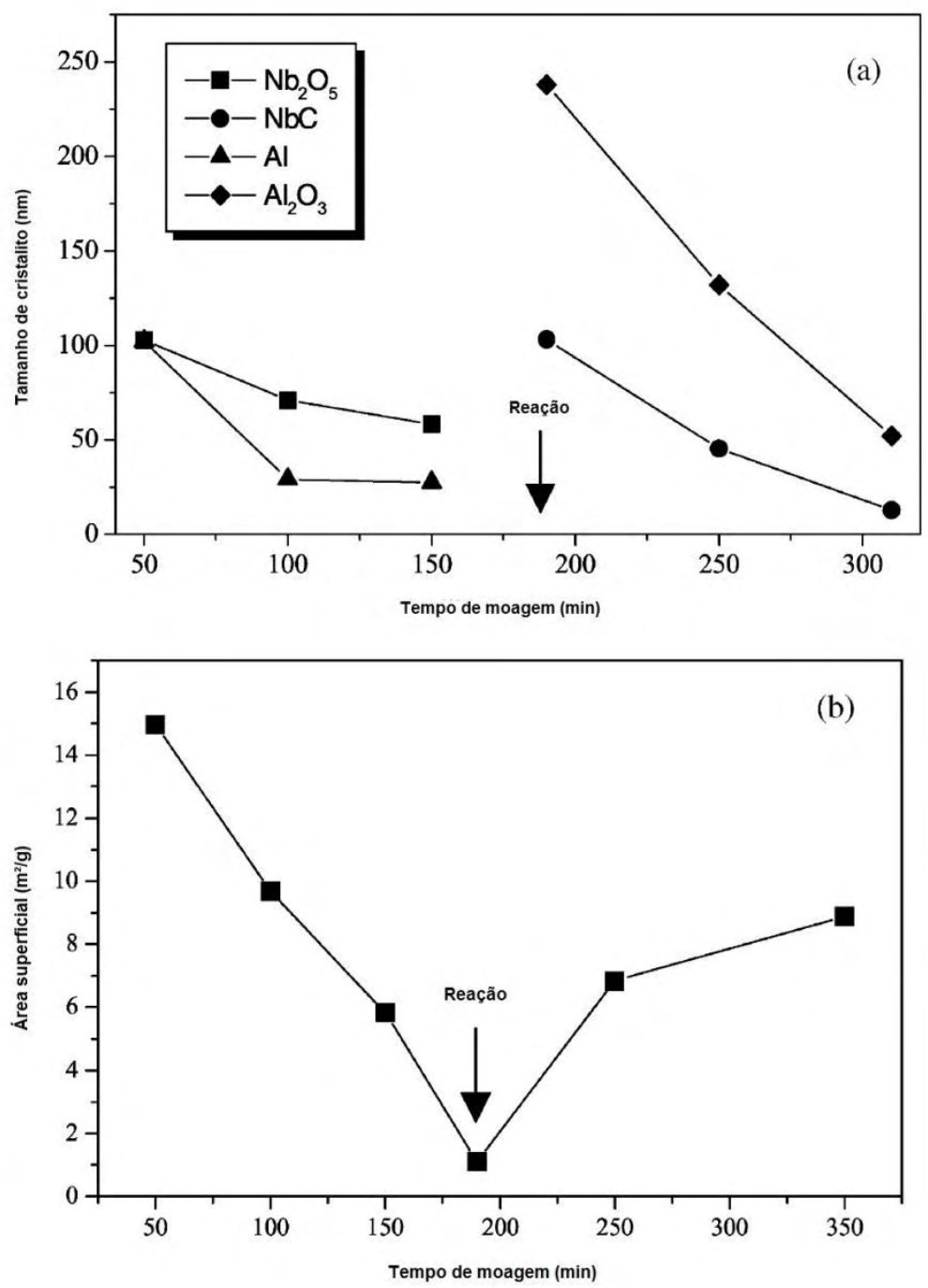

Fonte: Adaptado de PALLONE, E. M. J. A. TROMBINI, V.; BOTTA Fo, W. J.; TOMASI, R. Synthesis of $\mathrm{Al}_{2} \mathrm{O}_{3}-\mathrm{NbC}$ by reactive milling and production of nanocomposites. Journal of Materials Processing Technology, v. 143, pp. 185-190, 2003.

Um dos problemas relacionados com os processos de moagem de alta energia e aos seus longos tempos de processo característicos, é a contaminação do material processado com o meio de moagem. No caso do moinho tipo Spex, com a utilização de frasco e bolas de moagem de aço, a contaminação com ferro é inevitável no material, e isto faz com que seja necessário um tratamento subsequente de descontaminação do material em estudo. Além disso também é necessário uma desaglomeração dos pós resultantes devido a formação de aglomerados fortes (também chamados de agregados) durante a moagem (PALLONE, TOMASI, BOTTA Fo, 2000; PALLONE et al., 2003; TROMBINI, 2011). 


\subsection{Compósitos cerâmicos}

O termo "compósito", no seu senso mais geral, refere-se a qualquer estrutura polifásica. As propriedades cerâmicas resultantes e os requisitos de processo dependem das quantidades relativas, formas, distribuições e preparações dos dois ou mais constituintes (CHIANG, BIRNIE III, KINGERY, 1997). Como extensão deste conceito, o termo "nanocompósito" pode ser definido como compósito de mais de uma fase sólida Gibbsiana, dentre as quais pelo menos uma das fases possui dimensões na faixa nanométrica $(<100 \mathrm{~nm})$. As fases sólidas podem existir tanto no estado amorfo, como no estado semicristalino ou cristalino. O conceito de nanocompósitos cerâmicos estruturais foi proposto por Niihara (1991) em trabalho envolvendo os sistemas $\mathrm{Si}_{3} \mathrm{~N}_{4}-\mathrm{SiC}$ e $\mathrm{Al}_{2} \mathrm{O}_{3}-\mathrm{SiC}$, e figurou como a adoção de uma técnica utilizando materiais nanométricos no projeto da microestrutura de compósitos cerâmicos estruturais.

As cerâmicas, apesar de possuírem propriedades intrínsecas que as tornam atraentes para aplicações que requerem baixa densidade, alta refratariedade e boa inércia química, possuem uma inerente fragilidade, a qual é uma de suas principais características (STERNITZKE, 1997; TAGUCHI, 1987). Isso se deve à concentração de tensões ao redor de defeitos pré-existentes, tais como trincas, poros e riscos. Esta é uma das razões pelas quais as avaliações das propriedades dos materiais cerâmicos em uso prático ainda não atingiram o nível de desenvolvimento que, por exemplo, metais e suas ligas possuem (TAGUCHI, 1987; DE AZA et al., 2002; THÜMMLER, OBERACKER, 1993).

Existem apenas algumas propostas disponíveis para compensar a desvantagem da fragilidade de uma cerâmica e aumentar sua resistência. Segundo a abordagem de Griffith, a resistência à fratura de materiais frágeis pode somente ser melhorada pelo aumento da tenacidade à fratura ou pela redução do tamanho crítico de trinca (DAVIDGE, 1979). Desta forma, muitos esforços têm ocorrido para a sofisticação de processos de fabricação para reduzir o tamanho e a quantidade das falhas de processamento. Entretanto, o desenvolvimento de cerâmicas mais resistentes e tolerantes à existência de trincas é mais amplo, pois foca diretamente no material, e isso aumenta a confiabilidade de um componente com ele fabricado. A tenacidade à fratura pode ser aumentada pela incorporação de diversos 
componentes que dissipam a energia da trinca na microestrutura cerâmica. Esses componentes constituem reforços na forma de whiskers, plaquetas ou partículas (BOHMER, ALMOND, 1988; GLEITER, 1995; ZHAN et al., 1996; AGUILARELGUÉZABAL, BOCANEGRA-BERNAL, 2013). Os reforços servem para defletir a trinca ou fornecer elementos que evitem o seu crescimento. Outro conceito é a incorporação de materiais metálicos na matriz cerâmica, para formar elementos que absorvem a energia da propagação da trinca (STOLOFF, ALMAN, 1995; WANG, NAKAMURA, 2004; MUÑOZ et al., 2006; BARTOLOMÉ et al., 2008; SCHERM et al., 2010). Além disso, muitos benefícios têm sido obtidos a partir da incorporação de uma segunda fase, que sofre uma transição de fase em conjunto com uma expansão volumétrica, iniciada pelo campo de tensões de uma trinca se propagando: isto também pode aplicar uma força de fechamento na trinca (CHIANG, BIRNIE III, KINGERY, 1997; HANNINK, KELLY, MUDDLE, 2000; TSUKAMOTO, 2010).

Nos últimos anos, com o grande desenvolvimento de novos materiais da categoria dos carbetos, nitretos e boretos, têm se destacado pesquisas envolvendo a elaboração de compósitos de matriz cerâmica com adição dessas espécies, como alternativa aos tipos de segunda fase já exaustivamente pesquisados. Muitas fases têm sido introduzidas em matrizes de zircônia e alumina, como TiC, SiC, WC, TiB 2 , TiN, AIN, (Ti,W)C e NbC (DING, OBERACKER, THÜMLER, 1993; POORTEMAN, 1993; CLAUSSEN, WEISSKOPF, RUHLE, 1986; WAHI, ILSCHNER, 1980; VLEUGELS, VAN DER BIEST, 1997; NIIHARA et al., 1989; ACCHAR et al., 2012; ACCHAR, SILVA, CAIRO, 2010). Dependendo do tipo de inclusões, seu tamanho e quantidade, bem como das condições de sinterização, pode-se observar um significativo aumento na dureza, tenacidade e/ou resistência à flexão do material, chegando a valores extremamente altos, no caso de nanocompósitos. Uma das maiores dificuldades de trabalhar com materiais carbonáceos e não-óxidos como reforços é sua relativamente alta degradabilidade em determinados tipos de atmosfera, devido à facilidade de oxidação que possuem. Além disso, durante a sinterização, os mecanismos difusionais de densificação ocorrem apenas na matriz. Por exemplo, a presença de carbetos faz com que as forças motrizes do processo de sinterização se tornem tanto mais fracas quanto maior for a fração desses materiais. Portanto, nestes casos é necessário utilizar atmosferas inertes ou redutoras, combinadas com processos avançados de sinterização, como hot- 
pressing, ou processos não convencionais, como spark plasma sintering - SPS. (PĘDZICH, 2012; ZHAO, 2000).

\subsubsection{Nanocompósitos de zircônia-alumina ( $\left.\mathrm{t}-\mathrm{ZrO}_{2} / \mathrm{Al}_{2} \mathrm{O}_{3}\right)$}

Visando combinar a elevada dureza e resistência à abrasão da alumina com a elevada resistência à flexão e tenacidade à fratura da zircônia, o desenvolvimento de pesquisas envolvendo compósitos alumina-zircônia (ZTA - zirconia-toughened alumina) já conta algumas décadas (WANG, STEVENS, 1989; HWANG, LIN, 1991; KERN, PALMERO, 2013; GUTKNECHT et al., 2007; NEVÁREZ-RASCON et al., 2009), trazendo um forte desenvolvimento à ciência de compósitos cerâmicos e ao entendimento dos mecanismos de tenacificação. Mais recentemente, alguns autores (SCHNEIDER et al., 2008; NEVÁREZ-RASCON et al., 2009; CHAIM, 1992; TEKELI, 2007; VLEUGELS, YUAN, VAN DER BIEST, 2002; PABST et al., 2000) têm reportado estudos de compósitos zircônia/alumina (ATZ - alumina-toughened zirconia), em que a matriz predominante de zircônia recebe adições minoritárias de alumina. Esses materiais têm mostrado significativa melhora na resistência à degradação térmica em relação à zircônia monolítica. Além disso, nesses compósitos, o mecanismo de reforço em relação à zircônia e à alumina monolíticas consiste na retenção metaestável dos grãos tetragonais da zircônia por meio da estabilização resultante da dissolução limitada de alumina na zircônia, assim como acontece com a retenção elástica imposta pela matriz de alumina nos grãos de zircônia, gerando os efeitos de tenacificação por transformação de fase e por microtrincamento (CHAIM, 1992). Rajendran, Swain e Rossell (1988) mostraram que a alumina aumenta a estabilidade da zircônia tetragonal, diminuindo a transformação de fase tetragonal para monoclínica, aumentando também as densidades máximas atingíveis dos compósitos zircônia/alumina, suprimindo o desenvolvimento de poros a temperaturas mais altas de sinterização. Desta forma, é promissora a utilização de compósitos zircônia/alumina para aplicações estruturais, desde que o processo de sinterização seja adequado às propriedades desejadas do material. 


\subsection{Sinterização}

\subsubsection{O conceito de sinterização}

O processamento de cerâmicas constitui um desafio devido à sua refratariedade e fragilidade. Com a notável exceção dos vidros, poucas cerâmicas são processadas a partir do fundido - as temperaturas de fusão são simplesmente muito altas. Em vez disso, o ponto de início são pós normalmente finos que são moídos, misturados e moldados na forma desejada por uma variedade de processos e, em seguida, tratados termicamente ou queimados para convertê-los em sólidos densos (BARSOUM, 2003). O uso variado do processo de sinterização levou a uma variedade de estudos sobre o assunto. Na prática, o ceramista, desejando preparar um material com um determinado conjunto de propriedades, identifica a microestrutura necessária e tenta ajustar condições de processamento que produzirão essa microestrutura. O principal objetivo dos estudos em torno da sinterização é, portanto, entender como as variáveis de processo influenciam a evolução microestrutural (RAHAMAN, 2003).

De acordo com Chiang, Birnie III e Kingery (1997, p. 392), o conceito de sinterização se refere ao processo de queima e consolidação de um corpo conformado a partir de materiais particulados. Nesse processo, o corpo conformado é transformado em um corpo resistente, denso e coerente. Em uma definição alternativa dada por Herring (1950), sinterização é "entendida como significado de quaisquer mudanças na forma que uma partícula ou um grupo de partículas de composição uniforme sofre a alta temperatura". Na realidade, a sinterização é um fenômeno complexo, no qual vários processos ocorrem simultaneamente.

A sinterização pode ocorrer na presença ou na ausência de uma fase líquida. No primeiro caso, é chamada "sinterização via fase líquida", onde as composições e temperaturas de tratamento são selecionadas de forma que algum líquido seja formado durante o processamento, como mostrado na Figura 7(a). Este processo é de incomensurável importância e tecnologicamente é o preferível em termos de custo e facilidade de realização. Na ausência de fase líquida, o processo é chamado "sinterização no estado sólido" (Figura 7(b)). 
Figura 7 - (a) Sinterização via fase líquida; (b) Sinterização no estado sólido.

(a)

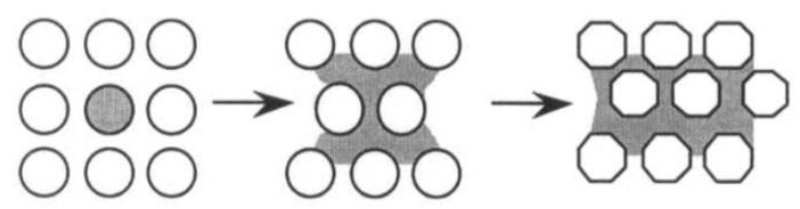

(b)



Fonte: Adaptado de BARSOUM, M. W. Fundamentals of Ceramics (Series in Materials Science and Engineering). New York: Taylor and Francis, 2003.

Em geral, os parâmetros de processamento e do material proveem um conjunto útil de variáveis para estudos de modelamento teórico e experimental. Alguns parâmetros, como a temperatura de sinterização, pressão aplicada, tamanho médio de partícula e atmosfera, podem ser controlados com suficiente precisão. Outros parâmetros, como as características morfológicas do pó e empacotamento das suas partículas, são mais difíceis de controlar, porém também possuem um efeito significativo na sinterização (RAHAMAN, 2003).

\subsubsection{A "força motriz" da sinterização}

Para a sinterização ocorrer, é necessário que haja uma diminuição da energia livre do sistema. A curvatura das superfícies livres e - quando utilizada - a pressão aplicada dão a principal motivação, i.e., a "força motriz", para ocorrer a sinterização. Entretanto, para se completar o processo em um tempo razoável, deve-se também considerar a cinética de difusão dos átomos, íons, ou quaisquer espécies carregadas. A difusão no estado sólido pode ocorrer por diversas formas, as quais definem os mecanismos de difusão e, portanto, os mecanismos de sinterização.

A taxa de difusão depende do tipo e da concentração de defeitos em um sólido. Desta forma, é importante conhecer a estrutura dos defeitos e as mudanças na sua concentração. Também é importante entender a relação desses defeitos com os parâmetros de entrada no processo de sinterização, principalmente temperatura, 
atmosfera e quantidade/tipo de dopantes eventualmente utilizados (solutos) (RAHAMAN, 2003).

\subsubsection{A sinterização no estado sólido}

A força motriz macroscópica que opera durante a sinterização é a redução da energia em excesso associada com as superfícies. Isto pode acontecer por dois modos: (1) Redução da área superficial total pelo aumento do tamanho médio das partículas, o que leva ao coalescimento das partículas (coarsening), e/ou (2) Eliminação das interfaces sólido/vapor e a criação de uma área de contorno de grão, seguida pelo crescimento de grão, o que leva à densificação. Esses dois mecanismos normalmente são competitivos. A Figura 8 mostra esquematicamente estes dois fenômenos.

Figura 8 - Representação esquemática das duas possíveis formas pelas quais um conjunto de partículas pode reduzir sua energia: Densificação seguida de crescimento de grão e coalescimento das partículas.
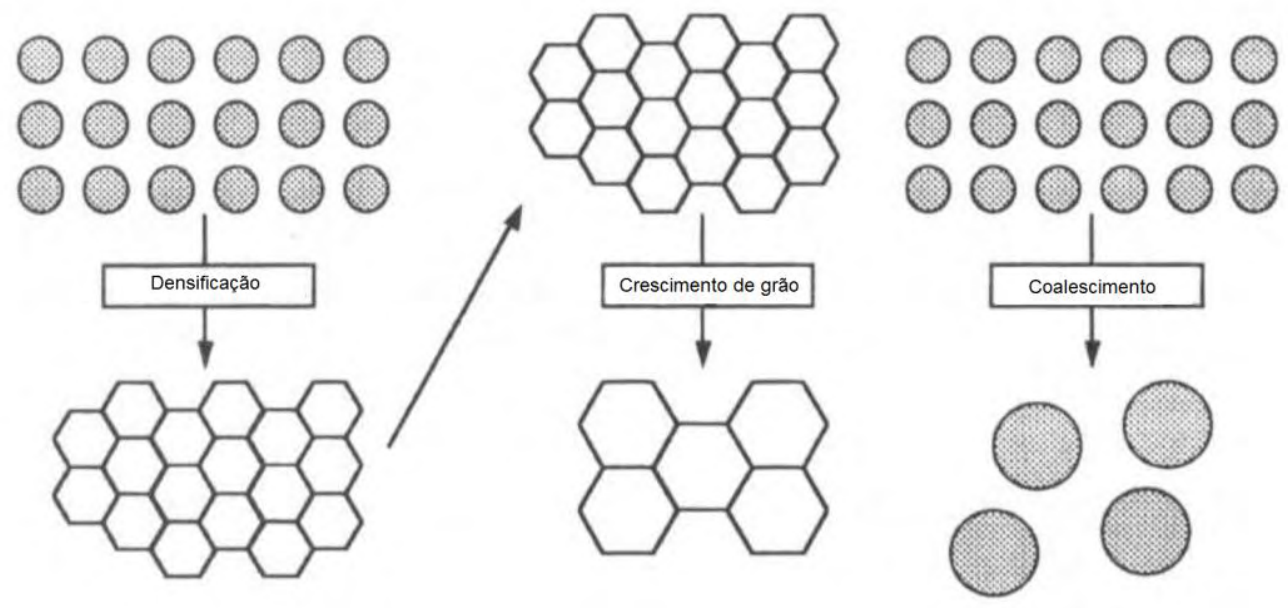

Fonte: Adaptado de BARSOUM, M. W. Fundamentals of Ceramics (Series in Materials Science and Engineering). New York: Taylor and Francis, 2003. p. 302.

Se os processos atômicos que levam à densificação forem dominantes, os poros se tornam cada vez menores e desaparecem com o tempo, levando à retração do compacto. Porém, se os processos atômicos que levam ao coalescimento das partículas forem mais rápidos, tanto os poros como os grãos aumentam com o tempo. 
Uma condição necessária para ocorrência da densificação é que a energia de contorno de grão $\gamma_{g b}$ seja menor do que o dobro da energia superficial sólido/vapor $\gamma_{S v}$. Isto implica que o ângulo diedral no equilíbrio, $\phi$, definido na Equação 3 , deve ser menor que $180^{\circ}$ :

$$
\gamma_{g b}=2 \gamma_{s v} \cos \frac{\phi}{2}
$$

Para a maior parte dos sistemas óxidos, o ângulo diedral é em torno de $120^{\circ}$, implicando que $\gamma_{g b} / \gamma_{s v} \approx 1$, em contraste com sistemas metálicos, onde essa razão é mais próxima a 0,25-0,5 (BARSOUM, 2003).

Os diferentes tipos de defeitos determinam se o caminho do transporte de matéria e difusão ao longo dos caminhos vai dar origem aos principais mecanismos de transporte de matéria: difusão pela rede (também chamada de difusão volumétrica), difusão por contorno de grão e difusão superficial.

O Quadro 1 e a Figura 9 mostram resumidamente os possíveis mecanismos de transporte de matéria durante o processo de sinterização.

Quadro 1 - Mecanismos de transporte de matéria na sinterização.

\begin{tabular}{|c|c|c|c|}
\hline $\begin{array}{c}\text { Número do } \\
\text { mecanismo }\end{array}$ & Tipo de transporte & Fonte de matéria & Destino da matéria \\
\hline 1 & Difusão superficial & Superfície & Pescoço \\
\hline 2 & $\begin{array}{c}\text { Difusão pela rede } \\
\text { Transporte de } \\
\text { vapor }\end{array}$ & Superfície & Pescoço \\
\hline 3 & $\begin{array}{c}\text { Difusão por } \\
\text { contorno }\end{array}$ & Contorno de grão & Pescoço \\
\hline 5 & Difusão pela rede & Contorno de grão & Pescoço \\
\hline 6 & Difusão pela rede & Discordâncias & Pescoço \\
\hline
\end{tabular}

Fonte: Adaptado de CHIANG, Y. M.; BIRNIE III, D.; KINGERY, W. D. Physical Ceramics: Principles for Ceramic Science and Engineering (The MIT Series in Materials Science and Engineering). John Wiley and Sons: New York, 1997. 
Figura 9 - Representação esquemática dos seis distintos mecanismos que podem contribuir para a sinterização de uma massa consolidada de partículas cristalinas.



Fonte: Adaptado de RAHAMAN, M. N. Sintering of Ceramics. New York: Taylor \& Francis, 2007. p. 46.

A difusão pela rede ocorre pelo movimento de defeitos pontuais através do interior da rede cristalina. Dependendo do tipo de defeitos, ela pode ocorrer por dois mecanismos principais: mecanismo da vacância ou mecanismo do intersticial. Estas são as mais importantes formas de difusão pela rede.

No mecanismo da vacância, um átomo em um ponto normal da rede troca de lugar com um sítio vago. O movimento do átomo é oposto ao movimento da vacância; pode-se, então, rastrear o movimento do átomo. A concentração de vacâncias em um material é determinada pela temperatura, soluto e atmosfera. Deve-se notar que, na difusão de vacâncias, o fluxo de vacâncias deve ser compensado por um fluxo igual e oposto de átomos; caso contrário, as vacâncias se 
acumulariam no cristal, produzindo poros. A formação de poros pode, de fato, ocorrer durante a interdifusão de dois átomos que têm coeficientes de difusão muito diferentes (BARSOUM, 2003; RAHAMAN, 2003).

O mecanismo do intersticial ocorre se os átomos do sistema forem pequenos o suficiente para migrar entre sítios intersticiais da rede cristalina.

No caso de difusão por contorno de grão, essas regiões de incoerência cristalográfica e grau de desordem relativamente mais alto (do que no interior das partículas) possuem um potencial que permite uma rapidez maior na difusão atômica do que no caso de difusão pela rede. Para uma largura constante de contorno de grão, a fração de sólido que é ocupada pelo contorno de grão aumenta com a diminuição do tamanho de grão. Desta forma, a taxa de difusão pelo contorno de grão é dependente do tamanho de grão (BARSOUM, 2003).

Uma vez que a superfície de um sólido cristalino é altamente energética e não é perfeitamente plana, ela contém algumas vacâncias (da mesma forma que no interior do cristal), além de outras imperfeições. A migração de vacâncias e o movimento de adátomos ${ }^{1}$ proveem os principais mecanismos de difusão superficial. Esse processo de difusão é confinado a uma fina camada superficial possuindo uma espessura de 0,5 a $1 \mathrm{~nm}$ (RAHAMAN, 2003).

\subsubsection{Estágios da sinterização}

De acordo com Coble (1961), um estágio de sinterização é um "intervalo de mudança geométrica no qual a forma do poro é totalmente definida (como o arredondamento dos pescoços durante o estágio inicial de sinterização) ou um intervalo de tempo durante o qual o poro permanece com forma constante enquanto seu tamanho diminui". Baseado nisto, são definidos três estágios: um estágio inicial, um intermediário e um final (RAHAMAN, 2003; BARSOUM, 2003).

Durante o estágio inicial (Figuras $10(\mathrm{a})$ e (b)), a área de contato entre partículas aumenta pelo crescimento do pescoço, e a densidade relativa aumenta

\footnotetext{
${ }^{1}$ Adátomos são átomos que estão na superfície de um cristal, e podem ser entendidos como o oposto de um vacância superficial, normalmente estando em um estado termodinamicamente desfavorável.
} 
em torno de 60 a $65 \%$. Esse crescimento ocorre por difusão, transporte de vapor e fluxo plástico (ou viscoso) (RAHAMAN, 2003).

O estágio intermediário se inicia quando os poros atingem suas formas de equilíbrio, sendo ainda contínua a fase de poros. Nos modelos de sinterização, a estrutura é usualmente idealizada como um arranjo de porosidade ao longo das bordas dos grãos (Figura 10(c)). Entende-se que a densificação ocorre simplesmente pela diminuição dos poros reduzindo sua seção transversal. Em alguns casos, alguns poros acabam se instabilizando em relação ao processo conjunto e ficam isolados; isso constitui o início do estágio final da sinterização. Nesse estágio, que normalmente cobre a maior parte do processo de sinterização, a densidade relativa aumenta de cerca de 65 a cerca de 90\% (RAHAMAN, 2003).

Figura 10 - Modelos idealizados para os três estágios da sinterização: (a) Estágio inicial; (b) Final do estágio inicial; (c) Estágio intermediário; (d) Estágio final.

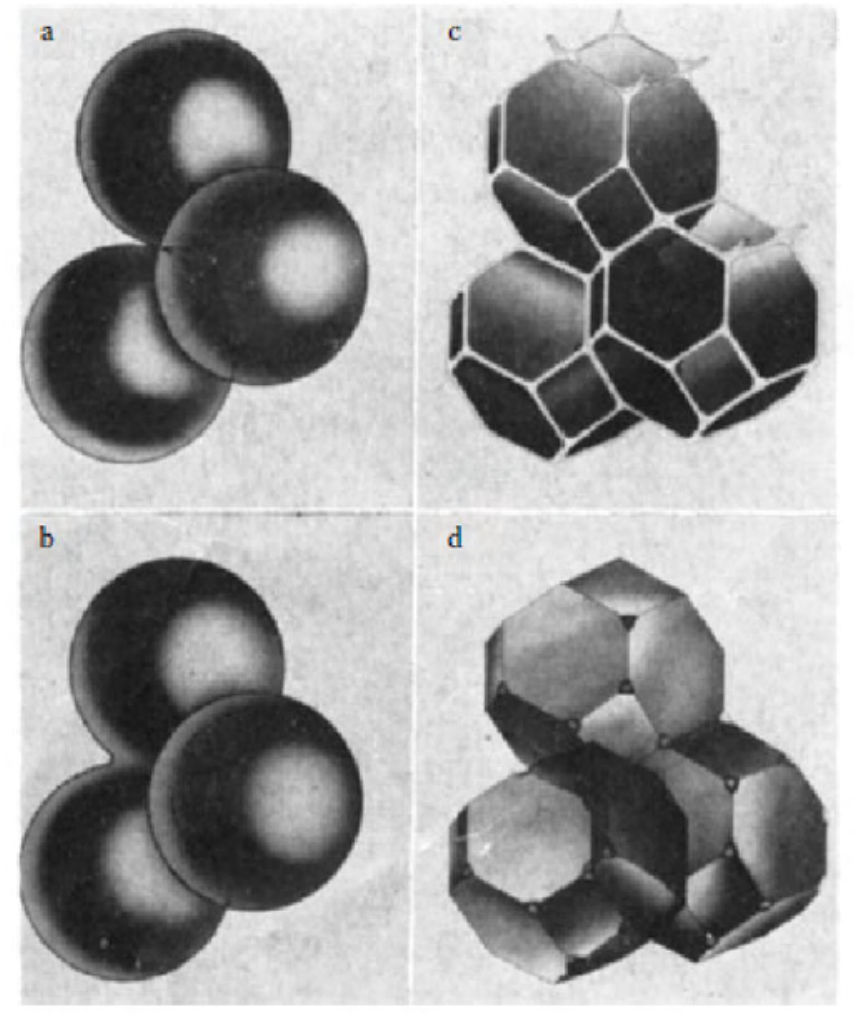

Fonte: Adaptado de COBLE, R. L. Sintering crystalline solids. II. Experimental Test of Diffusion Models in Powder Compacts. Journal of Applied Physics, v. 32, pp. 787-792, 1961.

No estágio final da sinterização (Figura 10(d)), os poros que ficaram isolados são eliminados por transporte de massa, do contorno de grão ao poro. De acordo com Chiang, Birnie III e Kingery (1997), uma difusão ambipolar envolvendo todos os 
íons constituintes também é necessária nesse processo. A microestrutura no estágio final pode se desenvolver de várias formas (RAHAMAN, 2003). Em uma das descrições mais simples, entende-se que os poros reduzam de tamanho continuamente e podem desaparecer todos juntos. Uma característica importante deste estágio é o aumento na mobilidade de poros e contornos de grãos, que devem ser controladas ao se visar atingir a densidade teórica no processo (BARSOUM, 2003). A Figura 11 mostra exemplos de microestruturas reais nos três estágios da sinterização.

Figura 11 - Exemplos de microestruturas reais (seções planares) para (a) estágio inicial; (b) estágio intermediário; (c) estágio final da sinterização.

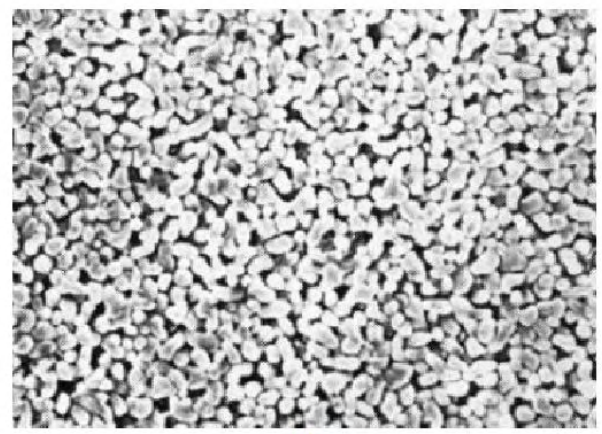

(a)

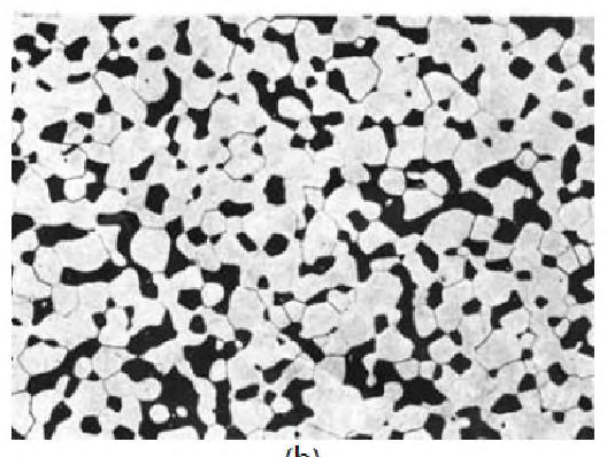

(b)

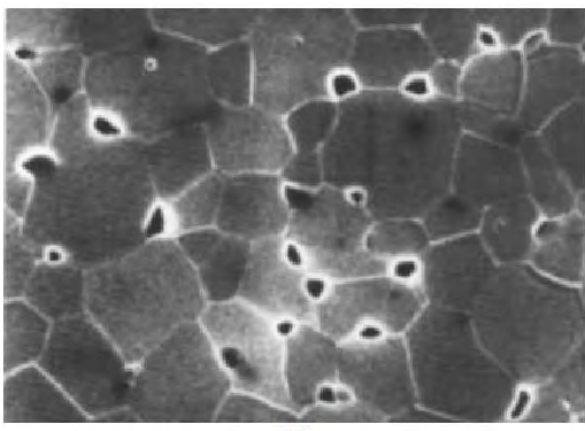

(c)

Fonte: RAHAMAN, M. N. Sintering of Ceramics. New York: Taylor \& Francis, 2007. p. 57.

\subsubsection{Utilização de atmosfera ou vácuo na sinterização convencional}

A atmosfera de sinterização pode ter diversos efeitos na densificação e no desenvolvimento microestrutural e, em muitos aspectos, pode ter um efeito decisivo em possibilitar atingir alta densidade com tamanho de grão controlado. Esses efeitos estão associados tanto com fenômenos físicos como com fenômenos químicos, como no caso do transporte de gás atmosférico em poros isolados no estágio final 
de sinterização e, em relação aos fenômenos químicos, particularmente quando podem ser modificados a volatilidade, estado de oxidação e química de defeitos no sistema (RAHAMAN, 2007).

Como exemplo de um fenômeno físico cuja ocorrência é associada à seleção da atmosfera de sinterização, Coble (1962) mostrou que a alumina dopada com $\mathrm{MgO}$ pode ser sinterizada até a densidade teórica em vácuo ou em uma atmosfera de $\mathrm{H}_{2}$ ou $\mathrm{O}_{2}$, que se difundem para fora da superfície do sólido, mas não em $\mathrm{He}, \mathrm{Ar}$ ou $\mathrm{N}_{2}$ (ou, portanto, ar), que têm uma solubilidade limitada na alumina.

O controle do estado de oxidação de algumas espécies químicas tem um efeito significativo na densificação de materiais, tais como óxidos contendo cromo. Neste caso, tem-se um exemplo da influência da atmosfera de sinterização, que pode provocar modificações do estado de oxidação do íon cromo, modificando o componente durante o processo. Isso pode trazer influências tanto microestruturais como nas propriedades finais do material (RAHAMAN, 2007).

\subsubsection{Métodos não convencionais de sinterização}

Dentre os métodos não convencionais de sinterização, destacam-se os processos assistidos por campo elétrico. Muitos processos vêm sendo estudados, visando aumentar a densificação. Esse campo elétrico pode ser aplicado usando corrente elétrica pulsada, alternada ou contínua.

Os mecanismos fundamentais de sinterização para estes processos não são ainda bem esclarecidos e permanecem em debate (LU, 2008). Durante a sinterização, as partículas são aquecidas à medida que uma corrente elétrica ou onda eletromagnética passa por elas. Isto causa uma ativação da superfície das partículas, combinada com taxas de difusão ampliadas nas regiões de contato, levando a uma ligação mais forte entre as partículas. Um rápido aquecimento, inerente a esses processos, acaba ignorando regiões de baixas temperaturas onde domina a sinterização controlada pela difusão superficial, e isso preserva a área superficial disponível para temperaturas nas quais os mecanismos de difusão densificadores são proeminentes. Devido a essas características, a sinterização assistida eletricamente favorece uma densificação rápida e total mantendo as microestruturas refinadas (RAHAMAN, 2003; LU, 2008). 


\subsubsection{Spark plasma sintering}

A técnica de spark plasma sintering (SPS) é uma das técnicas de sinterização assistida eletricamente mais largamente utilizadas, na pesquisa e em alguns materiais comerciais de alto desempenho. Algumas variações do nome da técnica de SPS incluem "sinterização ativada por plasma", "sinterização por pulso de corrente elétrica", e "sinterização com pressão e descarga de pulso". Todos são nomes diferentes para um único processo, dada a variedade de possíveis traduções.

Os sistemas de SPS oferecem muitas vantagens sobre os sistemas convencionais utilizando sinterização por prensagem a quente, prensagem isostática a quente ou fornos com atmosferas controladas, incluindo facilidade de operação e controle preciso da energia de sinterização, bem como alta velocidade de sinterização, alta reprodutibilidade, segurança e confiabilidade (LU, 2008).

Na SPS, a sinterização é realizada submetendo-se o compacto a verde a descargas de arco geradas por uma corrente elétrica pulsada. Um processo de descarga elétrica ocorre em nível microscópico e acelera a difusão do material. A densificação na sinterização ocorre sob uma pressão uniaxial e uma descarga elétrica de alta intensidade (de 2000 a 20000 A em poucos milissegundos). Os mecanismos básicos de formação de pescoço pela faísca de plasma são mostrados na Figura 12, apesar de os detalhes para esses processos ainda estarem em discussão.

Quando uma descarga de faísca aparece num espaço ou no ponto de contato entre as partículas, um estado de alta temperatura local de vários até dezenas de milhares de graus centígrados é gerado momentaneamente. Isto causa a evaporação e a fusão das superfícies das partículas, e "pescoços" são formados ao redor da área de contato entre elas. A pressão aplicada externamente é geralmente de 30-200 MPa. A taxa de aquecimento costuma variar de 100 a $1000^{\circ} \mathrm{C} / \mathrm{min}$, o que é muito mais rápido do que as técnicas de rápido aquecimento por resistência elétrica. Os ambientes de sinterização podem ser o vácuo, argônio, hidrogênio, ou ar. Uma vez que nenhuma corrente ou uma corrente muito fraca passa através de amostras não condutoras, a descarga origina-se do campo elétrico da corrente pulsada utilizada. A intensidade dessa descarga não é apenas dependente da intensidade dos pulsos aplicados, mas também de fatores como tamanho de 
partículas, tamanho de poros e densidade do compacto. O papel exato da corrente foi proposto por muitos autores, mas tem sido discutido por outros, por falta de evidências experimentais conclusivas. Os possíveis efeitos da corrente elétrica incluem modificação do "vento" de elétrons do fluxo de difusão (isto é, eletromigração), aumento na concentração de defeitos pontuais e redução na energia de ativação para mobilidade dos elétrons. A corrente elétrica pode também oferecer contornos de grão mais "limpos". Um dos resultados dessa combinação de fatores é a boa qualidade da ligação das nanopartículas (LU, 2008).

Figura 12 - Esquematização dos mecanismos básicos de formação de pescoço nos contatos das partículas na SPS.



Fonte: Adaptado de LU, K. Sintering of nanoceramics. International Materials Reviews, v. 53, pp. 21-38, 2008.

O sistema de SPS consiste de um sistema de carga mecânica, que age ao mesmo tempo como um circuito elétrico de alta potência, colocado sob uma atmosfera controlada. Graças à boa condutividade elétrica dos materiais utilizados no ferramental, baixas voltagens (geralmente abaixo de $10 \mathrm{~V}$ ) produzem altas correntes, levando a um aquecimento Joule eficiente. A Figura 13 mostra um esquema do aparato de SPS. Mesmo nos casos em que os pós a serem sinterizados não são bons condutores elétricos, o calor é transferido de forma rápida 
e eficiente para a amostra. A aplicação de pressão, simultaneamente à sinterização, é responsável pelo aumento da sinterização (GUILLON et al., 2014).

Figura 13 - Representação esquemática de um aparato de SPS.

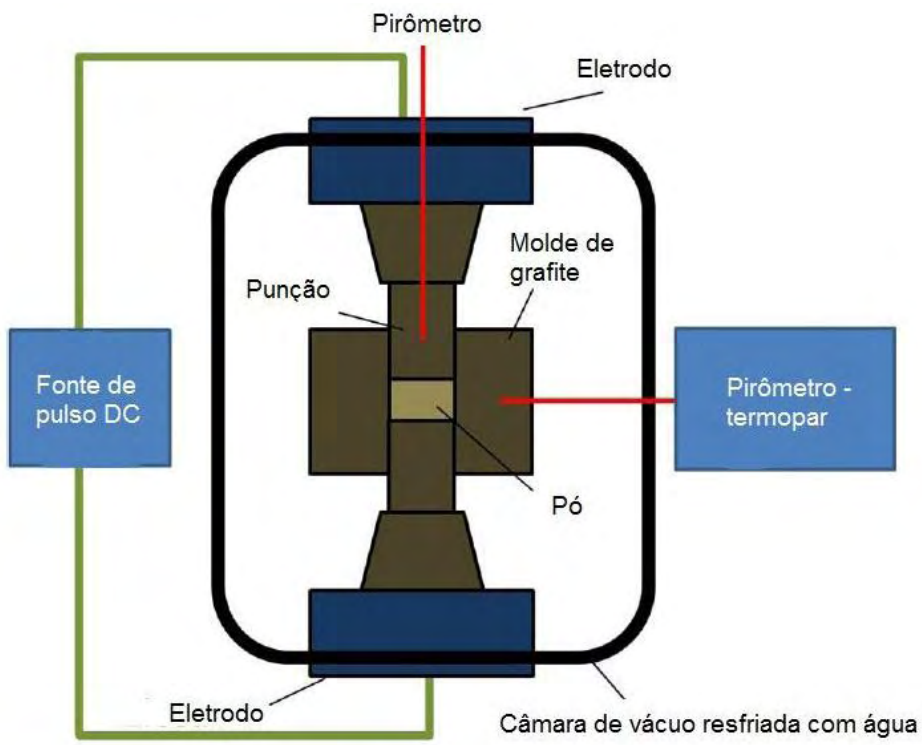

Fonte: Adaptado de GUILLON, O.; GONZALEZ-JULIAN, J.; DARGARTZ, B.; KESSEL, T.; SCHIERNING, G.; RÄTHEL, J.; HERMANN, M. Field-assisted sintering technology / Spark plasma sintering: Mechanisms, materials and technology developments. Advanced Engineering Materials, v. 16 , pp. 830-849, 2014.

A Figura 14 mostra os possíveis fluxos de corrente elétrica em um sistema de SPS. O aquecimento da amostra ou do conjunto completo depende da resistência elétrica dos componentes do sistema e do próprio material da amostra. Com uma amostra condutora, os melhores resultados podem ser atingidos utilizando-se um molde de material isolante elétrico, pois a corrente é forçada a passar através do material, gerando a maior densidade de corrente possível (Figura 14(b)). A forma pela qual é possível sinterizar um material não condutor é criando-se um padrão de aquecimento similar ao de um ciclo rápido de prensagem a quente (Figura 14(c)). Quando se utiliza um molde de grafite, a corrente pode ser forçada a passar pelo material da amostra aplicando-se revestimentos isolantes, como camadas de separação na superfície interna do molde.

No caso de um material compósito bifásico, em que uma fase é isolante e a outra é condutora, as mudanças na resistividade da amostra têm importantes consequências na evolução da temperatura e da corrente. À medida que o pó compósito começa a sinterizar, a corrente flui através do molde. Assim que os 
primeiros caminhos elétricos são estabelecidos, a corrente começa a fluir pela amostra (Figura 14(a)). Após densificar quase completamente o material, a resistividade pode cair significativamente, e a amostra age como um "ladrão" de corrente (GUILLON et al., 2014).

Figura 14 - Representação esquemática do fluxo de corrente em um sistema de SPS: (a) pó e molde condutores; (b) pó condutor, molde isolante; (c) pó não-condutor, molde condutor.


Fonte: GUILLON, O.; GONZALEZ-JULIAN, J.; DARGARTZ, B.; KESSEL, T.; SCHIERNING, G.; RÄTHEL, J.; HERMANN, M. Field-assisted sintering technology / Spark plasma sintering: Mechanisms, materials and technology developments. Advanced Engineering Materials, v. 16, pp. 830-849, 2014. 
Uma grande variedade de materiais cerâmicos nanométricos tem sido sinterizados com alta densificação pelo método de SPS. Esses materiais incluem óxidos, carbetos, nitretos e compósitos. A técnica de SPS é a que proporciona melhor densificação dentre outras técnicas de sinterização, que podem ser menos eficientes nos estágios finais do processo. Uma das propriedades mais notáveis da SPS é o pequeno tamanho de grão que o processo pode manter enquanto se atinge total densificação. Para os óxidos, tanto nanopartículas equiaxiais como alongadas foram densificadas com sucesso mantendo microestrutura nanométrica. Como exemplo, em trabalhos de Nygren e Shen (2003) e Morita e colaboradores (2005), t$\mathrm{ZrO}_{2}$ foi sinterizada até a densidade relativa total mantendo tamanho de grão abaixo de $100 \mathrm{~nm}$. No caso de nanopartículas de MgO, Morita e colaboradores (2005) obtiveram um material transparente com tamanho de grão médio de $52 \mathrm{~nm}$ e densidade de aproximadamente $100 \%$ da densidade teórica, usando temperaturas entre $700^{\circ} \mathrm{C}$ e $825^{\circ} \mathrm{C}$ sob pressões aplicadas de 100-150 MPa. Até mesmo nanopartículas alongadas de hidroxiapatita, no formato de bastonetes, com tamanho médio de $84 \times 33 \mathrm{~nm}$, foram consolidados por SPS à temperatura de $825^{\circ} \mathrm{C}$ por 3 minutos (GUO et al., 2005). O SiC é um exemplo de material cerâmico não-óxido cuja sinterização é difícil ou praticamente inviável por métodos convencionais. No entanto, sua sinterização por SPS tem sido frequentemente relatada com sucesso na literatura. Em trabalho de Yamamoto e colaboradores (2004), $\beta$-SiC com tamanho de partícula primária médio de 5 a $20 \mathrm{~nm}$, foi consolidado até a densidade relativa de $98 \%$ a $1700^{\circ} \mathrm{C}$ e $40 \mathrm{MPa}$ sem a utilização de aditivos. É importante ressaltar que, em grande parte dos trabalhos envolvendo a sinterização de sistemas com nanopartículas de carbetos, assim como neste trabalho, a moagem de alta energia foi fundamental para produzir as partículas em escala nanométrica. Alecrim e colaboradores (2017a) estudaram a sinterização de compósitos $\mathrm{Al}_{2} \mathrm{O}_{3}-\mathrm{NbC}$ por SPS, obtendo materiais com propriedades mecânicas superiores às obtidas com o mesmo material sinterizado em forno convencional com atmosfera.

O fluxo plástico e a difusão são considerados os mecanismos dominantes nos estágios inicial e final da sinterização por SPS, respectivamente. A sinterização por SPS é mais eficiente antes de os poros se isolarem. Após o fechamento dos poros, a difusão por contorno de grão e a migração dos contornos se tornam os processos determinantes da velocidade. A rápida transferência de calor e o aquecimento por resistência das partículas são os responsáveis pelo encurtamento significativo da 
exposição das partículas à alta temperatura, o que é essencial para preservar a nanoestrutura (LU, 2008). No entanto, há limitações no processo de SPS, como a dificuldade de separar os mecanismos de difusão e traçar o exato processo de sinterização. Atualmente, a literatura tem reportado excelentes resultados para diversos sistemas, no entanto sem aprofundar-se no entendimento do fenômeno. Portanto, são necessários estudos do processo em si, envolvendo os processos de deformação e difusão atômica. Ainda, uma limitação prática do processo de SPS é a dificuldade de se sinterizar geometrias complexas e amostras de grandes tamanhos, além dos altos custos dos equipamentos. A sinterização de amostras grandes, pelo próprio princípio do método, torna-se um desafio, uma vez que a formação de gradientes de temperatura é inevitável e pode comprometer a qualidade da peça sinterizada devido à heterogeneidade microestrutural gerada pela densificação diferencial (WANG, FU, 2002; ANSELMI-TAMBURINI et al., 2005; WANG et al., 1999).

\subsubsection{Flash sintering}

De acordo com Todd (2017), o relato mais antigo na literatura aberta sobre o uso do termo "flash sintering" é de Hill et al. (1952), que descreveu um processo de produção de cermetos pela aplicação de pressão com rápido aquecimento, fornecido pela passagem direta de uma corrente elétrica através do pó. No entanto, a inovação que deu origem ao processo de flash sintering como estudado atualmente foi proposta por Cologna et al. (2010), que estudou a sinterização de um pó nanométrico de zircônia num tempo inferior a 5 segundos por $850^{\circ} \mathrm{C}$. Neste trabalho, algumas diferenças fundamentais em relação ao trabalho pioneiro de Hill et al. (1952) são marcantes, como a sinterização sem uma pressão aplicada externamente, e um material isolante elétrico, que é a zircônia, diferente dos cermetos que possuem metais na sua composição. No trabalho de Cologna et al. (2010), destacaram-se principalmente o tempo e a temperatura que permitiram a densificação do pó, muito inferiores aos processos convencionais de sinterização, que requerem horas de processo na temperatura de patamar, bem como uma temperatura muito mais alta para pós cerâmicos se densificarem, ainda que sejam nanocristalinos. 
Após a inovação proposta por Cologna et al., muitos trabalhos foram exitosos no processamento de outros materiais pela técnica de flash sintering, como a zircônia estabilizada com 8\% mol de ítria (COLOGNA, PRETTE, RAJ, 2011), condutores protônicos $\left(\mathrm{BaCeO}_{3}\right.$ dopado com $\mathrm{Gd}$ ) (MUCCILLO, MUCCILLO, KLEITZ, 2012), óxidos condutores elétricos $\left(\mathrm{Co}_{2} \mathrm{MnO}_{4}\right)$ (PRETTE et al., 2011), cerâmicas tradicionais (TROMBIN, RAJ, 2014) e semicondutores covalentes (SiC) (ZAPATASOLVAS et al., 2013). Embora a maioria dos trabalhos tenham sido realizados com o uso de corrente contínua, a corrente alternada também tem sido utilizada com sucesso.

Como o processo de flash sintering e os seus mecanismos ainda permanecem em grande discussão no meio científico (TODD, 2017), a maior parte dos trabalhos recentes tem se concentrado em expandir a gama de materiais e investigar possíveis aplicações, e medições detalhadas das condições sob as quais o fenômeno de flash sintering ocorre para reunir evidências para os mecanismos envolvidos (TODD et al., 2015, ZHANG, JUNG, LUO, 2015). Não menos importantes, também são relatadas variações de configuração experimental e operacional para investigar outros regimes onde o uso de correntes elétricas nas cerâmicas possa ser útil (GRASSO et al., 2014; ZAPATA-SOLVAS et al., 2015). Ainda são poucos os trabalhos que se concentram em estudar as microestruturas e propriedades das cerâmicas sinterizadas por flash sintering.

A técnica de flash sintering se distingue de outras técnicas de sinterização assistidas por campo (FASTs), porque é uma técnica de sinterização da amostra "livre", sem estar confinada em um molde. A principal diferença em relação à sinterização por micro-ondas, por exemplo, que também se utiliza de amostra "livre", é marcada pelo simples fato de que não são utilizados micro-ondas e campos elétricos de corrente contínua. Em relação à SPS, a principal diferença é o fato de não haver uma pressão aplicada, tampouco moldes que encapsulam a amostra (MUNIR, ANSELMI-TAMBURINI, OHYANAGI, 2006). Na flash sintering, a amostra é aquecida diretamente por um forno convencional, e não pelas correntes elétricas em si. As tensões e correntes utilizadas são muito mais baixas na flash sintering do que nas técnicas de SPS, e isso denota uma energia total muito mais baixa. Por fim, os campos elétricos usados na flash sintering são estáticos e permanecem constantes por todo o processo de sinterização, se os limites de corrente da fonte de potência não são atingidos. 
Uma definição mais geral e completa de flash sintering foi proposta por Raj et al. (2013) em uma aplicação de patente, onde flash sintering é descrita como "Um método de sinterização de um material que compreende simultaneamente a exposição do material a um campo elétrico e ao calor, de forma tal que o material é sinterizado, enquanto o campo elétrico é entre $7,5 \mathrm{~V} / \mathrm{cm}$ e $1000 \mathrm{~V} / \mathrm{cm}$, e a ocorrência da sinterização é acompanhada por uma dissipação de potência entre 10 e 1000 $\mathrm{mW} \cdot \mathrm{mm}^{-3}$. Essa sinterização e acompanhada por um aumento não-linear na condutividade do material, e onde o tempo entre o início e final da sinterização é menor do que um minuto". O evento de flash ocorre após um tempo de incubação que depende do campo elétrico e da temperatura do flash.

Um exemplo de experimento típico de flash sintering pode ser baseado no trabalho de Cologna et al. (2010), onde os corpos cerâmicos a verde são suspensos na zona quente de um forno por dois fios de platina, cada um ligado a uma extremidade da amostra. Uma voltagem constante, $V$, é aplicada através da amostra por meio dos fios e o forno é programado para aquecer a uma taxa constante. No caso da (YSZ), que foi utilizada por Cologna et al. (2010), como esse material não conduz eletricidade a temperatura ambiente, nada acontece inicialmente. No entanto, ao atingir uma temperatura crítica no forno, a corrente $I$ e, portanto, a dissipação de potência elétrica $(V I)$ crescem rapidamente, como mostrado na Figura 15 (TODD et al., 2015).

Figura 15 - Exemplo do comportamento da dissipação de potência elétrica (linha cheia) em comparação com a previsão calculada por elementos finitos (linha pontilhada) em uma amostra de zircônia estabilizada com $3 \%$ mol de ítria sinterizada por flash sintering com um campo de $100 \mathrm{~V} / \mathrm{cm}$.



Fonte: Adaptado de: TODD, R. I.; ZAPATA-SOLVAS, E.; BONILLA, R. S.; SNEDDON, T.; WILSHAW, $P$. R. Electrical characteristics of flash sintering: thermal runaway of Joule heating. Journal of the European Ceramic Society, v. 35, pp. 1865-1877, 2015. 
Como a fonte de potência tem uma limitação, é programada para mudar para corrente constante quando I atinge um valor predeterminado. Neste ponto $(\mathrm{t}=0)$ na Figura 15, a dissipação de potência diminui novamente e eventualmente se estabiliza em um valor constante. O evento de "flash" ocorre por cerca de 15 segundos, e grande parte da sinterização em si ocorre durante um período de aproximadamente 5 segundos por volta do pico de dissipação de potência. Tal fenômeno é acompanhado por emissão de radiação, sendo grande parte eletroluminescência (TERAUDS et al., 2015); no entanto, existe uma concordância entre vários grupos de que a amostra se aquece por causa do aquecimento Joule (dissipação de potência elétrica). O aquecimento pode ser estimado indiretamente utilizando-se o balanço de energia entre a potência elétrica e a perda de calor e luz, e também foi medida por pirômetros (RAJ, 2012), e por determinação do parâmetro de rede in situ usando difração de raios X síncrotron (TERAUDS et al., 2015).

Outra variação experimental que vem sendo estudada para determinar a combinação crítica de temperatura do forno e corrente é suspender a amostra em um forno a temperatura constante e aumentar gradualmente a voltagem até que o evento flash ocorra. Além da utilização da platina como eletrodo, diversos materiais vêm sendo estudados, como prata (CALIMAN et al., 2016; BIESUZ, SGLAVO, 2016), carbono/grafite (ZAPATA-SOLVAS et al., 2013; BIESUZ, SGLAVO, 2016), em diversos formatos, como discos, cilindros e barras.

Os experimentos realizados por Cologna, Rashkova e Raj (2010), em que campos elétricos foram aplicados diretamente numa amostra de zircônia estabilizada com 3 mol\% de ítria, revelaram dois tipos de curvas de sinterização - Tipo A e Tipo B (Figura 16). Para as curvas de sinterização do tipo A, a taxa de sinterização é significativamente melhorada, em comparação com a sinterização convencional, quando baixos valores de campo elétrico são aplicados (valores menores que 40 $\mathrm{V} / \mathrm{cm}$ ). Esse comportamento tem sido atribuído à redução no crescimento do grão sob um campo elétrico aplicado durante a sinterização. No entanto, quando é aplicado um campo elétrico com valores maiores que $60 \mathrm{~V} / \mathrm{cm}$, um novo fenômeno é observado: sinterização quase que instantânea, como se fosse um flash (curvas de sinterização do tipo $\mathrm{B}$ ); ressalta-se também que a temperatura de sinterização decresce significativamente à medida que o campo elétrico aplicado é aumentado. 
Figura 16 - Curvas de sinterização com variação de campo elétrico para 3Y-TZP.

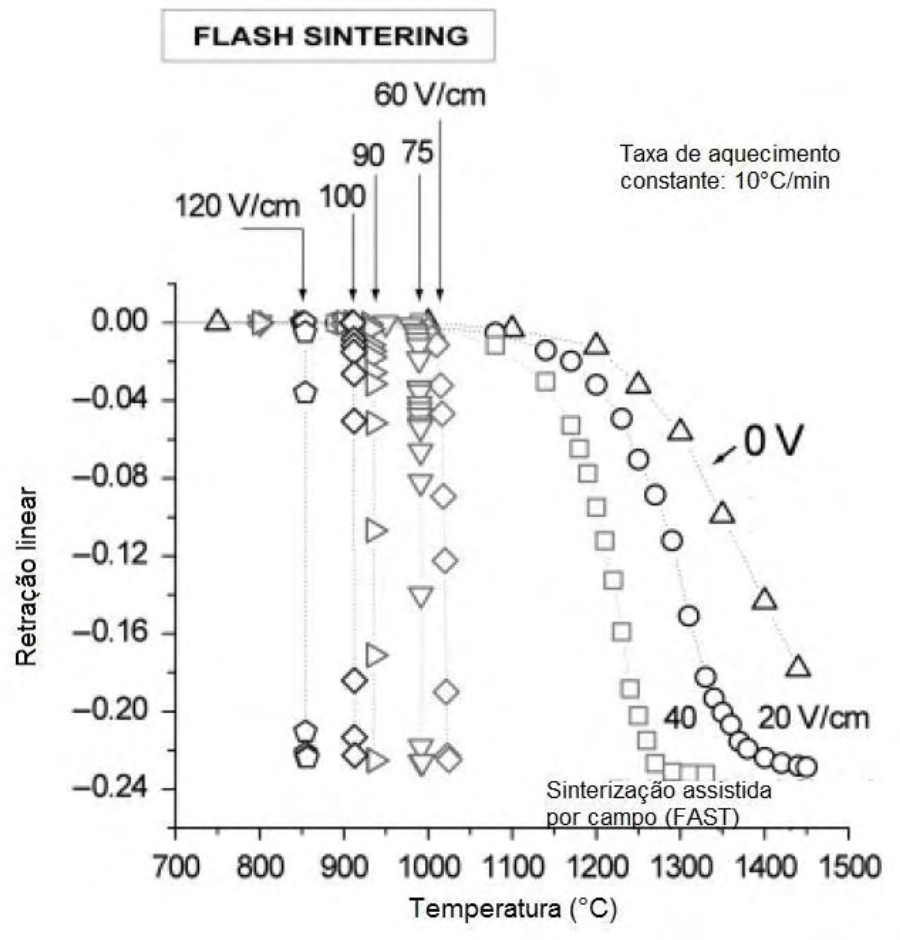

Adaptado de: COLOGNA, M.; RASHKOVA, B.; RAJ, R. Flash sintering of nanograin zirconia in $<5 s$ at $850^{\circ} \mathrm{C}$. Journal of The American Ceramic Society, v. 93, pp. 3556-3559, 2010.

As condições gerais de observação experimental nos processos de flash sintering têm encontrado concordância na literatura, no entanto não há um mecanismo universalmente aceito para a ocorrência do fenômeno. Uma característica é comum a todos os óxidos estudados: a sinterização é acompanhada por um aumento significativo e não linear na condutividade da amostra. Alguns autores interpretam esse processo por meio do aquecimento Joule, que aumenta a dissipação de energia e causa as altas taxas de sinterização (RAJ, 2012; FRANCIS, 2013; HAYAT, 2011). Porém, a temperatura medida da amostra durante a sinterização permanece muito abaixo do previsto para que a cerâmica possa ser sinterizada em tão curto tempo (NARAYAN, 2013; COLOGNA, FRANCIS, RAJ, 2011; FRANCIS, COLOGNA, RAJ, 2012; FRANCIS, 2013; HAYAT, 2011). Raj (2012), estudando a flash sintering da YSZ e o aquecimento Joule que ocorre durante o processo, estimou uma temperatura necessária de aproximadamente $1900^{\circ} \mathrm{C}$ em uma sinterização convencional para alcançar resultados semelhantes aos observados no processo de flash sintering. Portanto, muitos trabalhos têm proposto novos mecanismos de transporte de matéria relacionados com a carga elétrica do material. Alguns autores sugerem que o processo de flash sintering é 
uma consequência desses novos mecanismos, que são considerados no envolvimento da nucleação e crescimento de novas estruturas de defeitos no cristal (NAIK, SGLAVO, RAJ, 2014). Francis (2013) considera que as características térmicas e elétricas no processo de flash sintering são consequência clássica do coeficiente de temperatura negativo da resistividade, conduzindo à fuga do efeito Joule em uma tensão constante. Hewitt e colaboradores (2015) descreveram matematicamente as condições que levam a essa fuga térmica. Mucillo e Mucillo (2015) observaram emissão de luz durante a sinterização assistida por campo elétrico na zircônia estabilizada com ítria (que é um condutor iônico) e no dióxido de estanho (que é um condutor eletrônico), e isso indica que este fenômeno não é apenas dependente do comportamento elétrico das eletrocerâmicas. Baseado em

todas essas conclusões, pode-se afirmar que os mecanismos envolvendo a sinterização por flash sintering constituem um dos principais desafios da ciência básica no estudo deste novo método de sinterização.

\subsection{Caracterização das propriedades mecânicas de materiais cerâmicos}

Dentre as diversas técnicas de caracterização de propriedades mecânicas dos materiais cerâmicos, neste trabalho foram utilizadas as técnicas de microindentação e nanoindentação, para determinar a dureza, módulo de Young e a tenacidade à fratura dos materiais em estudo. Utilizando-se dessas caracterizações, amostras do sistema $\mathrm{t}-\mathrm{ZrO}_{2} / \mathrm{Al}_{2} \mathrm{O}_{3}-\mathrm{NbC}$ foram submetidas a ensaios de desgaste do tipo esfera-no-disco, para avaliar a taxa de desgaste, perda de volume e coeficiente de fricção. Em conjunto com essas características, a análise microestrutural das superfícies de desgaste permitiu avaliar os mecanismos de desgaste e, consequentemente, os regimes que governam o comportamento tribológico destes materiais. A caracterização de um material em relação a suas propriedades tribológicas, seguindo as normas, é um importante critério de seleção de um material visando à sua aplicação. Na seção a seguir, é feita uma breve revisão sobre a tribologia. 


\subsubsection{Tribologia}

A tribologia é a ciência e a tecnologia do atrito, da lubrificação e o desgaste das superficies que estão em movimento relativo (BHARAT, 2001). Trata-se de uma área da engenharia muito importante no projeto de maquinaria moderna, que envolve superfícies que se deslizam e rodam, em especial para as micromáquinas, onde há uma alta relação superfície/volume, e onde se trabalha com altas velocidades de deslizamento.

Uma das principais motivações dos estudos de tribologia é o ponto de vista econômico, considerando-se que mais de $80 \%$ dos elementos que se substituem nas máquinas se devem ao desgaste (BHARAT, 2001). A previsão adequada da evolução da fricção e do desgaste, e seu controle, portanto, constituem um dos pilares mais importantes no design de engenharia.

As cerâmicas estruturais têm sido parte de um campo crescente de pesquisa nos últimos 35 anos. Com isso, as pesquisas desenvolveram uma gama de aplicações que mostrou os meios de se utilizar as cerâmicas por causa das suas propriedades específicas. Nesse âmbito, mostrou-se que elas também poderiam ser adequadas a aplicações resistentes ao desgaste, mas a prática mostrou que havia muito a se avançar para atingir a resistência necessária (KERKWIJK, 1999).

Quando duas superfícies, normalmente planas, são colocadas em contato, a rugosidade superficial causa muitos pontos de contato discreto, como mostra a Figura 17.

Figura 17 - Contato entre duas superfícies: (a) duas superfícies rugosas em contato; (b) áreas de contato correspondentes.

a)

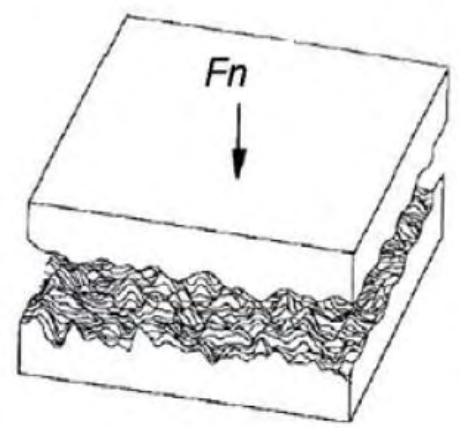

b)

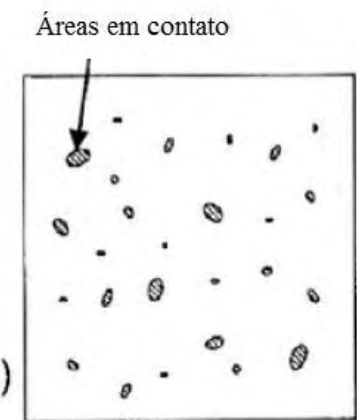

Fonte: Adaptado de: STACHOWIAK, G.; ANDREW, W.; BATCHELOR, W. Engineering Tribology. Oxford: Elsevier, 2001. 
A soma das áreas de todos os pontos de contato constitui a chamada "área de contato", que é uma função da textura superficial, das propriedades do material e das condições de carga (STACHOWIAK, ANDREW, BATCHELOR, 2001). A carga normal, $F_{n}$, limita o contato entre as superfícies sobre os pontos que a suportam.

Se a carga normal aplicada é incrementada, o número de pontos de contato aumenta e, portanto, a área de contato que tem que suportar a carga aplicada também se incrementa. Na região dos pontos em contato, ocorre deformação, que estabelece tensões opostas à carga aplicada (STACHOWIAK, ANDREW, BATCHELOR, 2001).

Como mostrado na Figura 17, a interação entre dois sólidos em movimento relativo se dá nas suas superfícies de contato. Levando-se em conta que uma superfície é considerada um defeito tridimensional de uma estrutura cristalina, geralmente as superfícies são descritas por sua topografia, por sua estrutura e por suas características físicas, químicas e propriedades mecânicas.

Para se obter um completo entendimento do comportamento tribológico de pares em contato, é necessário entender a interação entre as superfícies quanto ao tipo de contato químico e mecânico (TEDESCO, 2010).

Para permitir uma correta distinção das características tribológicas, é importante defini-las.

- Atrito: O atrito (ou fricção) é definido como a resistência ao movimento durante o deslizamento, quando um corpo está em contato com outro e se move tangencialmente a ele (BHUSHAN, 2000). Pode ser classificada como atrito deslizante ou atrito por laminação (BLAU, 2001). O coeficiente de atrito (ou coeficiente de fricção), $f$, é definido como a razão entre a força de atrito medida $\left(F_{a}\right)$ e a força normal aplicada $\left(F_{n}\right)$, como mostra a Equação 4:

$$
f=\frac{F_{a}}{F_{n}}
$$

- Lubrificação: A lubrificação é definida como "a introdução de um material sólido, líquido ou gasoso entre dois sólidos em contato que deslizam entre si com a função específica de reduzir o atrito e o desgaste, além de retirar o calor e os detritos gerados pelo movimento das superfícies deslizantes" (ASM, 1992). A forma 
como um processo de lubrificação ocorre depende da condição e aplicação tribológica, além de fatores como geometria de contato, carga, velocidade, temperatura, tipo de lubrificante eventualmente utilizado, da superfície e do tipo de material utilizado.

- Desgaste: O desgaste, por sua vez, define-se como "a perda progressiva de substância da superfície de operação de um corpo, ocorrendo como resultado do movimento relativo das superfícies" (MEDVEDOVSKI, 2001). O desgaste raramente é catastrófico, porém é um processo que leva à perda de eficiência e diminuição de vida útil do componente, pois gera mudanças geométricas, vibrações, desalinhamentos e crescimento microscópio de trincas (TEDESCO, 2010).

Atrito e desgaste não são características intrínsecas do material, e sim uma resposta do sistema tribológico. Essa resposta que se espera de um material é função do seu modo de operação e aplicação do componente. Há situações em que se requer atrito, como por exemplo em pastilhas de freio, porém não se deseja desgaste. No caso da superfície de um mancal, as dimensões têm de ser preservadas, e isso faz com que qualquer atrito, e consequente desgaste, sejam indesejáveis (TEDESCO, 2010).

\subsubsection{Desgaste e mecanismos de desgaste}

A resistência ao desgaste não é uma propriedades que pode simplesmente ser descrita especificamente para um material. Ela é influenciada por muitos parâmetros determinados tanto pelo sistema como pelo material que é utilizado. Considerandose que o desgaste é, a princípio, uma propriedade de sistema, que também depende da carga, velocidade e temperatura, ele é usualmente descrito e termos de uma taxa específica de desgasteTodos os materiais que são testados no seu comportamento tribológico são caracterizados por este parâmetro. Este parâmetro representa o desgaste apenas como função das condições do sistema.

Uma figura esquemática do desenvolvimento do volume de desgaste como função da distância de deslizamento é dada na Figura 18, onde a inclinação da curva (se dividida pela força normal aplicada e com um aumento linear no volume de desgaste) é uma representação da taxa de desgaste específica. (KERKWIJK, 1999). 
Figura 18 - Desenvolvimento do volume de desgaste com o tempo a uma determinada força normal aplicada; a inclinação da curva (dividida pela força normal aplicada) representa a taxa de desgaste específica.

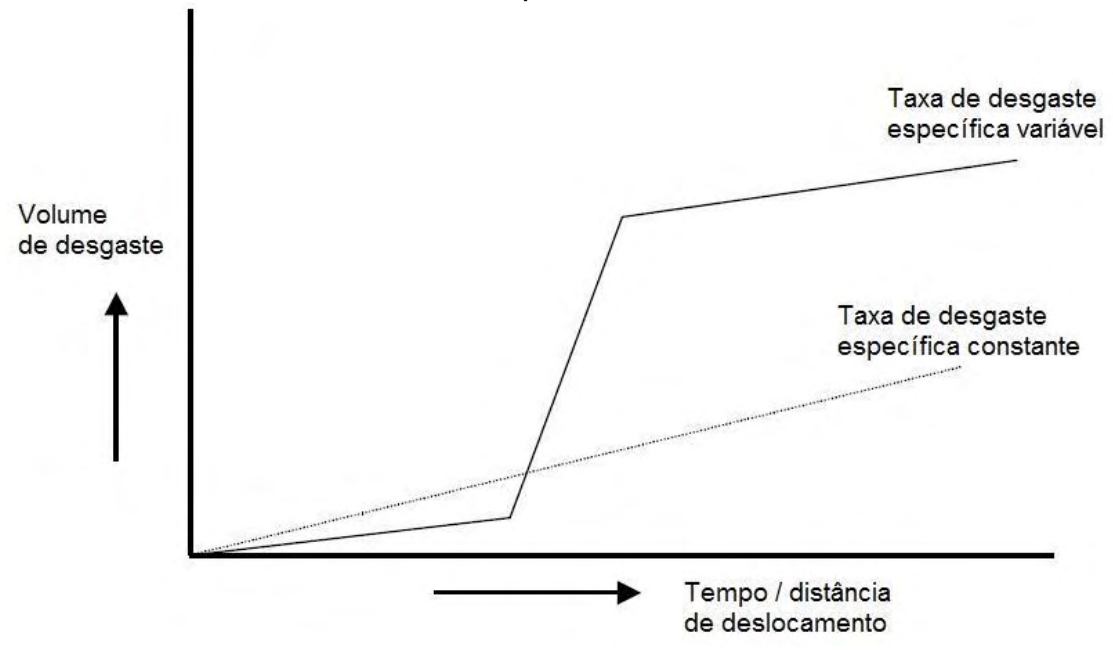

Fonte: Adaptado de KERKWIJK, B. Wear and friction of nanostructured zirconia and alumina ceramics and composites. 1999, $127 \mathrm{f}$. Tese (Doutorado) - Faculdade de Engenharia e Tecnologia, Universidade de Twente, Enschede, 1999. Disponível em:

<https://research.utwente.nl/en/publications/>. Acesso em: 24 jul. 2017.

Para o desgaste em geral, é importante conhecer os principais mecanismos que o causam. Há quatro principais mecanismos de desgaste que podem ocorrer em qualquer tipo de material: o desgaste abrasivo, o desgaste adesivo, o desgaste por delaminação e o desgaste corrosivo (ou triboquímico). A seguir serão expostas as principais características de cada tipo.

\subsection{Desgaste abrasivo}

O desgaste abrasivo é aquele em que ocorre a remoção ou o deslocamento de material causado pela presença de partículas duras entre as superfícies em movimento relativo, sejam soltas ou enclausuradas (CZICHOS et al., 1995). As partículas podem ser produto do processo, isto é, os fragmentos do desgaste, também denominados detritos (ou debris), ou estarem presentes no sistema de maneira intencional. Dependendo das propriedades das superfícies de desgaste, esse desprendimento de material pode resultar em diferentes micromecanismos de ação. Quando partículas duras são removidas, podem atuar como um material abrasivo adicional, causando desgaste da superfície de contato mais mole. Mais abrasão causa mais perda de material, o que resulta em superfícies severamente deformadas. Portanto, a dureza de um material é um parâmetro muito importante 
para este mecanismo de desgaste, especialmente a diferença de dureza entre os dois materiais de contato.

Foi desenvolvido um modelo geral (ZUM GAHR, 1987; 1988) que descreve o degaste abrasivo por distinção de quatro tipos de interações entre partículas abrasivas e um material em desgaste (Figura 19), denominadas microssulcamento, microcorte, microfadiga e microtrincamento. Em uma situação ideal, o microssulcamento devido a uma única passagem de uma partícula abrasiva não resulta em desprendimento de material da superfície sendo desgastada. Um sulco é formado à frente da partícula abrasiva, e o material é continuamente deslocado lateralmente, formando uma borda de material adjacente ao sulco produzido. Entretanto, a perda de volume pode ocorrer devido à ação de muitas partículas abrasivas ou à ação repetida de uma única partícula. $O$ material pode ser sulcado às laterais repetidamente ao se passarem as partículas e romper por fadiga de baixo ciclo, isto é, microfadiga.

O microcorte puro resulta em uma perda de volume por lascas equivalente ao volume dos sulcos de desgaste. O microtrincamento ocorre quando tensões altamente concentradas são impostas por partículas abrasivas, particularmente na superfície de materiais frágeis. Neste caso, grandes detritos de desgaste são removidos da superfície de desgaste, devido à formação e à propagação de trincas. O microssulcamento e o microcorte são os processos dominantes em materiais dúcteis, enquanto o microtrincamento é mais notado em materiais frágeis (ZUM GAHR, 1998).

Figura 19 - Representação esquemática das diferentes interações entre partículas abrasivas deslizantes e a superfície dos materiais.
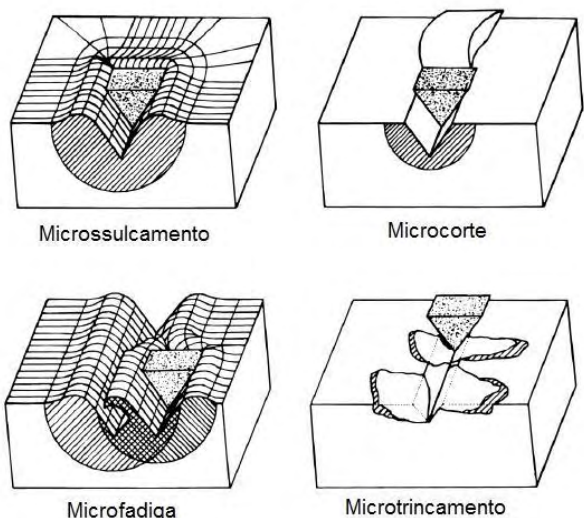

Fonte: Adaptado de: ZUM GAHR, K.-H., Wear by hard particles. Tribology International, v. 31, n. 10, pp. 587-596, 1998. 


\subsection{Desgaste adesivo}

O desgaste adesivo (ou desgaste por adesão) ocorre durante o processo de deslizamento, quando sólidos em contato se aderem e as forças dessa ligação na junção se tornam maiores do que aquelas em um dos sólidos (KERKWIJK, 1999). Isso resulta em deformação plástica causada pelo movimento de discordâncias e das superfícies deslizantes resultante da alta pressão entre as superfícies de contato e subsequente reação entre elas (HUTCHINGS, 1992). A dureza dos materiais também influencia o tipo de camada aderida que é formada (principalmente espessura), mas em geral, um dos três tipos a seguir é formado:

- Um filme fino contínuo aderido a ambas as superfícies de contato;

- Um filme espesso contínuo aderido a ambas as superfícies de contato ou a uma delas;

- Um filme espesso descontínuo aderido a ambas as superfícies de contato.

O desgaste adesivo é mais pronunciado em materiais dúcteis. No entanto, as cerâmicas podem apresentar este mecanismo em condições que provoquem altas temperaturas nos pontos de contato (TEDESCO, 2010).

\subsection{Desgaste por delaminação}

O desgaste por delaminação em cerâmicas é principalmente relacionado à nucleação de trincas subsuperficiais e sua propagação paralela à superfície. $O$ processo pode ocorrer pelos seguintes passos, de forma individual ou em sequência (KERKWIJK, 1999):

- Alisamento da superfície mais mole devido à deformação e/ou remoção de asperezas;

- Indução de deformação plástica na superfície mais mole pela presença de asperezas mais duras;

- Nucleação de trincas abaixo da superfície devido à deformação subsuperficial crescente;

- Delaminação de folhas de desgaste longas e finas em lugares onde as trincas conseguem se propagar à superfície. 
A Figura 20 exemplifica os estágios do desgaste por delaminação.

Figura 20 - Exemplo de estágios no desgaste por delaminação: (a) deformação plástica nas asperezas locais; (b) formação de trincas no maciço; (c) propagação de trincas paralelas à superfície; (d) delaminação da camada trincada.
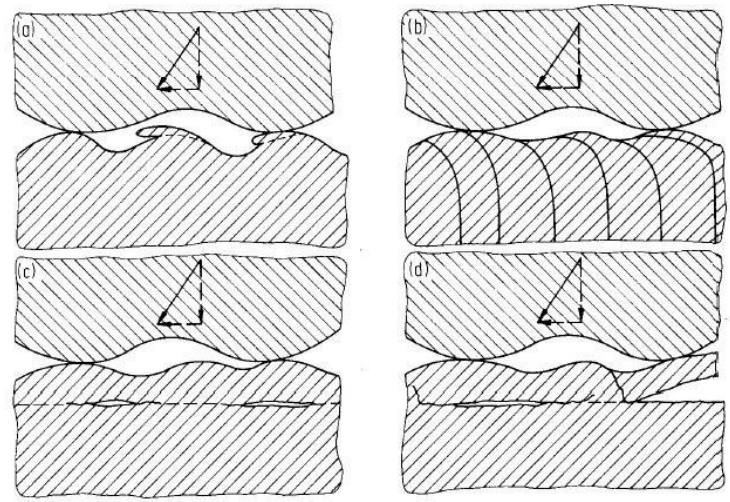

Fonte: KERKWIJK, B. Wear and friction of nanostructured zirconia and alumina ceramics and composites. 1999, 127 f. Tese (Doutorado) - Faculdade de Engenharia e Tecnologia, Universidade de Twente, Enschede, 1999. Disponível em:

<https://research.utwente.nl/en/publications/>. Acesso em: 24 jul. 2017.

\subsection{Desgaste corrosivo (ou triboquímico)}

O desgaste corrosivo (ou triboquímico) é causado principalmente por efeitos ambientais que podem ser divididos em três tipos (SASAKI, 1991):

- $\quad$ Formação de camadas adsorvidas;

- Mudança das propriedades da superfície, seguida pela adsorção;

- $\quad$ Formação de produtos triboquímicos.

A nova superfície formada por esse tipo de desgaste pode ser chamada de tribofilme, camada de transferência, intercamada, filme aglomerado, filme de detritos, camada particulada, camada superficial de materiais compactados, camada superficial de partículas de desgaste, substrato com aparência de filme, camada de fronteira e estrutura de transformação tribológica (ADACHI e KATO, 2000)

Sob condições de deslizamento a seco a influência do ambiente nos processos de desgaste triboquímico é principalmente relacionada à presença de água no ar (umidade relativa) ou temperaturas elevadas. Sob lubrificação, a presença da fase lubrificante no contato (p.ex., água, óleo, parafina) pode influenciar a triboquímica do processo de desgaste. Isto significa que o desgaste corrosivo ou triboquímico resulta da formação e remoção de produtos de reação química nas superfícies de contato. É notável que os processos de desgaste que são 
influenciados pela corrosão, ocorrem ainda mais rápido a temperaturas elevadas (KERKWIJK, 1999).

As reações triboquímicas em cerâmicas óxidas geralmente são benéficas aos sistemas de desgaste, pela criação da camada protetora que alisa a superfície, diminuindo a taxa de desprendimento de partículas e o atrito. (AJAYI, LUDEMA, 1990; JENG, YAN, 1993; WANG, HSU, 1996; ADACHI, KATO, 2000). No entanto, no caso das cerâmicas não-óxidas e dos metais, a formação do tribofilme geralmente deprecia as características do sistema, devido à alta taxa de reação da superfície com o meio e pelo tribofilme ser incoerente, o que provoca uma rápida delaminação deste. Além disso, o aumento do coeficiente de atrito devido à rugosidade da superfície formada diminui o contato entre os corpos. Este fenômeno pode ser exemplificado pela oxidação superficial do nitreto de silício e de aços (GEE, BUTTERFIELD, 1993).

Os quatro mecanismos de desgaste descritos podem causar tanto desgaste moderado como severo, dependendo dos parâmetros de sistema como carga, velocidade e umidade, além de propriedades do material, como dureza, tenacidade e condutividade térmica.

\subsubsection{Desgaste em cerâmicas}

Como mencionado na seção anterior, as cerâmicas mostram processos de fratura durante 0 desgaste que são típicos para materiais frágeis. 0 microtrincamento é a maior causa de desgaste em cerâmicas, mas a deformação plástica pode ocorrer em materiais de tamanho de grão refinado (em escala submicrométrica) ou quando as temperaturas locais se tornam extremamente altas. Outra importante característica do desgaste em cerâmicas é a transição de desgaste moderado para severo a certas cargas ou velocidades. Em geral, esta transição é notada por uma mudança na maneira pela qual o desgaste ocorre; o fenômeno de desgaste muda de deformação plástica para fratura frágil e microtrincamento. Como já mostrado pela Figura 18, o ponto de transição é encontrado onde o volume de desgaste medido mostra um aumento repentino em função do tempo (KERKWIJK, 1999). 
A razão principal para ocorrer essa transição é o aumento do arrancamento de material a cargas e velocidades mais altas (microtrincamento e delaminação), ou durante deslizamento prolongado. Esse arranchamento de material causa uma maior contribuição da abrasão ao processo de desgaste. A aplicação de cerâmicas sob condições de carga ou velocidade extrema favorece a transição, mas em condições sem lubrificação, o valor da carga de transição para cerâmicas é menor do que para metais. Portanto, é necessário desenvolver materiais cerâmicos que suportem maiores cargas e assim aumentar os valores de carga de transição (WANG, HSU, 1996; WOYDT et al., 1990).

\subsubsection{Regimes de desgaste}

O regime de desgaste se refere à taxa (ou velocidade) com que o desgaste ocorre. No caso das cerâmicas, é classificado em dois tipos: moderado e severo. Tal classificação se baseia na taxa específica de desgaste. A ocorrência de um regime ou outro depende, além dos materiais envolvidos, das demais condições de ocorrência do desagaste. A fratura frágil é considerada a condição crítica para a transição entre os regimes. Considera-se que a viabilidade de aplicação tribológica das cerâmicas é necessário existir uma condição de alta resistência ao desgaste somada a superfícies lisas que possam se manter ao longo do uso, o que equivale a um regime moderado de desgaste. $O$ atrito é estático, devido ao alisamento da superfície pela presença do tribofilme, e as taxas de desgaste não ultrapassam a ordem de $10^{-6} \mathrm{~mm}^{3}$.(N.m) $)^{-1}$ (PASARIBU, SLOETJES, SCHIPPER, 2004; ADACHI, KATO, CHEN, 1997; KATO, ADACHI, 2002). As superfícies desgastadas apresentam aspecto de uma superfície lisa ou polida, podendo conter alguns riscos ou sulcos, porém livres de fratura (PASARIBU, SLOETJES, SCHIPPER, 2004; ADACHI, KATO, CHEN, 1997; KATO, ADACHI, 2002).

$O$ desgaste severo ocorre pela formação cumulativa de microfraturas em grãos individuais, causadas pela fratura frágil. As taxas específicas de desgaste têm ordem de grandeza maior do que $10^{-6} \mathrm{~mm}^{3}$. (N.m $)^{-1}$ e há a formação de detritos da ordem de grandeza do tamanho de grão, formados pela delaminação ou quebra dos triboflmes eventualmente formados. O coeficiente de atrito, por sua vez, é dinâmico, uma vez que o contato entre as superfícies deslizantes varia devido à elevada 
rugosidade (PASARIBU, SLOETJES, SCHIPPER, 2004; ADACHI, KATO, CHEN, 1997; KATO, ADACHI, 2002). As superfícies de desgaste apresentam fratura frágil, arrancamento de grãos, riscamento, sulcamento, trincas e deformações da camada de tribofilme.

Entre os regimes moderado e severo de desgaste, há uma condição intermediária, chamada de região de transição. Esta região é considerada por alguns autores como sendo a que possui taxa específica de desgaste entre $10^{-4}$ e $10^{-6}$ $\mathrm{mm}^{3}$.(N.m) ${ }^{-1}$, porém são poucos os trabalhos disponíveis na literatura que chegam a um consenso sobre as características deste regime (TEDESCO, 2010).

Baseado nas características dos regimes de desgaste relatadas, de acordo com Kato e Adachi (2002), pode-se listar os mecanismos básicos de desgaste de materiais cerâmicos avançados em função de sua severidade pelas seguintes confirmações:

- O regime de desgaste cerâmico é reconhecido como moderado ou severo a partir dos pontos-de-vista de rugosidade superficial de desgaste e taxa de desgaste;

- No desgaste moderado, a rugosidade superficial de desgaste é menor do que o tamanho de grão na ordem de cerca de um décimo, e a taxa de desgaste é na faixa de $10^{-9}$ a $10^{-5} \mathrm{~mm}^{3}$. (N.m) ${ }^{-1}$;

- No desgaste severo, a rugosidade superficial de desgaste é da ordem do tamanho de grão, e a taxa de desgaste é na faixa de $10^{-5}$ a $10^{-2} \mathrm{~mm}^{3}$.(N.m $)^{-1}$;

- As condições críticas para a transição entre o desgaste moderado e severo são dadas por certos valores de $S_{c, m}$ (severidade mecânica de contato) e $S_{c, t}$ (severidade térmica de contato), e os mapas de desgaste cerâmico são descritos com esses dois parâmetros, para reconhecimento das regiões de desgaste moderado e severo;

- Reações triboquímicas e desgaste triboquímico ocorrem na interface de contato das cerâmicas ao ar ou com lubrificantes, que geram um alisamento na superfície de contato;

- Detritos finos de desgaste, menores do que o tamanho de grão na ordem de um décimo ou menos, são formados pelo desgaste mecânico. Eles aderem à superfície de desgaste e formam um tribofilme relativamente mole, alisando a superfície. 


\subsubsection{Cerâmicas resistentes ao desgaste}

De acordo com Czichos e colaboradores (1995), os materiais cerâmicos têm vantagem sobre os metais (p.ex., aços) com respeito às suas forças de massa mais baixas, melhor resistência à abrasão e comportamento triboquímico. Aspectos menos positivos das cerâmicas incluem pressões de contato que se tornam maiores em função do módulo de Young dos componentes do tribopar, a variação da tensão máxima de cisalhamento hertziana do interior para a superfície e o grande aumento da temperatura induzida pelo alto atrito, devido à baixa condutividade térmica inerente às cerâmicas óxidas. A baixa tenacidade à fratura também pode levar à formação espontânea de partículas de desgaste sob cargas de impulso.

Dentre os materiais cerâmicos mais importantes para aplicações estruturais, estão a t- $\mathrm{ZrO}_{2}$ (estabilizada com $\mathrm{Y}_{2} \mathrm{O}_{3}$ ), $\mathrm{Al}_{2} \mathrm{O}_{3}, \mathrm{SiC}, \mathrm{Si}_{3} \mathrm{~N}_{4}$ e $\mathrm{SiAION}$. Seu uso foi extensivamente estudado nas últimas décadas. Além disso, existe uma classe mais específica que são os boretos e nitretos (p.ex., $\mathrm{B}_{4} \mathrm{C}, \mathrm{TiC}, \mathrm{TiN}, \mathrm{AIN}$ e BN) e são utilizados por sua dureza extremamente alta, apesar de alguns fatores negativos, como seu alto custo e diversos fatores que afetam o comportamento desse material. A escolha de um par específico para um ensaio de desgaste esfera-no-disco depende principalmente da aplicação a ser estudada. A dureza e as propriedades químicas e térmicas variam entre as cerâmicas mencionadas. $O$ teste para avaliar determinada aplicação sob condições práticas para uma aplicação resulta em uma seleção para um material específico, como descrito por Jahanmir (1994). Os testes de desgaste desses materiais estudados devem simular a aplicação real do material. Sendo assim, os resultados desses testes constituem um critério de seleção para um material específico.

\subsection{Estado-da-arte no estudo de desgaste da Y-TZP e seus compósitos}

Nos últimos anos, muitos estudos de desgaste foram realizados nos materiais à base de zircônia, principalmente estabilizada com ítria na fase tetragonal (Y-TZP). O comportamento da Y-TZP é fortemente dependente da natureza da contraface (KERKWIJK, 1999). O maior problema encontrado nesses ensaios é a baixa condutividade térmica da Y-TZP, causando frequentemente altas temperaturas de 
contato. Portanto, é difícil comparar os resultados de ensaios de tribossistemas de $\mathrm{Y}$-TZP com outros materiais, como $\mathrm{Al}_{2} \mathrm{O}_{3}$ e $\mathrm{SiC}$, que possuem condutividade térmica mais alta e têm menores efeitos advindos da temperatura, como fusão local.

Breznak, Breval e MacMillan (1985;1986) apresentaram um estudo completo do comportamento de desgaste e da Y-TZP e do SiC à temperatura ambiente. Eles encontraram um coeficiente de fricção estático de 0,4 para os ensaios recíprocos de pares de Y-TZP, que são aproximadamente $50 \%$ menores do que os valores reportados anteriormente. O desgaste, no entanto, foi considerado muito mais alto em relação aos pares recíprocos de SiC (BREZNAK, BREVAL, MACMILLAN, 1986). Sua conclusão foi de que os pares estudados não são adequados para aplicação em motores sem lubrificação (BREZNAK, BREVAL, MACMILLAN, 1985). A maior tenacidade à fratura da Y-TZP comparada com o SiC resulta em um desgaste dominado por fratura intergranular para a Y-TZP, enquanto no caso do SiC esta é transgranular. O trabalho de Libsch e colaboradores (1986), que estudou a dependência do comportamento tribológico de zircônia parcialmente estabilizada com MgO (Mg-PSZ), zircônia estabilizada com ítria (Y-TZP) e compósitos aluminazircônia, mostrou que as zircônias apresentam uma dependência muito grande do comportamento tribológico em relação à velocidade de deslizamento utilizada nos ensaios. Isto se mostra diferente do caso de cerâmicas à base de alumina (WANG, HSU, 1996). Libsch (1986) também apresenta resultados de um compósito zircônia/alumina com formação de defeitos estruturais que não foram encontrados na Y-TZP.

Outros autores (STACHOWIAK, STACHOWIAK, 1991; WANG, LI, MAO, 1993; MEDEVIELLE, THÉVENOT, TRÉHEUX, 1995) estudaram o comportamento de desgaste de várias zircônias estabilizadas e seus compósitos com alumina em função do comportamento de transformação de fase na superfície induzida pelo deslizamento, apresentando resultados por vezes contraditórios. Medevielle e colaboradores (1995), em estudo realizado com Mg-PSZ, Y-TZP e Y-TZP com 20\% em peso de alumina, mostraram que nos compósitos $Y$-TZP com alumina a perda de massa no desgaste é menor do que nas zircônias sem reforço.

Baseado nos estudos relatados pode-se afirmar que não apenas as propriedades mecânicas intrínsecas do material podem explicar as diferenças entre seu comportamento em relação ao desgaste, mas também fenômenos como dieletricidade, energia de polarização e cargas e contato devem ser levados em 
conta. O trabalho de Woydt e colaboradores (1991) mostra que a Y-TZP também sofre um desgaste severo a velocidades de deslizamento entre 0,04 e 0,14 m/s sob uma carga de $10 \mathrm{~N}$. A magnitude do desgaste depende da tensão tribológica e de possíveis reações relacionadas às tensões, como pressão de contato cíclica, dilatação térmica e cíclica, e transições de fase, seja a seco, ou mesmo a úmido, uma vez que a Y-TZP sofre degradação hidrotérmica em determinadas condições (TSE, LAWSON, GILL, 1994).

De acordo com Kerkwijk (1999), a adição de uma fase mais dura à matriz de Y-TZP, como alumina, melhora a resistência ao desgaste da matriz, que é relativamente mais mole. Além do aumento da dureza do compósito, há um aumento da condutividade térmica do material, e isto pode colaborar com o desempenho no desgaste. Dependendo do tamanho de partícula da alumina e do teor adicionado à matriz de zircônia, pode-se obter maior tenacidade à fratura, que também contribui no desempenho e possibilita a utilização do compósito como ferramenta de corte. No entanto, a influência da tenacidade à fratura na resistência ao desgaste ainda não é totalmente clara, tanto quanto a influência da dureza (LI, WATANABE, 1995; KERKWIJK, 1999).

São poucos os trabalhos disponíveis na literatura que estudam 0 comportamento de desgaste da Y-TZP reforçada com carbetos. Mais numerosos são os estudos sobre compósitos de matriz de alumina com esta aplicação, pela relativamente mais alta dureza desta matriz, o que aumenta a gama de utilização em aplicações que requerem alta resistência ao desgaste. No entanto, o aumento da dureza da matriz de Y-TZP por meio da adição de alumina, carbetos e outros materiais de alta dureza sugerem que, apesar de ainda pouco estudados, esses compósitos também são potenciais materiais para este tipo de aplicação. Isto é corroborado pela alta tenacidade à fratura da Y-TZP frente aos demais materiais cerâmicos.

Bonny e colaboradores (2008) estudaram o comportamento ao desgaste de compósitos de Y-TZP com 40\% em volume de WC, com duas dimensões de tamanho de partícula do carbeto. O carbeto mais "fino" consistia de um pó comercial submicrométrico desaglomerado da ordem de 0,8-1,0 $\mu \mathrm{m}$, e o mais "grosso" era um pó agregado de tamanho médio de aglomerado inferior a $10 \mu \mathrm{m}$. Ambos os compósitos apresentaram diversos mecanismos de desgaste em ensaios esfera-nodisco, com esfera de WC-6\%Co, obtendo um coeficiente de atrito estático que variou 
entre 0,25 (para WC mais fino) e 0,80 (para WC mais grosso), a uma velocidade de $0,3 \mathrm{~m} / \mathrm{s}$, distância de $10 \mathrm{~km}$ e carga entre $15 \mathrm{~N}$ e $35 \mathrm{~N}$. Os mecanismos ativos identificados incluíram abrasão, delaminação, formação de filme de detritos, microtrincamento e lascamento. Observou-se que a fase secundária de WC influencia fortemente na presença desses mecanismos, assim como seu tamanho de grão. Embora o compósito com menor tamanho de partícula de WC tenha proporcionado a formação de um filme de detritos de partículas muito finas de carbeto, o compósito que tinha maior tamanho de grão do WC apresentou uma taxa de desgaste volumétrico três vezes menor que o outro material. Houve, portanto, uma transição nos mecanismos de desgaste para ambas as condições.

O estudo de nanocompósitos com adição de pequenas frações volumétricas de alumina e/ou carbetos, como trata este trabalho, são muito escassos na literatura. Por esse motivo, este trabalho tem como intenção contribuir com informações para este tipo de estudo, uma vez que os testes de desgaste foram conduzidos no nanocompósito de $\mathrm{Y}-\mathrm{TZP} / 5 \%$ vol $\left(\mathrm{Al}_{2} \mathrm{O}_{3}-\mathrm{NbC}\right)$. 


\section{MATERIAL E MÉTODOS}

A metodologia utilizada no desenvolvimento deste trabalho se divide em três partes principais: preparação, sinterização e caracterização dos compósitos dos dois sistemas estudados: $\mathrm{t}-\mathrm{ZrO}_{2} / \mathrm{Al}_{2} \mathrm{O}_{3}$ e $\mathrm{t}-\mathrm{ZrO}_{2} / \mathrm{Al}_{2} \mathrm{O}_{3}-\mathrm{NbC}$. A seguir, estão descritas as etapas, todas elas baseadas em trabalhos já realizados anteriormente (PALLONE et al., 2003; SALEM et al., 2018):

\subsection{Preparação dos compósitos}

Esta seção está dividida em duas partes: preparação dos compósitos t$\mathrm{ZrO}_{2} / \mathrm{Al}_{2} \mathrm{O}_{3}$ produzidos com pós comerciais e preparação dos compósitos $\mathrm{t}$ $\mathrm{ZrO}_{2} / \mathrm{Al}_{2} \mathrm{O}_{3}-\mathrm{NbC}$. A Figura 21 mostra os fluxogramas resumidos dos processos utilizados para produção, sinterização e caracterização dos compósitos $\mathrm{t}-\mathrm{ZrO}_{2} / \mathrm{Al}_{2} \mathrm{O}_{3}$ (Figura 21(a)) e t- $\mathrm{ZrO}_{2} / \mathrm{Al}_{2} \mathrm{O}_{3}-\mathrm{NbC}$ (Figura 21(b)).

Figura 21 - Fluxograma resumido das etapas realizadas no desenvolvimento do trabalho: (a) sistema $\mathrm{t}-\mathrm{ZrO}_{2} / \mathrm{Al}_{2} \mathrm{O}_{3} ;(\mathrm{b})$ sistema $\mathrm{t}-\mathrm{ZrO}_{2} / \mathrm{Al}_{2} \mathrm{O}_{3}-\mathrm{NbC}$.

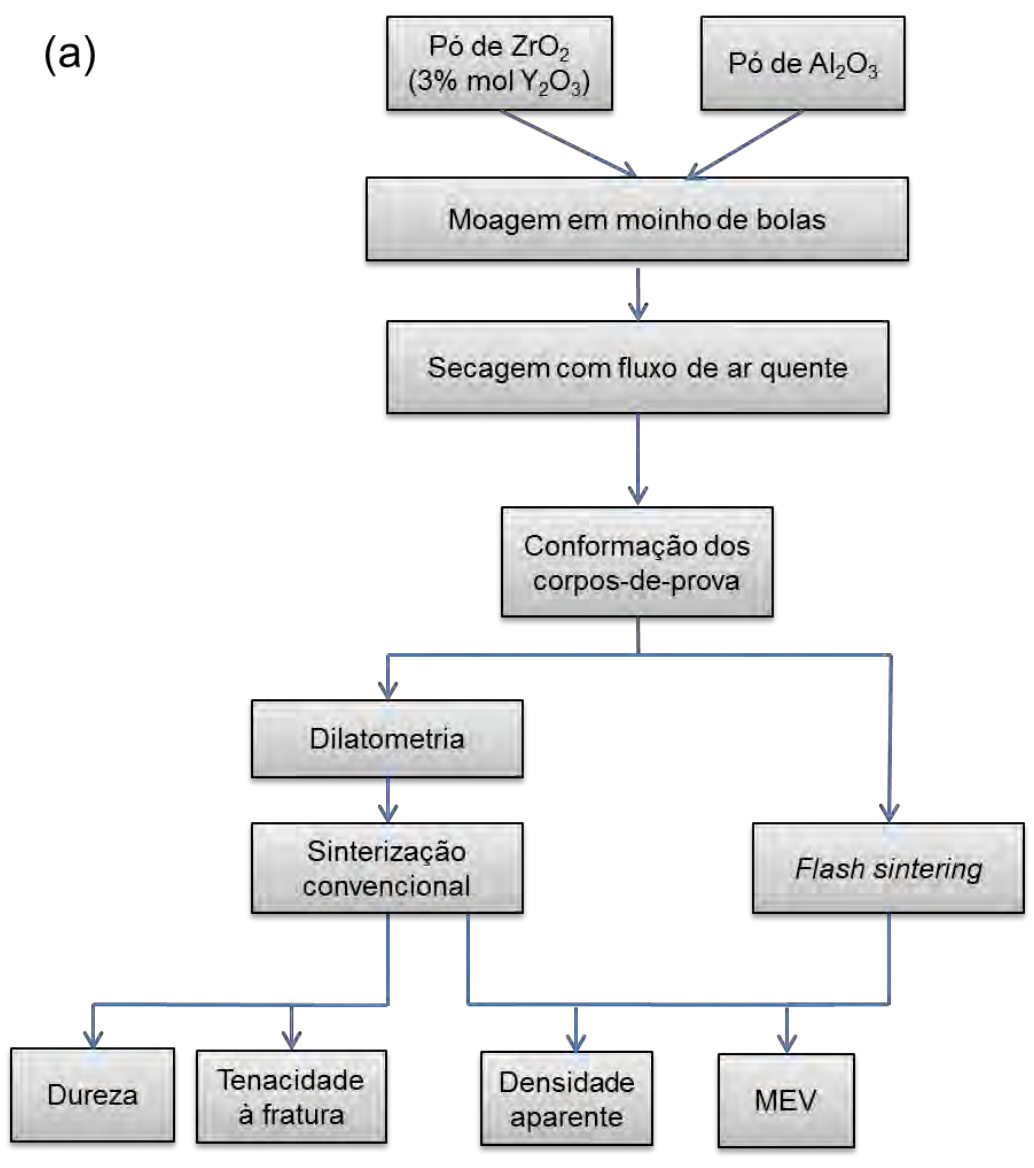




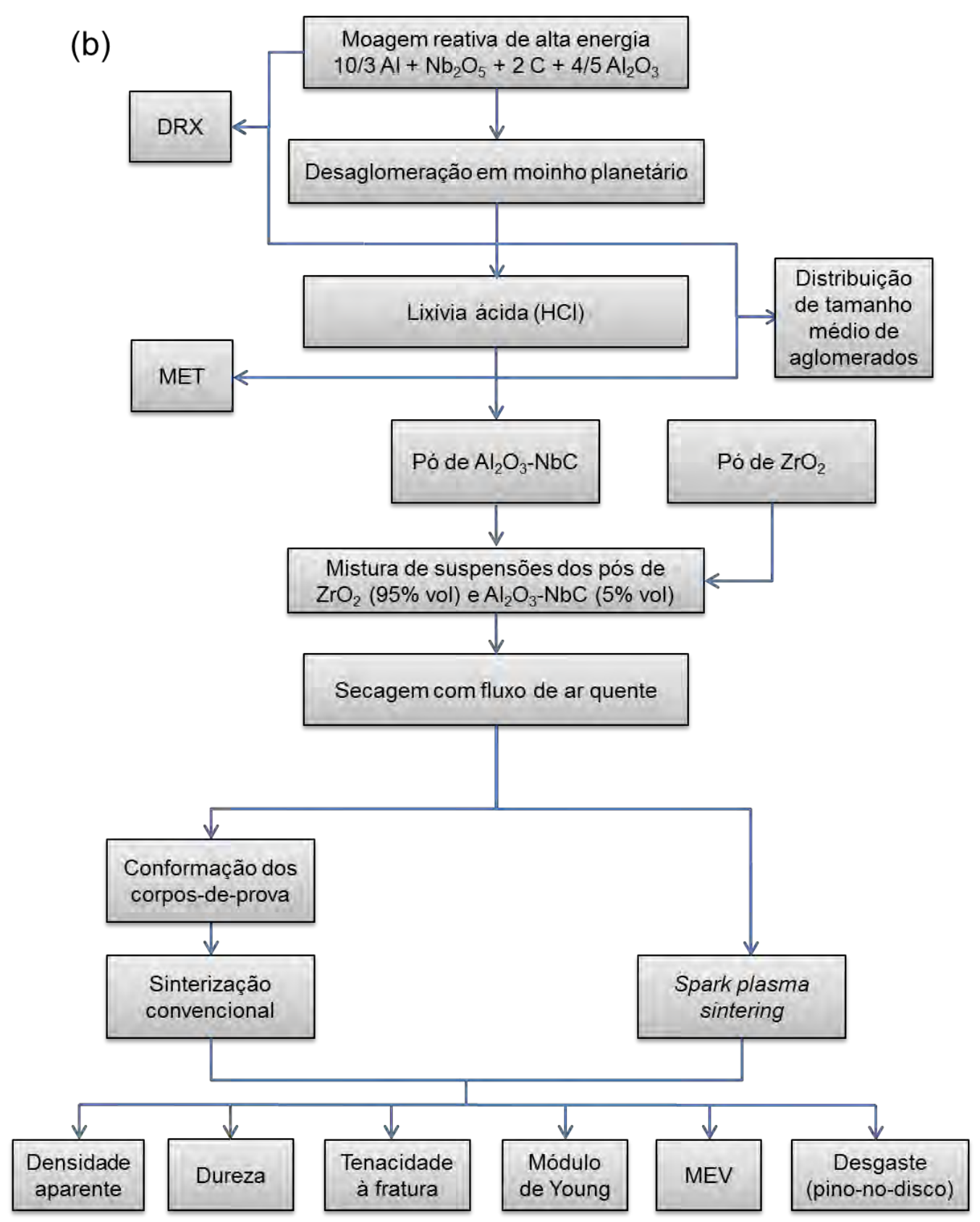

\subsubsection{Preparação dos compósitos do sistema $\mathrm{t}-\mathrm{ZrO}_{2} / \mathrm{Al}_{2} \mathrm{O}_{3}$}

\subsubsection{Materiais utilizados}

Os materiais utilizados para a preparação dos compósitos do sistema t$\mathrm{ZrO}_{2} / \mathrm{Al}_{2} \mathrm{O}_{3}$ foram pós comerciais, sendo a $\mathrm{t}-\mathrm{ZrO}_{2}$ um pó estabilizado na fase tetragonal por $3 \%$ em mol de $\mathrm{Y}_{2} \mathrm{O}_{3}$, marca Tosoh (Japão), referência TZ-3Y-E, com tamanho de partícula nominal médio de $40 \mathrm{~nm}$ e densidade de $6,05 \mathrm{~g} / \mathrm{cm}^{3}$, conforme 
informações fornecidas pelo fabricante (TOSOH, 2015). O pó de alumina utilizado nestes compósitos foi da marca Sumitomo Chemicals (Japão), referência AKP-53, da fase $\alpha-\mathrm{Al}_{2} \mathrm{O}_{3}$, com pureza $\geq 99,99 \%$, tamanho de partícula nominal médio de 180 $\mathrm{nm}$ (considerado submicrométrico) e densidade após queima entre 3,9-4,0 g/ $\mathrm{cm}^{3}$, conforme informações fornecidas pelo fabricante (SUMITOMO, 2014).

\subsubsection{Processo de mistura dos pós compósitos de $\mathrm{t}-\mathrm{ZrO}_{2} / \mathrm{Al}_{2} \mathrm{O}_{3}$}

A mistura dos pós foi realizada em meio alcoólico, utilizando álcool isopropílico P.A., utilizando um moinho de bolas convencional adaptado para jarros pequenos, com bolas de $\mathrm{t}-\mathrm{ZrO}_{2}$ de $5 \mathrm{~mm}$ de diâmetro em frasco de polipropileno sem carga, autoclavável (marca Nalgene). Foram preparados pós compósitos com matriz de $\mathrm{t}-\mathrm{ZrO}_{2}$ e frações de $\mathrm{Al}_{2} \mathrm{O}_{3}$ de 0,5 , e $15 \%$ em volume. Utilizou-se, na função de defloculante, ácido 4-aminobenzoico (PABA, marca Vetec), na proporção de 0,5\% em relação à massa total de pó, dissolvido previamente à adição dos óxidos. $\mathrm{O}$ processo de moagem de cada composição foi feito em etapas: por 12 horas para a zircônia, tendo sido adicionada a alumina após este período e continuado o processo por mais 22 horas. Ao fim deste período, uma fração de $2 \%$ em massa de ácido oleico P.A. (marca Vetec) foi adicionada como lubrificante para o processo de prensagem.

4.1.2 Preparação dos pós compósitos do sistema t- $\mathrm{ZrO}_{2} / \mathrm{Al}_{2} \mathrm{O}_{3}-\mathrm{NbC}$

\subsubsection{Obtenção do pó nanométrico de $\mathrm{Al}_{2} \mathrm{O}_{3}-\mathrm{NbC}$}

O pó nanométrico de $\mathrm{Al}_{2} \mathrm{O}_{3}-\mathrm{NbC}$ foi obtido por moagem reativa de alta energia em moinho do tipo SPEX, conforme a Equação 2.

A reação da Equação 2 foi tomada como base para o cálculo das massas dos reagentes, proporcionando uma reação autossustentada e integral. Determinou-se a massa total dos reagentes por meio de uma relação mássica entre bolas e material de 4:1. Os reagentes utilizados estão descritos no Quadro 2. 
Quadro 2 - Reagentes utilizados para produção do pó precursor de $\mathrm{Al}_{2} \mathrm{O}_{3}-\mathrm{NbC}$ em moinho de alta energia do tipo "Spex".

\begin{tabular}{|c|c|c|}
\hline Reagente & $\begin{array}{c}\text { Marca, país de } \\
\text { fabricação }\end{array}$ & Grau de pureza (\%) \\
\hline Alumínio em pó (Al) & ALCOA, Brasil & 99,7 \\
\hline Óxido de nióbio $\left(\mathrm{Nb}_{2} \mathrm{O}_{5}\right)$ & CBMM, Brasil & 98,5 \\
\hline Carbono amorfo $(\mathrm{C})$ & - & - \\
\hline Alumina $\left(\mathrm{Al}_{2} \mathrm{O}_{3}\right)$, AKP-53 & Sumitomo, Japão & 99,95 \\
\hline
\end{tabular}

Nesta mistura, a alumina foi utilizada com a função de diluente para reduzir a temperatura adiabática da reação, desta forma diminuindo a formação de agregados (PALLONE et al., 2003). O frasco e as bolas utilizados foram de aço temperado, sendo 5 bolas de $11 \mathrm{~mm}$ de diâmetro. $O$ tempo total de moagem foi de 330 minutos, sendo os primeiros 190 minutos para a reação no estado sólido e os 140 minutos finais para a cominuição dos pós até a escala nanométrica.

Após a moagem em moinho tipo SPEX, os pós foram caracterizados por difração de raios $X(D R X)$ em um difratômetro da marca Rigaku, modelo MiniFlex 600 , com radiação $K_{\alpha}(\mathrm{Cu})=1,54060 \AA$, operando com tensão de $40 \mathrm{kV}$ e corrente de $40 \mathrm{~mA}$. A velocidade do goniômetro utilizada foi de $2^{\circ} /$ minuto, variando $2 \theta$ de $5^{\circ} \mathrm{a}$ $90^{\circ}$.

A informação sobre o tamanho médio de cristalitos $D(h k l)$ numa dada direção cristalográfica $h k l$, foi obtida da largura a meia-altura (FWHM) do pico de difração mais intenso de cada fase analisada. O tamanho de cristalito em uma dada direção (hkl) pode ser determinado pela equação de Scherrer (CULLITY, 1978):

$$
D_{(h k l)}=\frac{0,89 \lambda}{\left(\beta_{(h k l)} \cos \theta_{(h k l)}\right)}
$$

Na Equação 6, $D$ é o tamanho do cristalito, $\lambda$ é o comprimento de onda dos raios $X, \beta$ é a largura à meia-altura do pico mais intenso da fase analisada e $\theta$ é o ângulo de difração desse pico.

Foi também realizada a caracterização do pó por microscopia eletrônica de varredura com canhão de emissão de campo (FEG-MEV), em um microscópio de 
marca TESCAN, modelo MIRA3. A medida de distribuição de tamanho de partícula foi realizada em um granulômetro a laser, marca Horiba, modelo LA-950 V2, com o pó disperso em álcool isopropílico P.A.

\subsection{Processamento do pó precursor de $\mathrm{Al}_{2} \mathrm{O}_{3}-\mathrm{NbC}$}

O pó nanométrico de $\mathrm{Al}_{2} \mathrm{O}_{3}-\mathrm{NbC}$, após ser preparado como descrito no item anterior, foi submetido a um beneficiamento para poder ser incorporado à matriz de $\mathrm{t}$-ZrO2. Este beneficiamento consistiu de 2 etapas: desaglomeração e lixívia ácida.

\subsection{Desaglomeração}

A fim de eliminar os agregados formados durante a moagem de alta energia, o pó de $\mathrm{Al}_{2} \mathrm{O}_{3}-\mathrm{NbC}$ foi desaglomerado em um moinho planetário, marca Fritsch, modelo Pulverisette 7. Este equipamento possui dois dispositivos rotativos para fixação dos frascos de moagem posicionados radial e axialmente simétricos sobre um disco, que executam um movimento de rotação em torno do seu próprio eixo e contrário ao de translação, descrito em torno do eixo de rotação do disco no qual são acoplados. A força centrífuga gerada por essa combinação de movimentos aumenta a força de impacto dos elementos de moagem, resultando na desaglomeração do pó.

Para a desaglomeração, foram utilizados dois frascos de moagem de aço temperado com tampa rosqueada, no interior dos quais foram adicionados as esferas de moagem de $11 \mathrm{~mm}$ de diâmetro e os pós precursores obtidos na moagem reativa de alta energia na proporção de 5:1, em meio alcoólico, adicionando-se 0,2\% em massa de ácido 4-aminobenzoico (PABA, marca Vetec), na função de defloculante.

$O$ pó desaglomerado foi também caracterizado por MEV, microscopia eletrônica de transmissão (MET), por medida de tamanho e distribuição de tamanho de partícula e por calorimetria diferencial exploratória em conjunto com termogravimetria (TG/DSC). 
A análise por MEV foi realizada no mesmo microscópio apresentado no item 4.1.2.1.1. A análise por MET foi realizada em um microscópio eletrônico de transmissão de alta resolução (HRTEM), marca FEI, modelo G2 F20. As medidas de tamanho e distribuição de tamanho de partícula foram realizadas pelo método de espalhamento a laser, no mesmo equipamento apresentado no item 4.1.2.1.1.

$\mathrm{O}$ estudo do comportamento térmico do pó de $\mathrm{Al}_{2} \mathrm{O}_{3}-\mathrm{NbC}$ foi realizado por TG/DSC em atmosfera de ar sintético, em equipamento de marca NETZSCH, modelo STA 449F3, à taxa de aquecimento de $10^{\circ} \mathrm{C} / \mathrm{min}$, até a temperatura de $1400^{\circ} \mathrm{C}$.

\subsection{Lixívia ácida}

Durante a moagem, a ação abrasiva do pó causa desgastes no frasco e nas esferas, liberando ferro. Sendo assim, foi necessário realizar a lixívia ácida, para eliminar esse ferro da mistura dos pós precursores. Essa lixívia foi feita com uma solução de $20 \%$ de ácido clorídrico $(\mathrm{HCl})$ em meio aquoso. O procedimento foi repetido por 5 vezes, até que a fase líquida se tornasse incolor, indicando ausência de contaminação por ferro. Após a sedimentação em proveta, descartou-se o ácido e lavou-se o pó com álcool etílico P.A. por duas vezes. O pó, até sua incorporação na matriz, foi mantido em um frasco com álcool etílico P.A., a fim de evitar a formação de aglomerados.

4.1.2.2 Incorporação do pó de $\mathrm{Al}_{2} \mathrm{O}_{3}-\mathrm{NbC}$ na matriz de $\mathrm{t}-\mathrm{ZrO}_{2}$ : ajuste da proporção volumétrica e processo de mistura

Antes da realização das misturas, os pós de $\mathrm{t}-\mathrm{ZrO}_{2}$ e $\mathrm{Al}_{2} \mathrm{O}_{3}-\mathrm{NbC}$ (resultante da moagem reativa), foram desaglomerados em moinho de bolas, com esferas de moagem de $\mathrm{t}-\mathrm{ZrO}_{2}$ de $5 \mathrm{~mm}$ de diâmetro e em meio alcoólico. Para isso, agitou-se por 15 minutos a suspensão com os pós desaglomerados, em um agitador magnético. Em seguida, foram preparadas duas suspensões em meio alcoólico: uma contendo o pó de $\mathrm{Al}_{2} \mathrm{O}_{3}-\mathrm{NbC}$ com $0,5 \%$ em peso de ácido 4-aminobenzóico (PABA, 
marca VETEC), usado como defloculante, e a outra com $\mathrm{t}-\mathrm{ZrO}_{2}$ contendo $0,2 \%$ em peso de PABA.

Em seguida, as duas suspensões foram transferidas para dois frascos de polipropileno contendo esferas de moagem de $\mathrm{t}-\mathrm{ZrO}_{2}$ de $5 \mathrm{~mm}$ de diâmetro e foram misturadas em moinho de bolas convencional. No frasco contendo o pó de $\mathrm{Al}_{2} \mathrm{O}_{3}-$ $\mathrm{NbC}$, utilizou-se a relação mássica de bolas/material de 5:1 e o material permaneceu no moinho por 12 horas. Já no frasco contendo o pó de $\mathrm{t}-\mathrm{ZrO}_{2}$, utilizou-se a relação mássica de bolas/material de 4:1 e deixou-se misturando no moinho por 1 hora.

Ao final da mistura individual dos componentes em moinho de bolas, as suspensões foram misturadas entre si e colocadas novamente no moinho por mais 22 horas. A proporção utilizada foi calculada de forma que resultou em $5 \%$ em volume da mistura $\mathrm{Al}_{2} \mathrm{O}_{3}-\mathrm{NbC}$ na matriz de $\mathrm{t}-\mathrm{ZrO}_{2}$. $\mathrm{O}$ cálculo foi baseado no volume de suspensão de $\mathrm{Al}_{2} \mathrm{O}_{3}-\mathrm{NbC}$ após um teste de secagem da suspensão com a concentração mantida constante.

\subsubsection{Secagem das suspensões}

Imediatamente após serem retiradas do moinho, as suspensões de t$\mathrm{ZrO}_{2} / \mathrm{Al}_{2} \mathrm{O}_{3}$ e de $\mathrm{t}-\mathrm{ZrO}_{2} / \mathrm{Al}_{2} \mathrm{O}_{3}-\mathrm{NbC}$ foram secas com fluxo de ar quente, sob agitação manual, até a quase completa eliminação do álcool. Após esse processo, os pós foram desaglomerados manualmente em almofariz de ágata e passados em peneira de nylon de malha 80 mesh.

\subsubsection{Conformação dos pós}

Os pós foram conformados na forma de pastilhas cilíndricas de $8 \mathrm{~mm}$ e de 20 $\mathrm{mm}$ de diâmetro (amostras de $\mathrm{t}-\mathrm{ZrO}_{2} / \mathrm{Al}_{2} \mathrm{O}_{3}-\mathrm{NbC}$ a serem sinterizadas convencionalmente para ensaio de desgaste), usando prensagem uniaxial em prensa hidráulica, com pressão de $150 \mathrm{MPa}$; em seguida, foram prensados isostaticamente em uma prensa automática de marca WICHARY AIP, modelo CP360, com 200 MPa de pressão. 


\subsection{Sinterização dos compósitos}

\subsubsection{Sinterização dos compósitos $\mathrm{t}-\mathrm{ZrO}_{2} / \mathrm{Al}_{2} \mathrm{O}_{3}$}

A sinterização dos compósitos $\mathrm{t}-\mathrm{ZrO}_{2} / \mathrm{Al}_{2} \mathrm{O}_{3}$ foi realizada em forno convencional de alta temperatura, ao ar, e pela técnica não-convencional de flash sintering. As condições de sinterização estão descritas a seguir.

\subsubsection{Dilatometria dos compósitos $\mathrm{t}-\mathrm{ZrO}_{2} / \mathrm{Al}_{2} \mathrm{O}_{3}$}

A dilatometria é uma importante técnica utilizada para investigar o processo de sinterização, possibilitando obter informações sobre o comportamento térmico do material através de todo o ciclo de sinterização (aquecimento, patamar e resfriamento) pelo qual uma amostra é submetida. Essas informações podem ser obtidas com base nas variações dimensionais da amostra com o tempo, com uma pequena expansão inicial, mas com altas taxas de retração, principalmente próximas à temperatura em que a máxima densificação ocorre (RIBEIRO et al., 2017, no prelo). Portanto, o ensaio de dilatometria dos compósitos $\mathrm{t}-\mathrm{ZrO}_{2} / \mathrm{Al}_{2} \mathrm{O}_{3}$ foi realizada a fim de se conhecer a curva de sinterização (retração linear versus temperatura e sua derivada - taxa de retração versus temperatura). Utilizou-se um equipamento de marca SETARAM, modelo SETSYS Evolution, com taxa de aquecimento de $10^{\circ} \mathrm{C} / \mathrm{min}$, da temperatura ambiente até $1500^{\circ} \mathrm{C}$ seguido de um patamar de $15 \mathrm{~min}$, e com resfriamento natural, sem controle de atmosfera.

4.2.1.2 Sinterização da $\mathrm{t}-\mathrm{ZrO}_{2}$ e dos compósitos $\mathrm{t}-\mathrm{ZrO}_{2} / \mathrm{Al}_{2} \mathrm{O}_{3}$ em forno convencional

Com base nos ensaios de dilatometria, foram selecionadas as temperaturas de $1350^{\circ} \mathrm{C}, 1400^{\circ} \mathrm{C}$ e $1500^{\circ} \mathrm{C}$ para sinterização da $\mathrm{t}-\mathrm{ZrO}_{2}$ e dos compósitos t$\mathrm{ZrO}_{2} / \mathrm{Al}_{2} \mathrm{O}_{3}$ com 5 e $15 \%$ em volume. A sinterização foi realizada ao ar, em forno de alta temperatura com resistência de $\mathrm{MoSi}_{2}$, de marca EDG, modelo EDG1800. As condições de sinterização foram: taxa de aquecimento de $5^{\circ} \mathrm{C} / \mathrm{min}$ da temperatura 
ambiente até $600^{\circ} \mathrm{C}$, com patamar de $1 \mathrm{~h}$, com objetivo de eliminar os resíduos orgânicos provenientes do processo de mistura. Após este patamar, foi utilizada uma taxa de aquecimento de $10^{\circ} \mathrm{C} / \mathrm{min}$ até as temperaturas de sinterização acima, com patamar de 2 h. Após o término deste ciclo, o resfriamento do forno ocorreu de forma natural, sem controle da taxa de resfriamento.

\subsubsection{Flash sintering da $\mathrm{t}-\mathrm{ZrO}_{2}$ e dos compósitos $\mathrm{t}-\mathrm{ZrO}_{2} / \mathrm{Al}_{2} \mathrm{O}_{3}$}

O objetivo desta etapa foi prover uma análise exploratória e inicial sobre 0 comportamento dos materiais estudados submetidos a flash sintering, motivo pelo qual foi realizado o ensaio de apenas uma amostra por composição / parâmetro de sinterização.

O equipamento de flash sintering usado foi uma adaptação de um forno tubular de alta temperatura, com fixação de amostra com sensor de temperatura, associado a um controlador que permite os ajustes temporizadores e de rampas de aquecimento do forno. Foram feitas adequações no sentido de permitir a aplicação de pressão, campo elétrico e corrente variáveis, com processo de medição automatizado.

A Figura 22 mostra a esquematização do forno tubular adaptado para flash sintering.

Figura 22 - Esquematização do forno adaptado para flash sintering.

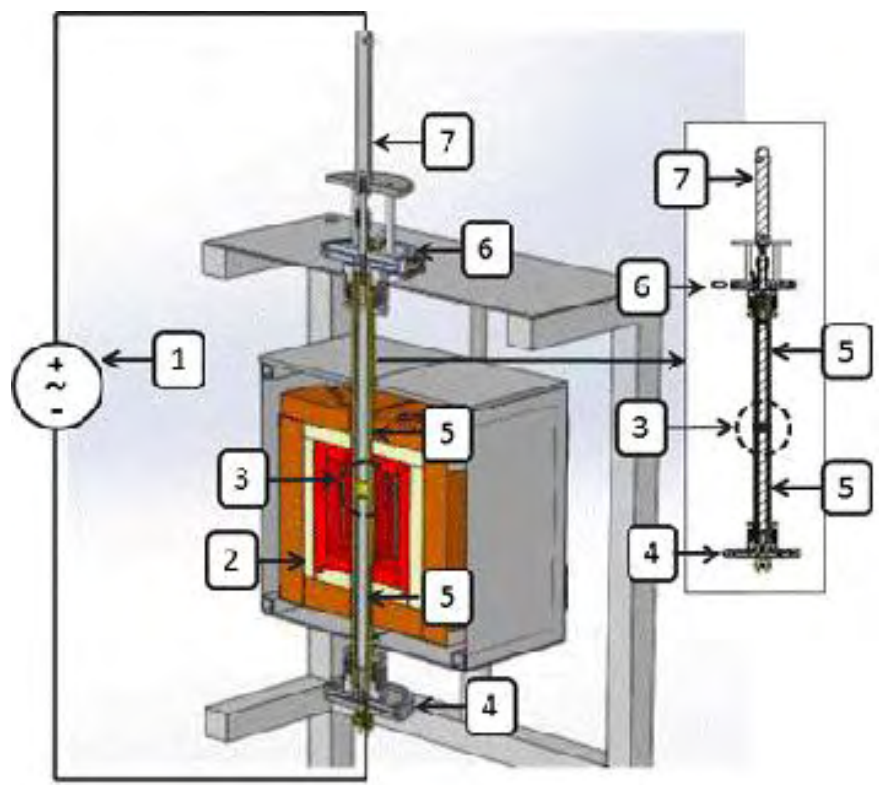


Na Figura 22, podem ser identificados os seguintes elementos do forno:

1) Fonte de alimentação (CA/CC);

2) Forno bipartido vertical em aço inoxidável;

3) Porta amostra: eletrodos de platina;

4) Flange inferior com suporte para termopar tipo $S$;

5) Tubo de alumina para suporte de eletrodos de platina antepostos e fios condutores;

6) Flange superior com suporte para carga de pressão e sensor de deslocamento;

7) Eixo para carga de pressão por mini-pistão.

As amostras foram calcinadas em etapa anterior à de flash sintering. Para isso utilizou-se uma mufla de marca EDG, até a temperatura de $800^{\circ} \mathrm{C}$ por $1 \mathrm{~h}$, com taxa de aquecimento de $5^{\circ} \mathrm{C} / \mathrm{min}$. Após esta etapa, as amostras foram submetidas ao processo de flash sintering usando eletrodos de platina em contato direto com as bases das amostras.

A configuração do ensaio de flash sintering foi feita da seguinte forma: tão logo o forno foi ligado à temperatura ambiente, foi também ligada a fonte, com uma tensão correspondente aos campos de $150 \mathrm{~V} / \mathrm{cm}$ e $200 \mathrm{~V} / \mathrm{cm}$, com corrente de $3 \mathrm{~A}$, nos modos de corrente alternada (CA) e corrente contínua (CC). As tensões para CA são dadas em rms. A taxa de aquecimento utilizada no forno foi de $20^{\circ} \mathrm{C} / \mathrm{min}$, até a temperatura de $1100^{\circ} \mathrm{C}$. O Quadro 3 mostra um resumo das condições de ensaio para as três composições:

Quadro 3 - Condições de sinterização para flash sintering.

\begin{tabular}{|c|c|c|}
\hline Composição & $\begin{array}{c}\text { Campo } \\
\text { elétrico }(\mathrm{V} / \mathrm{cm})\end{array}$ & Corrente \\
\hline \multirow{4}{*}{$\mathrm{t}-\mathrm{ZrO}_{2}$} & \multirow{2}{*}{150} & $\mathrm{CA} / 3 \mathrm{~A}$ \\
\hline & & $\mathrm{CC} / 3 \mathrm{~A}$ \\
\hline & \multirow[b]{2}{*}{200} & $\mathrm{CA} / 3 \mathrm{~A}$ \\
\hline & & $\mathrm{CC} / 3 \mathrm{~A}$ \\
\hline \multirow{4}{*}{$\mathrm{t}-\mathrm{ZrO}_{2} / 5 \%$ vol $\mathrm{Al}_{2} \mathrm{O}_{3}$} & \multirow{2}{*}{150} & $\mathrm{CA} / 3 \mathrm{~A}$ \\
\hline & & $\mathrm{CC} / 3 \mathrm{~A}$ \\
\hline & \multirow{2}{*}{200} & $\mathrm{CA} / 3 \mathrm{~A}$ \\
\hline & & $\mathrm{CC} / 3 \mathrm{~A}$ \\
\hline \multirow{4}{*}{$\mathrm{t}-\mathrm{ZrO}_{2} / 15 \%$ vol $\mathrm{Al}_{2} \mathrm{O}_{3}$} & \multirow{2}{*}{150} & $\mathrm{CA} / 3 \mathrm{~A}$ \\
\hline & & $\mathrm{CC} / 3 \mathrm{~A}$ \\
\hline & \multirow{2}{*}{200} & $\mathrm{CA} / 3 \mathrm{~A}$ \\
\hline & & $\mathrm{CC} / 3 \mathrm{~A}$ \\
\hline
\end{tabular}

*Nota: Para CA, utilizou-se a frequência de $1000 \mathrm{~Hz}$. 
Acompanhou-se, por meio de programa de monitoramento, o andamento do processo, de forma que, ao ocorrer o flash, a fonte foi mantida ligada por $1 \mathrm{~min}$ e em seguida desligada. O resfriamento do forno ocorreu naturalmente, sem controle da taxa de resfriamento.

\subsubsection{Sinterização dos compósitos $\mathrm{t}-\mathrm{ZrO}_{2} / \mathrm{Al}_{2} \mathrm{O}_{3}-\mathrm{NbC}$}

A sinterização dos compósitos $\mathrm{t}-\mathrm{ZrO}_{2} / \mathrm{Al}_{2} \mathrm{O}_{3}-\mathrm{NbC}$ foi realizada em forno convencional de alta temperatura e pela técnica não-convencional de spark plasma sintering. As condições de sinterização estão descritas a seguir.

\subsubsection{Sinterização dos compósitos $\mathrm{t}-\mathrm{ZrO}_{2} / \mathrm{Al}_{2} \mathrm{O}_{3}-\mathrm{NbC}$ em forno convencional}

Após um ensaio de dilatometria realizado até a temperatura de $1600^{\circ} \mathrm{C}$, em atmosfera de argônio, em equipamento de marca NETZSCH, modelo DIL-402C, à taxa de aquecimento de $5^{\circ} \mathrm{C} / \mathrm{min}$, a sinterização convencional dos compósitos t$\mathrm{ZrO}_{2} / \mathrm{Al}_{2} \mathrm{O}_{3}-\mathrm{NbC}$ foi feita às temperaturas de $1400^{\circ} \mathrm{C}, 1450^{\circ} \mathrm{C}, 1500^{\circ} \mathrm{C}$ e $1600^{\circ} \mathrm{C}$ por $2 \mathrm{~h}$, em um forno de alta temperatura com resistência de MoSi2 (marca EDG, modelo EDG1800). A calcinação prévia, para aumentar a resistência mecânica das amostras a verde e para a eliminação dos materiais orgânicos utilizados no processamento, foi feita no mesmo processo de sinterização, a $600^{\circ} \mathrm{C}$ por 1 hora, com taxa de aquecimento de $5^{\circ} \mathrm{C} / \mathrm{min}$. Após esse patamar, a taxa de aquecimento utilizada foi de $10^{\circ} \mathrm{C} / \mathrm{min}$ até a temperatura de sinterização, cujo patamar foi de 2 horas.

Para prevenir a oxidação do $\mathrm{NbC}$ presente no material, e considerando-se que não havia fluxo de gás inerte adaptado ao forno, a sinterização foi realizada dentro de um cadinho de alumina preenchido com pó de grafite P.A. (marca Biossintética) e coberto com pó de alumina calcinada A3000 (ALCOA), com o objetivo de proteger a amostra do contato com o oxigênio presente na atmosfera do forno. O cadinho foi tampado com uma tampa de alumina. Esta técnica de preparação de amostras sujeitas a oxidação, para sinterização em forno convencional sem atmosfera redutora, foi relatada com sucesso por Uehara (2015) e, portanto, utilizada como alternativa para a execução desta etapa. 
A Figura 23 mostra um esquema do preparo das amostras de $\mathrm{t}-\mathrm{ZrO}_{2} / \mathrm{Al}_{2} \mathrm{O}_{3}-$ $\mathrm{NbC}$ para o processo de calcinação/sinterização no forno convencional de alta temperatura.

Figura 23 - Configuração de amostra em cadinho de alumina com proteção de grafite para simular atmosfera redutora na sinterização em forno convencional.



Fonte: Adaptado de: UEHARA, J. L. H. S. Estudo de materiais com gradiente funcional (MGF) à base de alumina $\left(\mathrm{Al}_{2} \mathrm{O}_{3}\right)$ e carbeto de nióbio $(\mathrm{NbC})$ obtidos por diferentes técnicas de sinterização. 2015, 124 f. Dissertação (Mestrado em Ciência e Engenharia de Materiais) - Programa de Pós-Graduação em Ciência e Engenharia de Materiais, Escola de Engenharia de São Carlos, Universidade de São Paulo, São Carlos, 2015.

\subsubsection{Sinterização não convencional por SPS}

A sinterização não convencional por SPS foi realizada em um forno HP SPS D25/1 (FCT SystemeGmbH, Rauenstein, Alemanha), utilizando pressão de $80 \mathrm{MPa}$ usando molde de grafite de $20 \mathrm{~mm}$ de diâmetro. As temperaturas selecionadas para sinterização por SPS basearam-se em um ensaio prévio realizado no próprio forno com uma amostra até a temperatura de $1600^{\circ} \mathrm{C}$ e nas mesmas condições a serem utilizadas na sinterização, analisando-se a movimentação do pistão devida às variações dimensionais da amostra com a variação da temperatura.

Selecionaram-se as temperaturas de $1300^{\circ} \mathrm{C}, 1350^{\circ} \mathrm{C}$ e $1400^{\circ} \mathrm{C}$ e um tempo de 5 minutos de patamar para as sinterizações. A taxa de aquecimento utilizada foi de $150^{\circ} \mathrm{C} / \mathrm{min}$. Antes de qualquer análise, as amostras sinterizadas por SPS foram lixadas em todas as superfícies para retirar os resíduos de grafite que eventualmente difundiram na superfície das amostras, o que é uma característica inerente a esse processo. 


\subsection{Caracterização dos compósitos sinterizados dos sistemas $\mathrm{t}-\mathrm{ZrO}_{2} / \mathrm{Al}_{2} \mathrm{O}_{3} \mathrm{e}$ $\mathrm{t}-\mathrm{ZrO}_{2} / \mathrm{Al}_{2} \mathrm{O}_{3}-\mathrm{NbC}$}

\subsubsection{Caracterização física dos compósitos}

\subsubsection{Medidas de densidade aparente}

Os corpos-de-prova sinterizados foram caracterizados fisicamente por medidas de densidade aparente utilizando o princípio de Arquimedes (norma ASTM C373-88). As amostras foram imersas, em um líquido de densidade conhecida, neste caso, água destilada. A primeira etapa consistiu na imersão em água fervendo por $5 \mathrm{~h}$, seguida de imersão por $24 \mathrm{~h}$. Após esse período, foram medidas a massa úmida e a massa imersa. As amostras foram então secas em estufa à temperatura de $110^{\circ} \mathrm{C}$ e foi medida sua massa seca. A densidade aparente foi calculada utilizando a Equação 7:

$$
D A=\frac{m_{s}}{m_{u}-m_{i}} \rho_{a}
$$

Onde $D A$ corresponde à densidade aparente do corpo-de-prova $\left[\mathrm{g} / \mathrm{cm}^{3}\right] ; m_{s}$, à massa seca $[\mathrm{g}]$; $m_{u}$, à massa úmida $[\mathrm{g}]$; $m_{i}$, à massa úmida $[\mathrm{g}]$; $\rho_{a}$, à densidade da água na temperatura do ensaio. Os valores calculados de densidade aparente também foram apresentados como percentual da densidade teórica, ou seja, como densidade relativa.

\subsubsection{Caracterização microestrutural}

Para a caracterização microestrutural usando superfície polida e de fratura foi utilizado um microscópio eletrônico de varredura com canhão de emissão de campo (FEG-MEV, marca TESCAN, modelo MIRA3).

Para a caracterização da superfície polida dos compósitos, tanto microestrutural como mecânica, as amostras foram polidas com pasta de diamante de 6, 3 e $1 \mu \mathrm{m}$ em politriz automática, marca Buehler, modelo AutoMet 300.

Após o polimento, as amostras de $\mathrm{t}-\mathrm{ZrO}_{2} / \mathrm{Al}_{2} \mathrm{O}_{3}$ sinterizadas em forno convencional foram submetidas a um ataque térmico (MULLINS, 1957), consistindo de rampa rápida e patamar de 15 minutos em uma temperatura de $50^{\circ} \mathrm{C}$ abaixo da 
temperatura de sinterização, a fim de revelar os contornos de grão e facilitar a análise microestrutural.

Devido à impossibilidade de ataque térmico, as amostras de $\mathrm{t}-\mathrm{ZrO}_{2} / \mathrm{Al}_{2} \mathrm{O}_{3}$ sinterizadas por flash sintering e as amostras de $\mathrm{t}-\mathrm{ZrO}_{2} / \mathrm{Al}_{2} \mathrm{O}_{3}-\mathrm{NbC}$ sinterizadas em forno convencional e por SPS tiveram apenas sua superfície de fratura analisadas.

\subsubsection{Caracterização das propriedades mecânicas dos compósitos}

\subsubsection{Ensaios de microdureza}

A microdureza dos compósitos foi medida com as amostras polidas, em um microdurômetro Vickers (marca Leica, modelo VMHT-MOT), com carga de 9,81 N (1 kgf) e tempo de indentação de $12 \mathrm{~s}$, seguindo a metodologia proposta pela norma ASTM C1327-03 (2003). Foram realizadas 10 indentações em cada amostra.

\subsubsection{Determinação do módulo de Young}

\subsection{Compósitos de $\mathrm{t}-\mathrm{ZrO}_{2} / \mathrm{Al}_{2} \mathrm{O}_{3}$}

Os módulos de Young dos compósitos $\mathrm{t}-\mathrm{ZrO}_{2} / \mathrm{Al}_{2} \mathrm{O}_{3}$, em função das frações volumétricas de seus componentes, foram inicialmente estimados por meio de uma equação de interpolação projetada (Equação 8) para compósitos densos de alumina/zircônia assumindo tamanho de grão micrométrico, conforme demonstrado por Caruta (2006):

$$
E=400-245,9 \varphi_{Z}+56,3 \varphi_{Z}^{2}
$$

Onde $E$ corresponde ao módulo de Young do compósito [MPa] e $\phi_{Z}$ à fração volumétrica de $\mathrm{t}-\mathrm{ZrO}_{2}$. Para a validade desta equação, foram considerados os valores de $E$ de $400 \mathrm{GPa}$ para a $\mathrm{Al}_{2} \mathrm{O}_{3}$ pura e de $210 \mathrm{GPa}$ para a $\mathrm{t}-\mathrm{ZrO}_{2}$. 


\subsection{Compósitos de t- $\mathrm{ZrO}_{2} / \mathrm{Al}_{2} \mathrm{O}_{3}-\mathrm{NbC}$}

Os módulos de Young dos compósitos de $\mathrm{t}-\mathrm{ZrO}_{2} / \mathrm{Al}_{2} \mathrm{O}_{3}-\mathrm{NbC}$ foram determinados por meio da técnica de nanoindentação, em um equipamento de marca MTS, modelo G200, à temperatura ambiente e umidade controlada. Foram feitas matrizes $5 \times 4$, totalizando 20 nanoindentações em cada amostra, até a profundidade de $2000 \mathrm{~nm}$, à taxa de $10 \mathrm{~nm} / \mathrm{s}$. Utilizou-se o método de medição de rigidez contínua (continuous stiffness measurement - CSM) (OLIVER, PHARR, 2004), com oscilações da amplitude de $2 \mathrm{~nm}$ e frequência de $45 \mathrm{~Hz}$. Para análise dos resultados, foi assumido um coeficiente de Poisson de 0,3 para todas as amostras, e os módulos de Young foram calculados como média dos valores obtidos na faixa de medição de profundidade 1000 a 1500 nm, considerada de maior estabilidade do nanoindentador, com base nos resultados preliminares obtidos.

\subsubsection{Cálculo da tenacidade à fratura pelo método da indentação}

A tenacidade à fratura dos compósitos foi determinada pelo método da indentação, utilizando a equação calibrada por Niihara, Morena e Hasselman (1982), para trincas do tipo Palmqvist, descrita na Equação 9. Essa equação permite estimar a tenacidade à fratura com base na medida do centro da diagonal até a ponta das trincas geradas pela indentação em um ensaio de dureza com carga suficiente que permita a formação de trincas. Para este cálculo, cinco indentações foram feitas em cada composição. Nos compósitos de $\mathrm{t}-\mathrm{ZrO}_{2} / \mathrm{Al}_{2} \mathrm{O}_{3}$, utilizou-se um microdurômetro Vickers (marca Leica, modelo VMHT-MOT), com carga de 19,62 N (2 kgf) e tempo de indentação de $60 \mathrm{~s}$. Devido à ausência de trincas nos testes realizados com as amostras de $\mathrm{t}-\mathrm{ZrO}_{2} / \mathrm{Al}_{2} \mathrm{O}_{3}-\mathrm{NbC}$ na carga e tempo máximo do microdurômetro, para estes compósitos foi necessário utilizar um durômetro convencional universal com indentador Vickers (marca LARYEE, modelo HBRVU-187.5) com carga de 196,2 N (20 kgf) e tempo de indentação de $10 \mathrm{~s}$.

$$
K_{C}=0,035\left(\frac{l}{a}\right)^{-\frac{1}{2}}\left(\frac{H_{V}}{E \phi}\right)^{-\frac{2}{5}}\left(\frac{H_{V} a^{\frac{1}{2}}}{\phi}\right)
$$


$\mathrm{Na}$ Equação 9, $K_{I C}$ corresponde à tenacidade à fratura [MPa.m $\left.{ }^{1 / 2}\right] ; E$, ao módulo de Young do compósito [MPa]; HV, à dureza Vickers do material [MPa]; a, o comprimento médio das meias-diagonais da indentação $[\mathrm{m}]$; $I$, à média dos comprimentos das trincas geradas pela indentação [m] e $\phi$ é uma constante de valor aproximadamente 3 .

\subsubsection{Ensaios de desgaste nos compósitos de $\mathrm{t}-\mathrm{ZrO}_{2} / \mathrm{Al}_{2} \mathrm{O}_{3}-\mathrm{NbC}$}

$\mathrm{O}$ ensaio de desgaste realizado nos compósitos de $\mathrm{t}-\mathrm{ZrO}_{2} / \mathrm{Al}_{2} \mathrm{O}_{3}-\mathrm{NbC}$ foi realizado pelo método do esfera-no-disco (ball-on-disc), seguindo a norma ASTM G99-17 em um equipamento de marca MICROTEST, modelo MT2/60/SCM/T. Os ensaios foram realizados nas amostras prensadas em molde de $20 \mathrm{~mm}$ de diâmetro com bolas de $5 \mathrm{~mm}$ (contra material) de $\mathrm{Al}_{2} \mathrm{O}_{3}\left(\mathrm{HV}_{30}=19,7 \mathrm{GPa}\right)$ e de WC-6\% Co $\left(\mathrm{HV}_{30}=16,8 \mathrm{GPa}\right)$ de diâmetro de $5 \mathrm{~mm}$, de marca FRITSCH. A carga utilizada para os ensaios foi de $15 \mathrm{~N}$, com uma velocidade de deslizamento de $0,1 \mathrm{~m} / \mathrm{s}$ e distância de deslizamento de $2000 \mathrm{~m}$, com um raio de pista de desgaste configurado para 3 $\mathrm{mm}$. Todos os ensaios foram realizados em condições controladas (temperatura ambiente de $23 \pm 2{ }^{\circ} \mathrm{C}$ e umidade relativa de $60 \pm 2 \%$ ). As superfícies testadas foram polidas e limpas antes do ensaio, mantendo-se um controle de rugosidade superficial de 0,5 $\mu \mathrm{m}$, medida por um rugosímetro de marca MAHR, modelo Perthometer M2.

Os dados determinados para comparação dos resultados foram a perda volumétrica e a taxa de desgaste, descritas pelas Equações 10 e 11:

$$
\begin{gathered}
p_{v}=\frac{p_{m}}{d} \\
w=\frac{p_{v}}{F_{N} d}
\end{gathered}
$$

Na Equação 10, $p_{v}$ é a perda de volume [mm³], $p_{m}$ é a perda de massa $[\mathrm{g}]$ e $d$ é distância de deslizamento [m]. Na Equação 11, $w$ é a taxa de desgaste $\left[\mathrm{mm}^{3} .(\mathrm{N} . \mathrm{m})^{-1}\right], p_{v}$ é a perda de volume $\left[\mathrm{mm}^{3}\right], F_{N}$ é a força normal (carga) aplicada 
durante o ensaio [N] e $d$ é a distância de deslizamento [m]. A perda de massa foi determinada pesando-se a amostra antes e após o ensaio em balança analítica, com precisão de 5 casas decimais. As superfícies de desgaste foram caracterizadas por microscopia eletrônica de varredura com emissão de campo, em equipamento de marca ZEISS, modelo Ultra-55. 


\section{RESULTADOS E DISCUSSÃO}

\subsection{Caracterização da $\mathrm{t}-\mathrm{ZrO}_{2}$ e dos compósitos de $\mathrm{t}-\mathrm{ZrO}_{2} / \mathrm{Al}_{2} \mathrm{O}_{3}$}

5.1.1 Sinterização convencional

A Figura 24 apresenta as curvas de retração linear versus temperatura obtidas por ensaio de dilatometria das composições contendo 0\%, 5\% e 15\% em volume de $\mathrm{Al}_{2} \mathrm{O}_{3}$ na matriz de $\mathrm{t}-\mathrm{ZrO}_{2}$ até a temperatura de $1500^{\circ} \mathrm{C}$.

Figura 24 - Curvas de retração versus temperatura da $\mathrm{t}-\mathrm{ZrO}_{2}$ e dos compósitos $\mathrm{t}-\mathrm{ZrO}_{2} / \mathrm{Al}_{2} \mathrm{O}_{3}$ obtidas por dilatometria.



Observa-se que, quanto maior a quantidade de $\mathrm{Al}_{2} \mathrm{O}_{3}$, maior a temperatura necessária para o início da retração linear das amostras ensaiadas. Isto acontece porque a presença de $\mathrm{Al}_{2} \mathrm{O}_{3}$ na matriz dificulta o processo de densificação, bem como suprime o crescimento de grão, requerendo maior energia para a evolução microestrutural do material como um todo durante a sinterização.

A derivada da curva de retração linear versus temperatura obtida por dilatometria, i.e., curva de taxa de retração instantânea, é mais sensível a pequenas 
mudanças, quando comparada à curva de retração linear versus temperatura ou tempo. O ponto de mínimo das curvas derivadas permite estimar a temperatura de sinterização, além do fato de que sua forma, altura e largura proveem informações muito importantes para a avaliação do comportamento de sinterização (RIBEIRO et al., 2017).

A Figura 25 mostra as curvas de taxa de retração linear (derivada da retração linear) versus temperatura para cada composição.

Figura 25 - Curvas da taxa de retração linear versus temperatura dos compósitos $\mathrm{t}-\mathrm{ZrO}_{2} / \mathrm{Al}_{2} \mathrm{O}_{3}$ obtidas por dilatometria.

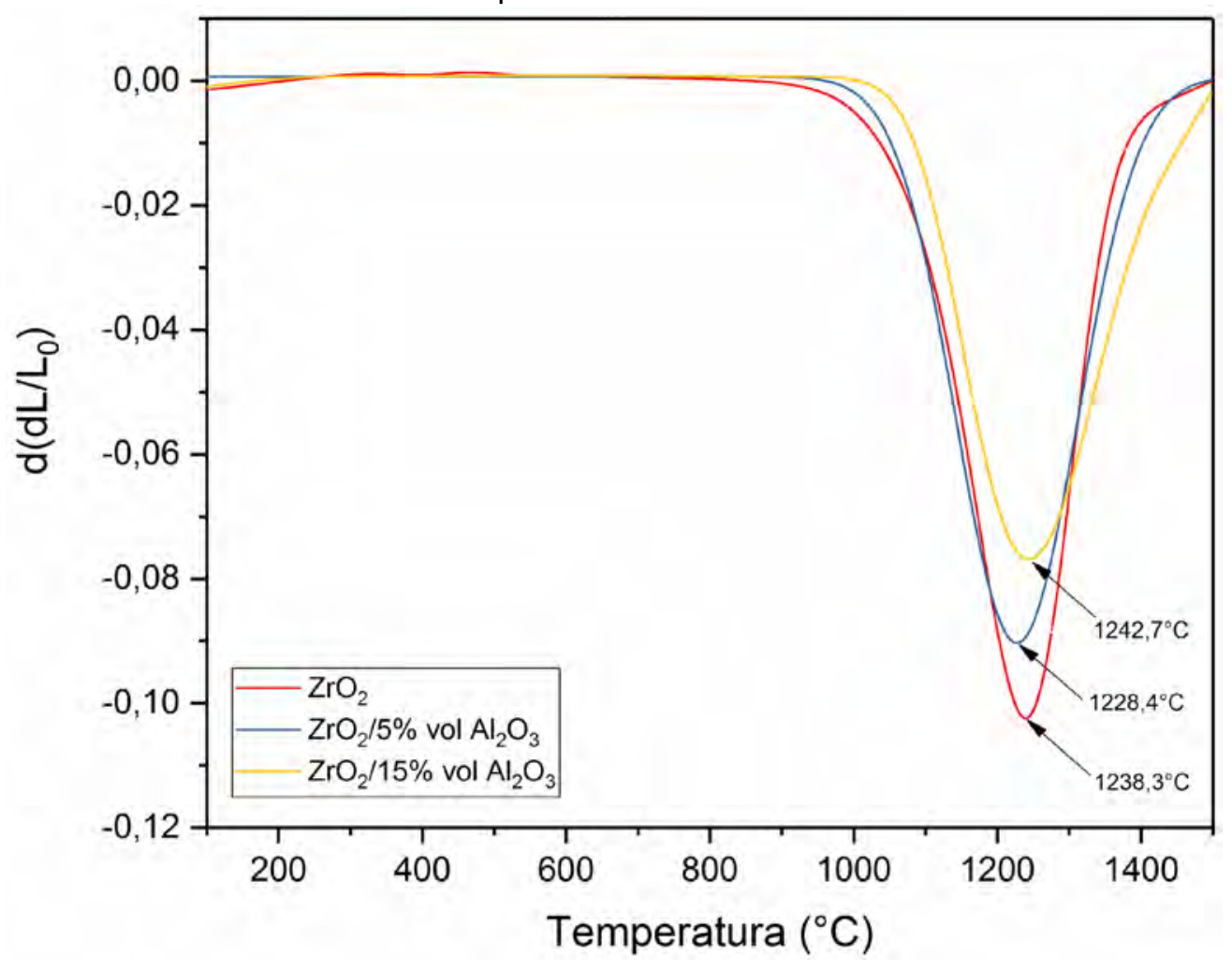

Observa-se que a $\mathrm{t}-\mathrm{ZrO}_{2}$ possui uma curva derivada mais longa, no entanto com pouca diferença de largura das demais curvas. Curvas mais longas e estreitas correspondem a taxas de retração mais altas do corpo a verde, enquanto curvas mais curtas e largas sugerem taxas de retração mais baixas. Isso vem de encontro ao efeito reportado na literatura quanto à adição de $\mathrm{Al}_{2} \mathrm{O}_{3}$ na $\mathrm{t}-\mathrm{ZrO}_{2}$ (NEVÁREZRASCON et al., 2009), como mencionado na análise das curvas de retração linear versus temperatura. Consequentemente, a presença de inclusões de $\mathrm{Al}_{2} \mathrm{O}_{3}$ torna 0 processo de densificação mais lento e diminui as taxas de retração, 
consequentemente suprimindo o crescimento de grão e aumentando a temperatura necessária para consolidar a microestrutura.

Shi et al. (1993) e Luo et al. (1998) relatam que a presença de um pico único e uniforme nas curvas de derivada da retração linear versus temperatura corresponde a uma distribuição de porosidade homogênea no compacto a verde. Muccillo e Muccillo (2002) e Theunissen et al. (1993) também reportaram a presença de um pico único na sinterização de YSZ, atribuindo esse comportamento à presença de uma distribuição monomodal de porosidade no compacto a verde. Esse tipo de distribuição de poros, por sua vez, indica a presença de aglomerados fracos facilmente dispersáveis (GHOSH et al., 2007).

Com base nessas observações relatadas na literatura, pode-se afirmar que, analisando as curvas de derivada da retração linear versus temperatura para todas as composições, estas tiveram um pico único, indicando que os compactos a verde tiveram boa dispersão e, portanto, resultaram em uma microestrutura com distribuição homogênea de poros. No entanto, isso não exclui a possibilidade de haver aglomerados, ainda que em menor quantidade, em todas as composições.

Os pontos de mínimo das curvas derivadas da Figura 25, que indicam a temperatura de ocorrência de máxima taxa de retração linear, tiveram uma ligeira variação $\left(1228,4^{\circ} \mathrm{C}\right.$ para $\mathrm{t}-\mathrm{ZrO}_{2} / 5 \%$ vol $\mathrm{Al}_{2} \mathrm{O}_{3}, 1238,3^{\circ} \mathrm{C}$ para $\mathrm{t}-\mathrm{ZrO}_{2}$ e $1242,7^{\circ} \mathrm{C}$ para $\mathrm{t}-\mathrm{ZrO}_{2} / 15 \%$ vol $\mathrm{Al}_{2} \mathrm{O}_{3}$ ). Essa pequena variação indica que a homogeneidade do material de partida, tanto em termos de mistura, como em tamanho inicial de partícula das duas fases, proporcionou uma dispersão tal que provocasse pouca influência dos grãos de $\mathrm{Al}_{2} \mathrm{O}_{3}$ na densificação da $\mathrm{t}-\mathrm{ZrO}_{2}$ e na mudança dos mecanismos de difusão ocorrentes durante a sinterização. Esperava-se que o compósito $\mathrm{t}-\mathrm{ZrO}_{2} / 5 \%$ vol $\mathrm{Al}_{2} \mathrm{O}_{3}$ tivesse uma temperatura de máxima taxa de retração intermediária, e não inferior à temperatura para a t-ZrO2. Essa ligeira diferença pode ser atribuída a uma distribuição de tamanho de partícula e grau de dispersão que proporcionaram melhor empacotamento na amostra de $5 \%$ vol $\mathrm{Al}_{2} \mathrm{O}_{3}$, ou um pior empacotamento na amostra de $\mathrm{t}-\mathrm{ZrO}_{2}$, o que influencia fortemente a capacidade de densificação da composição. Porém, nas curvas de retração versus temperatura (Figura 24) não houve essa inversão, e sim, apenas um pequeno "degrau" no final da curva do compósito $\mathrm{t}-\mathrm{ZrO}_{2} / 5 \% \mathrm{Al}_{2} \mathrm{O}_{3}$.

A escolha das temperaturas de sinterização dos compósitos $t-\mathrm{ZrO}_{2} / \mathrm{Al}_{2} \mathrm{O}_{3}$, baseou-se, além das temperaturas de máxima taxa de retração nos ensaios de 
dilatometria, na intenção de se obter um material completamente sinterizado e verificar a microestrutura final para cada composição. Deste modo, elegeram-se as temperaturas de $1350^{\circ} \mathrm{C}, 1400^{\circ} \mathrm{C}$ e $1500^{\circ} \mathrm{C}$ para a sinterização das amostras. A Tabela 2 mostra os dados de densidade relativa (\%DT) para os compósitos em função da composição e da temperatura.

Tabela 2 - Valores de densidades dos compósitos sinterizados em diferentes temperaturas.

\begin{tabular}{c|c|c|c}
\hline \multirow{2}{*}{$\begin{array}{c}\text { Temperatura de } \\
\text { sinterização }\left[{ }^{\circ} \mathbf{C}\right]\end{array}$} & \multicolumn{3}{|c}{ Densidade (\%DT) } \\
\cline { 2 - 4 } & $\mathbf{t}-\mathbf{Z r O}_{\mathbf{2}}$ & $\mathbf{t}-\mathbf{Z r O}_{\mathbf{2}} / \mathbf{5} \%$ vol $\mathbf{A l}_{\mathbf{2}} \mathbf{O}_{\mathbf{3}}$ & $\mathbf{t}-\mathbf{Z r O}_{\mathbf{2}} / \mathbf{1 5} \%$ vol $\mathbf{A l}_{\mathbf{2}} \mathbf{O}_{\mathbf{3}}$ \\
\hline 1350 & $97,6 \pm 1,0$ & $98,8 \pm 0,6$ & $97,4 \pm 0,2$ \\
\hline 1400 & $97,9 \pm 0,7$ & $98,7 \pm 0,9$ & $98,3 \pm 0,5$ \\
\hline 1500 & $99,7 \pm 0,2$ & $98,7 \pm 0,4$ & $99,0 \pm 1,0$ \\
\hline
\end{tabular}

Pelas medidas de densidade, observa-se que todas as composições tiveram densificação quase completa, atingindo um valor mínimo de 97,4\% de densidade relativa à teórica. Isso mostra que os processos de mistura e dispersão da $\mathrm{Al}_{2} \mathrm{O}_{3}$ na matriz proporcionaram resultados satisfatórios. Em relação à variação de temperatura para uma mesma composição, verifica-se que 0 aumento da temperatura, como esperado, colabora para o aumento da densificação no mesmo tempo de sinterização, tornando-a quase completa, uma vez que todas as temperaturas selecionadas para estudo foram superiores às temperaturas de máxima taxa de retração, conforme verificado pelos ensaios de dilatometria (Figura 25).

A Figura 26 apresenta as micrografias obtidas por MEV dos compósitos de t$\mathrm{ZrO}_{2} / \mathrm{Al}_{2} \mathrm{O}_{3}$ sinterizados nas temperaturas de $1350^{\circ} \mathrm{C}, 1400^{\circ} \mathrm{C}$ e $1500^{\circ} \mathrm{C}$.

Considerando-se que a densidade relativa para todas as composições nas temperaturas estudadas superaram os $97,4 \%$ da densidade teórica, observam-se em geral microestruturas densas e finas, compostas de grãos majoritariamente submicrométricos (maiores que $100 \mathrm{~nm}$ e menores que $1 \mu \mathrm{m}$ ). Nos compósitos, os grãos mais claros correspondem à matriz de $\mathrm{t}-\mathrm{ZrO}_{2}$, enquanto os grãos mais escuros correspondem à segunda fase $\mathrm{Al}_{2} \mathrm{O}_{3}$. O processo de mistura convencional em moinho de bolas proporcionou uma boa dispersão da $\mathrm{Al}_{2} \mathrm{O}_{3}$ na matriz, com pouca presença de aglomerados. No entanto, alguns grãos de $\mathrm{Al}_{2} \mathrm{O}_{3}$ cresceram mais do que a média, sobretudo nos compósitos de $5 \%$ e $15 \%$ em volume de $\mathrm{Al}_{2} \mathrm{O}_{3}$ sinterizadas a $1500^{\circ} \mathrm{C}$. O formato dos grãos denota um processo que chegou a um 
estágio avançado da sinterização, em concordância com o que era previsto pela dilatometria.

Figura 26 - Micrografias obtidas por MEV dos compósitos $\mathrm{t}-\mathrm{ZrO}_{2} / \mathrm{Al}_{2} \mathrm{O}_{3}$ sinterizados.

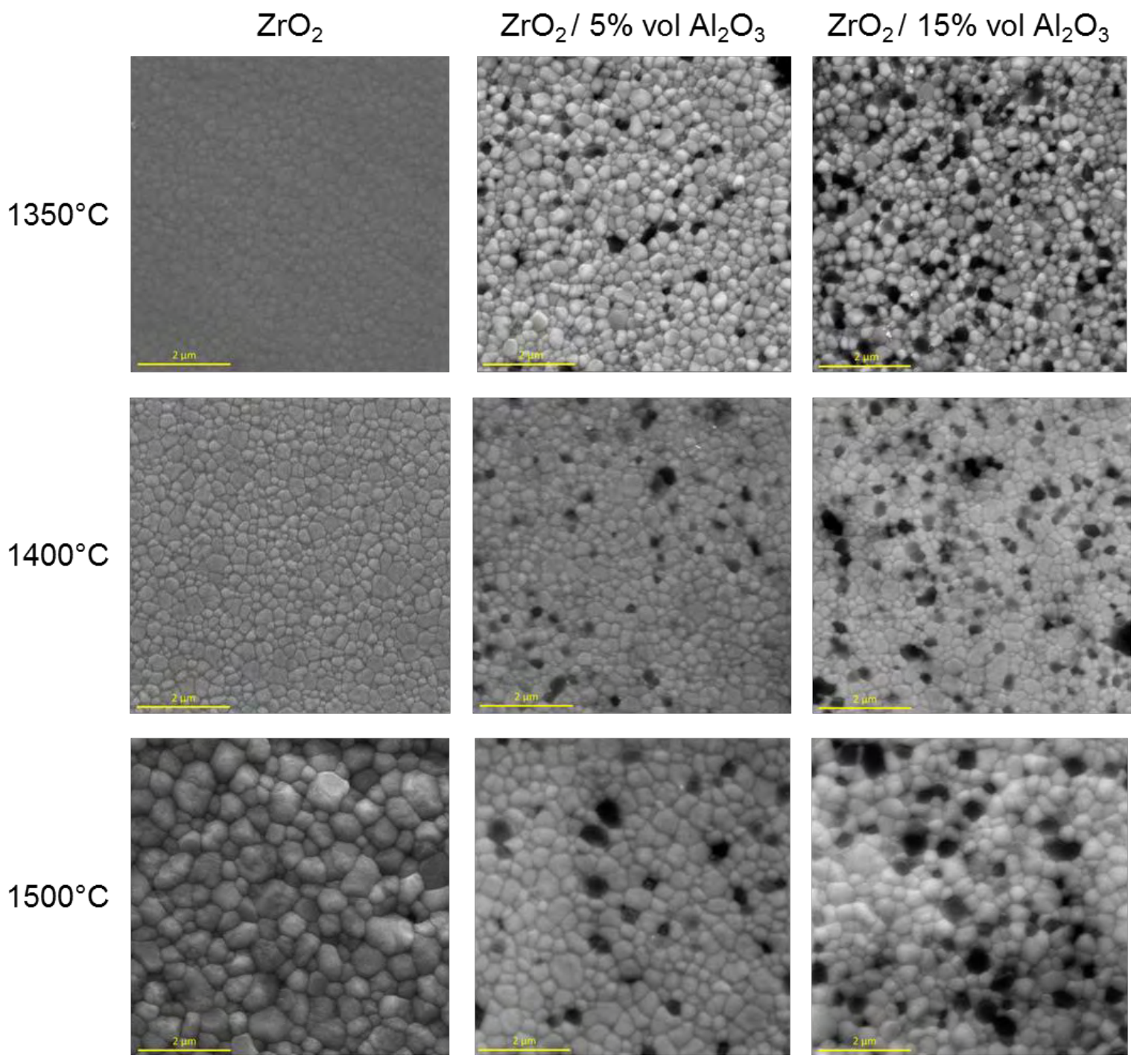

Fixando-se uma composição, o crescimento de grão foi pouco notável com o aumento da temperatura de $1350^{\circ} \mathrm{C}$ para $1400^{\circ} \mathrm{C}$. No entanto, foi bastante significativo o crescimento de grão à temperatura de $1500^{\circ} \mathrm{C}$. De forma mais notável nos compósitos sinterizados a $1500^{\circ} \mathrm{C}$, observa-se que a presença de grãos de $\mathrm{Al}_{2} \mathrm{O}_{3}$ restringiu o crescimento de grão da matriz, sobretudo nas áreas com dispersão mais homogênea. Em concordância com os resultados de NevárezRascon et al. (2009), observa-se que a dispersão das partículas de $\mathrm{Al}_{2} \mathrm{O}_{3}$ na matriz de $\mathrm{t}-\mathrm{ZrO}_{2}$ age como um inibidor do crescimento de grão, de forma mais notável nas regiões em que a dispersão das partículas é homogênea. Por outro lado, em regiões 
da microestrutura em que a dispersão é heterogênea, devido a uma mistura ineficiente, o tamanho médio de grão de ambas as fases foi maior.

Para observar-se uma melhor qualidade da dispersão da $\mathrm{Al}_{2} \mathrm{O}_{3}$ na matriz de t$\mathrm{ZrO}_{2}$, a Figura 27 mostra as micrografias obtidas por MEV dos compósitos de t$\mathrm{ZrO}_{2} / 5 \%$ vol $\mathrm{Al}_{2} \mathrm{O}_{3}$ e $\mathrm{t}-\mathrm{ZrO}_{2} / 15 \%$ vol $\mathrm{Al}_{2} \mathrm{O}_{3}$ obtidas com detecção de elétrons retroespalhados (BSE), e menor aumento, em que se destacam com mais brilho os compostos que contêm metais de maior peso atômico. Desta forma, os grãos de t$\mathrm{ZrO}_{2}$ se veem mais brilhantes, enquanto os pontos mais escuros correspondem à fase $\mathrm{Al}_{2} \mathrm{O}_{3}$.

Figura 27 - Micrografias obtidas por MEV dos compósitos $\mathrm{t}-\mathrm{ZrO}_{2} / \mathrm{Al}_{2} \mathrm{O}_{3}$ sinterizados a $1350^{\circ} \mathrm{C}$ :

(a) $\mathrm{t}-\mathrm{ZrO}_{2} / 5 \%$ vol $\mathrm{Al}_{2} \mathrm{O}_{3} ;$ (b) $\mathrm{t}-\mathrm{ZrO}_{2} / 15 \%$ vol $\mathrm{Al}_{2} \mathrm{O}_{3}$.
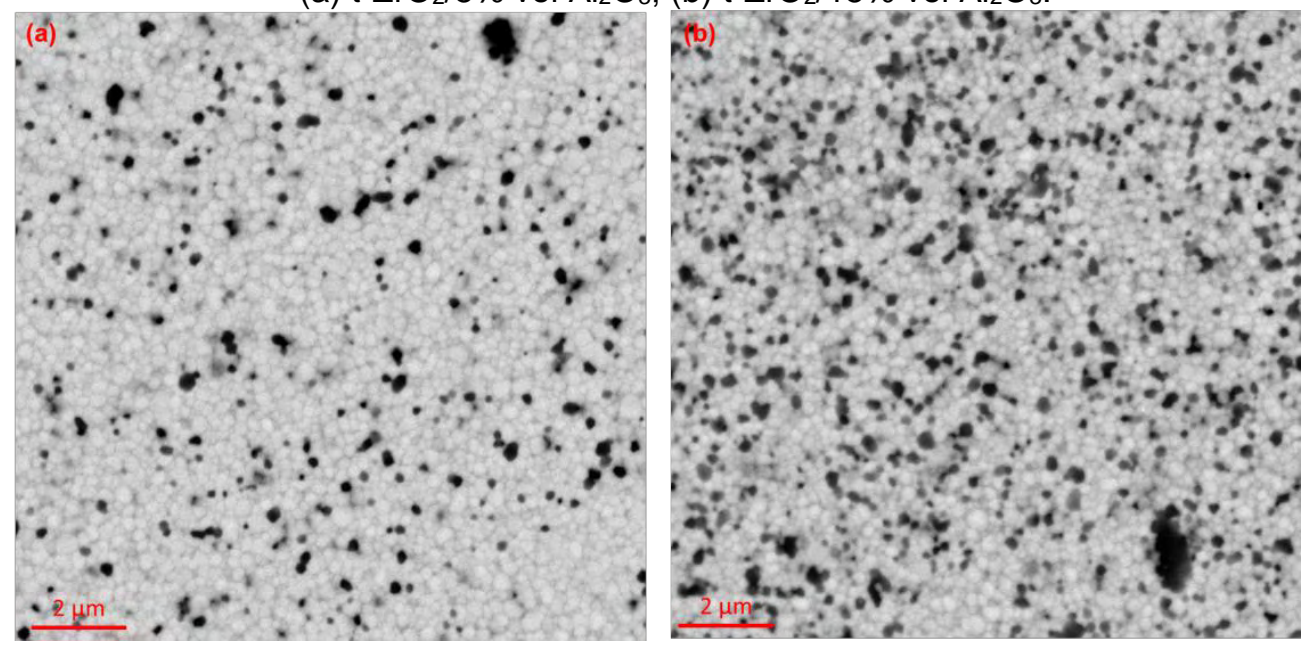

Quanto à porosidade, esta é quase ausente, não sendo observada na maioria das micrografias. Isso denota uma microestrutura bastante densa e com poucos defeitos.

Com base na análise das micrografias, pode-se afirmar que a dispersão do pó de $\mathrm{Al}_{2} \mathrm{O}_{3}$ na matriz de $\mathrm{t}-\mathrm{ZrO}_{2}$ em moinho de bolas foi eficiente para as composições estudadas.

A Tabela 3 apresenta os valores dos módulos de Young, estimados pela Equação 8, e utilizados no cálculo de tenacidade à fratura pelo método da indentação, para a t- $\mathrm{ZrO}_{2}$ e os seus compósitos com 5 e $15 \%$ em volume de $\mathrm{Al}_{2} \mathrm{O}_{3}$. 
Tabela 3 - Valores de Módulos de Young da $\mathrm{t}-\mathrm{ZrO}_{2}$ e dos compósitos $\mathrm{t}-\mathrm{ZrO}_{2} / \mathrm{Al}_{2} \mathrm{O}_{3}$ com $5 \%$ e $15 \%$ em volume de $\mathrm{Al}_{2} \mathrm{O}_{3}$.

\begin{tabular}{c|c}
\hline Material & $\begin{array}{c}\text { Módulo de Young } \\
\text { (GPa) }\end{array}$ \\
\hline $\mathrm{t}-\mathrm{ZrO} 2$ & 210 \\
\hline $\mathrm{t}-\mathrm{ZrO}_{2} / 5 \%$ vol $\mathrm{Al}_{2} \mathrm{O}_{3}$ & 217,2 \\
\hline $\mathrm{t}-\mathrm{ZrO}_{2} / 15 \%$ vol $\mathrm{Al}_{2} \mathrm{O}_{3}$ & 232,4 \\
\hline
\end{tabular}

A Tabela 4 mostra os valores de microdureza Vickers e tenacidade à fratura calculada pelo método da indentação, utilizando a equação de Niihara, Morena e Hasselman (1982) (Equação 9), para as composições e temperaturas de sinterização estudadas.

Tabela 4 - Valores de microdureza e tenacidade à fratura da $\mathrm{t}-\mathrm{ZrO}_{2}$ e da $\mathrm{t}-\mathrm{ZrO}_{2} / \mathrm{Al}_{2} \mathrm{O}_{3}$ com $5 \%$ e $15 \%$ em volume de $\mathrm{Al}_{2} \mathrm{O}_{3}$.

\begin{tabular}{c|c|c|c|c|c|c}
\hline \multirow{2}{*}{ Compósito } & \multicolumn{3}{|c|}{$\begin{array}{c}\text { Microdureza Vickers, } \mathbf{H V} \\
\text { [GPa] }\end{array}$} & \multicolumn{3}{c}{ Tenacidade à fratura, $\mathbf{K}_{\mathrm{IC}}$ (Niihara) } \\
\cline { 2 - 7 } & $\mathbf{1 3 5 0 ^ { \circ } \mathbf { C }}$ & $\mathbf{1 4 0 \mathbf { m } ^ { \circ } \mathbf { C }} \mathbf{C}$ & $\mathbf{1 5 0 0 ^ { \circ } \mathbf { C }}$ & $\mathbf{1 3 5 0 ^ { \circ } \mathbf { C }}$ & $\mathbf{1 4 0 0 ^ { \circ } \mathbf { C }}$ & $\mathbf{1 5 0 0 ^ { \circ } \mathbf { C }}$ \\
\hline $\mathrm{t}-\mathrm{ZrO}_{2}$ & $11,66 \pm 1,14$ & $11,38 \pm 0,35$ & $13,97 \pm 0,35$ & $3,59 \pm 0,17$ & $3,48 \pm 0,07$ & $4,42 \pm 0,21$ \\
\hline $\begin{array}{c}\mathrm{t}-\mathrm{ZrO}_{2} / 5 \% \text { vol } \\
\mathrm{Al}_{2} \mathrm{O}_{3}\end{array}$ & $13,09 \pm 0,59$ & $11,78 \pm 0,63$ & $13,66 \pm 0,83$ & $3,90 \pm 0,22$ & $3,36 \pm 0,29$ & $4,43 \pm 0,19$ \\
\hline $\begin{array}{c}\mathrm{t}-\mathrm{ZrO}_{2} / 15 \% \\
\mathrm{vol} \mathrm{Al}_{2} \mathrm{O}_{3}\end{array}$ & $13,62 \pm 0,74$ & $11,49 \pm 0,42$ & $14,52 \pm 0,73$ & $3,70 \pm 0,46$ & $3,31 \pm 0,36$ & $3,66 \pm 0,13$ \\
\hline
\end{tabular}

As amostras sinterizadas a $1350^{\circ} \mathrm{C}$ apresentaram um aumento significativo da dureza nos compósitos $\mathrm{t}-\mathrm{ZrO}_{2} / \mathrm{Al}_{2} \mathrm{O}_{3}$ (13,09 GPa para $\mathrm{t}-\mathrm{ZrO}_{2} / 5 \%$ vol $\mathrm{Al}_{2} \mathrm{O}_{3}$ e 13,62 GPa para $\mathrm{t}-\mathrm{ZrO}_{2} / 15 \%$ vol $\left.\mathrm{Al}_{2} \mathrm{O}_{3}\right)$ em relação à $\mathrm{t}-\mathrm{ZrO}_{2}(11,66 \mathrm{GPa})$. Isso se deve à presença das partículas de $\mathrm{Al}_{2} \mathrm{O}_{3}$, que aumentaram a dureza do compósito, a despeito da porosidade ser ligeiramente maior do que nas temperaturas mais altas de sinterização. A $1400^{\circ} \mathrm{C}$, não houve diferença significativa na dureza em função da composição, porém os valores foram todos semelhantes aos da $\mathrm{t}-\mathrm{ZrO}_{2}$ sinterizada a $1350^{\circ} \mathrm{C}$. Esse fato pode ser atribuído a uma inibição da ação dos grãos de $\mathrm{Al}_{2} \mathrm{O}_{3} \mathrm{em}$ concorrência com a porosidade ainda remanescente, associada ao ligeiro crescimento de grão da matriz, sendo estes, fatores que contribuem para uma diminuição da dureza.

A literatura relata uma grande divergência nos valores de dureza e tenacidade para $\mathrm{t}-\mathrm{ZrO}_{2}$ e compósitos $\mathrm{t}-\mathrm{ZrO}_{2} / \mathrm{Al}_{2} \mathrm{O}_{3}$. A princípio, é um consenso geral que a adição de pequenas quantidades de $\mathrm{Al}_{2} \mathrm{O}_{3}$ em uma matriz de $\mathrm{t}-\mathrm{ZrO}_{2}$ produz cerâmicas com tenacidade e dureza melhoradas. No entanto, nem sempre os resultados são consistentes. Fukuhara (1989) mostrou que a adição de $\mathrm{Al}_{2} \mathrm{O}_{3}$ na t- 
$\mathrm{ZrO}_{2}$ aumenta a tenacidade, no entanto reduz a dureza. Kihara et al. (1988) estudaram a influência de pequenas quantidades de $\mathrm{Al}_{2} \mathrm{O}_{3}(0,375-0,5 \% \mathrm{~mol})$ em uma matriz de $\mathrm{t}-\mathrm{ZrO}_{2}$. A tenacidade, nesses compósitos, aumentou $17 \%$ e $15 \% \mathrm{com}$ a adição de $1 \%$ e $4 \%$ mol, respectivamente. Por outro lado, Bhaduri et al. (1998) reportaram dureza de $4,45 \mathrm{GPa}$ e tenacidade à fratura de $8,38 \mathrm{MPa}^{1 / 2}$ para compósitos nanocristalinos de $\mathrm{t}-\mathrm{ZrO}_{2} / \mathrm{Al}_{2} \mathrm{O}_{3}$ totalmente densificados. Lange (1989) reportou uma dureza de $15 \mathrm{GPa}$ para um compósito similar processado de forma convencional. Nevárez-Rascon et al. (2009) encontraram dureza de 14 GPa e tenacidade de 7,25 MPa.m ${ }^{1 / 2}$ para um compósito $\mathrm{t}-\mathrm{ZrO}_{2} / 20 \%$ em peso de $\mathrm{Al}_{2} \mathrm{O}_{3}$.

No caso das amostras sinterizadas a $1500^{\circ} \mathrm{C}$, todas as composições apresentaram valores de dureza superiores a 13,66 GPa, denotando uma microestrutura mais bem consolidada (com pouca porosidade), na qual efetivamente se observa uma ação da presença de $\mathrm{Al}_{2} \mathrm{O}_{3}$, que é mais dura e contribui para o aumento da dureza do compósito por esse fato, e também pela restrição mais notável do crescimento de grão da matriz. O grau de porosidade, por sua vez, não é alto o suficiente para comprometer a dureza do compósito. E, apesar do crescimento de grão poder contribuir para a diminuição da dureza, o grau de consolidação da t$\mathrm{ZrO}_{2}$ e t-ZrO$/ \mathrm{Zl}_{2} \mathrm{O}_{3}$, a essa temperatura de sinterização, fez com que as amostras apresentassem os maiores valores de dureza em comparação com as amostras sinterizadas às temperaturas mais baixas.

Com base nos resultados, confrontados com a literatura, a existência de porosidade residual e seu volume em função das combinações de composição/temperatura para compósitos cerâmicos sinterizados, atrapalha 0 incremento na sua dureza, uma vez que, quanto maior a quantidade de $\mathrm{Al}_{2} \mathrm{O}_{3}$, maior deve ser a temperatura de sinterização para se obter total densificação. Este resultado vem a corroborar a análise de Suzuki et al. (1999), que reportou que a dureza Vickers é correlacionada com a porosidade nos estágios iniciais de sinterização, enquanto nos estágios finais o tamanho de grão se torna o principal fator influente na dureza. Apesar disso, poucos trabalhos reportam a relação entre a porosidade remanescente na dureza e na tenacidade à fratura de compósitos cerâmicos (SUZUKI et al., 1999; VASYLKIV, SAKKA, SKOROKHOD, 2003; NEVÁREZ-RASCON et al., 2009).

$\mathrm{Na}$ análise da tenacidade à fratura pelo método da indentação, com o uso do microdurômetro, pelo menos dois tipos de trincas são produzidos por um indentador 
Vickers: a trinca de Palmqvist e a trinca mediana-radial (ou trinca half-penny). Geralmente, em um material tenaz, são observadas trincas de Palmqvist. No entanto, a maioria dos materiais exibem ambos os sistemas de trinca, dependendo da carga aplicada (LIN, DUH, 2002). Em diversos materiais frágeis relatados na literatura, as trincas de Palmqvist foram formadas em regimes de baixa carga (geralmente inferiores a 20 N) (ĆORIĆ, ĆURKOVIĆ, RENJO, 2017). Uma das formas de se classificar o tipo de trinca em um material analisado pelo método da indentação é por meio da relação c/a, ou seja, a razão entre a distância do centro da indentação e a ponta da trinca, e a meia-diagonal da indentação. Se c/a < 2,5, 0 material mostra o sistema de trincas de Palmqvist (NIIHARA, MORENA, HASSELMAN, 1982; LIN, DUH, 2002; MORAES et al., 2004). Com cargas mais altas de indentação (geralmente superiores a $100 \mathrm{~N}$ ) é frequente a ocorrência de trincas medianas-radiais, o que é confirmado pela razão $c / a>2,5$, ou pelo critério $0,25<1 / a$ $<2,5$, sendo $c=I+a$. Neste trabalho, todas as amostras ensaiadas apresentaram uma relação I/a inferior a 2,5, fato pelo qual foi utilizada a Equação 9, calibrada para trincas de Palmqvist.

Com base no exposto, analisando os resultados calculados pela equação de Niihara (Equação 9), não se observa uma variação significativa na tenacidade à fratura dos compósitos sinterizados a $1350^{\circ} \mathrm{C}$ e a $1400^{\circ} \mathrm{C}$ em relação à $\mathrm{t}-\mathrm{ZrO}_{2}$. $\mathrm{O}$ mesmo efeito se observa na $\mathrm{t}-\mathrm{ZrO}_{2} / 15 \%$ vol $\mathrm{Al}_{2} \mathrm{O}_{3}$ sinterizada a $1500^{\circ} \mathrm{C}$. Porém, na t$\mathrm{ZrO}_{2}$ e no compósito com $5 \%$ vol $\mathrm{Al}_{2} \mathrm{O}_{3}$ sinterizados a $1500^{\circ} \mathrm{C}$, houve um aumento na tenacidade à fratura. Da mesma forma que ocorreu com os resultados de dureza, é possível que a influência da porosidade remanescente até a temperatura de $1400^{\circ} \mathrm{C}$ tenha reduzido a tenacidade, por eventuais interseções de uma trinca com poros presentes na microestrutura. Como as amostras de $1500^{\circ} \mathrm{C}$ apresentaram maior densidade, esse efeito foi amenizado, possibilitando um aumento da tenacidade. No caso do compósito com $15 \%$ vol $\mathrm{Al}_{2} \mathrm{O}_{3}$, é possível que a quantidade de $\mathrm{Al}_{2} \mathrm{O}_{3}$ tenha tido um efeito negativo no aumento da tenacidade pelo fato de as trincas terem maiores interações com grãos de $\mathrm{Al}_{2} \mathrm{O}_{3}$, que é menos tenaz, em seu caminho. Analisando-se por meio da Equação 9, isso se reflete na razão entre 0 comprimento da trinca $(I$ e a meia-diagonal da indentação (a), isto é, I/a. As amostras sinterizadas a $1500^{\circ} \mathrm{C}$ apresentam as menores razões $\mathrm{l} / \mathrm{a}$ quando comparadas com as demais temperaturas, com valores variando aproximadamente entre 0,6 e 0,9 . Nas amostras sinterizadas a $1350^{\circ} \mathrm{C}$ e a $1400^{\circ} \mathrm{C}$, por outro lado, a 
razão foi superior a 0,9, chegando a 1,25. Essa diferença entre as dimensões que compõem a análise do conjunto meia-diagonal de indentação/trinca podem ser relacionadas à natureza da trinca ocorrente naquelas condições, sendo que, quanto maior a razão $/ / a$ (e consequentemente a razão c/a), mais próximo se está de um regime de transição entre as trincas de Palmqvist e de trincas com um caráter mediano-radial.

Com base nos valores obtidos de propriedades mecânicas da $\mathrm{t}-\mathrm{ZrO}_{2}$ e dos compósitos $\mathrm{t}-\mathrm{ZrO}_{2} / \mathrm{Al}_{2} \mathrm{O}_{3}$ estudados nas diferentes temperaturas e sua confrontação com os resultados disponíveis na literatura, conclui-se que, além da diferença de composição e curvas de sinterização, os materiais de partida, bem como os processamentos utilizados para a fabricação, são fundamentais e determinantes para o comportamento mecânico dos materiais.

\subsubsection{Sinterização pela técnica de flash sintering}

Os resultados apresentados nesta seção são baseados nas observações experimentais e caracterizações preliminares sobre o efeito da sinterização por flash sintering da $\mathrm{t}-\mathrm{ZrO}_{2}$ e da $\mathrm{t}-\mathrm{ZrO}_{2} / \mathrm{Al}_{2} \mathrm{O}_{3}$ com $5 \%$ e $15 \%$ em volume de $\mathrm{Al}_{2} \mathrm{O}_{3}$. Todas as composições submetidas às curvas de aquecimento propostas, em que foi aplicado simultaneamente um campo elétrico de corrente contínua e alternada, sofreram uma retração linear significativa durante o processo.

As Figuras 28 (a), (b) e (c), apresentam, respectivamente, o comportamento de retração linear versus temperatura das amostras sinterizadas por flash sintering, em comparação também com as curvas de dilatometria apresentadas na Seção 5.1 (Figura 24), referentes à sinterização a da $\mathrm{t}-\mathrm{ZrO}_{2}$ e os compósitos $\mathrm{t}-\mathrm{ZrO}_{2} / 5 \%$ vol $\mathrm{Al}_{2} \mathrm{O}_{3}$ e $\mathrm{t}-\mathrm{ZrO}_{2} / 15 \%$ vol $\mathrm{Al}_{2} \mathrm{O}_{3}$. 
Figura 28 - Curvas de retração linear versus temperatura dos materiais sinterizados por flash sintering e por sinterização convencional: (a) $\mathrm{t}-\mathrm{ZrO}_{2}$; (b) $\mathrm{t}-\mathrm{ZrO}_{2} / 5 \%$ vol $\mathrm{Al}_{2} \mathrm{O}_{3}$; (c) $\mathrm{t}-\mathrm{ZrO}_{2} / 15 \%$ vol $\mathrm{Al}_{2} \mathrm{O}_{3}$.
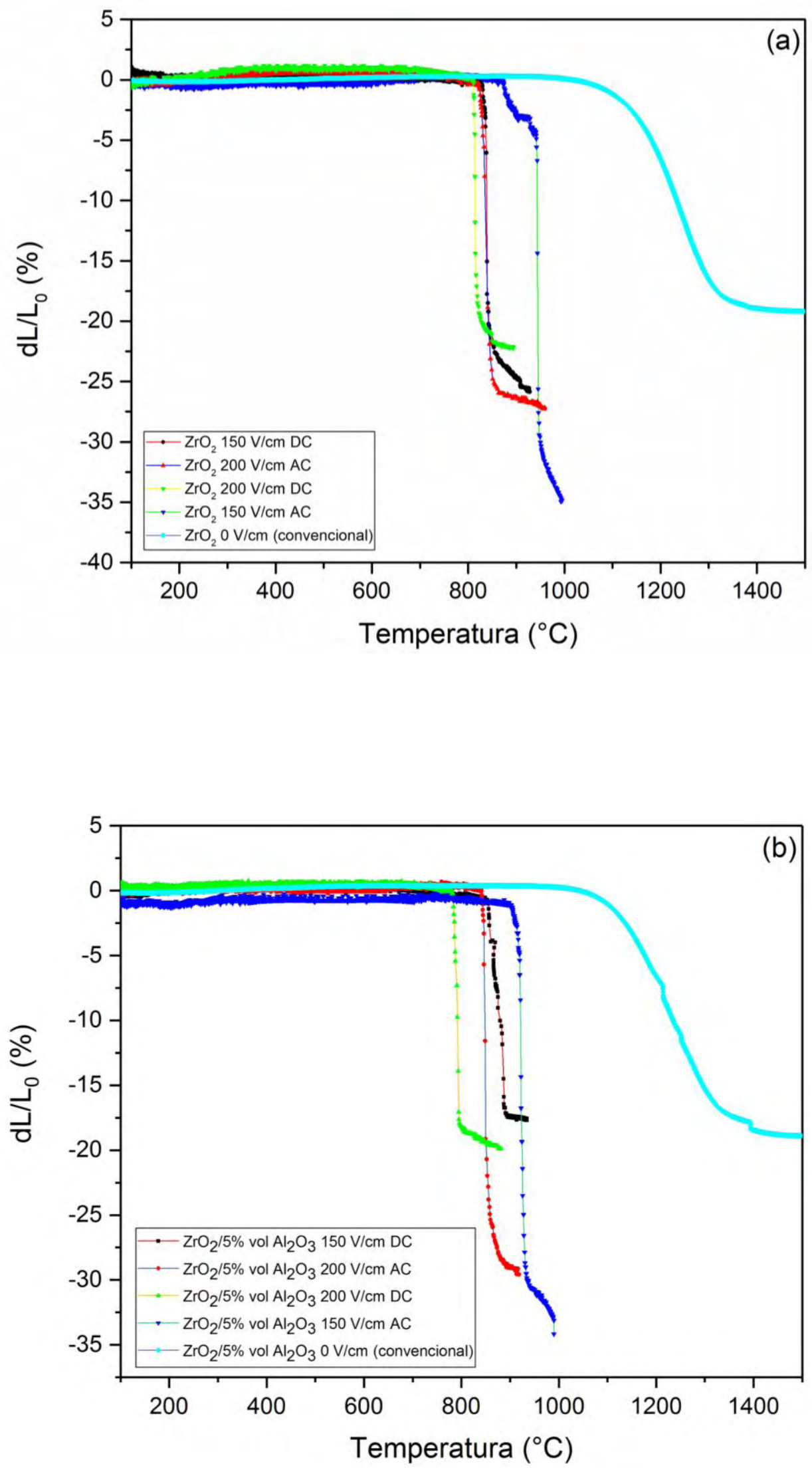


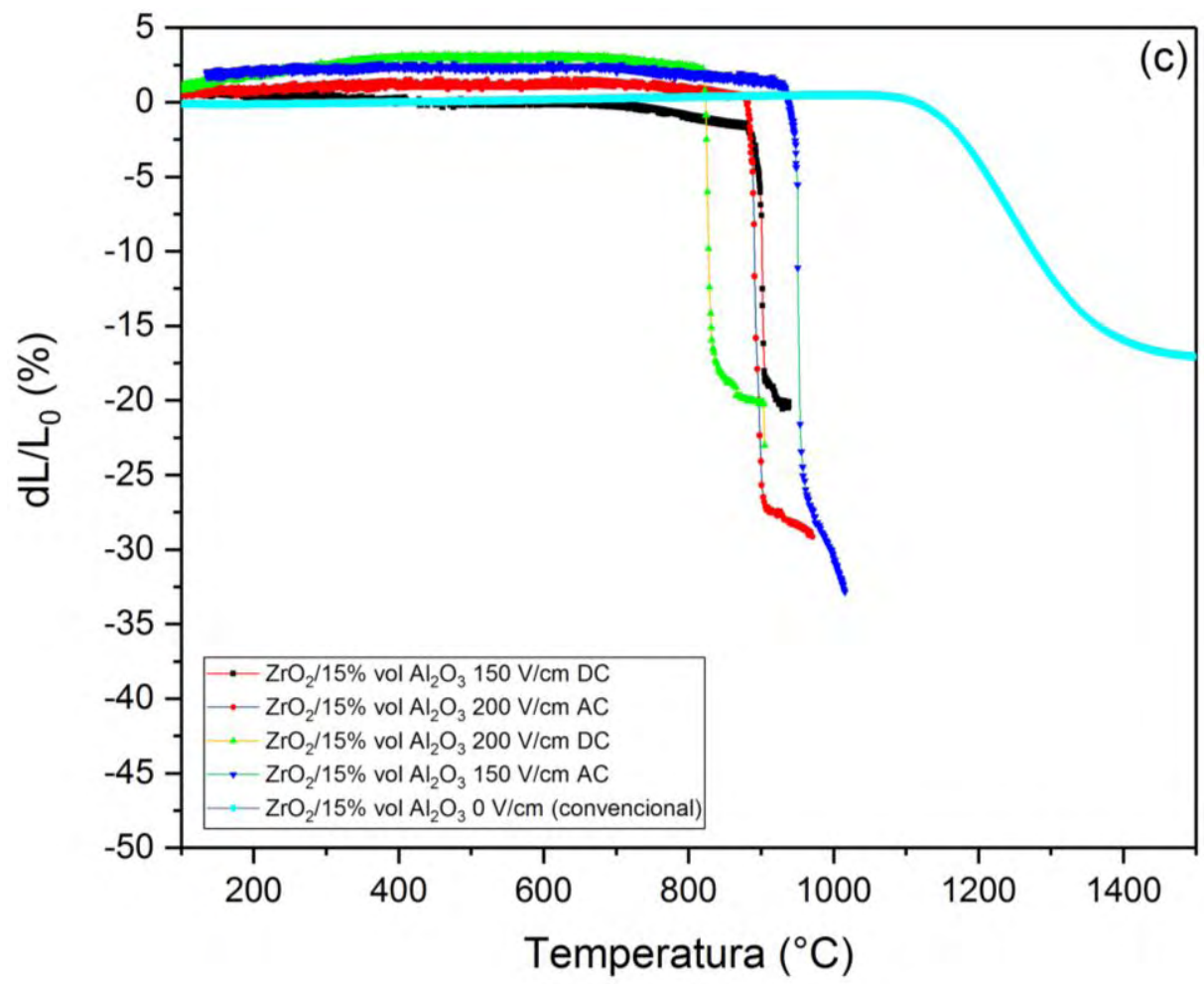

Com base na análise das curvas de retração observadas na Figura 28, observa-se que, para as condições estudadas, o fenômeno de flash sintering ocorreu em todas as composições e parâmetros ensaiados. Caracteriza-se o fenômeno pela queda brusca no comprimento da amostra em relação ao inicial, em temperaturas significativamente inferiores às temperaturas nas quais se inicia 0 processo de densificação da t-ZrO2 e dos seus compósitos com $5 \%$ e $15 \%$ vol de $\mathrm{Al}_{2} \mathrm{O}_{3}$ por sinterização convencional $(0 \mathrm{~V} / \mathrm{cm})$. Todas as amostras apresentaram retração linear superior a $15 \%$ em relação ao comprimento inicial, chegando a superar os $35 \%$, nos casos de sinterização com corrente alternada.

Em um estudo com $\mathrm{t}-\mathrm{ZrO}_{2}$ cúbica, Downs e Sglavo (2013) obtiveram o fenômeno de flash sintering em temperaturas a partir de $390^{\circ} \mathrm{C}$, com campo elétrico de $2250 \mathrm{~V} / \mathrm{cm}$, obtendo uma retração linear de $8,5 \%$. Com campos mais baixos, a temperatura na qual o flash ocorreu foi superior, porém com maior retração, chegando a $28,1 \%$ em campo de $60 \mathrm{~V} / \mathrm{cm}$, com o flash ocorrendo a $960^{\circ} \mathrm{C}$. Em seu trabalho, ponderam que uma das razões para a diferença da retração em função do campo elétrico utilizado é que um caminho de condução preferencial é seguido no caso de campos elétricos mais altos, criando efetivamente um curto-circuito ao longo da amostra. Um dos efeitos do curto-circuito criado é uma sinterização anisotrópica, i.e., amostras com formatos distorcidos em relação ao formato inicial. A redução 
desse efeito pode ser obtida com a utilização de eletrodos planos, em contato direto com a superfície da amostra. No entanto, outros fatores também podem causar uma heterogeneidade microestrutural, como o crescimento descontrolado da corrente elétrica através da amostra, à medida que esta vai perdendo sua resistência (DOWNS, SGLAVO, 2013).

Nas amostras estudadas neste trabalho, observou-se que houve uma tendência de retração mais alta nas amostras sinterizadas por corrente alternada em relação às amostras sinterizadas por corrente contínua. Esse efeito ficou mais evidenciado no caso dos compósitos $\mathrm{t}-\mathrm{ZrO}_{2} / \mathrm{Al}_{2} \mathrm{O}_{3}$. Por outro lado, a intensidade do campo elétrico, variada entre 150 e $200 \mathrm{~V} / \mathrm{cm}$, não teve influência notável na retração das amostras. É importante ressaltar que, além dos parâmetros de sinterização, fatores relacionados com a distribuição de inclusões de segunda fase, grau de empacotamento, densidade a verde, geometria da amostra e outros parâmetros relacionados ao processamento do material, podem ter influência no resultado final dos ensaios, alterando o grau de retração, bem como a temperatura na qual o fenômeno de flash sintering ocorre. Além disso, o setup do forno, a pressão de contato dos eletrodos com a amostra durante o aquecimento, atmosfera do forno e outros fatores operacionais também têm se demonstrado como importantes variáveis que interferem na reprodutibilidade dos ensaios.

Uma observação experimental permitiu verificar que as amostras sinterizadas por corrente contínua apresentavam uma variação no diâmetro das amostras cilíndricas ao longo do comprimento. As amostras estavam mais densas na região que esteve em contato com o eletrodo negativo, demonstrando uma significativa anisotropia macroscópica. Este efeito pode estar relacionado a uma variação na condutividade da amostra devido à movimentação das espécies carregadas. Nos experimentos com corrente contínua, em que se tem um eletrodo positivo e um negativo, os íons de $\mathrm{O}^{2-}$ tendem a migrar para o eletrodo positivo, desta forma ocupando os sítios disponíveis para as lacunas existentes na $\mathrm{t}-\mathrm{ZrO}_{2}$ estabilizada. Isso diminui a condutividade da amostra nos arredores do eletrodo positivo. O oxigênio do ar, que é incorporado ao processo, forma mais íons de $\mathrm{O}^{2-}$ devido à presença do campo elétrico e, embora o eletrodo negativo os tente repelir, não há lacunas suficientes para a ocupação dessas espécies, que ficam no caminho devido à resistência superior criada ao longo do restante da amostra. Dessa forma, há uma tendência de maior retração de uma parte da amostra em relação à outra, devido ao 
efeito Joule. Os íons que migraram para o eletrodo positivo recebem elétrons e voltam ao estado de oxigênio gasoso (MUCCILLO, 2008; MUCCILLO, KLEITZ, MUCCILLO, 2011; YU et al., 2017).

A Tabela 5 apresenta as temperaturas no instante em que ocorreu uma queda na tensão $\left(T_{i}\right)$ e um aumento na densidade de corrente que, por sua vez, ocorre em sincronia com o início da densificação, indicando o início do estágio de sinterização por flash sintering, em corrente contínua e corrente alternada; além disso, são apresentados os tempos de espera $(\Delta t)$, períodos nos quais a retração ocorreu com um aumento da densidade de corrente, até o instante aproximado em que o comprimento da amostra voltou a se estabilizar, para as amostras estudadas. Os dados da Tabela 5 foram obtidos diretamente dos gráficos apresentados na Figura 28.

Tabela 5 - Temperaturas de início da retração linear durante a sinterização por flash sintering e tempo de espera para a $\mathrm{t}-\mathrm{ZrO}_{2}, \mathrm{t}-\mathrm{ZrO}_{2} / 5 \%$ vol $\mathrm{Al}_{2} \mathrm{O}_{3}$ e $\mathrm{t}-\mathrm{ZrO}_{2} / 15 \%$ vol $\mathrm{Al}_{2} \mathrm{O}_{3}$.

\begin{tabular}{|c|c|c|c|c|c|c|c|c|}
\hline \multirow{4}{*}{ Composição } & \multicolumn{8}{|c|}{ Parâmetros de sinterização } \\
\hline & \multicolumn{4}{|c|}{ Corrente contínua (DC) } & \multicolumn{4}{|c|}{ Corrente alternada (AC) } \\
\hline & \multicolumn{2}{|c|}{$\begin{array}{c}\text { Campo }=150 \\
V / c m\end{array}$} & \multicolumn{2}{|c|}{$\begin{array}{c}\text { Campo }=200 \\
\text { V/cm }\end{array}$} & \multicolumn{2}{|c|}{$\begin{array}{c}\text { Campo }=150 \\
\text { V/cm }\end{array}$} & \multicolumn{2}{|c|}{$\begin{array}{c}\text { Campo }=200 \\
V / c m\end{array}$} \\
\hline & $\mathrm{T}_{\mathrm{i}}\left({ }^{\circ} \mathrm{C}\right)$ & $\Delta t(s)$ & $\mathrm{T}_{\mathrm{i}}\left({ }^{\circ} \mathrm{C}\right)$ & $\Delta t(s)$ & $\mathrm{T}_{\mathrm{i}}\left({ }^{\circ} \mathrm{C}\right)$ & $\Delta t(s)$ & $\mathrm{T}_{\mathrm{i}}\left({ }^{\circ} \mathbf{C}\right)$ & $\Delta t(s)$ \\
\hline $\mathrm{t}-\mathrm{ZrO}_{2}$ & 837,9 & 41 & 814,4 & 27 & 944,0 & 30 & 832,9 & 11 \\
\hline $\begin{array}{c}\mathrm{t}-\mathrm{ZrO}_{2} / 5 \% \text { vol } \\
\mathrm{Al}_{2} \mathrm{O}_{3}\end{array}$ & 875,4 & 16 & 785,6 & 15 & 921,2 & 18 & 846,6 & 34 \\
\hline $\begin{array}{c}\mathrm{t}-\mathrm{ZrO}_{2} / 15 \% \\
\mathrm{vol} \mathrm{Al}_{2} \mathrm{O}_{3}\end{array}$ & 899,2 & 43 & 824,5 & 30 & 950,4 & 18 & 891,3 & 27 \\
\hline
\end{tabular}

É importante ressaltar que as temperaturas descritas na Tabela 5, bem como as temperaturas presentes nos gráficos da Figura 28 são as temperaturas registradas por um termopar de Pt-Rh (tipo S) localizado próximo da amostra.

As temperaturas em que se iniciou a flash sintering para todas as amostras estudadas variaram entre $785,6^{\circ} \mathrm{C}$ e $950,4^{\circ} \mathrm{C}$, o que corresponde a uma faixa de temperaturas significativamente mais baixa do que a necessária para a sinterização convencional desses materiais. Pela análise da Tabela 5, fixando-se uma composição, para ambos os tipos de corrente utilizadas, pode-se observar que a temperatura de início da ocorrência do flash diminuiu com o aumento do campo elétrico. Entre as correntes contínua e alternada, a corrente contínua proporcionou a ocorrência do flash em temperaturas menores do que com a corrente alternada. Sendo assim, para os parâmetros estabelecidos nos ensaios, a t-ZrO 2 apresentou a 
menor temperatura de ocorrência do flash usando campo elétrico de $200 \mathrm{~V} / \mathrm{cm}$, sendo de $814,4^{\circ} \mathrm{C}$. Nos compósitos $\mathrm{t}-\mathrm{ZrO}_{2} / \mathrm{Al}_{2} \mathrm{O}_{3}$, a menor temperatura foi de $785,6^{\circ} \mathrm{C}$ para a amostra de $\mathrm{t}-\mathrm{ZrO}_{2} / 5 \%$ vol $\mathrm{Al}_{2} \mathrm{O}_{3}$ usando campo elétrico de $200 \mathrm{~V} / \mathrm{cm}$. Os tempos nos quais a retração ocorreu não apresentam, no entanto, regularidade com relação à composição e/ou parâmetros de sinterização. A Tabela 6 apresenta as densidades relativas (\%DT) das amostras sinterizadas por flash sintering.

Tabela 6 - Valores de densidade das amostras sinterizadas por flash sintering.

\begin{tabular}{|c|c|c|c|c|}
\hline \multirow{3}{*}{ Composição } & \multicolumn{4}{|c|}{ Densidade (\%DT) } \\
\hline & \multicolumn{2}{|c|}{ Corrente contínua (3 A) } & \multicolumn{2}{|c|}{$\begin{array}{c}\text { Corrente alternada } \\
\text { (3 A/ } 1000 \mathrm{~Hz})\end{array}$} \\
\hline & $E=150 \mathrm{~V} / \mathrm{cm}$ & $E=200 \mathrm{~V} / \mathrm{cm}$ & $E=150 \mathrm{~V} / \mathrm{cm}$ & $E=200 \mathrm{~V} / \mathrm{cm}$ \\
\hline $\mathrm{t}-\mathrm{ZrO}_{2}$ & 85,5 & 90,6 & 94,6 & 90,9 \\
\hline $\begin{array}{c}\mathrm{t}-\mathrm{ZrO}_{2} / 5 \% \text { vol } \\
\mathrm{Al}_{2} \mathrm{O}_{3}\end{array}$ & 88,7 & 84,4 & 81,7 & 85,5 \\
\hline $\begin{array}{c}\mathrm{t}-\mathrm{ZrO}_{2} / 15 \% \text { vol } \\
\mathrm{Al}_{2} \mathrm{O}_{3}\end{array}$ & 87,6 & 88,3 & 94,1 & 79,4 \\
\hline
\end{tabular}

Com base nos valores de densidade, levando-se em conta que a densidade a verde das amostras variou entre $51 \%$ e $53 \%$ da densidade teórica, observa-se que todas as amostras apresentaram uma razoável densificação, sendo a menor densificação registrada na amostra de $\mathrm{t}-\mathrm{ZrO}_{2} / 15 \%$ vol $\mathrm{Al}_{2} \mathrm{O}_{3}$ sinterizada com campo elétrico de $200 \mathrm{~V} / \mathrm{cm}$ em corrente alternada (79,4\%DT). No entanto, assim como ocorreu com o tempo de espera (Tabela 5), não há uma regularidade em função da composição ou da temperatura de ocorrência do flash. Como mencionado na seção, 4.2.1, foi realizado o ensaio de uma amostra por composição / parâmetro de sinterização, onde se observou que ocorreu o fenômeno de flash sintering para todas as composições / parâmetros de sinterização.

Pelos gráficos da Figura 28, bem como pelos dados apresentados na Tabela 5, observa-se que a retração completa das amostras sinterizadas por flash sintering ocorre em temperatura bem inferior à sinterização convencional e em muito menos tempo. O fenômenor de flash sintering, grosso modo, pode ser caracterizado por uma retração abrupta no comprimento da amostra, medido in loco durante o processo. Diversos autores propuseram mecanismos para explicar a sinterização por flash sintering. Até o presente, ainda não há um consenso entre as diversas teorias descritas na literatura. 
As Figuras 29, 30 e 31 apresentam as micrografias das regiões mais representativas das superfícies de fraturas da $\mathrm{t}-\mathrm{ZrO}_{2}, \mathrm{t}-\mathrm{ZrO} / 5 \%$ vol $\mathrm{Al}_{2} \mathrm{O}_{3}$ e t$\mathrm{ZrO}_{2} / 15 \% \mathrm{Al}_{2} \mathrm{O}_{3}$ sinterizados por flash sintering, respectivamente. De modo geral, observou-se certa heterogeneidade nas microestruturas, no entanto, as micrografias representam as regiões que predominaram na superfície de fratura. Alguns exemplos da heterogeneidade da superfície de fratura serão expostos adiante.

\section{Figura 29 - Micrografias de MEV das superfícies de fratura das amostras de $\mathrm{t}-\mathrm{ZrO}_{2}$ sinterizadas por} flash sintering: (a) Campo de $150 \mathrm{~V} / \mathrm{cm}, \mathrm{AC}, 1000 \mathrm{~Hz}$; (b) Campo de $200 \mathrm{~V} / \mathrm{cm}, \mathrm{AC}, 1000 \mathrm{~Hz}$; (c) Campo de 150 V/cm, DC; (d) Campo de 200 V/cm, DC.
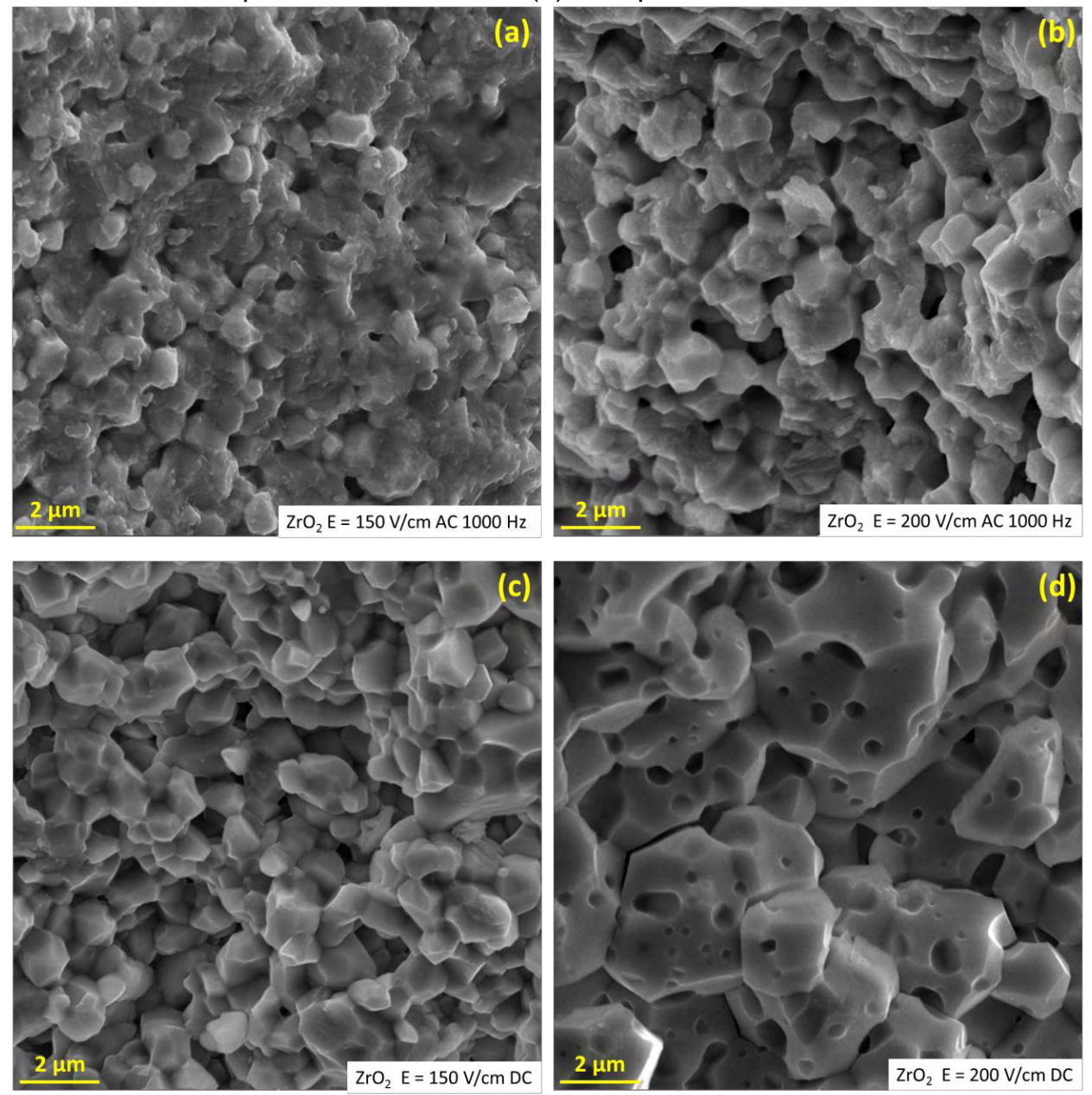

De modo geral, observam-se regiões predominantes de microestrutura com alta densificação, indicando que as amostras atingiram o estágio final de sinterização. No entanto, todas as amostras de $\mathrm{t}^{-\mathrm{ZrO}_{2}}$ (Figura 29) mostraram superfícies de fratura com porosidade significativa. As amostras sinterizadas com corrente alternada (Figuras 29 (a) e (b)) mostraram um modo de fratura misto (intergranular e intragranular), especialmente na amostra sinterizada com campo 
elétrico de $150 \mathrm{~V} / \mathrm{cm}$, e com um visível crescimento de grão com o aumento do campo elétrico. Um significativo crescimento de grão também foi observado com o aumento do campo elétrico nas amostras sinterizadas com corrente contínua (Figuras 29 (c) e (d)). Nessas amostras, observou-se um modo de fratura intergranular e, na amostra sinterizada com campo de $200 \mathrm{~V} / \mathrm{cm}$ (Figura 29 (d)) foi notável a presença de uma porosidade intragranular, que pode estar relacionada com o rápido crescimento de grão ocorrido nessa amostra, impedindo que os poros se fechassem devido às diferentes cinéticas de ambos os processos (STEIL et al., 2013).

A Figura 30 mostra as micrografias das superfícies de fratura dos compósitos $\mathrm{t}-\mathrm{ZrO} / 5 \%$ vol $\mathrm{Al}_{2} \mathrm{O}_{3}$.

Figura 30 - Micrografias de MEV das superfícies de fratura das amostras de $\mathrm{t}-\mathrm{ZrO} / 5 \%$ vol $\mathrm{Al}_{2} \mathrm{O}_{3}$ sinterizadas por flash sintering: (a) Campo de $150 \mathrm{~V} / \mathrm{cm}, \mathrm{AC}, 1000 \mathrm{~Hz}$; (b) Campo de $200 \mathrm{~V} / \mathrm{cm}, \mathrm{AC}$, $1000 \mathrm{~Hz}$; (c) Campo de 150 V/cm, DC; (d) Campo de 200 V/cm, DC.
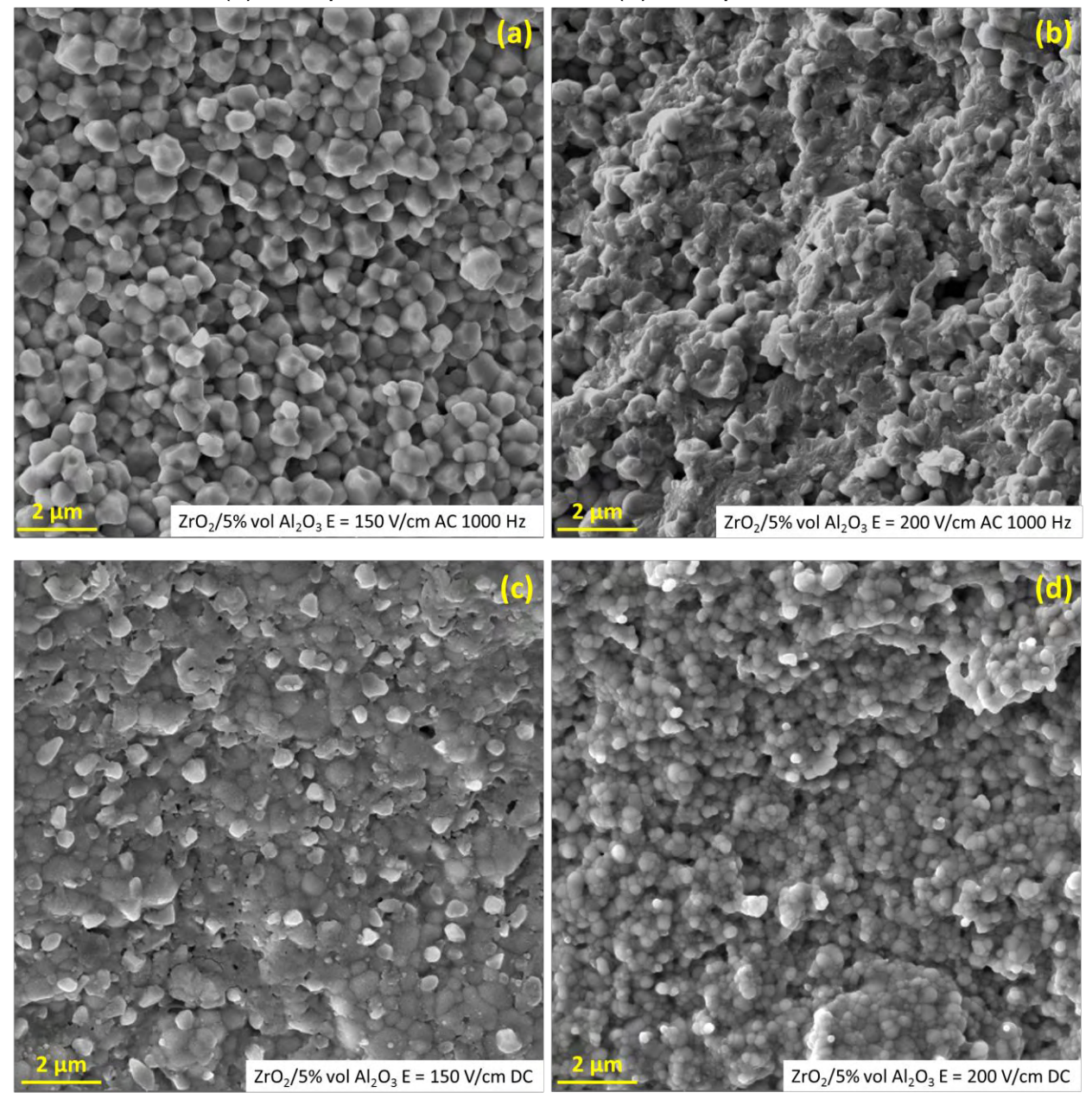

As micrografias da Figura 30 mostram uma diferença mais significativa na morfologia das superfícies de fratura das diferentes amostras. Observaram-se 
regiões com grãos de tamanho inferior a $1 \mu \mathrm{m}$ em todas as amostras. No entanto, a heterogeneidade microestrutural mais evidente nesta composição não permite comparar o tamanho de grão dos compósitos, haja vista que as micrografias apresentaram superfícies de fratura com morfologias variadas. Portanto, não se pode afirmar categoricamente que a adição de $\mathrm{Al}_{2} \mathrm{O}_{3}$ na matriz tenha favorecido a supressão do crescimento de grão, embora seja possível. De modo geral, nas regiões de fratura apresentadas na Figura 30, o tamanho de grão médio das amostras é inferior ao observado nas amostras de $\mathrm{t}-\mathrm{ZrO}_{2}$, com pouco crescimento em relação ao tamanho de partícula dos pós de partida, e baixa porosidade.

A Figura 31 mostra as micrografias das superfícies de fratura dos compósitos $\mathrm{t}-\mathrm{ZrO}_{2} / 15 \%$ vol $\mathrm{Al}_{2} \mathrm{O}_{3}$.

Figura 31 - Micrografias de MEV das superfícies de fratura das amostras de $\mathrm{t}-\mathrm{ZrO}_{2} / 15 \%$ vol $\mathrm{Al}_{2} \mathrm{O}_{3}$ sinterizadas por flash sintering: (a) Campo de $150 \mathrm{~V} / \mathrm{cm}, \mathrm{AC}, 1000 \mathrm{~Hz}$; (b) Campo de $200 \mathrm{~V} / \mathrm{cm}, \mathrm{AC}$, $1000 \mathrm{~Hz}$; (c) Campo de 150 V/cm, DC; (d) Campo de 200 V/cm, DC.


Assim como ocorreu nos compósitos com $5 \%$ em volume de $\mathrm{Al}_{2} \mathrm{O}_{3}$, os compósitos com $15 \%$ vol de $\mathrm{Al}_{2} \mathrm{O}_{3}$ (Figura 31 ) apresentaram superfícies de fratura 
com morfologias diferentes entre si, em função do campo aplicado ou do tipo de corrente. O compósito sinterizado com campo elétrico de $150 \mathrm{~V} / \mathrm{cm}$ em corrente alternada (Figura 31(a)) apresenta regiões que parecem ter sofrido uma fusão localizada, com regiões solidificadas em meio a grãos micrométricos. Na amostra sinterizada com o mesmo campo, mas com corrente contínua (Figura 31(c)), por outro lado, observa-se uma microestrutura mais fina, com tamanhos de grão muito menores, sem indícios de fusão localizada na região.

A Figura 32 mostra um exemplo da heterogeneidade de microestrutura observada na amostra de $\mathrm{t}-\mathrm{ZrO}_{2}$ sinterizada com campo elétrico de $200 \mathrm{~V} / \mathrm{cm}$, com corrente contínua, por meio da micrografia de uma "fronteira" entre duas regiões significativamente distintas da superfície de fratura.

Figura 32 - Micrografia de MEV da fronteira entre duas regiões com distintos tamanhos de grão na superfície de fratura da $\mathrm{t}-\mathrm{ZrO}_{2}$ sinterizada por flash sintering com campo elétrico de $200 \mathrm{~V} / \mathrm{cm}$ e corrente contínua (DC).
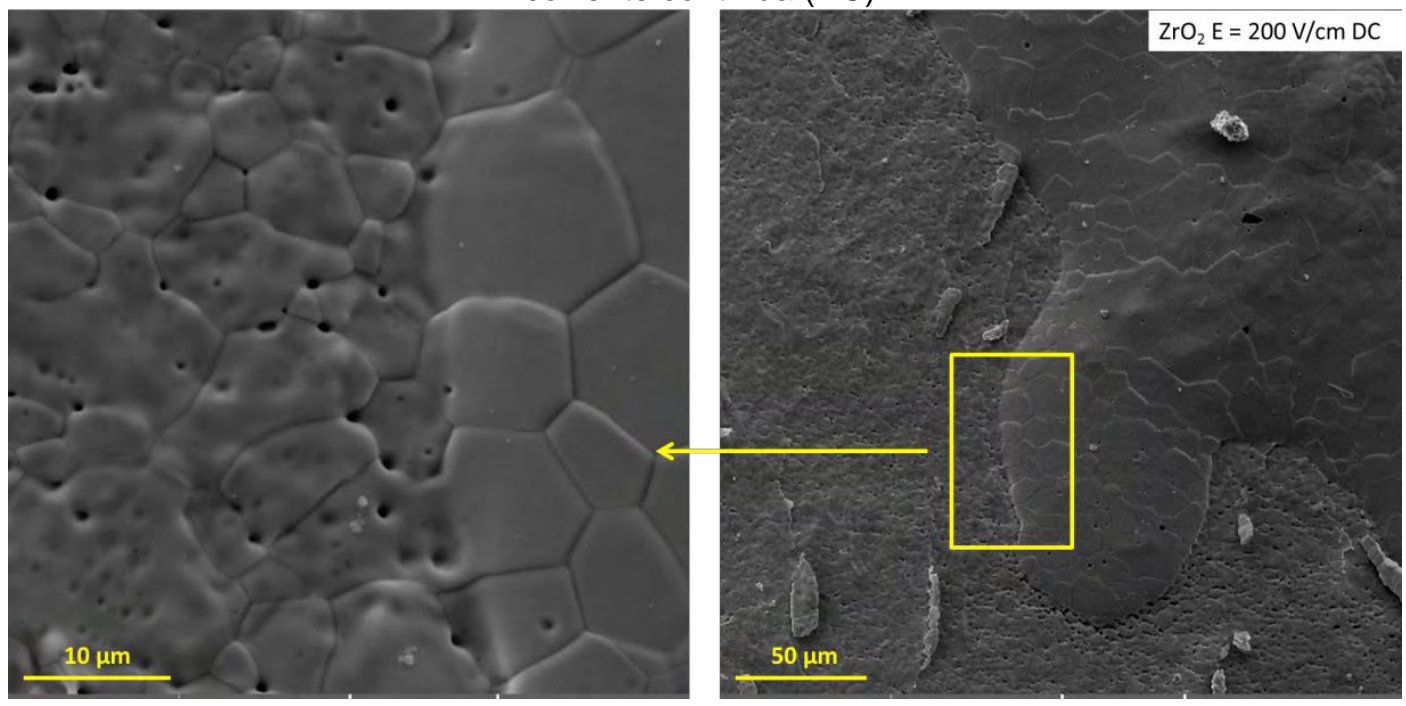

$\mathrm{Na}$ micrografia, observa-se a existência de duas regiões da superfície de fratura com distintos crescimentos de grão e graus de porosidade. A região com menor tamanho médio de grão apresentou um grau de porosidade maior, com poros intergranulares e intragranulares. A região em que houve maior crescimento de grão, por sua vez, apresentou porosidade quase nula e grãos mais definidos. Por meio deste exemplo, pode-se confirmar que a passagem da corrente pela amostra durante a flash sintering favoreceu diferentes mecanismos de difusão no material, dependendo da movimentação dos íons pelas lacunas, causando um gradiente de 
resistência durante a sinterização, combinados com outros mecanismos que promoveram uma rápida, porém anisotrópica densificação.

Outro exemplo de heterogeneidade observada na análise por MEV, especificamente na superfície de fratura do compósito $\mathrm{t}-\mathrm{ZrO}_{2} / 15 \%$ vol $\mathrm{Al}_{2} \mathrm{O}_{3}$ sinterizado com campo elétrico de $200 \mathrm{~V} / \mathrm{cm}$ e corrente alternada, foi a formação de uma microestrutura eutética em algumas regiões isoladas da amostra. A Figura 33 mostra as micrografias dessas regiões.

Figura 33 - Micrografia de MEV de região com formação de eutético no compósito $\mathrm{t}-\mathrm{ZrO}_{2} / 15 \%$ vol $\mathrm{Al}_{2} \mathrm{O}_{3}$ sinterizado por flash sintering com campo elétrico de $200 \mathrm{~V} / \mathrm{cm}$ e corrente alternada.
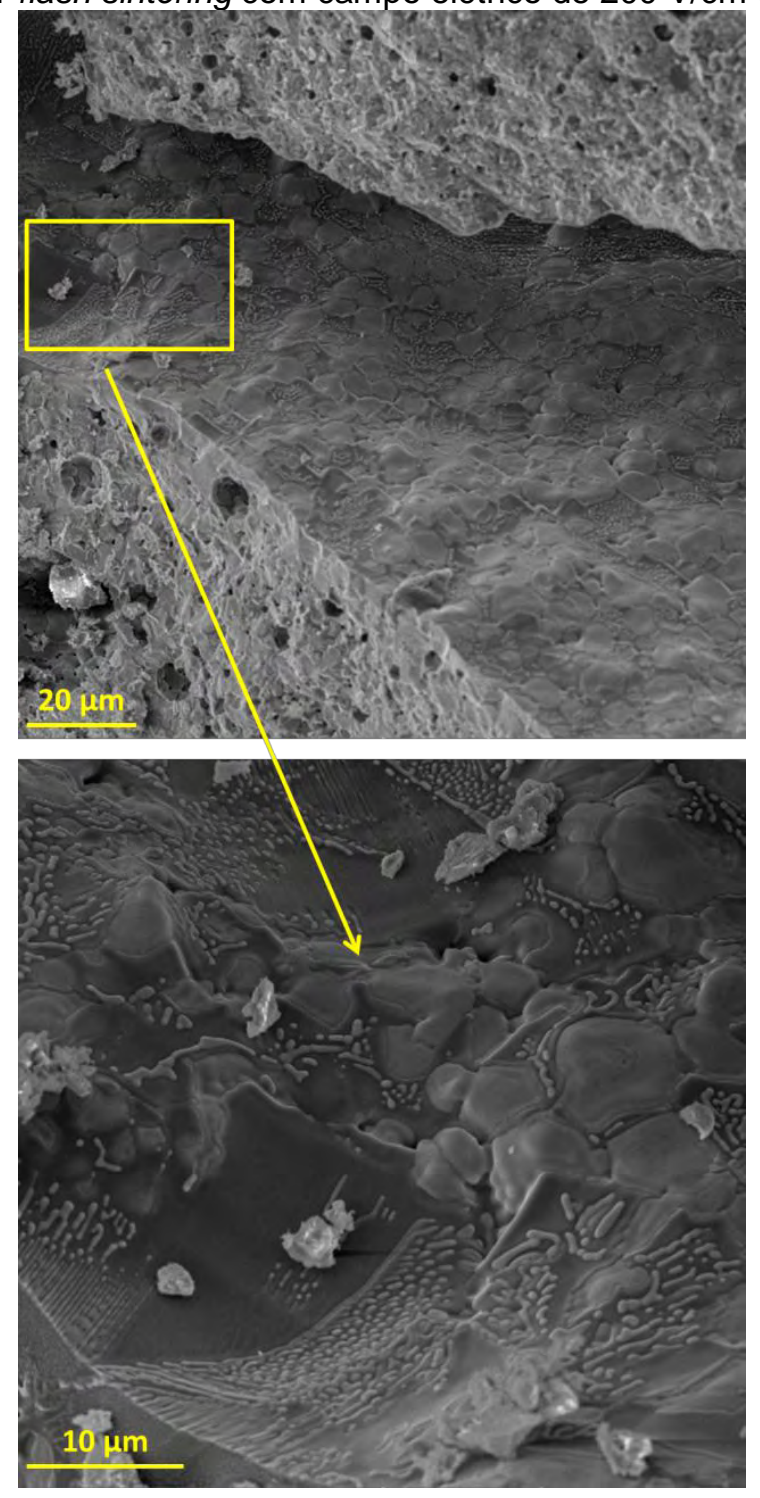

A microestrutura mostrada na Figura 33 evidencia um crescimento de grão significativo de $\mathrm{t}_{-} \mathrm{ZrO}_{2}$ em uma matriz de líquido solidificado. A formação da microestrutura evidencia que a temperatura atingida pela amostra durante o flash 
sintering em algumas regiões superou a temperatura de formação de eutético do sistema, comprovando que, também em corrente alternada, houve um aquecimento não uniforme da amostra, a ponto de criar uma microestrutura heterogênea. É importante ressaltar que tal microestrutura não foi observada nas demais amostras sinterizadas, inclusive da mesma composição. A Figura 34 mostra uma micrografia de outra região da mesma amostra de $\mathrm{t}-\mathrm{ZrO}_{2} / 15 \%$ vol $\mathrm{Al}_{2} \mathrm{O}_{3}$ sinterizada com campo elétrico de $200 \mathrm{~V} / \mathrm{cm}$ e corrente alternada, com ampliação da região de eutético, e uma micrografia comparativa obtida com elétrons retroespalhados.

Figura 34 - Micrografia de MEV de região com formação de eutético no compósito $\mathrm{t}-\mathrm{ZrO}_{2} / 15 \%$ vol $\mathrm{Al}_{2} \mathrm{O}_{3}$ sinterizado por flash sintering com campo elétrico de $200 \mathrm{~V} / \mathrm{cm}$ e corrente alternada: (a) obtida com elétrons secundários; (b) obtida com elétrons retroespalhados; (c) ampliação da região de eutético.
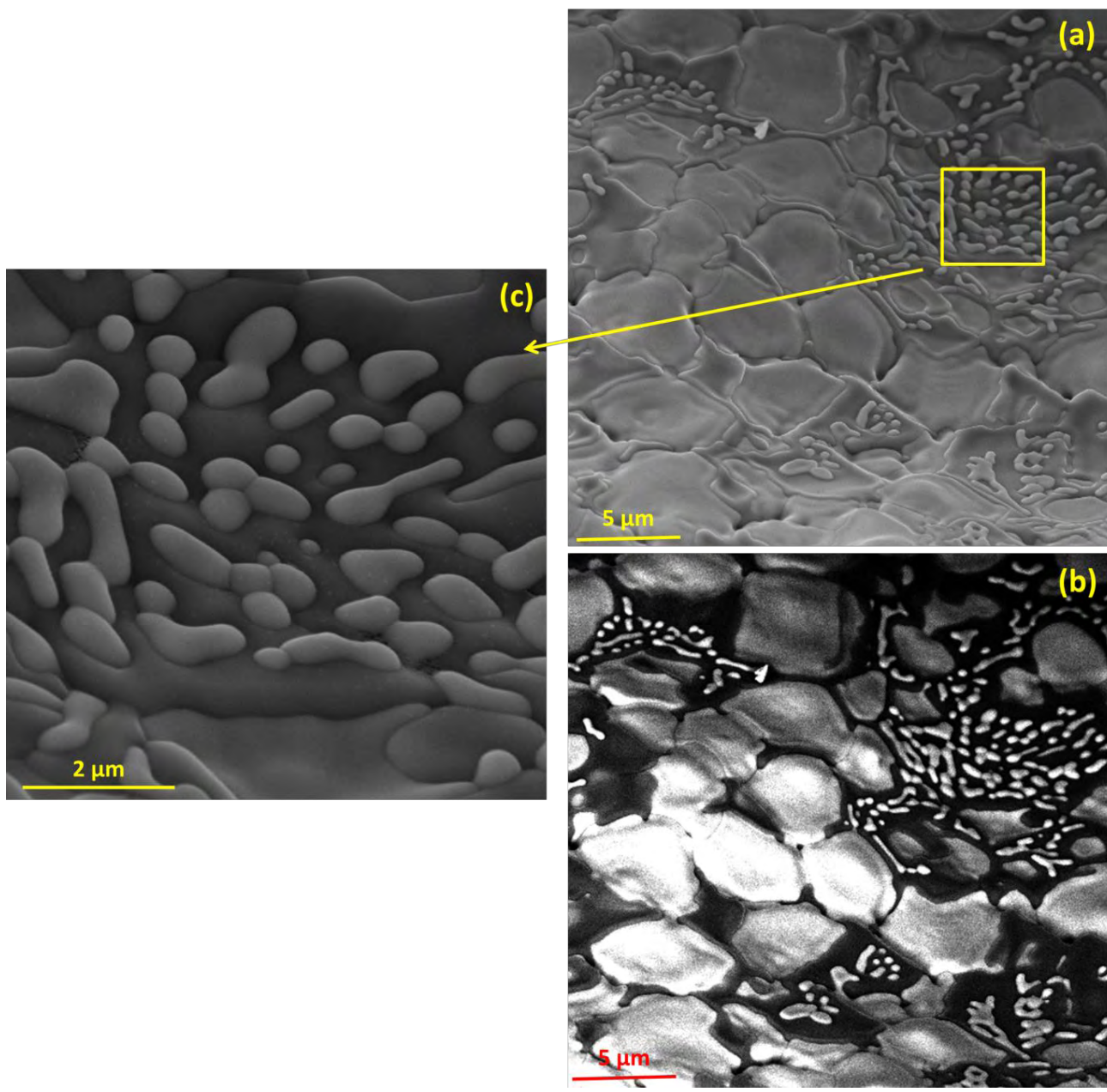

Pela Figura 34(a), obtida por detecção de elétrons secundários, observa-se com mais nitidez os contornos de fases, em que se vê uma fase solidificada circundando grãos micrométricos predominantes na microestrutura, indicando que houve sinterização via fase líquida nessa região. A Figura 34(b) mostra um maior 
contraste relativo à massa atômica das espécies químicas presentes, e permite sugerir que os grãos têm composição rica em t-ZrO2, por estarem mais claros na micrografia, enquanto a matriz solidificada é mais escura, podendo ser associada a uma composição rica em $\mathrm{Al}_{2} \mathrm{O}_{3}$. As estruturas mostradas em destaque na Figura 34(c) têm tamanho submicrométrico e são ricas em $\mathrm{t}-\mathrm{ZrO}_{2}$, distribuídas de forma aleatória em algumas regiões da microestrutura. Devido à limitada disponibilidade de material, não foi possível fazer uma análise mais aprofundada da composição das fases observadas nas micrografias.

Microestruturas heterogêneas em cerâmicas de $\mathrm{t}-\mathrm{ZrO}_{2}$ obtidas por flash sintering têm sido reportadas por diversos autores. Steil et al. (2013) estudou a sinterização por flash sintering da $\mathrm{t}-\mathrm{ZrO}_{2}$ (estabilizada com $8 \%$ mol $\mathrm{Y}_{2} \mathrm{O}_{3}$ ), em condições relativamente severas (o que denominou como hyper-flash), como densidades de corrente na faixa de $20 \mathrm{~A} / \mathrm{cm}^{2}$ e campo elétrico de $170 \mathrm{~V} / \mathrm{cm}$. Nas amostras sinterizadas com essas condições, observaram-se heterogeneidades significativas nas microestruturas. As periferias das amostras apresentaram um tamanho de grão significativamente menor que o seu centro. Todas as amostras sinterizadas por flash sintering apresentaram características semelhantes às reportadas. Essa observação traz um novo argumento no atual debate sobre o efeito Joule e, mais especificamente, no regime de dissipação de potência. Com base nisso, a potência suprida é dissipada a partir da superfície da amostra, essencialmente por radiação. Isso implica um fluxo de calor do centro para a superfície da amostra e, portanto, um gradiente de temperatura no interior da amostra. Essa heterogeneidade presente nas microestruturas pode ser explicada por esse argumento. No entanto, o risco de se obterem amostras de microestrutura heterogênea constitui uma importante limitação da técnica de flash sintering, devendo ser estudado o ajuste de parâmetros de forma a uniformizar a microestrutura final dos materiais sinterizados por essa técnica.

Com base nos resultados expostos, pode-se concluir que a técnica de flash sintering permitiu a sinterização da $\mathrm{t}-\mathrm{ZrO}_{2}$ e dos compósitos de $\mathrm{t}-\mathrm{ZrO}_{2}$ com $5 \%$ e $15 \%$ em volume de $\mathrm{Al}_{2} \mathrm{O}_{3}$ sinterizados em temperaturas significativamente inferiores às necessárias para a sinterização convencional, possibilitando a obtenção de microestruturas finas e com alta retração linear. Estes efeitos, em diferentes níveis, foram observados em corrente contínua e corrente alternada, com campos de 150 $\mathrm{V} / \mathrm{cm}$ e $200 \mathrm{~V} / \mathrm{cm}$. As microestruturas, por sua vez, apresentaram significativas 
diferenças entre as composições e parâmetros de sinterização, bem como foi observado um certo grau de anisotropia macroscópica e uma heterogeneidade microestrutural na maioria das amostras. Por se tratar de um tema relativamente novo, a elucidação dos mecanismos responsáveis pela flash sintering permanece em grande discussão, com pontos de vista opostos apresentando constantemente novos resultados na literatura (BIESUZ, SGLAVO, 2016; CALIMAN et al., 2016; GAO et al., 2017; Jl et al., 2017; SILVA et al., 2017; KOK et al., 2017; TODD, 2017).

\subsection{Caracterização dos nanocompósitos $\mathrm{t}-\mathrm{ZrO}_{2} / \mathrm{Al}_{2} \mathrm{O}_{3}-\mathrm{NbC}$}

5.2.1 Caracterização do pó de $\mathrm{Al}_{2} \mathrm{O}_{3}-\mathrm{NbC}$ sintetizado por moagem reativa de alta energia

A Figura 35 mostra os difratogramas de raios $X$ dos materiais utilizados antes e depois do processo de moagem reativa de alta energia. O difratograma inferior apresenta os picos de todos os reagentes, sendo alumínio (Al), carbono (C), óxido de nióbio $\left(\mathrm{Nb}_{2} \mathrm{O}_{5}\right)$ e alumina $\left(\mathrm{Al}_{2} \mathrm{O}_{3}\right.$, utilizada como diluente). No difratograma superior, observa-se que há apenas os picos dos produtos esperados, isto é, $\mathrm{Al}_{2} \mathrm{O}_{3} \mathrm{e}$ $\mathrm{NbC}$, mostrando que a reação ocorreu de forma autossustentada (SHS), como descrito na literatura (PALLONE et al., 2003). A diferença de intensidade e alargamento dos picos no difratograma superior denota um material de partículas primárias bastante pequenas no produto, indicando um material nanocristalino.

Figura 35 - Difratogramas de raios $X$ da mistura de pós $\mathrm{Al}+\mathrm{C}+\mathrm{Nb}_{2} \mathrm{O}_{5}+\mathrm{Al}_{2} \mathrm{O}_{3}$ antes e após a




O difratograma do material após a moagem foi ajustado e utilizado para a determinação dos tamanhos de cristalito de cada fase, calculados utilizando a Equação 6, bem como a sua proporção relativa em volume, pelo método de Rietveld, com auxílio do software de análise do difratômetro de raios $\mathrm{X}$ (Rigaku PDXL). A Tabela 7 mostra esses valores e sua comparação com a proporção relativa de fases calculada pela relação estequiométrica.

Tabela 7 - Tamanho de cristalito e fração volumétrica de cada fase calculada pelo método de Rietveld com base no difratograma de raios $X$ do produto de moagem.

\begin{tabular}{c|c|c|c}
\hline Fase & Tamanho de cristalito (nm) & $\begin{array}{c}\text { Proporção } \\
\text { volumétrica (\%vol) }\end{array}$ & $\begin{array}{c}\text { Proporção } \\
\text { volumétrica teórica } \\
\text { (\%vol) }\end{array}$ \\
\hline $\mathrm{Al}_{2} \mathrm{O}_{3}$ & 9,1 & 56,6 & 54,9 \\
\hline $\mathrm{NbC}$ & 9,7 & 43,4 & 45,1 \\
\hline
\end{tabular}

Após o processo em moinho de alta energia do tipo SPEX, que levou à formação do pó de $\mathrm{Al}_{2} \mathrm{O}_{3}-\mathrm{NbC}$, em um tempo de 190 min, a moagem foi continuada por mais $140 \mathrm{~min}$, totalizando um tempo total de processo de $330 \mathrm{~min}$. Esse tempo foi necessário para a diminuição do tamanho dos aglomerados formados. No entanto, tratando-se de aglomerados fortes (agregados), o pó, após o processamento em moinho do tipo "Spex", passou por outra etapa de moagem em moinho planetário, com o objetivo de reduzir ainda mais o tamanho de aglomerado.

A Figura 36 mostra as curvas acumuladas de distribuição de tamanho de aglomerado do pó de $\mathrm{Al}_{2} \mathrm{O}_{3}-\mathrm{NbC}$ antes e depois da desaglomeração em moinho planetário. Observa-se que houve, após essa etapa de desaglomeração, um deslocamento significativo da curva de distribuição para a esquerda (Figura 36(b)), demonstrando que o processo foi eficiente na redução do tamanho de aglomerado, obtendo-se tamanho médio inferior a $1 \mu \mathrm{m}$. 
Figura 36 - Curvas de distribuição acumulada de tamanho de partículas do pó de $\mathrm{Al}_{2} \mathrm{O}_{3}-\mathrm{NbC}$ : (a) antes da moagem em moinho planetário; (b) depois da moagem em moinho planetário.

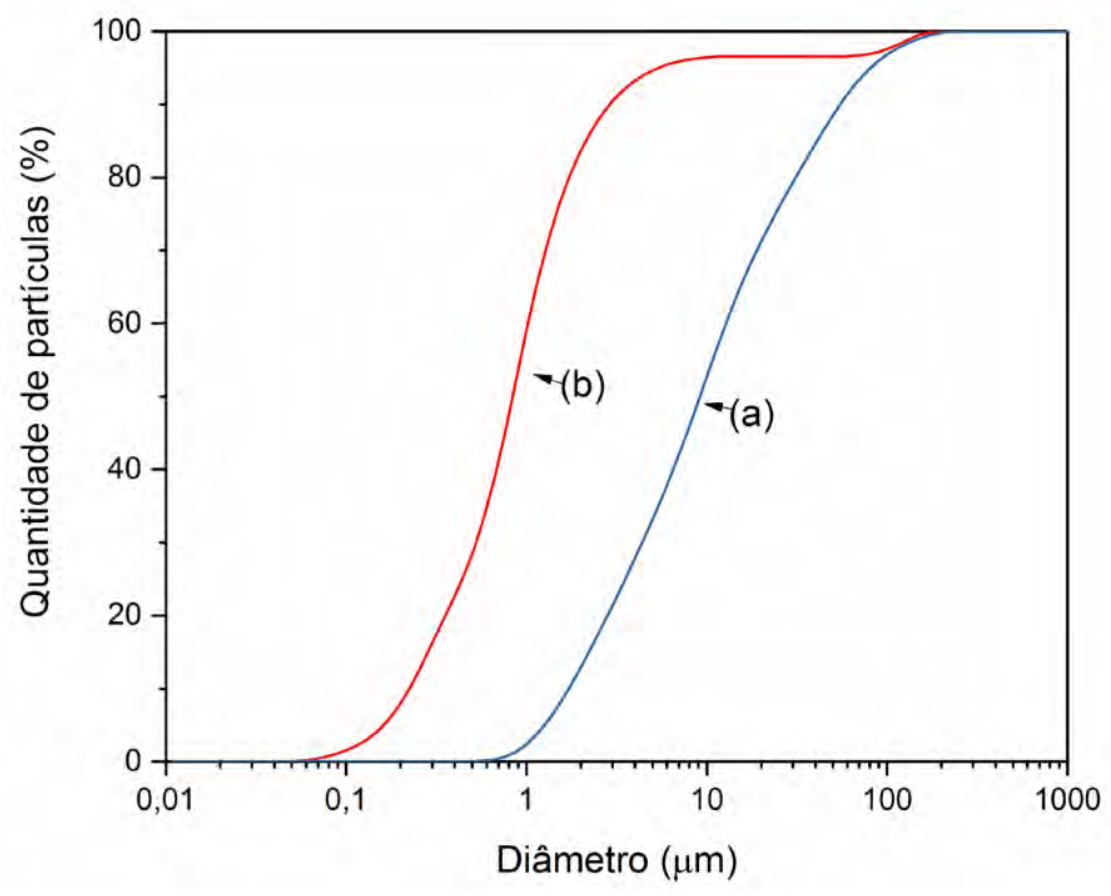

Pode-se observar que o tamanho médio de partícula (aglomerado) medido após a moagem em moinho planetário reduziu de forma significativa. No entanto, ainda se consideram os tamanhos medidos pelo ensaio como sendo de aglomerados, e não das partículas primárias, uma vez que estas não estão completamente dispersas.

A Figura 37 mostra uma micrografia do pó de $\mathrm{Al}_{2} \mathrm{O}_{3}-\mathrm{NbC}$ obtida $\mathrm{MET}$ (em campo claro e campo escuro), após a desaglomeração em moinho planetário. Observa-se que os pós são aglomerados de ordem nanométrica e submicrométrica (de diâmetro médio inferior a $500 \mathrm{~nm}$ ), em que se observam, na micrografia de campo escuro, partículas mais claras e mais escuras. Essas partículas primárias possuem diâmetro condizente com o valor determinado pela análise de Rietveld, inferior a $10 \mathrm{~nm}$ de diâmetro médio. A difração de elétrons da região selecionada na Figura 37(a) em conjunto com a análise elementar da região por EDS, mostram uma região rica em $\mathrm{Nb}$, com presença de $\mathrm{Al}$ e $\mathrm{O}$. 
Figura 37 - Micrografia obtida por MET dos pós de $\mathrm{Al}_{2} \mathrm{O}_{3}-\mathrm{NbC}$ : (a) campo escuro; (b) campo claro.



Com o objetivo de verificar como ocorre a oxidação do $\mathrm{NbC}$, a análise térmica e termogravimétrica (TG/DSC) do pó de $\mathrm{Al}_{2} \mathrm{O}_{3}-\mathrm{NbC}$, realizada em atmosfera de ar sintético, é apresentada na Figura 38. Considerando-se que a reação ocorreu de forma estequiométrica e não foram detectados traços de reagentes na análise de DRX realizada após a reação, e que a $\mathrm{Al}_{2} \mathrm{O}_{3}$ é estável em toda a faixa de temperaturas estudada, atribuem-se a maioria das reações detectadas pelo TG/DSC a transformações ocorrentes no NbC.

Figura 38 - Análise de TG/DSC do pó de $\mathrm{Al}_{2} \mathrm{O}_{3}-\mathrm{NbC}$ sintetizado por moagem de alta energia em atmosfera de ar sintético.

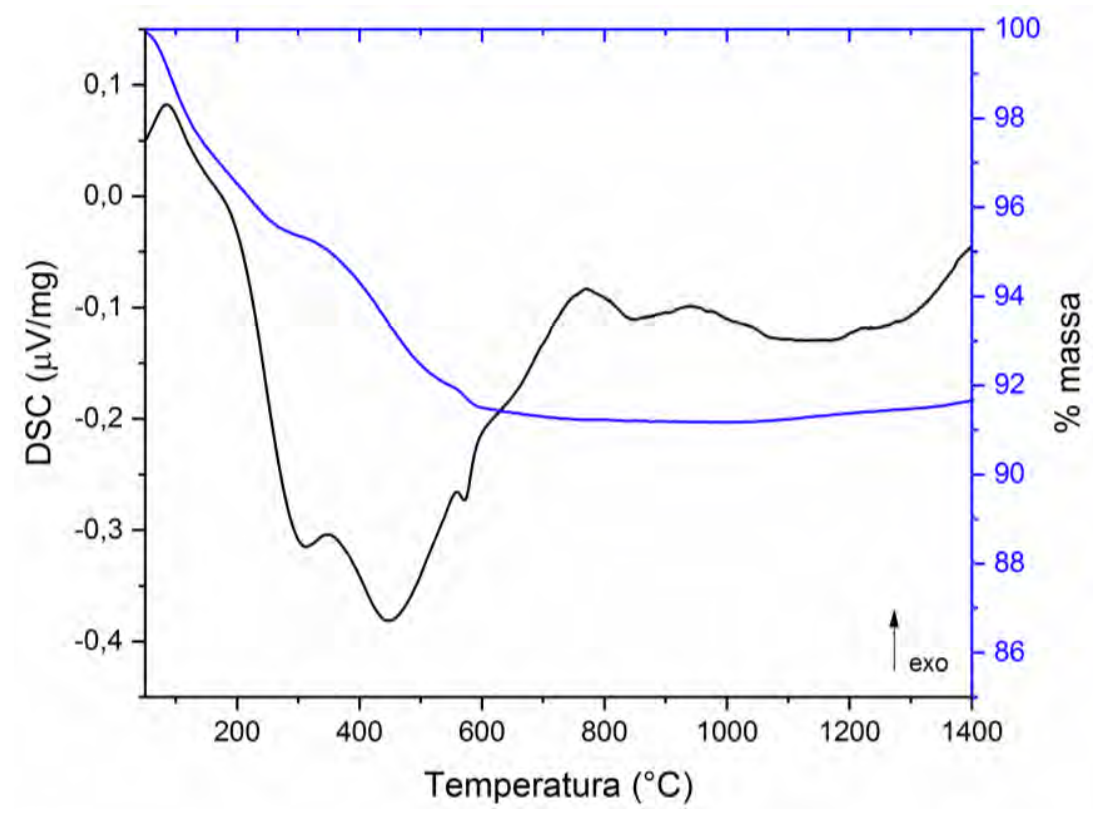


Inicialmente, observa-se um primeiro pico exotérmico em torno de $150^{\circ} \mathrm{C}$, combinado com uma significativa perda de massa. Esse pico e essa perda de massa são atribuídos à evaporação do resíduo de álcool isopropílico, em que a amostra estava suspensa. A partir dessa etapa, observa-se uma sequência de transformações e alterações de massa detectadas pelo ensaio de TG/DSC.

Como descrito por Shimada e Inagaki (1993), observa-se que o processo de oxidação do $\mathrm{NbC}$ se inicia a temperaturas inferiores a $490^{\circ} \mathrm{C}$, o que é indicado por um pico exotérmico em torno da temperatura de $350^{\circ} \mathrm{C}$. A partir desse ponto, o processo de oxidação torna-se mais lento, procedendo dessa maneira até a temperatura de $490^{\circ} \mathrm{C}$. De acordo com Shi e colaboradores (2005), essa redução na taxa de oxidação está relacionada com a formação de uma camada de óxido protetiva na superfície das partículas do carbeto. A perda de massa correspondente a essa etapa está envolvida com a reação de parte do carbono com o oxigênio do ar. Com o aumento da temperatura, uma nova etapa de oxidação se inicia, causando a destruição dessa camada protetiva de óxido e um aumento na taxa de oxidação. Nessa etapa, na faixa de $550-600^{\circ} \mathrm{C}$, uma leve perda de massa é observada, podendo ser atribuída à oxidação de uma pequena quantidade de carbono residual presente na amostra. Acima de $750^{\circ} \mathrm{C}$, o ganho de massa torna-se praticamente constante, havendo um pequeno incremento devido à incorporação de oxigênio durante a transformação dos óxidos de nióbio não estequiométricos $\left(\mathrm{NbO}_{\mathrm{x}}\right)$ em pentóxido de dinióbio $\left(\mathrm{Nb}_{2} \mathrm{O}_{5}\right)$, a forma mais estável do óxido (SHIMADA, INAGAKI, 1993; SHI et al., 2005). As variações de energia no DSC mostram de forma proporcional que o processo de oxidação do $\mathrm{NbC}$ é bastante complexo, ocorrendo em etapas que possuem diferentes características e, portanto, diferentes comportamentos cinéticos.

Comportamentos semelhantes de oxidação são observados em carbetos dos metais de transição (p.ex.: Zr, Ta, Hf). Desmaison-Brut et al. (1997) estudaram o comportamento de oxidação de dois carbetos de tântalo ( $\mathrm{TaC}$ e $\mathrm{Ta}_{2} \mathrm{C}$ ). Seus resultados mostram que a oxidação dos carbetos de tântalo ocorre da mesma forma que demonstrado por Shimada e Inagaki (1994) e replicado por Shi et al. (2005), ou seja, uma oxidação em etapas com distintas cinéticas. De forma geral, as reações são governadas por um processo interfacial localizado na interface carbeto-óxido. O fato de que os carbetos desses metais não são completamente estequiométricos, faz com que haja uma disponibilidade de sítios vacantes serem facilmente ocupados 
por oxigênio, o que confere essa característica de uma rápida oxidação superficial, criando a camada de óxido protetiva mencionada anteriormente. Quanto menos estequiométrico é o carbeto (principalmente o que ocorre nos monocarbetos), mais fácil é essa incorporação do oxigênio nos sítios vacantes.

No caso específico do NbC, os resultados de Shimada (1994) mostram que a reação de oxidação tanto do pó, como de monocristais de $\mathrm{NbC}$ essencialmente é baseada em uma reação controlada por contorno de fase.

Esse resultado é corroborado por Connoley, Starink e Reed (2000), que mostraram o efeito da oxidação de carbetos na resistência à iniciação de trincas por fadiga na liga Inconel 718. A presença do $\mathrm{NbC}$ e do $\mathrm{TiC}$ como reforço da matriz metálica durante o tratamento térmico causou a formação de trincas, geradas por uma expansão volumétrica decorrente da oxidação dos carbetos. A interface óxido/carbeto criada durante o tratamento térmico da liga proveu um caminho de difusão preferencial do oxigênio, criando um processo contínuo de oxidação dos carbetos. Como consequência, empilhavam-se camadas de óxido causando erupções em forma de "torre" e outros formatos irregulares, que ao expandir, geravam tensões na vizinhança e acabavam por formar trincas na matriz. $O$ crescimento contínuo dessas erupções causadas pela oxidação dos carbetos em um eixo preferencial promoveu a degradação das propriedades mecânicas da liga metálica em estudo.

As temperaturas em que os picos de oxidação e as perdas de massa ocorrem na análise térmica são muito sensíveis a diversos parâmetros experimentais. Uma vez que, na amostra estudada, as partículas de NbC estão aglomeradas com partículas de $\mathrm{Al}_{2} \mathrm{O}_{3}$, espera-se que haja um perfil um pouco diferente do encontrado na literatura para o $\mathrm{NbC}$ comercial e sintetizado em laboratório. A presença da $\mathrm{Al}_{2} \mathrm{O}_{3}$, embora estável, afeta o comportamento calorimétrico e termogravimétrico do $\mathrm{NbC}$; no entanto, os resultados apresentados estão de acordo com a sequência proposta na literatura, por diversos autores (SHEVCHENKO et al., 1980; SHIMADA, INAGAKI, 1993).

Shevchenko et al. (1980) ressaltam que os mecanismos de oxidação dos carbetos de metais de transição consistem de uma série de reações paralelas e consecutivas, cujas taxas relativas dependem das condições experimentais, tais como pressão parcial de $\mathrm{O}_{2}$ no equilíbrio, e temperatura. Além disso, a composição e as características das amostras, como a razão carbono/metal, a densidade, 
quantidade de impurezas, entre outras características, são determinantes para o comportamento desses mecanismos. Isso explica a falta de concordância entre autores em diversos aspectos do estudo da oxidação dos carbetos. Não obstante, as quantidades de produtos intermediários formados nesses processos são muito pequenas e frequentemente de difícil detecção, e possíveis deformações apreciáveis da rede cristalina das espécies envolvidas tornam ainda maior o desafio do completo entendimento desses mecanismos.

5.2.2 Caracterização dos nanocompósitos de $\mathrm{t}-\mathrm{ZrO}_{2} / \mathrm{Al}_{2} \mathrm{O}_{3}-\mathrm{NbC}$ sinterizados convencionalmente

A Figura 39 mostra as curvas de retração linear e taxa de retração linear versus temperatura do nanocompósito $\mathrm{ZrO}_{2} / \mathrm{Al}_{2} \mathrm{O}_{3}-\mathrm{NbC}$ obtidas pelo ensaio de dilatometria.

É importante ressaltar que, para um compósito com $5 \%$ em volume da mistura $\mathrm{Al}_{2} \mathrm{O}_{3}-\mathrm{NbC}$ na matriz de $\mathrm{t}-\mathrm{ZrO}_{2}$, a proporção volumétrica de fase resulta em $95 \%$ em volume de $\mathrm{t}-\mathrm{ZrO}_{2}, 2,83 \%$ em volume de $\mathrm{Al}_{2} \mathrm{O}_{3}$ e $2,17 \%$ em volume de $\mathrm{NbC}$. Esta proporção entre as fases corresponde à proporção calculada com base na porcentagens de fase obtidas pela $\mathrm{DRX}$ do pó de $\mathrm{Al}_{2} \mathrm{O}_{3}-\mathrm{NbC}$.

Figura 39 - Curvas de retração linear e taxa de retração linear versus temperatura do nanocompósito $\mathrm{t}-\mathrm{ZrO}_{2} / \mathrm{Al}_{2} \mathrm{O}_{3}-\mathrm{NbC}$ sinterizado convencionalmente, obtidas pelo ensaio de dilatometria em fluxo de ar sintético.

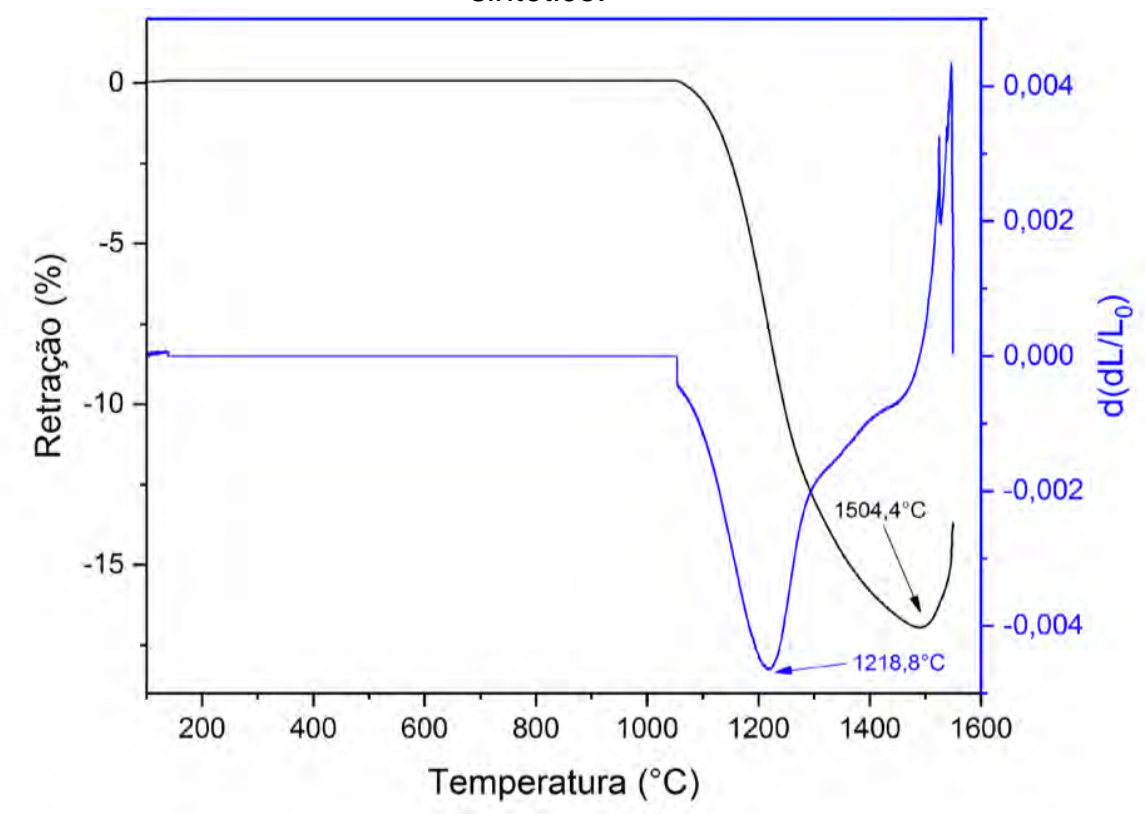


A retração linear para a amostra ensaiada chegou a $16,94 \%$ à temperatura de $1490,9^{\circ} \mathrm{C}$. A partir desta temperatura, houve uma expansão linear, retornando a um valor de $13,70 \%$ de retração (expansão de $3,24 \%$ ), à temperatura de $1549,1^{\circ} \mathrm{C}$, que foi o limite do ensaio e da coleta de dados. A curva de taxa de retração versus temperatura indicou $1218,8^{\circ} \mathrm{C}$ como sendo a temperatura de máxima taxa de retração linear. Com base neste estudo, foram selecionadas as temperaturas de $1400^{\circ} \mathrm{C}, 1450^{\circ} \mathrm{C}, 1500^{\circ} \mathrm{C}$ e $1600^{\circ} \mathrm{C}$ para a sinterização convencional do nanocompósito, uma vez que para a técnica de SPS foram selecionadas as temperaturas de $1300^{\circ} \mathrm{C}, 1350^{\circ} \mathrm{C}$ e $1400^{\circ} \mathrm{C}$.

A expansão linear que ocorre após uma ligeira estabilização da retração linear, a uma temperatura próxima de $1504,4^{\circ} \mathrm{C}$, pode estar relacionada com uma oxidação parcial do $\mathrm{NbC}$ presente nos nanocompósitos, e consequentes fenômenos que serão discutidos ao longo desta Seção. Como exposto na Seção 5.2.1, o NbC é uma espécie fortemente sujeita à oxidação em ar, processo no qual os complexos mecanismos de oxidação ocorrem por etapas (SHEVCHENKO et al., 1980; SHIMADA, 1994), formando um empilhamento de camadas de $\mathrm{Nb}_{2} \mathrm{O}_{5}$ formando colunas e acarretando uma expansão volumétrica significativa. A oxidação, dependendo das condições de processamento e da composição do material do qual o $\mathrm{NbC}$ faz parte, pode ter um grau de severidade tal que pode se tornar um processo catastrófico, incorrendo na degradação de propriedades do compósito (CONNOLEY, STARINK, REED, 2000A). Considerando que a t-ZrO 2 é uma matriz frágil, perante os casos em que a matriz é metálica (dúctil), a oxidação do $\mathrm{NbC}$, ainda que em pequena quantidade acompanhada pela expansão volumétrica, pode comprometer a microestrutura do material, degradando suas propriedades mecânicas. A uma temperatura próxima de $1504,4^{\circ} \mathrm{C}$, em que se nota a expansão linear do material de forma significativa pela curva de retração, observam-se dois picos compridos e estreitos na curva de taxa de retração, indicando que está ocorrendo um processo rápido e em etapas. No entanto, a temperatura é muito superior à relatada na literatura para o início da oxidação do $\mathrm{NbC}$. A princípio, esse fato poderia ser explicado pela "proteção" conferida pela matriz e pela dispersão das nanopartículas de $\mathrm{NbC}$, que, de certa forma, "retardam" o início do processo, porém, não o evitam. Diante da impossibilidade de realizar o ensaio de dilatometria com a proteção de grafite utilizada na sinterização convencional dos nanocompósitos $\mathrm{t}-\mathrm{ZrO}_{2} / \mathrm{Al}_{2} \mathrm{O}_{3}-\mathrm{NbC}$ 
estudados neste trabalho, é possível afirmar que a proteção de grafite seja um adendo na prevenção dessa oxidação inerente ao material.

A Tabela 8 mostra as densidades relativas (\%DT) e as propriedades mecânicas dos nanocompósitos $\mathrm{t}-\mathrm{ZrO}_{2} / \mathrm{Al}_{2} \mathrm{O}_{3}-\mathrm{NbC}$ sinterizados convencionalmente.

Tabela 8 - Valores de densidade relativas (\%DT) e propriedades mecânicas dos nanocompósitos t$\mathrm{ZrO}_{2} / \mathrm{Al}_{2} \mathrm{O}_{3}-\mathrm{NbC}$ sinterizados convencionalmente.

\begin{tabular}{c|c|c|c|c}
\hline \multirow{2}{*}{ Propriedades } & \multicolumn{3}{|c}{ Temperatura de sinterização $\left({ }^{\circ} \mathbf{C}\right)$} \\
\cline { 2 - 5 } & $\mathbf{1 4 0 0}$ & $\mathbf{1 4 5 0}$ & $\mathbf{1 5 0 0}$ & $\mathbf{1 6 0 0}$ \\
\hline $\begin{array}{c}\text { Densidade aparente } \\
\text { (\%DT) }\end{array}$ & $95,8 \pm 0,2$ & $97,5 \pm 0,3$ & $96,7 \pm 1,2$ & $94,5 \pm 0,3$ \\
\hline $\begin{array}{c}\text { Dureza } \\
\text { (GPa) }\end{array}$ & $9,8 \pm 0,3$ & $10,8 \pm 0,4$ & $13,2 \pm 0,3$ & $11,0 \pm 0,3$ \\
\hline $\begin{array}{c}\text { Módulo de Young } \\
\text { (GPa) }\end{array}$ & $219 \pm 9,0$ & $225 \pm 3,0$ & $230 \pm 4,0$ & $220 \pm 12,0$ \\
\hline $\begin{array}{c}\text { Tenacidade } \\
\text { (MPa.m1/2) }\end{array}$ & $8,1 \pm 1,1$ & $8,7 \pm 1,2$ & $6,5 \pm 0,3$ & $4,3 \pm 0,9$ \\
\hline
\end{tabular}

${ }^{*}$ Nota: as amostras sinterizadas a $1600^{\circ} \mathrm{C}$ foram testadas com carga de $1,962 \mathrm{~N}(0,2 \mathrm{kgf})$ para microdureza e 19,62 N (1 kgf) para tenacidade à fratura, pois as cargas utilizadas nas demais amostras não puderam ser utilizadas devido à fragilidade do material.

A menor densidade obtida foi a $1600^{\circ} \mathrm{C}$, de $94,5 \pm 0,3 \% \mathrm{DT}$, e a $1450^{\circ} \mathrm{C}$ a

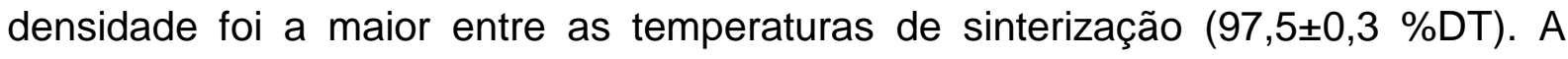
temperatura de $1500^{\circ} \mathrm{C}$ teve uma densidade relativa intermediária, provavelmente relacionada a algum processo de oxidação do $\mathrm{NbC}$ presente nos nanocompósitos. Essa redução na densidade à temperatura de $1600^{\circ} \mathrm{C}$ foi ainda mais pronunciada, confirmando a hipótese de oxidação do $\mathrm{NbC}$, em conjunto com o resultado de dilatometria, que mostra uma expansão significativa acima de $1490,9^{\circ} \mathrm{C}$. Com exceção da ressalva referente à oxidação do $\mathrm{NbC}$, de modo geral, os nanocompósitos tiveram boa densificação, porém menor do que os compósitos t$\mathrm{ZrO}_{2} / \mathrm{Al}_{2} \mathrm{O}_{3}$ sinterizados convencionalmente, que apresentaram como densidade mais baixa o valor de $97,4 \pm 0,2 \% \mathrm{DT}$ para o compósito $\mathrm{t}-\mathrm{ZrO}_{2} / 15 \%$ vol $\mathrm{Al}_{2} \mathrm{O}_{3}$ sinterizado a $1350^{\circ} \mathrm{C}$. Apesar das densidades relativas obtidas poderem ser consideradas altas, as temperaturas de sinterização selecionadas foram bem superiores à temperatura de máxima taxa de densificação determinada pela dilatometria. Com base nisso, pode-se afirmar que as nanopartículas de $\mathrm{Al}_{2} \mathrm{O}_{3}-\mathrm{NbC}$ tiveram um papel limitador na densificação do material no estágio final de sinterização, tornando-a mais difícil em face da sua alta refratariedade e estabilidade química. 
É importante ressaltar que os valores dos módulos de Young medidos pela técnica de nanoindentação foram bastante semelhantes aos calculados pela Equação 8 e descritos na Tabela 3 para a t- $\mathrm{ZrO}_{2}$ e os compósitos $\mathrm{t}-\mathrm{ZrO}_{2} / \mathrm{Al}_{2} \mathrm{O}_{3}$. Este fato confirma a proximidade entre os valores teóricos e medidos experimentalmente, considerando-se que pouca é a influência da presença do $\mathrm{NbC}$ na microestrutura na quantidade estudada.

Ademais do que já foi discutido sobre a influência da $\mathrm{Al}_{2} \mathrm{O}_{3}$ na densificação da matriz de t-ZrO2 (Seção 5.1.1), a influência do $\mathrm{NbC}$ na cinética de sinterização de compósitos de matriz cerâmica tem sido relatada por diversos autores. Coutinho (2004), estudando a sinterização de compósitos de matriz de $\mathrm{Si}_{3} \mathrm{~N}_{4}$ com adição de $\mathrm{TiC}, \mathrm{SiC}, \mathrm{TaC}$ e NbC, em forno com resistência de grafite, mostra que a presença das partículas de $\mathrm{NbC}$ dificulta o processo de sinterização via fase líquida do compósito, não reagindo com a matriz, tampouco com os aditivos de sinterização. No entanto, em comparação com a adição de SiC e TiC, o grau de dificuldade da sinterização imposto pela presença do NbC não limita tanto a densificação do material. Isso é devido ao fato de não formar fases metaestáveis, sendo seu efeito de supressão de crescimento de grão fundamentalmente baseado na sua distribuição nos pontos tríplices (e eventualmente no interior dos grãos), e na pouca interação com a vizinhança. Hernandes (2006), estudando a sinterização de compósitos $\mathrm{Al}_{2} \mathrm{O}_{3} / \mathrm{NbC}$ com frações volumétricas de $\mathrm{NbC}$ de 1,3 e $5 \%$, também relata que, mesmo em pequenas quantidades, o $\mathrm{NbC}$ exerce forte efeito na sinterabilidade dos materiais estudados, sendo, no caso da matriz de $\mathrm{Al}_{2} \mathrm{O}_{3}$, um obstáculo para a densificação do material. Por outro lado, Santos et al. (2008), estudando compósitos de $\mathrm{t}-\mathrm{ZrO}_{2} / \mathrm{NbC}$ obtidos por hot-pressing, obtiveram densificação superior a $99 \%$ DT a $1600^{\circ} \mathrm{C}$.

A Figura 40 mostra as micrografias obtidas por MEV das superfícies de fratura dos nanocompósitos $\mathrm{t}-\mathrm{ZrO}_{2} / \mathrm{Al}_{2} \mathrm{O}_{3}-\mathrm{NbC}$ sinterizados convencionalmente a $1400^{\circ} \mathrm{C}$, $1450^{\circ} \mathrm{C}$ e $1500^{\circ} \mathrm{C}$. As micrografias do nanocompósito sinterizado a $1600^{\circ} \mathrm{C}$ serão apresentadas posteriormente. 
Figura 40 - Micrografias obtidas por MEV das superfícies de fratura dos nanocompósitos $\mathrm{t}-\mathrm{ZrO}_{2} / \mathrm{Al}_{2} \mathrm{O}_{3}$ $\mathrm{NbC}$ sinterizados convencionalmente a: (a) $1400^{\circ} \mathrm{C} / 2 \mathrm{~h}$; (b) $1450^{\circ} \mathrm{C} / 2 \mathrm{~h}$; (c) $1500^{\circ} \mathrm{C} / 2 \mathrm{~h}$.
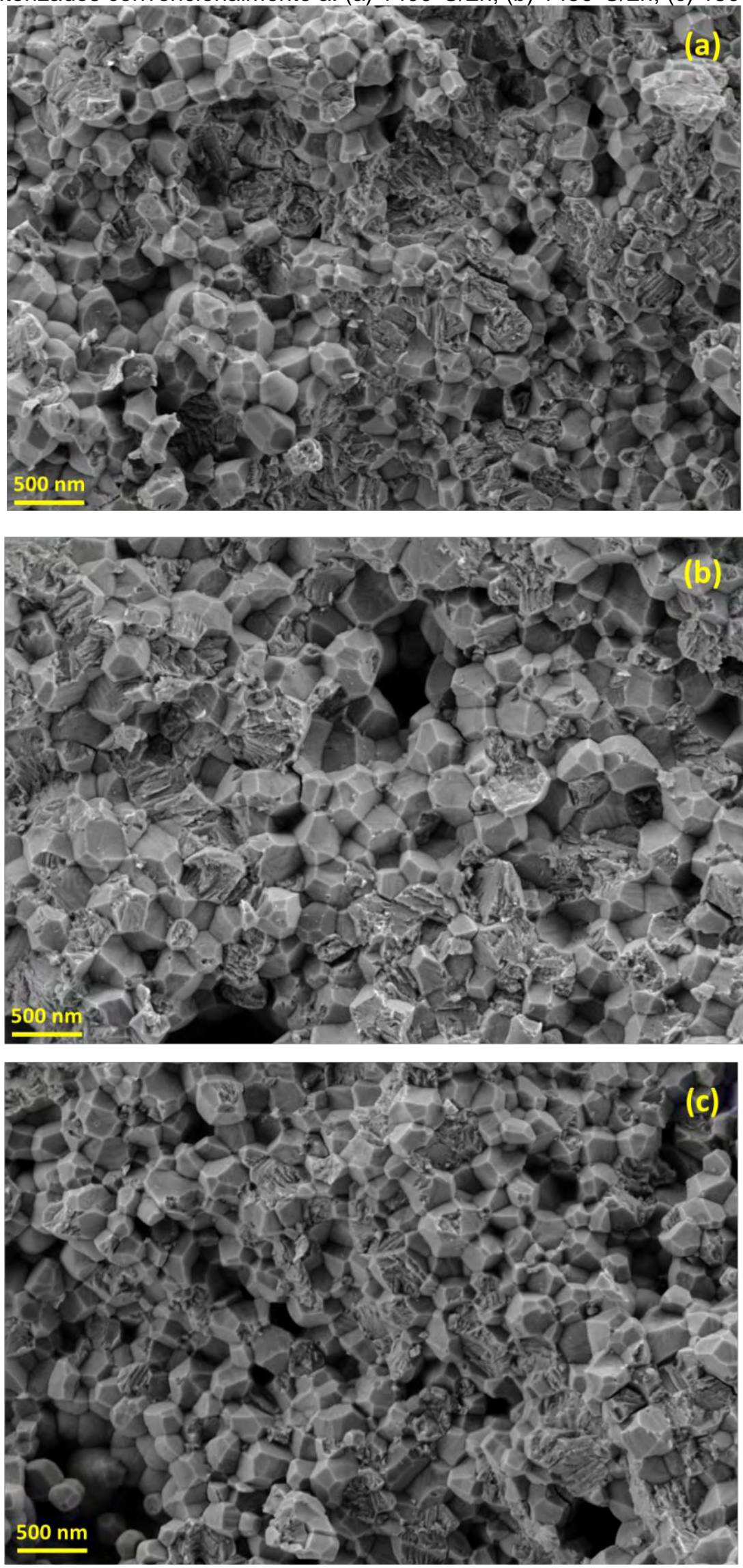
Nesta faixa de temperaturas, observa-se uma superfície de fratura composta de grãos submicrométricos, com nanogrãos dispersos nos contornos de grão de dentro dos grãos da matriz. Estes nanogrãos possuem diâmetros inferiores a $70 \mathrm{~nm}$ e são correspondentes às fases $\mathrm{Al}_{2} \mathrm{O}_{3}$ e $\mathrm{NbC}$ dispersas na matriz. Observa-se também alguma porosidade, ainda que em pequena quantidade. É interessante ressaltar que o modo de fratura é um misto de fratura intergranular e intragranular em todas as temperaturas para os nanocompósitos sinterizados convencionalmente.

A Figura 41 mostra as micrografias obtidas por MEV da superfície polida do nanocompósito de $\mathrm{t}-\mathrm{ZrO}_{2} / \mathrm{Al}_{2} \mathrm{O}_{3}-\mathrm{NbC}$ sinterizado a $1400^{\circ} \mathrm{C}$ e atacada termicamente em atmosfera de argônio.

Figura 41 - Micrografia da superfície polida do nanocompósito $\mathrm{t}-\mathrm{ZrO}_{2} / \mathrm{Al}_{2} \mathrm{O}_{3}-\mathrm{NbC}$ sinterizado convencionalmente a $1400^{\circ} \mathrm{C} / 2 \mathrm{~h}$ : (a) com menor aumento; (b) com maior aumento.

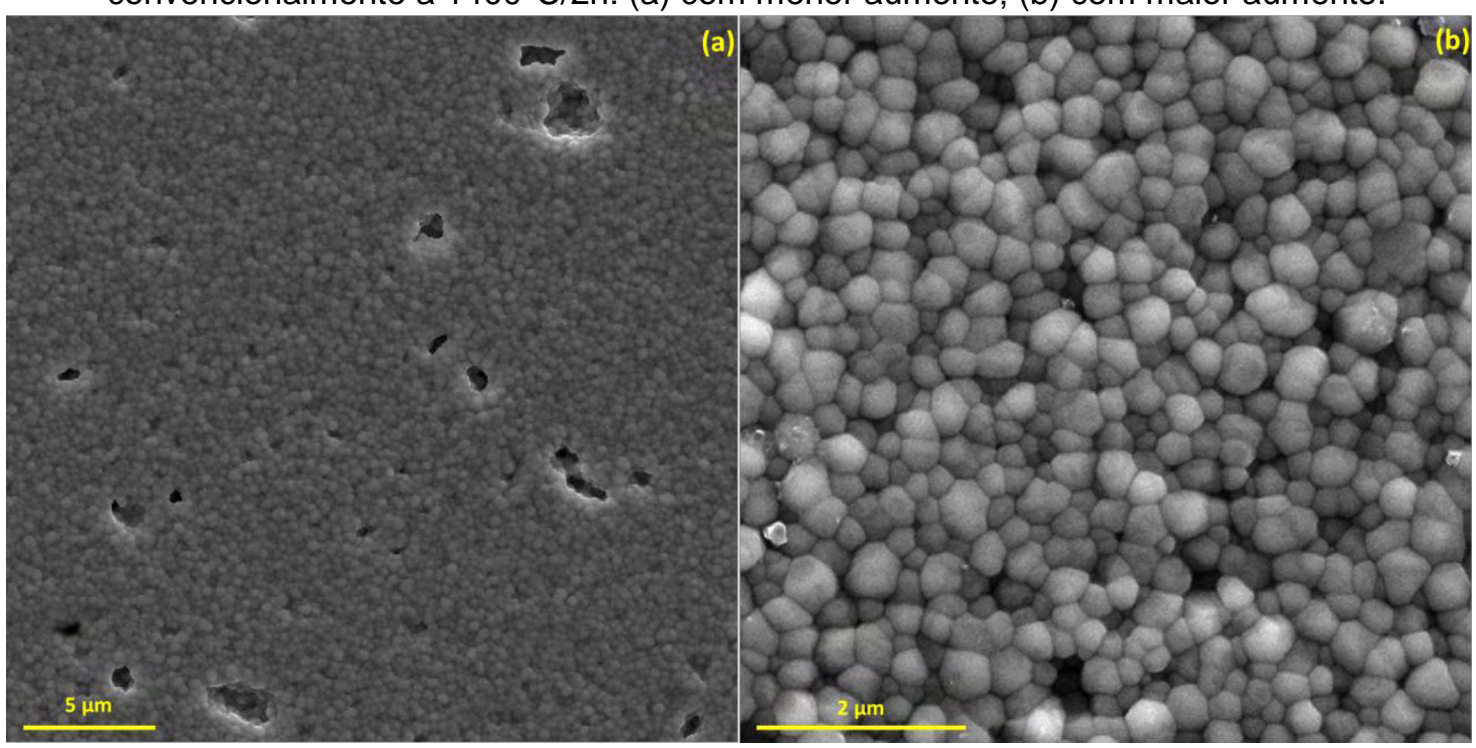

Pela micrografia da superfície polida, é possível observar o grau de porosidade e tamanho dos poros, bem como o tamanho e formato dos grãos. $\mathrm{Na}$ Figura 41(b), com maior aumento, observam-se grãos mais escuros (pretos) que correspondem a grãos de $\mathrm{Al}_{2} \mathrm{O}_{3}$ que tiveram um crescimento maior, tendo tamanho igual ou maior do que a média do tamanho de grão da matriz.

Comparando-se as micrografias da superfície polida do nanocompósito sinterizado a $1400^{\circ} \mathrm{C} / 2 \mathrm{~h}$ (Figura 41 ) e a da superfície de fratura (Figura 40), observase que nas superfícies polidas é mais difícil identificar o $\mathrm{NbC}$, que está alojado no contorno de grão e no interior dos grãos. Por outro lado, no caso da micrografia das superfícies fraturadas, além de se identificar as nanopartículas (pontos mais claros) 
dispersas na matriz, é possível observar sítios em que houve arrancamento dessas partículas.

A Figura 42 mostra as micrografias de fratura de duas diferentes regiões do nancompósito $\mathrm{t}-\mathrm{ZrO}_{2} / \mathrm{Al}_{2} \mathrm{O}_{3}-\mathrm{NbC}$ sinterizado a $1600^{\circ} \mathrm{C}$. Observa-se que essa amostra teve um comportamento peculiar observável a olho nu: ocorreu uma espécie de "inchamento" na direção longitudinal de toda a amostra sinterizada, de forma que esta ficou densa, porém com muitas trincas macroscópicas. Outra amostra teve um trincamento da superfície, fazendo sair uma "camada" facilmente. Isso denota uma expansão volumétrica significativa no processo de sinterização e/ou no resfriamento, que se evidencia por meio da micrografia das superfícies fraturadas. Observa-se na Figura 42(a) que, além de um crescimento de grão muito mais pronunciado do que nas amostras sinterizadas até $1500^{\circ} \mathrm{C}$, houve a nucleação de uma nova fase na forma de nanopartículas agregadas em algumas regiões da microestrutura (destacadas com círculos).

Figura 42 - Micrografias obtidas por MEV da superfície de fratura do nanocompósito $\mathrm{t}-\mathrm{ZrO}_{2} / \mathrm{Al}_{2} \mathrm{O}_{3}-\mathrm{NbC}$ sinterizado em forno convencional a $1600^{\circ} \mathrm{C} / 2 \mathrm{~h}$ : (a) nanopartículas de nova fase formada; (b) eclosão de provável fase líquida.
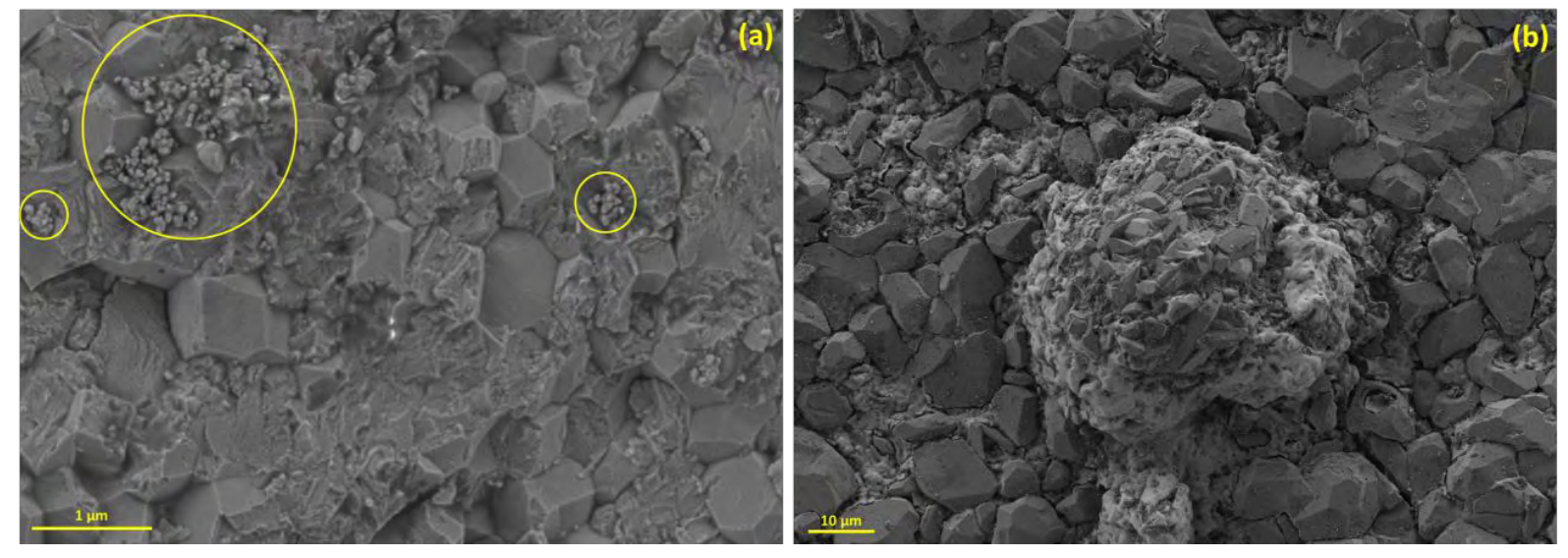

A Figura 42(b) mostra uma região em que houve a "eclosão" de uma fase aparentemente formada por fase líquida solidificada, envolvendo grãos da mesma tonalidade da matriz, porém de tamanho muito menor.

A Figura 43 apresenta as micrografias obtidas por elétrons secundários (Figura 43(a)) e por elétrons retroespalhados (Figura 43(b)) de uma mesma região, na mesma amostra analisada na Figura 42. 
Figura 43 - Micrografias de MEV da região vicinal a uma trinca macroscópica formada espontaneamente no nanocompósito de $\mathrm{t}-\mathrm{ZrO}_{2} / \mathrm{Al}_{2} \mathrm{O}_{3}-\mathrm{NbC}$ sinterizado convencionalmente a $1600^{\circ} \mathrm{C}$ :

(a) imagem de elétrons secundários; (b) imagem de elétrons retroespalhados.
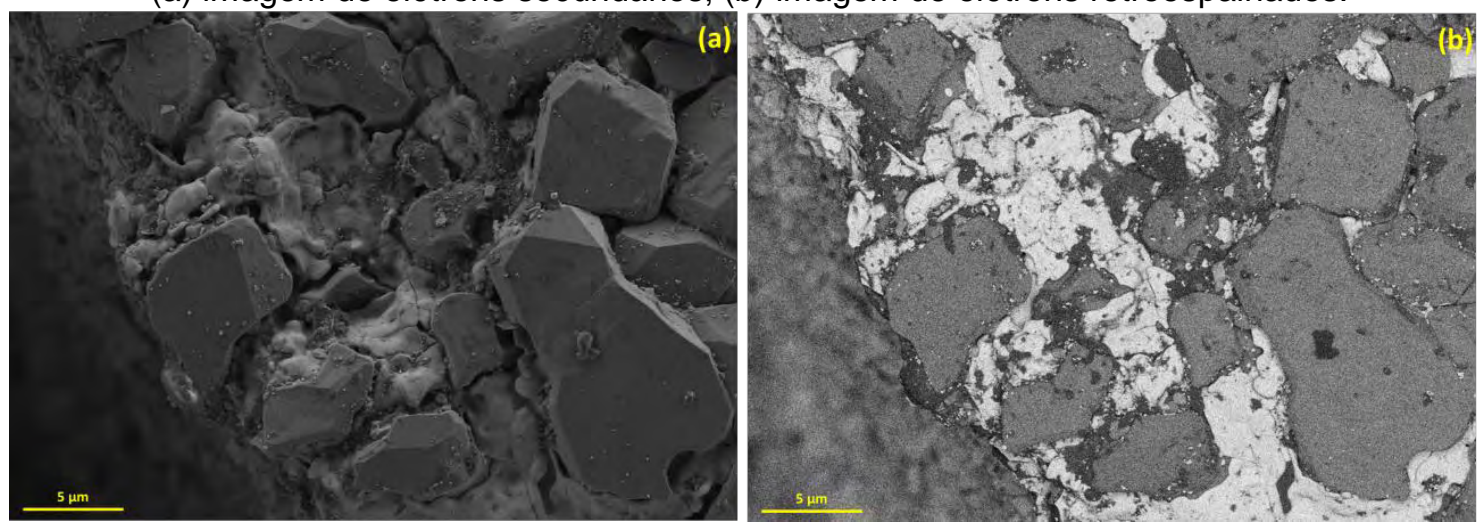

A região mostrada na Figura 43 corresponde a uma zona próxima a uma das trincas macroscópicas que se formou espontaneamente na superfície da amostra, devido à expansão volumétrica. Considerando que as imagens obtidas com elétrons retroespalhados priorizam o contraste por composição, na Figura 43(b), a região com tonalidade mais clara corresponde na Figura 43(a) ao que se assemelha a uma fase líquida envolvendo os grãos de tonalidade média (provavelmente da matriz), e com regiões mais escuras, que são provavelmente zonas ricas em $\mathrm{Al}_{2} \mathrm{O}_{3}$.

Essas significativas alterações na microestrutura do material sinterizado a $1600^{\circ} \mathrm{C}$, pode estar associada à significativa oxidação do $\mathrm{NbC}$ e à consequente formação do óxido de nióbio, o qual reage com a $\mathrm{Al}_{2} \mathrm{O}_{3}$ com ponto de eutético (Figura 44) em torno de $1425^{\circ} \mathrm{C}$ (ROTH et al., 1981; HERNANDES, 2007), levando à formação de fase líquida nos contornos de grãos durante a sinterização, sendo essa fase um niobato de alumínio de estequiometria variável. Além disso, essa formação de fase líquida parece eclodir de forma abrupta também a partir do interior dos grãos, gerando trincas que culminaram em uma fragilização de toda a amostra. Assim, tendo em vista uma oxidação considerável do NbC na amostra sinterizada a $1600^{\circ} \mathrm{C}$, não se pode afirmar se a sua densidade relativa é real, uma vez que muda a composição e a densidade teórica do material, não sendo possível precisá-la com o método utilizado. O crescimento de grão da matriz de $\mathrm{t}-\mathrm{ZrO}_{2}$, muito mais pronunciado na amostra sinterizada a $1600^{\circ} \mathrm{C}$, também é um fator que sugere a interrupção da ação das nanopartículas de $\mathrm{NbC}$ e de $\mathrm{Al}_{2} \mathrm{O}_{3}$ na supressão do crescimento de grão, uma vez que a maior parte dessas fases pode ter formado o líquido que se espalhou e mudou completamente os mecanismos de sinterização atuantes nesta condição. 
A Figura 44 apresenta o diagrama de equilíbrio do sistema $\mathrm{Al}_{2} \mathrm{O}_{3}-\mathrm{Nb}_{2} \mathrm{O}_{5}$. Considerando-se que à temperatura em torno de $1425^{\circ} \mathrm{C}$ já se identifica a formação de eutético, é provável a presença desse fenômeno em áreas pontuais dos nanocompósitos sinterizados a $1450^{\circ} \mathrm{C}$ e a $1500^{\circ} \mathrm{C}$. Porém, tais alterações não foram identificadas nas micrografias analisadas.

Figura 44 - Diagrama de equilíbrio do sistema $\mathrm{Al}_{2} \mathrm{O}_{3}-\mathrm{Nb}_{2} \mathrm{O}_{5}$, sendo $\mathrm{AN}$ : $\mathrm{AlNbO}_{4}, \mathrm{AN}_{11}$ : $\mathrm{AlNb}_{11} \mathrm{O}_{29} \mathrm{e}$ $\mathrm{AN}_{49}: \mathrm{AlNb}_{49} \mathrm{O}_{124}$.

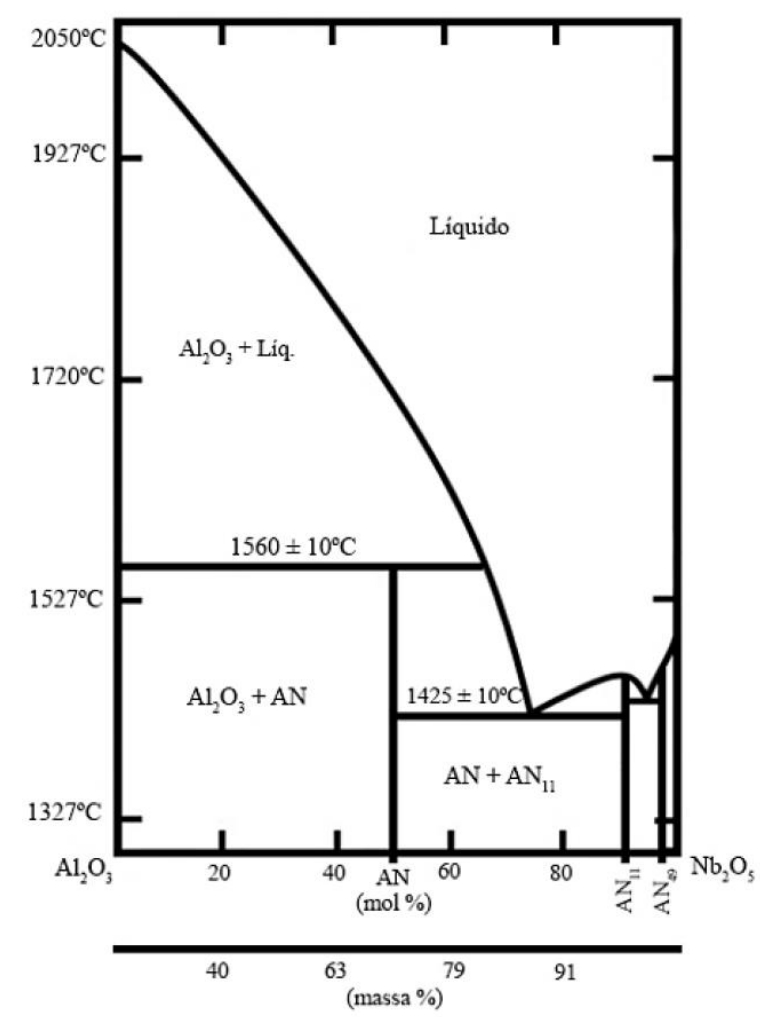

Fonte: Adaptado de ROTH, R.; NEGAS, T.; COOK, L. Phase diagrams for ceramists. Columbus: The American Ceramic Society, 1981, v. 4, p. 117.

Os nanocompósitos sinterizados a $1400^{\circ} \mathrm{C}$ e a $1450^{\circ} \mathrm{C}$ tiveram valores baixos de dureza em relação à $\mathrm{t}-\mathrm{ZrO}_{2}$. Com o aumento da temperatura de sinterização, houve um aumento na dureza dos nanocompósitos, até a temperatura de $1500^{\circ} \mathrm{C}$. No entanto, a dureza em todas as faixas de temperatura foi menor ou próxima da t$\mathrm{ZrO}_{2}$ e dos compósitos $\mathrm{t}-\mathrm{ZrO}_{2} / \mathrm{Al}_{2} \mathrm{O}_{3}$. Porém, os nanocompósitos sinterizados a $1600^{\circ} \mathrm{C}$ apresentaram uma diminuição no valor de dureza. O módulo de Young, determinado por nanoindentação, também teve um ligeiro aumento em função da temperatura de sinterização, exceto na temperatura de $1600^{\circ} \mathrm{C}$. O mesmo aumento da tenacidade à fratura foi observado nos nanocompósitos sinterizados a $1400^{\circ} \mathrm{C}$ e a $1450^{\circ} \mathrm{C}$. O maior valor de tenacidade à fratura foi observado nas nanocompósitos de 
$1450^{\circ} \mathrm{C}$, sendo $8,7 \mathrm{MPa} \cdot \mathrm{m}^{1 / 2}$, praticamente o dobro do valor máximo obtido para a t$\mathrm{ZrO}_{2}$ pura $\left(4,42 \mathrm{MPa} \cdot \mathrm{m}^{1 / 2}, \mathrm{~T}_{\text {sint }}=1500^{\circ} \mathrm{C} / 2 \mathrm{~h}\right)$.

Com base nos resultados obtidos, observa-se que a incorporação do pó de $\mathrm{Al}_{2} \mathrm{O}_{3}-\mathrm{NbC}$ na matriz de $\mathrm{t}-\mathrm{ZrO}_{2}$ provoca uma diferença significativa nas propriedades mecânicas. A dureza, assim como no caso dos compósitos $\mathrm{t}-\mathrm{ZrO}_{2} / \mathrm{Al}_{2} \mathrm{O}_{3}$, é muito suscetível à porosidade existente no material. Apesar de uma relativamente boa densificação, os nanocompósitos sinterizados convencionalmente apresentaram uma densidade máxima de $97,5 \% \mathrm{DT}$ quando sinterizadas a $1450^{\circ} \mathrm{C}$. Já no caso dos nanocompósitos sinterizados a $1500^{\circ} \mathrm{C}$ e a $1600^{\circ} \mathrm{C}$, é provável que a oxidação do $\mathrm{NbC}$ e consequentes reações com a $\mathrm{Al}_{2} \mathrm{O}_{3}$, conforme relatado, tenham sido também fator de influência para as propriedades mecânicas dos nanocompósitos. A tenacidade à fratura diminuiu para $6,5 \mathrm{MPa} \cdot \mathrm{m}^{1 / 2}$ no nanocompósito sinterizado a $1500^{\circ} \mathrm{C}$ e para $4,3 \mathrm{MPa} \cdot \mathrm{m}^{1 / 2}$ no nanocompósito sinterizado a $1600^{\circ} \mathrm{C}$.

As amostras de nanocompósitos sinterizados a $1600^{\circ} \mathrm{C}$, devido às trincas superficiais, foram ensaiadas com cargas menores do que as outras temperaturas. Os valores obtidos corroboram a hipótese de que a oxidação do $\mathrm{NbC}$ e consequente formação de fase líquida degradaram significativamente as propriedades mecânicas do nanocompósito, anulando o efeito das inclusões.

É notório que o valor final de cada propriedade mecânica é influenciado por diversos fatores relacionados ao histórico de processamento do material e sua sinterabilidade.

5.2.3 Caracterização dos nanocompósitos de $\mathrm{t}-\mathrm{ZrO}_{2} / \mathrm{Al}_{2} \mathrm{O}_{3}-\mathrm{NbC}$ sinterizados por SPS

Previamente à sinterização por SPS, a fim de definir as melhores temperaturas de sinterização do nanocompósito de $\mathrm{t}-\mathrm{ZrO}_{2} / \mathrm{Al}_{2} \mathrm{O}_{3}-\mathrm{NbC}$ por esse processo, foi feito um teste inicial até a temperatura de $1600^{\circ} \mathrm{C}$. A Figura 45 apresenta a curva de velocidade e de deslocamento do pistão em função da temperatura durante a sinterização. Neste ciclo, a pressão máxima de $80 \mathrm{MPa}$ foi aplicada entre $1100^{\circ} \mathrm{C}$ e $1400^{\circ} \mathrm{C}$, realizando a compactação do pó. 
Figura 45 - Velocidade e deslocamento do pistão versus temperatura durante a sinterização por SPS dos nanocompósitos de $\mathrm{t}-\mathrm{ZrO}_{2} / \mathrm{Al}_{2} \mathrm{O}_{3}-\mathrm{NbC}$.

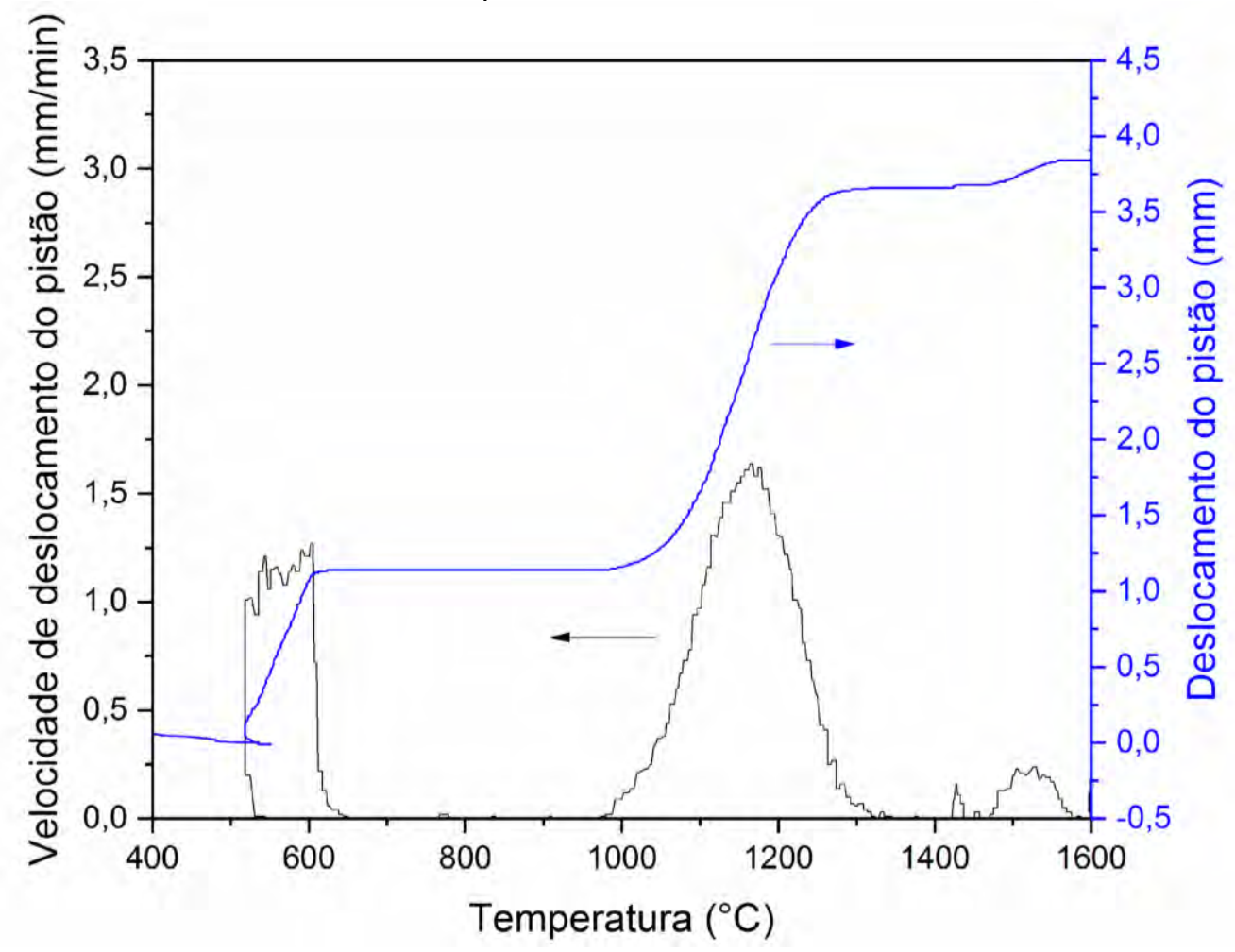

Com base nas curvas de deslocamento e de velocidade de deslocamento versus temperatura, observa-se que na temperatura de $1400^{\circ} \mathrm{C}$, já ocorreu a densificação quase completamente. Sendo assim, foram escolhidas as temperaturas de $1300^{\circ} \mathrm{C}, 1350^{\circ} \mathrm{C}$ e $1400^{\circ} \mathrm{C}$ para o estudo da sinterização por SPS. Também se observa, na faixa de temperatura entre $500^{\circ} \mathrm{C}$ e $650^{\circ} \mathrm{C}$, uma primeira etapa de deslocamento do pistão acompanhada por uma variação na velocidade. Essa característica está relacionada com o início da captação de dados ter sido ativado apenas nesse intervalo de temperaturas.

A Tabela 9 apresenta as propriedades dos nanocompósitos de $\mathrm{t}-\mathrm{ZrO}_{2} / \mathrm{Al}_{2} \mathrm{O}_{3}-$ $\mathrm{NbC}$ sinterizados por SPS. A densidade dos nanocompósitos sinterizados por SPS não variou de forma significativa em função da temperatura, porém todas as temperaturas apresentaram densidades superiores às dos nanocompósitos sinterizados convencionalmente. A dureza aumentou com o acréscimo da temperatura de $1300^{\circ} \mathrm{C}$ para $1350^{\circ} \mathrm{C}$, com ligeira diminuição a $1400^{\circ} \mathrm{C}$.

Da mesma forma que a densidade, a variação do módulo de Young não foi significativa (234-240 GPa), porém foi maior do que os valores medidos para os nanocompósitos sinterizados convencionalmente. Por outro lado, a tenacidade, 
apesar de ter aumentado com a temperatura de sinterização, teve seu máximo valor de 8,1 MPa.m $\mathrm{m}^{1 / 2}$, sendo este inferior ao máximo valor alcançado pelos nanocompósitos sinterizados convencionalmente.

Tabela 9 - Valores de densidade aparente (\%DT) e propriedades mecânicas dos nanocompósitos t$\mathrm{ZrO}_{2} / \mathrm{Al}_{2} \mathrm{O}_{3}-\mathrm{NbC}$ sinterizados por SPS.

\begin{tabular}{c|c|c|c}
\hline \multirow{2}{*}{ Propriedades } & \multicolumn{3}{|c}{ Temperatura de sinterização $\left({ }^{\circ} \mathbf{C}\right)$} \\
\cline { 2 - 4 } & $\mathbf{1 3 0 0}$ & $\mathbf{1 3 5 0}$ & $\mathbf{1 4 0 0}$ \\
\hline $\begin{array}{c}\text { Densidade aparente } \\
(\% \mathrm{OD})\end{array}$ & $98,4 \pm 0,1$ & $98,1 \pm 0,9$ & $98,7 \pm 0,4$ \\
\hline Dureza (GPa) & $11,3 \pm 0,4$ & $12,7 \pm 0,2$ & $12,1 \pm 0,6$ \\
\hline $\begin{array}{c}\text { Módulo de Young } \\
(\mathrm{GPa})\end{array}$ & $237 \pm 3,0$ & $240 \pm 3,0$ & $234 \pm 4,0$ \\
\hline Tenacidade (MPa.m $\left.{ }^{1 / 2}\right)$ & $6,3 \pm 1,0$ & $7,2 \pm 1,4$ & $8,1 \pm 1,9$ \\
\hline
\end{tabular}

A Figura 46 mostra as micrografias obtidas por MEV das superfícies de fratura dos nanocompósitos de $\mathrm{t}-\mathrm{ZrO}_{2} / \mathrm{Al}_{2} \mathrm{O}_{3}-\mathrm{NbC}$ sinterizados a $1300^{\circ} \mathrm{C}, 1350^{\circ} \mathrm{C}$ e $1400^{\circ} \mathrm{C}$, por SPS, usando patamar de $5 \mathrm{~min}$.

As superfícies de fratura dos nanocompósitos sinterizados por SPS apresentam microestruturas muito semelhantes às da maioria dos nanocompósitos sinterizados convencionalmente $\left(\mathrm{a} 1400^{\circ} \mathrm{C}, 1450^{\circ} \mathrm{C}\right.$ e $1500^{\circ} \mathrm{C}$ ). A porosidade é escassa, em uma microestrutura de grãos submicrométricos e de tamanho homogêneo. Observa-se com mais facilidade as nanopartículas de $\mathrm{Al}_{2} \mathrm{O}_{3}-\mathrm{NbC}$ dispersas na microestrutura (pontos claros) e pontos em que houve o arrancamento dessas partículas, nos vértices dos grãos. Diferentemente dos nanocompósitos sinterizados convencionalmente, o modo de fratura predominante observado é intergranular, havendo poucos pontos onde a fratura ocorreu no interior do grão. 
Figura 46 - Micrografias das superfícies de fratura dos nanocompósitos $\mathrm{t}-\mathrm{ZrO}_{2} / \mathrm{Al}_{2} \mathrm{O}_{3}-\mathrm{NbC}$ sinterizados por SPS a: (a) $1300^{\circ} \mathrm{C}$; (b) $1350^{\circ} \mathrm{C}$; (c) $1400^{\circ} \mathrm{C}$.

A Figura 47 apresenta as micrografias de fratura dos nanocompósitos de t$\mathrm{ZrO}_{2} / \mathrm{Al}_{2} \mathrm{O}_{3}-\mathrm{NbC}$ sinterizados convencionalmente (Figura 47(a)) e por SPS (Figura $47\left(\right.$ b)) a $1400^{\circ} \mathrm{C}$, com maior aumento.

Figura 47 - Micrografias das superfícies de fratura dos nanocompósitos de $\mathrm{t}-\mathrm{ZrO}_{2} / \mathrm{Al}_{2} \mathrm{O}_{3}-\mathrm{NbC}$ sinterizados a $1400^{\circ} \mathrm{C}$ : (a) convencionalmente; (b) por SPS.
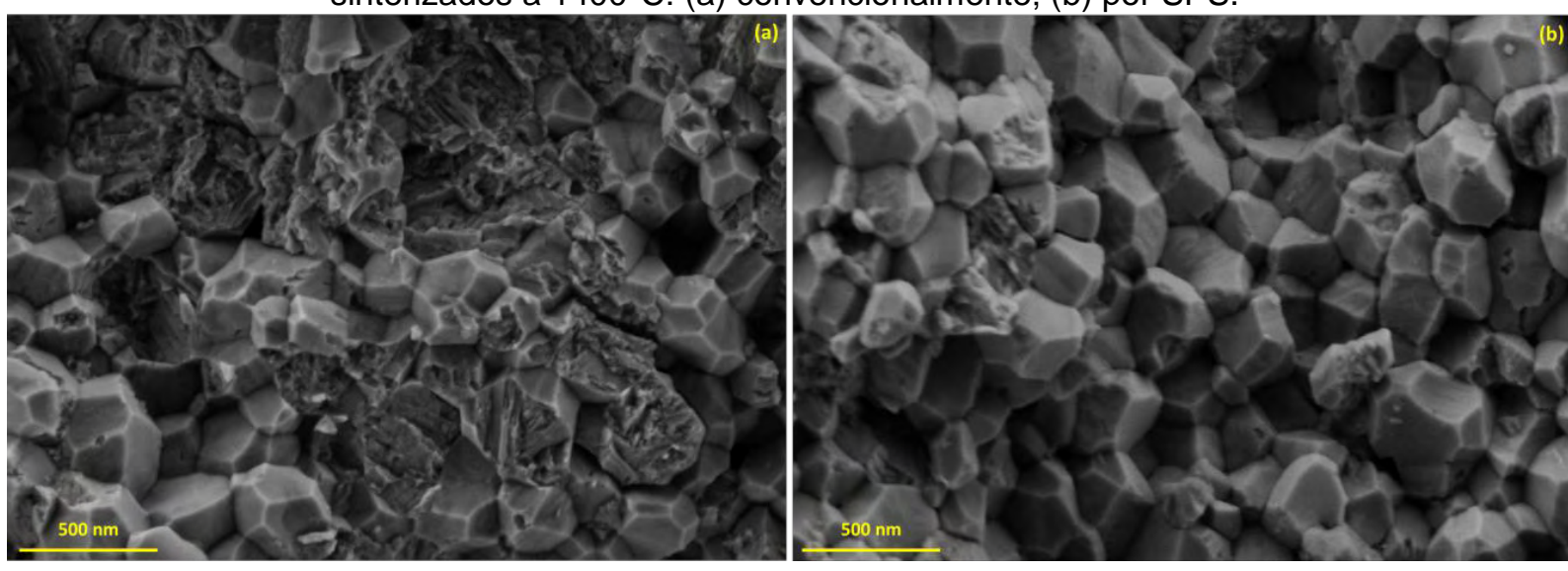

Por meio da comparação da Figura 47, fica mais evidente que o modo de fratura é misto nos nanocompósitos sinterizados convencionalmente e predominantemente intergranular nos sinterizados por SPS. Essa diferença no modo de fratura entre as amostras sinterizadas convencionalmente e por SPS pode estar relacionada à forma da distribuição das partículas de segunda fase na microestrutura. A pressão aplicada durante a sinterização por SPS, associada à rapidez do processo de densificação, podem ter favorecido diferentes mecanismos de difusão durante a sinterização, em relação aos nanocompósitos sinterizados convencionalmente, o que pode ter feito variar a fração relativa de nanopartículas de segunda fase no interior dos grãos e nos contornos de grão, dessa forma favorecendo um ou outro modo de fratura (OVID'KO, 2015; CHEN et al., 2016).

Isso também pode ser notado pela diferença de quantidade de partículas visíveis nos contornos de grão entre as duas sinterizações: no caso da SPS, é maior a quantidade das nanopartículas visíveis entre os contornos de grão, bem como seus vestígios que ficaram nos vértices do grão por decorrência da fratura, enquanto esse fenômeno é pouco observado nos nanocompósitos sinterizados convencionalmente. Os efeitos dessa diferença entre as técnicas de sinterização serão discutidos a seguir, onde serão apresentados os resultados dos ensaios de desgaste pelo método esfera-no-disco para os nanocompósitos. 
5.2.3.1 Caracterização da resistência ao desgaste dos nanocompósitos de t- $\mathrm{ZrO}_{2} /$ $\mathrm{Al}_{2} \mathrm{O}_{3}-\mathrm{NbC}$

Esta seção trata da análise dos resultados dos ensaios de desgaste pelo método esfera-no-disco realizados nos nanocompósitos $t-\mathrm{ZrO}_{2} / \mathrm{Al}_{2} \mathrm{O}_{3}-\mathrm{NbC}$ sinterizados em forno convencional e por SPS, utilizando contramateriais (bolas) de $\mathrm{Al}_{2} \mathrm{O}_{3}$ e de WC-6\%Co. Primeiramente, serão expostos os resultados dos coeficientes de fricção, seguidos pelas taxas de desgaste e da análise das micrografias das regiões desgastadas. Finalmente, será feita a classificação dos regimes de desgaste, com base nas taxas de desgaste e na análise dos mecanismos de desgaste identificados por meio da análise das superficies desgastadas.

\subsection{Coeficientes de fricção}

A Figura 48 apresenta as médias dos coeficientes de fricção obtidos durante o ensaio de desgaste usando carga de $15 \mathrm{~N}$ dos nanocompósitos t- $\mathrm{ZrO}_{2} / \mathrm{Al}_{2} \mathrm{O}_{3}-\mathrm{NbC}$, sinterizados nas diferentes condições, com contramateriais de $\mathrm{Al}_{2} \mathrm{O}_{3}$ e de WC$6 \%$ Co. A força de fricção foi medida ao longo de todo o ensaio, utilizando uma célula de carga com um transdutor piezoelétrico no braço de carga.

Figura 48 - Coeficiente de fricção dos nanocompósitos $\mathrm{t}-\mathrm{ZrO}_{2} / \mathrm{Al}_{2} \mathrm{O}_{3}-\mathrm{NbC}$ ensaiados com esferas de $\mathrm{Al}_{2} \mathrm{O}_{3}$ e de WC-6\%Co e carga de $15 \mathrm{~N}$.



Nota: SC = Sinterização convencional. Desvio padrão inferior a $5 \%$ em todos os casos. 
Pela Figura 48, observa-se que os coeficientes de friç̧ão tiveram uma variação significativa em função do contramaterial, e da temperatura e do tipo de sinterização. Apenas o nanocompósito sinterizado por SPS a $1350^{\circ} \mathrm{C}$ teve um coeficiente de fricção maior quando ensaiada com bolas de $\mathrm{Al}_{2} \mathrm{O}_{3}$ do que quando ensaiados com bolas de WC-6\%Co, comportamento contrário do observado com as demais amostras. De modo geral, a fricção foi mais alta no tribopar nanocompósito/WC-6\%Co.

Um dos fatores preponderantes na dimensão dos coeficientes de fricção é a relação entre a dureza do material ensaiado e do contramaterial. De acordo com Bayer (2004), a dureza e a densidade de um material são diretamente proporcionais à sua resistência ao desgaste, uma vez que tais propriedades aumentam a resistência à fricção e ao arrancamento de grãos. No entanto, os valores obtidos de coeficiente de friç̧ão foram, de modo geral, menores para os nanocompósitos sinterizados convencionalmente, ainda que tenha havido significativa diferença nas durezas e densidades com relação aos nanocompósitos sinterizados por SPS, como demonstrado nas Tabelas 8 e 9.

Os coeficientes de fricção, além de dependerem da dureza e da densidade dos materiais que foram o tribopar, são fortemente dependentes da carga e da velocidade de ensaio (ZUM GAHR, 1989).

Ambos os contramateriais utilizados são mais duros do que os nanocompósitos $\mathrm{t}-\mathrm{ZrO}_{2} / 5 \%$ vol $\mathrm{Al}_{2} \mathrm{O}_{3}$. As durezas medidas para os contramateriais foram de $1970 \mathrm{HV} 30$ para a esfera de $\mathrm{Al}_{2} \mathrm{O}_{3}$ e $1680 \mathrm{HV} 30$ para a esfera de WC$6 \%$ Co. Quanto maior a dureza da esfera em relação ao material ensaiado, espera-se que maior seja o coeficiente de fricção e o desgaste da esfera (ZUM GAHR, 1989). No entanto, o coeficiente de fricção foi mais alto nos ensaios com esfera de WC$6 \%$ Co, enquanto a taxa de desgaste foi menor, quando comparado com os ensaios feitos com esfera de $\mathrm{Al}_{2} \mathrm{O}_{3}$, como será mostrado a seguir.

\subsection{Taxa de desgaste}

A classificação dos regimes de desgaste em função da taxa de desgaste é ainda discutida na literatura (TEDESCO, 2010). A condição limite entre os regimes moderado e severo de desgaste não é exatamente definida, sendo caracterizada pela rugosidade e demais características da superfície desgastada. A condição 
crítica para a transição entre os dois regimes é a fratura frágil, a qual se deve a aspectos mecânicos e técnicos. Considerando-se que, para viabilizar a aplicação tribológica dos materiais cerâmicos, é essencial que exista uma condição em que haja resistência ao desgaste e superfícies lisas que possam ser mantidas ao longo do uso, acredita-se que essa seja a condição de desgaste moderado (KATO, ADACHI, 2002; PASARIBU, SLOETJES, SCHIPPER, 2004). Em termos de taxa de desgaste, consideram-se como desgaste moderado os casos em que a taxa de desgaste não ultrapassa os $10^{-6} \mathrm{~mm}^{3}$.(N.m) $)^{-1}$, enquanto valores superiores a esse são classificados como desgaste severo. Quanto ao regime de transição, alguns autores reportaram que taxa de desgaste para essa região se encontra entre $10^{-4} \mathrm{e}$ $10^{-6} \mathrm{~mm}^{3}$.(N.m) ${ }^{-1}$, porém não há um consenso em relação à superfície de desgaste para este regime (TEDESCO, 2010; PASARIBU, SLOETJES, SCHIPPER, 2004).

Portanto, para a correta determinação dos regimes de desgaste nas condições analisadas, é necessária a confrontação dos resultados calculados de taxa de desgaste com as micrografias das superfícies de desgaste, a fim de identificar os mecanismos atuantes e predominantes, dessa forma podendo classificar os regimes com maior precisão (ALECRIM et al., 2017b).

A Tabela 10 apresenta os valores de taxa de desgaste dos materiais ensaiados, calculados com base na perda de volume de material durante o ensaio (Equações 10 e 11). Além disso, é exposto o regime de desgaste para cada amostra, determinado com base nos valores de taxa de desgaste calculados. A princípio, para efeitos de classificação de regime de desgaste, consideraram-se como regime moderado as taxas de desgaste inferiores a $10^{-6} \mathrm{~mm}^{3}$.(N.m) ${ }^{-1}$; regime de transição as taxas de desgaste superiores a $10^{-6} \mathrm{~mm}^{3}$. (N.m $)^{-1}$ e inferiores a $10^{-5}$ $\mathrm{mm}^{3}$.(N.m) $)^{-1}$; e, finalmente, para regime severo, as taxas de desgaste superiores a $10^{-5} \mathrm{~mm}^{3} \cdot(\mathrm{N} \cdot \mathrm{m})^{-1}$.

Tabela 10 - Taxas de desgaste dos nanocompósitos $\mathrm{t}-\mathrm{ZrO}_{2} / \mathrm{Al}_{2} \mathrm{O}_{3}-\mathrm{NbC}$ ensaiados com esferas de $\mathrm{Al}_{2} \mathrm{O}_{3}$ e de WC- $6 \%$ Co e carga de $15 \mathrm{~N}$.

\begin{tabular}{c|c|c|c|c}
\hline $\begin{array}{c}\text { Método e } \\
\text { temperatura de } \\
\text { sinterização }\left({ }^{\circ} \mathbf{C}\right)\end{array}$ & $\begin{array}{c}\text { Taxa de desgaste - } \\
\text { bola de } \mathrm{Al}_{2} \mathbf{O}_{3}, \mathbf{x} \mathbf{1 0}^{-6} \\
{\left[\mathbf{m m}^{3} .(\mathbf{N} \cdot \mathbf{m})^{-1}\right]}\end{array}$ & $\begin{array}{c}\text { Regime de } \\
\text { desgaste }\end{array}$ & $\begin{array}{c}\text { Taxa de desgaste }- \\
\text { bola de WC-6\%Co, } \\
\mathbf{x} 10^{-6}\left[\mathbf{m m}^{3} .(\mathbf{N} \cdot \mathbf{m})^{-1}\right]\end{array}$ & $\begin{array}{c}\text { Regime de } \\
\text { desgaste }\end{array}$ \\
\hline $\mathrm{SPS}-1300^{\circ} \mathrm{C}$ & 5,22 & Transição & 5,78 & Transição \\
\hline $\mathrm{SPS}-1350^{\circ} \mathrm{C}$ & 42,2 & Severo & 1,19 & Transição \\
\hline $\mathrm{SPS}-1400^{\circ} \mathrm{C}$ & 54,9 & Severo & 19,2 & Severo \\
\hline $\mathrm{SC}-1400^{\circ} \mathrm{C}$ & 1,33 & Transição & 2,43 & Transição \\
\hline $\mathrm{SC}-1450^{\circ} \mathrm{C}$ & 1,82 & Transição & 0,05 & Moderado \\
\hline $\mathrm{SC}-1500^{\circ} \mathrm{C}$ & 0,396 & Moderado & 0,453 & Moderado \\
\hline
\end{tabular}

Nota: SC = Sinterização convencional. Desvio padrão inferior a $5 \%$ em todos os casos. 
Com base nas taxas de desgaste calculadas, observa-se que a taxa de desgaste foi significativamente mais alta nos nanocompósitos sinterizados por SPS do que nos sinterizados convencionalmente, no caso do ensaio com esferas de $\mathrm{Al}_{2} \mathrm{O}_{3}$, especialmente nos nanocompósitos sinterizados por SPS a $1350^{\circ} \mathrm{C}$ e a $1400^{\circ} \mathrm{C}$. Por outro lado, apenas a amostra sinterizada por SPS a $1400^{\circ} \mathrm{C}$ apresentou um regime de desgaste classificado como severo nos ensaios com esferas de WC$6 \%$ Co. Isso vai contra o que se poderia esperar baseado na densidade e na dureza dos nanocompósitos, uma vez que os nanocompósitos sinterizados por SPS possuem maior densidade e maior dureza do que os nanocompósitos sinterizados convencionalmente. Porém, é importante ressaltar que os nanocompósitos sinterizados convencionalmente apresentaram maior tenacidade à fratura, o que pode, dependendo dos mecanismos de desgaste mais atuantes, ter uma interferência maior do que a densidade e a dureza propriamente ditas.

\subsection{Análise das superfícies de desgaste}

A fim de verificar os mecanismos de desgaste ocorrentes nas superfícies dos nanocompósitos após o ensaio de desgaste, foram feitas micrografias por MEV das trilhas desgastadas. A Figura 49 mostra as micrografias obtidas por MEV dos nanocompósitos de $\mathrm{t}-\mathrm{ZrO}_{2} / \mathrm{Al}_{2} \mathrm{O}_{3}-\mathrm{NbC}$ sinterizados por $\mathrm{SPS}$ a $1300^{\circ} \mathrm{C}, 1350^{\circ} \mathrm{C}$ e $1400^{\circ} \mathrm{C}$ e ensaiados com esferas de $\mathrm{Al}_{2} \mathrm{O}_{3}$.

Figura 49 - Micrografias de MEV das superfícies de desgaste dos nanocompósitos de $\mathrm{t}-\mathrm{ZrO}_{2} / \mathrm{Al}_{2} \mathrm{O}_{3}$ $\mathrm{NbC}$ sinterizados por SPS a: (a) $1300^{\circ} \mathrm{C}$; (b) $1350^{\circ} \mathrm{C}$; (d) $1400^{\circ} \mathrm{C}$, ensaiados com esferas de $\mathrm{Al}_{2} \mathrm{O}_{3} \mathrm{e}$ carga de $15 \mathrm{~N}$.
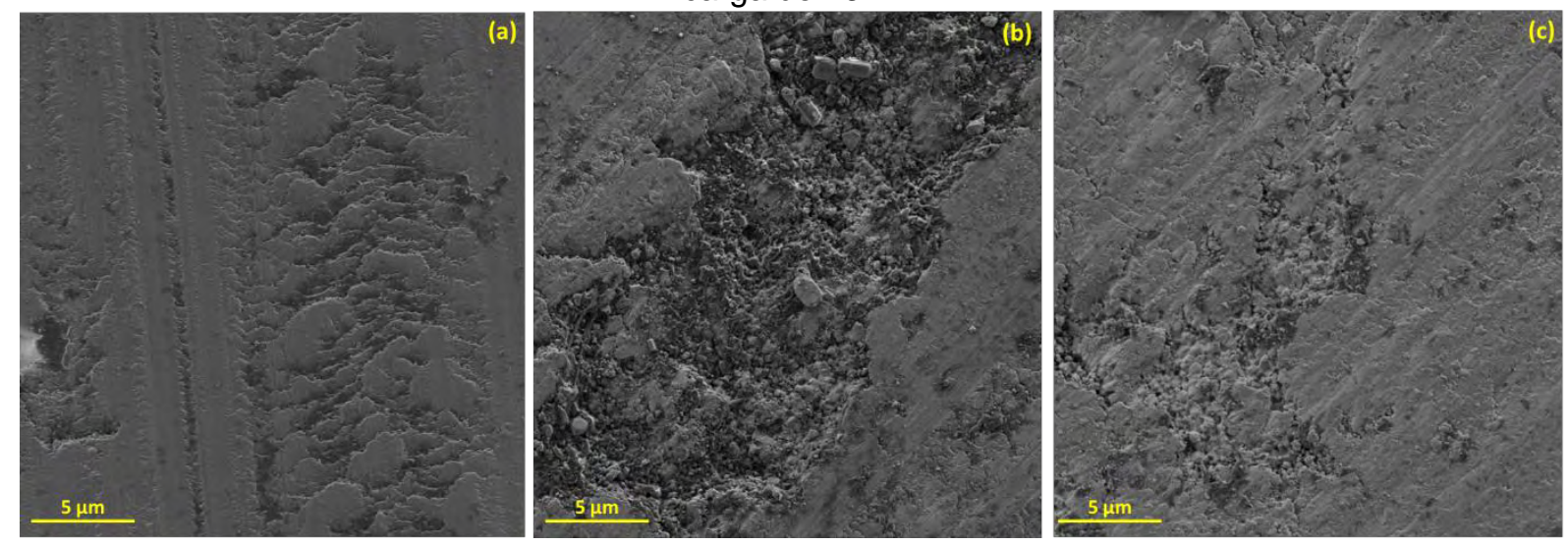
A análise das trilhas de desgaste da Figura 49 mostra que estas apresentam uma variação nas características, sendo identificada no nanocompósito sinterizado a $1300^{\circ} \mathrm{C}$ (Figura 49(a)) uma descontinuidade na superfície desgastada, com uma parte da superfície composta por riscos paralelos relativamente profundos, porém conservando a superfície inicial, e outra com a formação de uma aspereza contínua no sentido de movimentação da esfera, caracterizando a coexistência dos mecanismos de sulcamento e de microtrincamento gerado pela junção de microtrincas da camada compactada. No nanocompósito sinterizado a $1350^{\circ} \mathrm{C}$, representado pela Figura 49(b), observa-se uma combinação mais agressiva de mecanismos, causando em parte riscamento, regiões de arrancamento da camada superior e formação de detritos, correspondendo aos mecanismos de adesão e de delaminação. Comportamento semelhante foi observado no nanocompósito sinterizado a $1400^{\circ} \mathrm{C}$ (Figura 49 (c)), onde se identificam regiões de arrancamento da camada superficial e de fratura frágil e trincamento da camada compactada. Estas características indicam a existência dos mecanismos de adesão, delaminação e fadiga superficial, consequentes de um desgaste severo por abrasão do tribopar.

A Figura 50 apresenta as micrografias das trilhas de desgaste dos nanocompósitos sinterizados convencionalmente e ensaiados com esferas de $\mathrm{Al}_{2} \mathrm{O}_{3}$.

Figura 50 - Micrografias de MEV das superfícies de desgaste dos nanocompósitos de t- $\mathrm{ZrO}_{2} / \mathrm{Al}_{2} \mathrm{O}_{3}$ $\mathrm{NbC}$ sinterizados convencionalmente a: (a) $1400^{\circ} \mathrm{C}$; (b) $1450^{\circ} \mathrm{C}$; (d) $1500^{\circ} \mathrm{C}$, ensaiados com esferas de $\mathrm{Al}_{2} \mathrm{O}_{3}$ e carga de $15 \mathrm{~N}$.
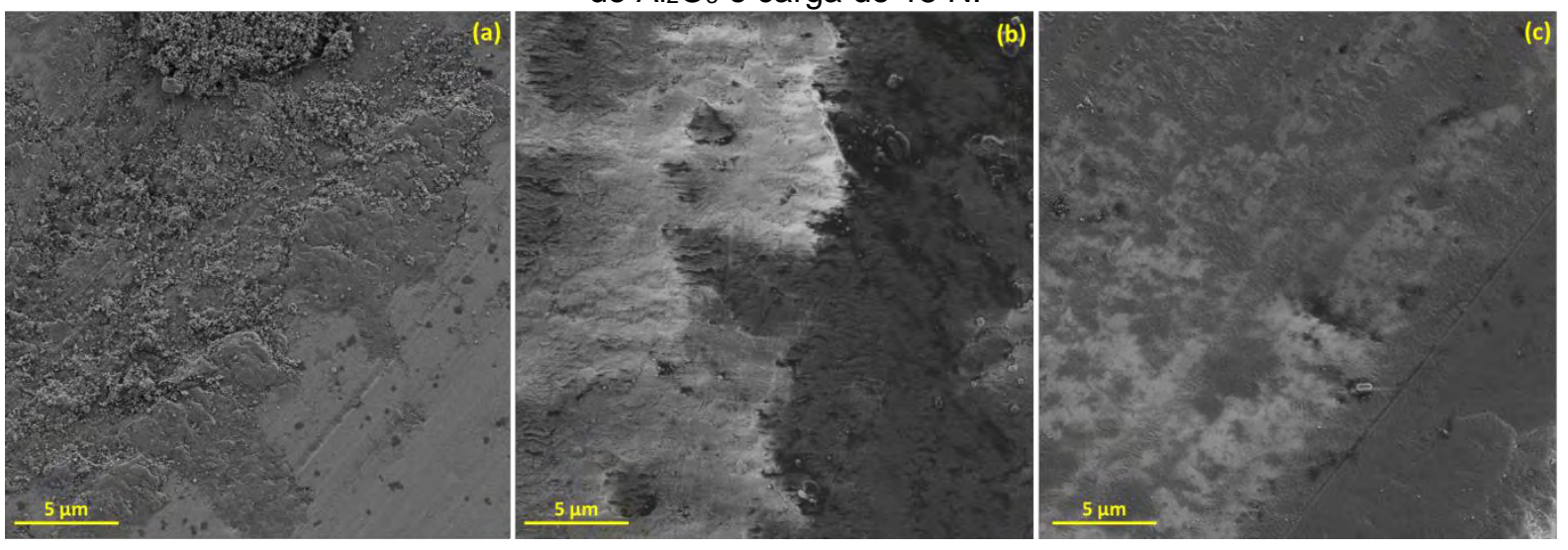

Nas micrografias da Figura 50, também se observaram diferentes mecanismos de desgaste, porém com menor grau de severidade quando comparados com os nanocompósitos da Figura 49. No nanocompósito sinterizado convencionalmente a $1400^{\circ} \mathrm{C}$ (Figura $50(\mathrm{a})$ ), observaram-se áreas mais "lisas", 
indicando um riscamento mais superficial e conservando grande parte da superfície original. Em algumas regiões foi observada a existência de uma camada compactada de detritos finos, combinada com arrancamento de uma camada superficial. Estas características denotam a existência dos mecanismos de sulcamento e deformação plástica da superfície ensaiada.

No nanocompósito sinterizado a $1450^{\circ} \mathrm{C}$ (Figura 50(b)), observou-se a formação de microtrincas em uma das partes da superfície, combinada com a compactação da camada superficial, e nas regiões mais claras identifica-se a formação de um tribofilme, que também foi verificado no nanocompósito sinterizado a $1500^{\circ} \mathrm{C}$ (Figura 50 (c)). Nesta amostra, o sulcamento causado pelo contato com a esfera promoveu também a formação de trincas longas e paralelas à direção de movimentação da esfera, evidenciando o mecanismo de delaminação. No entanto, nas Figuras 50 (b) e (c) não se observa a formação de detritos, tampouco arrancamento de uma camada superficial.

É importante ressaltar que, embora as micrografias destaquem regiões em que houve diferentes mecanismos de desgaste, os nanocompósitos sinterizados convencionalmente tiveram uma quantidade menor de regiões em que o desgaste mais agressivo ocorreu, bem como a profundidade das trilhas de desgaste foi visivelmente menor. Esta pode ser uma das razões pelas quais os nanocompósitos sinterizados convencionalmente tenham tido as menores taxas de desgaste quando ensaiados com esferas de $\mathrm{Al}_{2} \mathrm{O}_{3}$.

A Figura 51 apresenta as micrografias das trilhas de desgaste dos nanocompósitos sinterizados por SPS e ensaiados com esferas de WC-6\%Co.

Figura 51 - Micrografias de MEV das superfícies de desgaste dos nanocompósitos de $\mathrm{t}-\mathrm{ZrO}_{2} / \mathrm{Al}_{2} \mathrm{O}_{3}-$ $\mathrm{NbC}$ sinterizados por SPS a: (a) $1300^{\circ} \mathrm{C}$; (b) $1350^{\circ} \mathrm{C}$; (d) $1400^{\circ} \mathrm{C}$, ensaiados com esferas de WC-

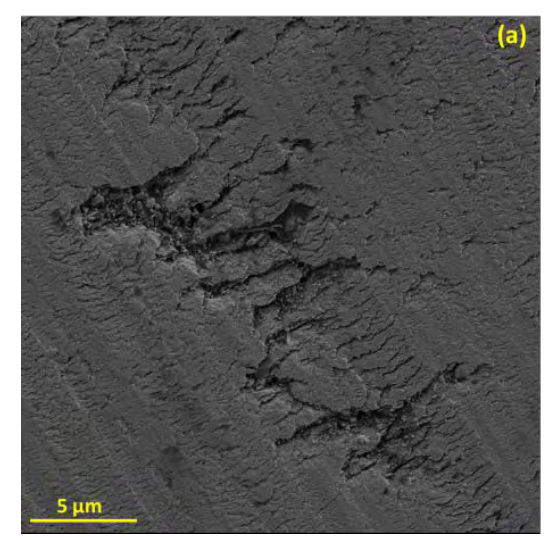
$6 \%$ Co e carga de $15 \mathrm{~N}$.
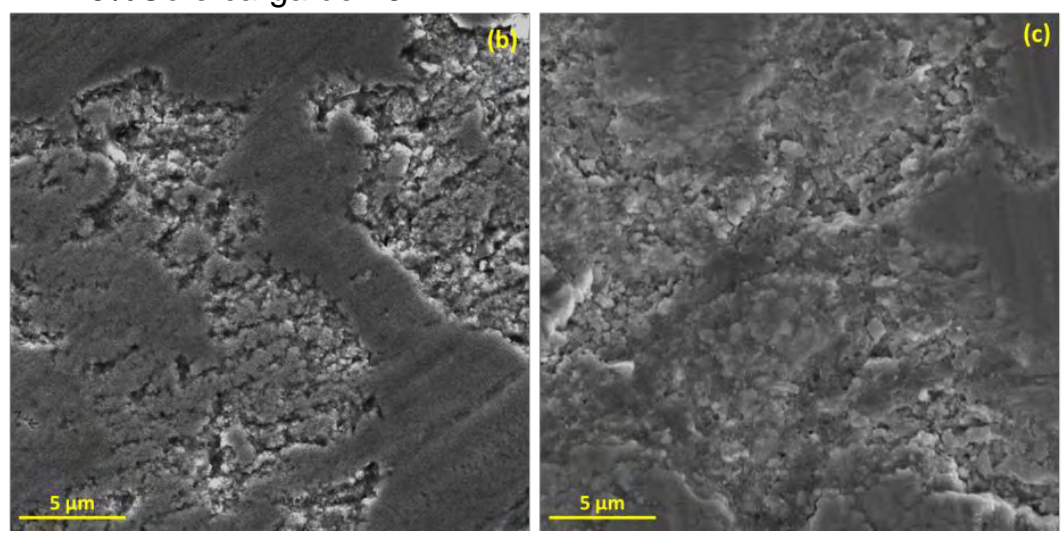
A Figura 51(a), que mostra a superfície de desgaste do nanocompósito sinterizado a $1300^{\circ} \mathrm{C}$, mostra uma trilha de riscamento na qual houve um significativo microtrincamento por toda a superfície, combinado com regiões pontuais de arrancamento de grãos e arrancamento da camada superficial, causando fraturas intergranulares da superfície e expondo a microestrutura interna. No entanto, regiões como a destacada na Figura 51(a) foram esparsas ao longo da trilha de desgaste, Nas Figuras 51(b) e (c), correspondendo respectivamente aos nanocompósitos sinterizados a $1350^{\circ} \mathrm{C}$ e a $1400^{\circ} \mathrm{C}$, também se observa a trilha de riscamento, porém sem uma quantidade significativa de trincas. É dado destaque às regiões onde houve arrancamento de camada superficial e fraturas intergranulares. Os detritos formados foram pressionados no interior dessas regiões, indicando os mecanismos de sulcamento, delaminação e deformação plástica e delaminação. Quando comparados com os nanocompósitos sinterizados convencionalmente, os nanocompósitos sinterizados por SPS, assim como no caso dos ensaios com esferas de $\mathrm{Al}_{2} \mathrm{O}_{3}$, também apresentaram maiores taxas de desgaste, embora relativamente menores do que nos ensaios com esferas de $\mathrm{Al}_{2} \mathrm{O}_{3}$. Este fato pode estar associado à menor dureza da esfera de WC-6\%Co e à própria característica desse material, que não promoveu uma formação significativa de detritos durante o ensaio.

A Figura 52 mostra as micrografias das trilhas de desgaste dos nanocompósitos sinterizados convencionalmente e ensaiados com esferas de WC$6 \%$ Co.

Figura 52 - Micrografias de MEV das superfícies de desgaste dos nanocompósitos de $\mathrm{t}-\mathrm{ZrO}_{2} / \mathrm{Al}_{2} \mathrm{O}_{3}$ $\mathrm{NbC}$ sinterizados convencionalmente a: (a) $1400^{\circ} \mathrm{C}$; (b) $1450^{\circ} \mathrm{C}$; (d) $1500^{\circ} \mathrm{C}$, ensaiados com esferas de WC-6\%Co e carga de $15 \mathrm{~N}$.
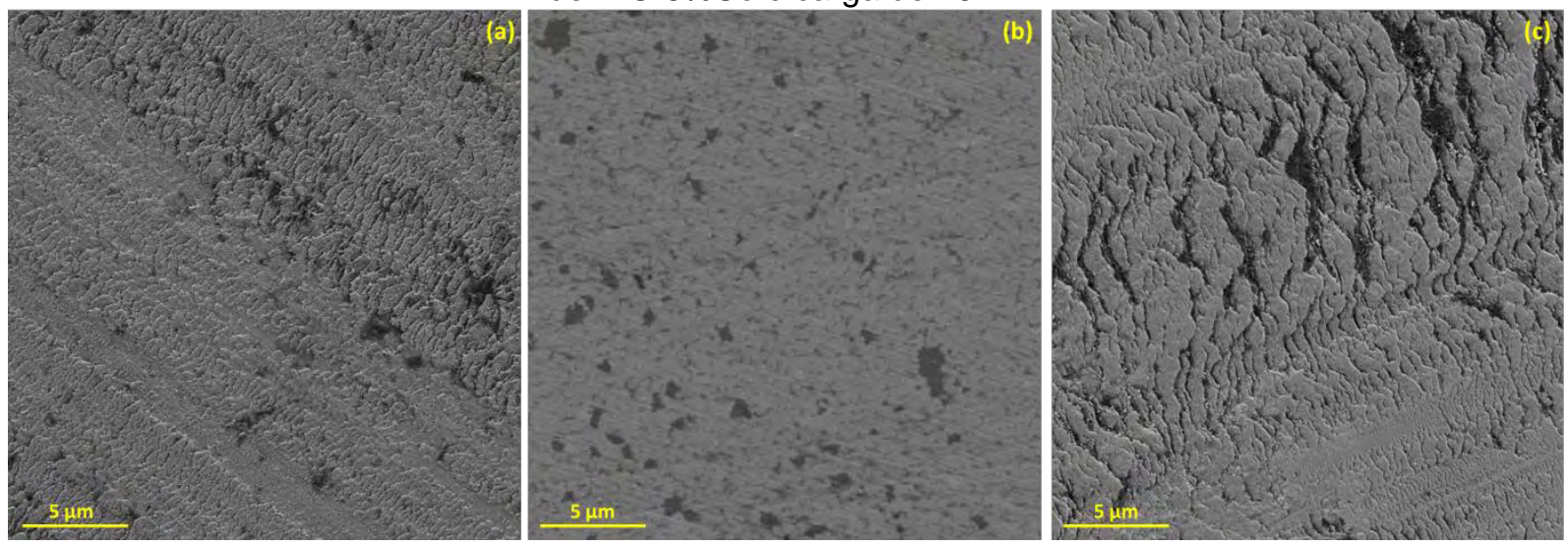
A análise das superfícies apresentadas na Figura 52 permite verificar que, de modo geral, ocorreu um desgaste por sulcamento e compactação de camada desgastada mais uniforme, sem ocorrências de desgaste severo, especialmente nos nanocompósitos sinterizados a $1400^{\circ} \mathrm{C}$ e a $1500^{\circ} \mathrm{C}$ (Figuras $52(\mathrm{a})$ e (c), respectivamente). No caso do nanocompósito sinterizado a $1450^{\circ} \mathrm{C}$ (Figura $52($ b)), este apresentou uma taxa de desgaste quase nula $\left(0,05 \times 10^{-6} \mathrm{~mm}^{3}(\mathrm{~N} \cdot \mathrm{m})^{-1}\right)$, o que foi comprovado pela análise da superficie, que não apresenta sinais de desgaste marcante, exceto um leve riscamento que em quase nada alterou a superfície de ensaio. Este nanocompósito foi o que, dentre todos os nanocompósitos ensaiados, apresentou a menor taxa de desgaste, embora os coeficientes de fricção tenham sido entre os mais altos.

Considerando a importância de se classificar os regimes de desgaste não apenas pelas taxas de desgaste calculadas, bem como pela análise das superfícies de desgaste, visando a manutenção das características fundamentais das superfícies de desgaste após o uso prolongado dos materiais a serem aplicados, foi feita a confrontação dos resultados. A Tabela 11 apresenta a confirmação ou a eventual reclassificação do regime de desgaste, com base na confrontação da Tabela 10 com as superfícies de desgaste analisadas por MEV nas Figuras 49, 50, 51 e 52. Os regimes de desgaste eventualmente alterados em relação à análise apresentada na Tabela 10 estão destacados em negrito.

Tabela 11 - Confirmação dos regimes de desgaste dos nanocompósitos de $\mathrm{t}-\mathrm{ZrO}_{2} / \mathrm{Al}_{2} \mathrm{O}_{3}-\mathrm{NbC}$ ensaiados com esferas de $\mathrm{Al}_{2} \mathrm{O}_{3}$ e de WC-6\%Co, utilizando carga de $15 \mathrm{~N}$.

\begin{tabular}{c|c|c|c|c}
\hline \multirow{2}{*}{$\begin{array}{c}\text { Método e } \\
\text { temperatura de } \\
\text { sinterização }\left({ }^{\circ} \mathrm{C}\right)\end{array}$} & \multicolumn{4}{|c}{ Regime de desgaste } \\
\cline { 2 - 5 } & Esfera de $\mathbf{A l}_{2} \mathbf{O}_{3}$ & \multicolumn{2}{c}{ Esfera de WC-6\%Co } \\
\hline SPS $-1300^{\circ} \mathrm{C}$ & Transição & Transição & Pransição & Severo \\
\hline $\mathrm{SPS}-1350^{\circ} \mathrm{C}$ & Severo & Severo & Transição & Transição \\
\hline $\mathrm{SPS}-1400^{\circ} \mathrm{C}$ & Severo & Severo & Severo & Severo \\
\hline $\mathrm{SC}-1400^{\circ} \mathrm{C}$ & Transição & Transição & Transição & Transição \\
\hline $\mathrm{SC}-1450^{\circ} \mathrm{C}$ & Transição & Transição & Moderado & Moderado \\
\hline $\mathrm{SC}-1500^{\circ} \mathrm{C}$ & Moderado & Severo & Moderado & Moderado \\
\hline
\end{tabular}

Observa-se que foram alterados os regimes de desgaste previamente classificados apenas em dois nanocompósitos, o nanocompósito sinterizado convencionalmente a $1500^{\circ} \mathrm{C}$ ensaiado com esfera de $\mathrm{Al}_{2} \mathrm{O}_{3}$ e o nanocompósito sinterizado por SPS a $1300^{\circ} \mathrm{C}$ ensaiado com esfera de WC-6\%Co. Isto demonstra que o critério utilizado para a classificação do regime de desgaste com base na taxa 
de desgaste foi razoavelmente preciso, porém alterações na superfície de desgaste das amostras cujo regime foi reclassificado evidenciaram a importância de se analisar minuciosamente as superfícies desgastadas, a fim de prever de forma mais correta o comportamento do material frente ao desgaste.

A análise dos resultados dos ensaios de desgaste permite concluir que os nanocompósitos sinterizados convencionalmente apresentaram, de modo geral, um comportamento mais satisfatório em relação ao desgaste. Tal diferença, contrária ao que se previa baseado na dureza e na densidade dos materiais, pode estar relacionada à maior tenacidade à fratura encontrada para os nanocompósitos sinterizados convencionalmente, que por sua vez tiveram um modo de fratura misto (integranular e intragranular). É interessante observar que o nanocompósito sinterizado convencionalmente a $1500^{\circ} \mathrm{C}$, em contato com a esfera de $\mathrm{Al}_{2} \mathrm{O}_{3}$ (mais dura que a de $\mathrm{WC}-6 \% \mathrm{Co}$ ), apresentou regime de desgaste severo. Isso vem de encontro com a redução na tenacidade associada ao início da oxidação do NbC presente no material, bem como a uma consequente reação do óxido formado com a $\mathrm{Al}_{2} \mathrm{O}_{3}$. O nanocompósito sinterizado a $1600^{\circ} \mathrm{C}$ não foi submetido ao ensaio de desgaste, devido à fragilidade observada nas amostras, o que impossibilitou uma análise mais detalhada desse comportamento.

Com base na análise dos resultados das caracterizações dos nanocompósitos de $\mathrm{t}-\mathrm{ZrO}_{2} / \mathrm{Al}_{2} \mathrm{O}_{3}-\mathrm{NbC}$ sinterizados convencionalmente e por SPS, pode-se concluir que as inclusões de $\mathrm{Al}_{2} \mathrm{O}_{3}-\mathrm{NbC}$ tiveram um papel importante na melhoria das propriedades mecânicas em relação à $\mathrm{t}-\mathrm{ZrO}_{2}$ monolítica, especialmente na tenacidade à fratura, em geral, levando a um bom desempenho frente aos ensaios de desgaste. A variação das temperaturas e das técnicas de sinterização permitiu observar um ponto fraco no processamento desses materiais, que foi a sensibilidade do $\mathrm{NbC}$ a atmosferas oxidantes em temperaturas superiores a $1450^{\circ} \mathrm{C}$. Tal oxidação, seguida de provável reação eutética com a $\mathrm{Al}_{2} \mathrm{O}_{3}$ presente nos nanocompósitos, promoveu uma degradação significativa das propriedades mecânicas que foram inicialmente melhoradas, principalmente a tenacidade à fratura e a resistência ao desgaste. Deste modo, é possível sugerir uma "janela de processamento" mais adequada para os nanocompósitos de $\mathrm{t}-\mathrm{ZrO}_{2} / \mathrm{Al}_{2} \mathrm{O}_{3}-\mathrm{NbC}$ sinterizados por quaisquer técnicas, que consiste na limitação da temperatura de sinterização a $1450^{\circ} \mathrm{C}$ e na necessidade da utilização de atmosfera redutora. Dentro dessa "janela de processamento", podem ser obtidos nanocompósitos de $\mathrm{t}-\mathrm{ZrO}_{2} / \mathrm{Al}_{2} \mathrm{O}_{3}-\mathrm{NbC}$ de forma 
relativamente simples e com bom desempenho em aplicações que requerem alta tenacidade à fratura, boas propriedades tribológicas e, consequentemente, durabilidade dos materiais. 


\section{CONCLUSÕES}

A partir dos resultados obtidos neste trabalho, pode-se concluir:

\section{a) Sistema t- $\mathrm{ZrO}_{2} / \mathrm{Al}_{2} \mathrm{O}_{3}$ :}

- A sinterização convencional da $\mathrm{t}-\mathrm{ZrO}_{2}$ e de $\mathrm{t}-\mathrm{ZrO}_{2} / \mathrm{Al}_{2} \mathrm{O}_{3}$ promoveu materiais altamente densificados, com boa dispersão das inclusões na matriz, tamanho de grão submicrométrico e densidades superiores a $97 \%$ DT;

- A porosidade remanescente, ainda que pouca, não permitiu observar um aumento da dureza e da tenacidade nos compósitos $\mathrm{t}-\mathrm{ZrO}_{2} / \mathrm{Al}_{2} \mathrm{O}_{3}$ sinterizados a $1350^{\circ} \mathrm{C}$ e $1400^{\circ} \mathrm{C}$, em relação à $\mathrm{t}-\mathrm{ZrO}_{2}$. No entanto, um aumento da dureza e da tenacidade foi observado nos compósitos sinterizados a $1500^{\circ} \mathrm{C}$, os quais apresentaram as maiores densidades relativas.

- A sinterização por flash sintering permitiu a obtenção de $\mathrm{t}-\mathrm{ZrO}_{2}$ e $\mathrm{t}-\mathrm{ZrO}_{2} / \mathrm{Al}_{2} \mathrm{O}_{3}$ com densidades relativas entre $79,4 \%$ e $94,6 \%$, com densificação ocorrente em temperaturas que variaram entre $785,6^{\circ} \mathrm{C}$ e $950,4^{\circ} \mathrm{C}$;

- A sinterização por flash sintering promoveu uma microestrutura predominantemente homogênea, com algumas regiões heterogêneas apresentando grãos submicrométricos/micrométricos e sinais de fase líquida.

\section{b) Sistema t- $\mathrm{ZrO}_{2} / \mathrm{Al}_{2} \mathrm{O}_{3}-\mathrm{NbC}$ :}

- A moagem de alta energia foi completa e eficaz na obtenção de pós nanométricos de $\mathrm{Al}_{2} \mathrm{O}_{3}-\mathrm{NbC}$, com tamanhos de cristalito de $9,10 \mathrm{~nm}$ e 9,66 $\mathrm{nm}$ e porcentagens de fase de $56,6 \%$ e $43,4 \%$ para as fases $\mathrm{Al}_{2} \mathrm{O}_{3}$ e $\mathrm{NbC}$, respectivamente;

- Os nanocompósitos de $\mathrm{t}-\mathrm{ZrO}_{2} / \mathrm{Al}_{2} \mathrm{O}_{3}-\mathrm{NbC}$ sinterizados convencionalmente apresentaram dureza inferior ou similar à da $\mathrm{t}^{-\mathrm{ZrO}_{2}}$. A sinterização por SPS promoveu maior densificação, e os valores de dureza foram superiores ao da $\mathrm{t}-\mathrm{ZrO}_{2}$. A tenacidade à fratura foi mais alta nos nanocompósitos sinterizados a $1350^{\circ} \mathrm{C}$ (SPS), $1400^{\circ} \mathrm{C}$ (SPS/convencional) e $1450^{\circ} \mathrm{C}$ (convencional), e diminuiu nos sinterizados a $1500^{\circ} \mathrm{C}$ e a $1600^{\circ} \mathrm{C}$ (convencional), devido a uma provável oxidação do $\mathrm{NbC}$ e formação de fase líquida; 
- Os ensaios de desgaste mostraram que os nanocompósitos sinterizados convencionalmente a $1400^{\circ} \mathrm{C}$ e a $1450^{\circ} \mathrm{C}$ sofreram menor desgaste (regime moderado) do que os sinterizados por SPS em relação a ambos os contramateriais $\left(\mathrm{Al}_{2} \mathrm{O}_{3}\right.$ e WC-6\%Co). De modo geral, o contramaterial $\mathrm{Al}_{2} \mathrm{O}_{3}$ ocasionou mais desgaste do que o WC-6\%Co nos nanocompósitos sinterizados pelas duas técnicas, devido à sua dureza mais elevada. 


\section{SUGESTÕES PARA TRABALHOS FUTUROS}

O presente trabalho trouxe muitas questões, que não puderam ser respondidas, devido à limitação de tempo e recursos, inerentes a um doutoramento. Esta seção apresenta algumas sugestões para trabalhos futuros, com base nos resultados alcançados.

- Investigar sistematicamente os parâmetros operacionais e de processamento por flash sintering da $\mathrm{t}-\mathrm{ZrO}_{2}$ e seus compósitos, e seu efeito na heterogeneidade microestrutural, grau de densificação e retração linear da t$\mathrm{ZrO}_{2}$ e seus compósitos com $\mathrm{Al}_{2} \mathrm{O}_{3}$.

- Investigar o comportamento do $\mathrm{NbC}$ nanocristalino como inclusão em compósitos de matriz de $\mathrm{t}-\mathrm{ZrO}_{2}$ durante a sinterização com e sem atmosfera redutora, e o grau de limitação que este possui no tocante à sua oxidação e à reação com a matriz ou outros componentes do material;

- Investigar a cinética de oxidação do NbC por espectroscopia de infravermelho e espetroscopia Raman;

- Investigar o grau de transformação de fase da $\mathrm{t}^{-\mathrm{ZrO}_{2}}$ durante 0 processamento por moagem de bolas e na sinterização de seus compósitos, bem como os eventuais mecanismos de tenacificação ocorrentes devido à transformação;

- Investigar sistematicamente a influência do modo de fratura na resistência à flexão, na dureza e na tenacidade de nanocompósitos $\mathrm{t}-\mathrm{ZrO}_{2} / \mathrm{Al}_{2} \mathrm{O}_{3}$ e t$\mathrm{ZrO}_{2} / \mathrm{Al}_{2} \mathrm{O}_{3}-\mathrm{NbC}$;

- Investigar o comportamento tribológico do nanocompósito $\mathrm{t}-\mathrm{ZrO}_{2} / \mathrm{Al}_{2} \mathrm{O}_{3}-\mathrm{NbC}$ em função da carga de ensaio pelo método esfera-no-disco;

- Investigar a sinterização do nanocompósito $\mathrm{t}-\mathrm{ZrO}_{2} / \mathrm{Al}_{2} \mathrm{O}_{3}-\mathrm{NbC}$ com diferentes frações volumétricas de $\mathrm{Al}_{2} \mathrm{O}_{3}-\mathrm{NbC}$;

- Investigar a sinterização por flash sintering do nanocompósito t- $\mathrm{ZrO}_{2} / \mathrm{Al}_{2} \mathrm{O}_{3}$ $\mathrm{NbC}$ usando atmosfera redutora. 


\section{REFERÊNCIAS}

ACCHAR, W.; SILVA, Y. B. F.; CAIRO, C. A. Mechanical properties of hot-pressed $\mathrm{ZrO}_{2}$ reinforced with $(\mathrm{W}, \mathrm{Ti}) \mathrm{C}$ and $\mathrm{Al}_{2} \mathrm{O}_{3}$ additions. Materials Science and Engineering A, v. 527, pp. 480-484, 2010.

ACCHAR, W.; CÂMARA, C. R. F.; CAIRO, C. A. A.; FILGUEIRA, M. Mechanical performance of alumina reinforced with $\mathrm{NbC}, \mathrm{TiC}$ and $\mathrm{WC}$. Materials Research, $\mathrm{V}$. 15, n. 6, pp. 821-824, 2012.

ADACHI, K.; KATO, K.; CHEN, N., Wear map of ceramics, Wear, v. 203-204, pp. 291-301, 1997.

ADACHI, K.; KATO, K.; Formation of smooth wear surfaces on alumina ceramics by embedding and tribo-sintering of fine particles, Wear, v. 245, pp. 84-91, 2000.

AGUILAR-ELGUÉZABAL, A.; BOCANEGRA-BERNAL, M. H. Alumina toughened zirconia nanocomposite incorporating $\mathrm{Al}_{2} \mathrm{O}_{3}$ whiskers. International Journal of Applied Ceramic Technology, v. 10, n. 2, pp. 215-223, 2013.

AJAYI, O., O., LUDEMA, K.C., Mechanism of transfer film formation during repeat pass sliding of ceramic materials, Wear, v. 140, pp. 191-206, 1990.

ALECRIM, L. R. R.; FERREIRA, J. A.; GUTIÉRREZ-GONZÁLEZ, C. F.; SALVADOR, M. D.; BORRELL, A.; PALLONE, E. M. J. A. Effect of reinforcement NbC phase on the mechanical properties of $\mathrm{Al}_{2} \mathrm{O}_{3}-\mathrm{NbC}$ nanocomposites obtained by spark plasma sintering. International Journal of Refractory Metals and Hard Materials, v. 64, pp. 255-260, 2017a.

ALECRIM, L. R. R.; FERREIRA, J. A.; GUTIÉRREZ-GONZÁLEZ, C. F.; SALVADOR, M. D.; BORRELL, A.; PALLONE, E. M. J. A. Sliding wear behavior of $\mathrm{Al}_{2} \mathrm{O}_{3}-\mathrm{NbC}$ composites obtained by conventional and nonconventional techniques. Tribology International, v. 110, pp. 216-221, 2017b.

ANSELMI-TAMBURINI, U.; GENNARI, S.; GARAY, J. E.; MUNIR, Z. A. Fundamental investigations on the spark plasma sintering/synthesis process: II. Modelling of current and temperature distribution. Materials Science and Engineering A, v. 394, pp. 139-145, 2005.

ANSTIS, G. R.; CHANTIKUL, P.; LAWN, B. R.; MARSHALL, D. B. A critical evaluation of indentation techniques for measuring fracture toughness: I, Direct crack measurements. Journal of the American Ceramic Society, v. 46, 533-538, 1981.

ASM International. Friction, lubrication and wear technology, ASM International, v. 18, 1992.

ASTM C 1327-03. Standard Test Method for Vickers Indentation Hardness of Advanced Ceramics. pp. 1-8, 2003. 
ASTM C 373-88. Standard Test Method for Water Absorption, Bulk Density, Apparent Porosity, and Apparent Specific Gravity of Fired Whiteware Products. pp. 2, 2006.

ASTM G 99-17. Standard Test Method for Wear Testing with a Pin-on-disk Apparatus. pp. 1-6, 2017.

BARSOUM, M. W. Fundamentals of Ceramics (Series in Materials Science and Engineering). New York: Taylor and Francis, 2003.

BARTOLOMÉ, J. F.; BELTRÁN, J. I.; GUTIÉRREZ-GONZÁLEZ, C. F.; PECHARROMÁN, C.; MUÑOZ, M. C.; MOYA, J. S. Influence of ceramic-metal interface adhesion on crack growth resistance of $\mathrm{ZrO}_{2}-\mathrm{Nb}$ ceramic matrix composites. Acta Materialia, v. 56, pp. 3358-3366, 2008.

BAYER, R. G. Mechanical wear fundamentals and testing. 2 ed. New York: Marcel Dekker Inc., 2004.

BECHER, P. F.; SUN, E. Y.; PLUCKNETT, K. P.; ALEXANDER, K. B.; HSUEH, C. H.; LIN, H. T.; WATERS, S. B.; WESTMORELAND, C. G. Microstructural design of silicon nitride with improved fracture toughness: I, Effects of grain shape and size. Journal of the American Ceramic Society, v. 81, n. 11, pp. 2821-2830, 1998.

BHADURI, S.; BHADURI, S. B.; ZHOU, E. Auto ignition synthesis and consolidation of $\mathrm{Al}_{2} \mathrm{O}_{3}-\mathrm{ZrO}_{2}$ nano/nano composite powders. Journal of Materials Research, v. 13, n. 1, pp. 156-165, 1998.

BHARAT, B. Modern Tribology Handbook: Volume 1: Principles of Tribology. New York: CRC Press, 2001.

BHUSHAN, B. Tribology: Friction, Wear, and Lubrication. In: DORF, R. C. (Ed.), The Engineering Handbook. Boca Raton, CRC Press, 2000.

BIESUZ, M.; SGLAVO, V. M. Flash sintering of alumina: Effect of different operating conditions on densification. Journal of the European Ceramic Society, v. 36, pp. 2535-2542, 2016.

BLAU, P. J. The significance and use of the friction coefficient. Tribology International, v. 34, pp. 585-591, 2001.

BOCH, P.; NIÈPCE, J. C. Ceramic Materials: Processes, Properties and Applications. 2 ed. London: ISTE, 2007.

BOHMER, M.; ALMOND, E. A. Mechanical properties and wear resistance of a whisker-reinforced zirconia-toughened alumina. Materials Science and Engineering A, v. 105-106, pp. 105-116, 1988.

BONNY, K.; DE BAETS, P.; VLEUGELS, J.; SALEHI, A.; VAN DER BIEST, O.; LAUWERS, B.; LIU, W. Sliding wear of electrically conductive $\mathrm{ZrO}_{2}-\mathrm{WC}$ composites against WC-Co cemented carbide. Tribology Letters, v. 30, pp. 191-198, 2008. 
BOTTA Fo, W. J.; TOMASI, R.; PALLONE, E. M. J. A.; YAVARI, A. R. Nanostructured composites obtained by reactive milling. Scripta Materialia, v. 44, pp. 1735-1740, 2001.

BREZNAK, J.; BREVAL, E; MACMILLAN, N. H. Sliding friction and wear of structural ceramics, Part 1: Room temperature behaviour. Journal of Materials Science, v. 20, pp. 4657-4680, 1985.

BREZNAK, J.; BREVAL, E; MACMILLAN, N. H. Sliding friction and wear of structural ceramics, Part 2: Analysis of room temperature wear debris. Journal of Materials Science, v. 21, pp. 931-935, 1986.

CALIMAN, L. B.; BOUCHET, R.; GOUVEA, D.; SOUDANT, P.; STEIL, M. Flash sintering of ionic conductors: The need of a reversible electrochemical reaction. Journal of the European Ceramic Society, v. 36, pp. 1253-1260, 2016.

CARUTA, B. M. (ed.) Ceramics and Composite Materials: New Research. New York: Nova Science Publishers, 2006.

CHAIM, R. Pressureless sintering of ATZ and ZTA ceramic composites. Journal of Materials Science, v. 27, pp. 5597-5602, 1992.

CHAIM, R.; MARDER, R.; ESTOURNÉS, C.; SHEN, Z. Densification and preservation of ceramic nanocrystalline character by spark plasma sintering. Advances in Applied Ceramics, v. 111, pp. 280-285, 2012.

CHEN, F.; ZHAO, B.; JIA, X.; TONH, J. Study on fracture behaviors of nanocomposite ceramics under a high cycle stress. Advances in Mechanical Engineering, v. 8, pp. 1-9, 2016.

CHIANG, Y. M.; BIRNIE III, D.; KINGERY, W. D. Physical Ceramics: Principles for Ceramic Science and Engineering (The MIT Series in Materials Science and Engineering). New York: John Wiley and Sons, 1997.

CHINELATTO, A. S. A. Sinterização de pós ultra finos de alumina para a obtenção de cerâmicas densas e com pequenos tamanhos de grãos. 2002, 195 f. Tese de doutorado (Programa de Pós-graduação em Ciência e Engenharia de Materiais) - Centro de Ciências Exatas e de Tecnologia, Universidade Federal de São Carlos, São Carlos, 2002.

CLAUSSEN, N.; WEISSKOPF, K. L.; RUHLE, M. Tetragonal zirconia polycrystals reinforced with $\mathrm{SiC}$ whiskers. Journal of the American Ceramic Society, v. 68, pp. 288-292, 1986.

COBLE, R. L. Sintering crystalline solids. II. Experimental Test of Diffusion Models in Powder Compacts. Journal of Applied Physics, v. 32, pp. 787-792, 1961.

COBLE, R. L. Sintering alumina: effect of atmospheres. Journal of the American Ceramic Society, v. 45, n. 3, pp. 123-127, 1962. 
COLOGNA, M.; RASHKOVA, B.; RAJ, R. Flash sintering of nanograin zirconia in $<5 \mathrm{~s}$ at $850^{\circ} \mathrm{C}$. Journal of the American Ceramic Society, v. 93, pp. 3556-3559, 2010.

COLOGNA, M., FRANCIS, J.S.C.; RAJ, R. Field assisted and flash sintering of alumina and its relationship to conductivity and $\mathrm{MgO}$-doping. Journal of the European Ceramic Society, v. 31, pp. 2827-2837, 2011.

COLOGNA, M.; PRETTE, A. L. G.; RAJ, R. Flash sintering of cubic yttria-stabilized zirconia at $750^{\circ} \mathrm{C}$ for possible use in SOFC manufacturing. Journal of the American Ceramic Society, v. 94, pp. 316-319, 2011.

CONNOLEY, T.; STARINK, M. J.; REED, P. A. S. Effect of oxidation on high temperature fatigue crack initiation and short crack growth in Inconel 718 . Superalloys, v. 1, pp. 435-444, 2000.

ĆORIĆ, D.; ĆURKOVIĆ, L.; RENJO, M. M. Statistical analysis of Vickers indentation fracture toughness of Y-TZP ceramics. Transactions of Famena, v. 17, n. 2, pp. 116, 2017.

COUTINHO, A. C. S. Influência da adição de carbetos (NbC, TaC, SiC e TiC) na sinterização de cerâmicas à base de $\mathrm{Si}_{3} \mathrm{~N}_{4}$. 2005, 152 f. Tese (Doutorado em Tecnologia Nuclear) - Instituto de Pesquisas Energéticas e Nucleares, São Paulo, 2005.

CULLITY, B.D., Elements of X-ray diffraction. 2 ed. Massachusetts: AddisonWesley, 1978.

CZICHOS, H.; KLAFFKE, D.; SANTNER, E.; WOYDT, M., Advances in tribology: the materials point of view, Wear, v. 190, pp. 155-161, 1995.

DAVIDGE, R. W. Mechanical Behaviour of Ceramics. Cambridge University Press: Cambridge, 1979.

DE AZA, A.H.; CHEVALIER, J.; FANTOZZI, G. et al. Crack growth resistance of alumina, zirconia and zirconia toughened alumina ceramics for joint prostheses. Biomaterials, v. 23, pp. 937-945, 2002.

DING, Z.; OBERACKER, R.; THÜMMLER, F. Microstructure and mechanical properties of yttria stabilized zirconia polycrystals (Y-TZP) containing dispersed silicon carbide particles. Journal of the European Ceramic Society, v. 12, n. 5, pp. 377-383, 1993.

DOWNS, J. A.; SGLAVO, V. M. Electric field assisted sintering of cubic zirconia at $390^{\circ} \mathrm{C}$. Journal of the American Ceramic Society, v. 96, n. 5, pp. 1342-1344, 2013.

FRANCIS, J.S.C.; COLOGNA, M.; RAJ, R. Particle size effects in flash sintering. Journal of the European Ceramic Society, v. 32, pp. 3129-3136, 2012. 
FRANCIS, J.S.C. A study on the phenomena of flash-sintering with tetragonal zirconia. 2013, 173 f. Tese (Doutorado) - Departamento de Engenharia Mecânica, Universidade do Colorado, Boulder, 2013. Disponível em:

$<$ http://scholar.colorado.edu/cgi/viewcontent.cgi?article=1066\&context=mcen_gradet ds>. Acesso em: 20 jul. 2017.

FRENKEL, J. Viscous flow of crystalline bodies under the action of surface tension. Journal of Physics (USSR), v. 8, p. 386, 1945.

FUKUHARA, M. Properties of $(\mathrm{Y}) \mathrm{ZrO}_{2}-\mathrm{Al}_{2} \mathrm{O}_{3}$ e $(\mathrm{Y}) \mathrm{ZrO}_{2}-\mathrm{Al}_{2} \mathrm{O}_{3}-(\mathrm{Ti}$ or Si)C composites. Journal of the American Ceramic Society, v. 72, n. 2, pp. 236-242, 1989.

GAO, Y.; LIU, F.; LIU, D.; LIU, J.; WANG, Y.; AN, L. Electrical-field induced nonlinear conductive behavior in dense zirconia ceramic. Journal of Materials Science \& Technology, v. 33, n. 8, pp. 897-900, 2017.

GEE, M.G.; BUTTERFIELD, The combined effect of speed and humidity on the wear and friction of silicon nitride, Wear, v. 162-164, pp. 234-245, 1993.

GHOSH, A.; SURI, A. K.; RAO, B. T.; RAMAMOHAN, T. R. Low-temperarure sintering and mechanical property evaluation of nanocrystalline $8 \%$ mol yttria fully stabilized zirconia. Journal of the American Ceramic Society, v. 90, n. 7, pp. 20152023, 2007.

GLEITER, H. Nanostructured materials: State of art and perspectives. NanoStructured Materials. v. 6, p. 3-14, 1995.

GLEITER, H. Nanostrctured materials: Basic concepts and microstructure. Acta Materialia, v. 48, pp. 1-29, 2000.

GRASSO, S.; SAUNDERS, T.; PORWAL, $\mathrm{H}_{\text {.; }}$ CEDILLOS-BARRAZA, O.; JAYASEELAN, D. D.; LEE, W. E. Flash spark plasma sintering (FSPS) of pure ZrB2. Journal of the American Ceramic Society, v. 97, pp. 2405-2408, 2014.

GUILLON, O.; GONZALEZ-JULIAN, J.; DARGARTZ, B.; KESSEL, T.; SCHIERNING, G.; RÄTHEL, J.; HERMANN, M. Field-assisted sintering technology / Spark plasma sintering: Mechanisms, materials and technology developments. Advanced Engineering Materials, v. 16, pp. 830-849, 2014.

GUO, X.; XIAO, P.; LIU, J.; SHEN, Z. Fabrication of nanostructured hydroxyapatite via hydrothermal synthesis and spark plasma sintering. Journal of the American Ceramic Society, v. 88, n. 4, pp. 1026-1029, 2005.

GUTKNECHT, D.; CHEVALIER, J.; GARNIER, V.; FANTOZZI, G. Key role of processing to avoid low temperature ageing in alumina zirconia composites for orthopaedic application. Journal of the European Ceramic Society, v. 27, pp. 1547-1552, 2007.

HAMPDEN-SMITH, M. J.; KLEMPERER, W. G.; BRINKER, C. J. Better ceramics through chemistry V. Vol. 271. Materials Research Society: Pittsburgh, 1992. 
HANNINK, R. H. J.; KELLY, P. M.; MUDDLE, B. C. Transformation toughening in zirconia-containing ceramics. Journal of the American Ceramic Society, v. 83, n. 3, pp. 461-187, 2000.

HAYAT, M.D. Electric Field Assisted Sintering of Metal Oxides. 2011, $54 \mathrm{f}$. Dissertação (Mestrado) - Departamento de Materiais e Tecnologia de Fabricação. Universidade Tecnológica de Chalmers, Gothenburg, 2011. Disponível em:

<http://publications.lib.chalmers.se/records/fulltext/149151.pdf>. Acesso em: 20 jul. 2017.

HERNANDES, V. T. Sinterização e propriedades de nanocompósitos de matriz de alumina. 2007, $231 \mathrm{f}$. Tese (Doutorado em Engenharia e Ciência de Materiais) Universidade Federal de São Carlos, São Carlos, 2007.

HERRING, C. Effect of change of scale on sintering phenomena. Journal of Applied Physics, v. 21, pp. 301-303, 1950.

HEWITT, I.J.; LACEY, A.A.; TODD, R.I. A mathematical model for flash sintering. Mathematical Modelling of Natural Phenomena, v. 10, pp. 77-89, 2015.

HILL, M.; TAYLOR, M. E.; MIKHALAPOV, G. S.; TOUCEDA, E. G.; CLARK, C. L.; KNOPP, W. V.; SHAW, J. D. Production of cermets by flash sintering process. WADC Technical Report, 52-106, 1952.

HIRAGA, K. Development of high-strain-rate superplastic oxide ceramics. Journal of the Ceramic Society of Japan, v. 115, n. 7, pp. 395-401, 2007.

HUTCHINGS, I., M., Tribology - friction and wear of engineering materials, London: Edward Arnold, 1992.

HWANG, C. S.; LIN, W. H. Preparation and sinterability of zirconia-toughened alumina composite powder. Nippon Seramikkusu Kyoukai Gakujutsu Ronbunshi, v. 99 , n. 4 , pp. 271-275, 1991.

JAHANMIR, S. Friction and wear of ceramics. New York: Marcel Dekker, 1994.

JENG, M.-C., YAN, L.-Y., Environmental effects on wear of alumina, Wear, v. 161, pp. 111-119, 1993.

JI, W.; PARKER, B.; FALCO, S. et al. Ultra-fast firing: Effect of heating rate on sintering of $3 Y S Z$, with and without an electric field. Journal of the European Ceramic Society. v. 37, pp. 2547-2551, 2017.

KATO, K.; ADACHI, K., Wear of advanced ceramics, Wear, v. 253, pp. 1097-1104, 2002.

KERKWIJK, B. Wear and friction of nanostructured zirconia and alumina ceramics and composites. 1999, 127 f. Tese (Doutorado) - Faculdade de Engenharia e Tecnologia, Universidade de Twente, Enschede, 1999. Disponível em: <https://research.utwente.nl/en/publications/>. Acesso em: 24 jul. 2017. 
KERN, F.; PALMERO, P. Microstructure and mechanical properties of alumina $5 \%$ vol zirconia nanocomposites prepared by powder coating and powder mixing routes. Ceramics International, v. 39, pp. 673-682, 2013.

KIHARA, M.; OGATA, T.; NAKAMURA, K.; KOBAYASHI, K. Effects of $\mathrm{Al}_{2} \mathrm{O}_{3}$ addition on mechanical properties and microstructures of Y-TZP. Journal of the Ceramic Society of Japan, v. 96, n. 6, pp. 646-653, 1988.

KIM, B. N.; HIRAGA, K.; MORITA, K.; SAKKA, Y. A high-strain-rate superplastic ceramic. Nature, v. 413, pp. 288-291, 2001.

KINGERY, W. D.; BOWEN, H. K.; UHLMANN, D. R. Introduction to ceramics. 2 ed. New Jersey: Wiley Interscience, 1976.

KOK, D.; JHA, S. K.; RAJ, R.; MECARTNEY, M. L. Flash sintering of a three-phase alumina, spinel and yttria-stabilized zirconia composite. Journal of the American Ceramic Society, v. 100, n. 7, pp. 3262-3268, 2017.

LANGE, F. F. Powder processing science and technology for increased reliability. Journal of the American Ceramic Society, v. 72, n. 1, pp. 3-15, 1989.

LEE, W. E.; RAINFORTH, M. Ceramic Microstructures: Property control by processing. London: Springer, 1994.

LEE, Y. I.; KIM, Y. W.; MITOMO, M.; KIM, D. Y. Fabrication of dense nanostructured silicon carbide through two-step sintering. Journal of the American Ceramic Society, v. 86, n. 10, pp. 1803-1805, 2003.

LI, J.-F.; WATANABE, R. Fracture toughness of $\mathrm{Al}_{2} \mathrm{O}_{3}$-particle-dispersed $\mathrm{Y}_{2} \mathrm{O}_{3}-$ partially stabilized zirconia. Journal of the American Ceramic Society, v. 78, pp. 1079-1082, 1995.

LIBSCH, T. A.; BECKER, P. C.; RHEE, S. K. Dry friction and wear of toughened zirconias and toughened aluminas against steel. Wear, v.110, pp. 263-283, 1986.

LIN, J. D.; DUH, J. G. Fracture toughness and hardness of ceria- and yttria-doped tetragonal zirconia ceramics. Materials Chemistry and Physics, v. 78, pp. 235-261, 2002.

LU, K. Sintering of nanoceramics. International Materials Reviews, v. 53, pp. 2138, 2008.

LUO, J.; ADAK, S.; STEVENS, R. Microstrcuture evolution and grain growth in the sintering of 3Y-TZP ceramics. Journal of Materials Science, v. 33, n. 12, pp. 5301$5309,1998$.

MATTEAZZI, P.; LE CAER, G. Synthesis of nanocrystalline alumina-metal composite by room-temperature ball milling of metallic oxides and aluminum. Journal of the American Ceramic Society, v. 74, n. 6, pp.1382-1390, 1991. 
MAYO, M. J. Processing of nanocrystalline ceramics from ultrafine particles. International Materials Reviews, v. 41, n. 3, pp. 85-115, 1996.

McCORMICK, P. G.; SCHAFFER, G. B. Reduction of metal oxides by mechanical alloying. Applied Physics Letters, v. 55, pp. 45-46, 1989.

MEDEVIELLE, A.; THÉVENOT, F.; TRÉHEUX, D. Wear resistance of stabilized zirconias. Journal of the European Ceramic Society, v. 15, pp. 1193-1199, 1995.

MEDVEDOVSKI, E., Wear-resistant engineering ceramics, Wear, v. 249, pp. 821 828, 2001.

MILAK, P. C.; MINATTO, F. D.; DE NONI JR., A.; MONTEDO, O. R. K. Wear performance of alumina-based ceramics - a review of the influence of the microstructure on erosive wear. Cerâmica, v. 61, pp. 88-103, 2015.

MORAES, M. C. C. S. B.; ELIAS, C. N.; FILHO, J. D.; OLIVEIRA, L. G. Mechanical properties of alumina-zirconia composites for ceramic abutments. Materials Research, v. 7, pp. 643-649, 2004.

MORITA, K.; HIRAGA, K.; KIM, B. N.; YOSHIDA, H.; SAKKA, Y. Fabrication and microstructural characterization of nano-crystalline $\mathrm{ZrO}_{2}$-based composite. Reviews on Advanced Materials Science, v. 10, pp. 39-44, 2005.

MUCCILLO, E. N. S.; MUCCILLO, R. Physical and electrical properties of yttria stabilized zirconia prepared from nano size powders. British Ceramic Transactions, v. 101, n. 6, pp. 259-262, 2002.

MUCCILLO, E. N. S. Condutores de íons oxigênio: uma breve revisão. Cerâmica, v. 54, pp. 129-144, 2008.

MUCCILLO, R.; KLEITZ, M.; MUCCILLO, E. N. S. Flash grain welding in yttria stabilized zirconia. Journal of the European Ceramic Society, v. 31, pp. 15171521, 2011.

MUCCILLO, R.; MUCCILLO, E. N. S.; KLEITZ, M. Densification and enhancement of the grain boundary conductivity of gadolinium-doped barium cerate by ultra fast flash grain welding. Journal of the European Ceramic Society, v. 32, pp. 2311-2316, 2012.

MUCCILLO, R.; MUCCILLO, E.N.S. Light emission during electric field-assisted sintering of electroceramics. Journal of the European Ceramic Society, vol. 35, p. 1653-1656, 2015.

MULLINS, W. W. Theory of thermal grooving. Journal of Applied Physics, v. 28, pp. 333-339, 1957.

MUNIR, Z.; ANSELMI-TAMBURINI, U.; OHYANAGI, M. The effect of electric field and pressure on the synthesis and consolidation of materials: A review of the spark plasma sintering method. Journal of Materials Science, v. 41, pp. 763-777, 2006. 
MUÑOZ, M. C.; GALLEGO, S.; BELTRÁN, J. I.; CERDÁ, J. Adhesion at metal-ZrO2 interfaces. Surface Science Reports, v. 61, pp. 303-344, 2006.

NAIK, K.; SGLAVO, V.M.; RAJ, R. Flash sintering as a nucleation phenomenon and a model there of. Journal of the European Ceramic Society, v. 34, pp. 4065-4067, 2014.

NALWA, H. S. Nanostructured materials and nanotechnology. 2 ed. Academic Press: London, 2002.

NARAYAN, J. A new mechanism for field-assisted processing and flash sintering of materials. Scripta Materialia, v. 69, pp. 107-111, 2013.

NEVAREZ-RASCON, A.; AGUILAR-ELGUEZABAL, A.; ORRANTIA, E.; BOCANEGRA-BERNAL, M. $\mathrm{H}$. On the wide range of mechanical properties of ZTA and ATZ based dental composites by varying the $\mathrm{Al}_{2} \mathrm{O}_{3}$ and $\mathrm{ZrO}_{2}$ content. International Journal of Refractory Metals and Hard Materials, v. 27, pp. 962970, 2009.

NIIHARA, K.; MORENA, R.; HASSELMAN, D. F. H. Evaluation of KIc of brittle solids by the indentation method with low crack-to-indent ratios. Journal of Materials Science, v. 11, pp. 13-16, 1982.

NIIHARA, K.; NAKAHIRA, A. Structural ceramic nanocomposites by sintering method: Roles of nano-size particles. In: Ceramics: Towards the 21st Century. The Ceramic Society of Japan, pp. 404-417, 1991.

NIIHARA, K.; NAKAHIRA, A.; SASAKI, G.; HIRABAYASHI, M. Development of strong $\mathrm{Al}_{2} \mathrm{O}_{3} / \mathrm{SiC}$ composites. Materials Research Society - Znt. Meeting on Advanced Materials, v. 4. Pp. 129-134, 1989.

NYGREN, M.; SHEN, Z. J. On the preparation of bio-, nano- and structural ceramics and composites by spark plasma sintering. Solid State Sciences, v. 5, pp. 125-131, 2003.

OLIVER, W. C.; PHARR, G. M. Measurement of hardness and elastic modulus by instrumented indentation: Advances in understanding and refinements to methodology. Journal of Materials Research, v. 19, pp. 3-20, 2004.

OVID'KO, I. A. Micromechanics of fracturing in nanoceramics. Philosophical Transactions A, v. 373, 20140129, pp. 1-14, 2015.

PABST, W.; HAVRDA, J.; GREGOROVÁ, E.; KRCMOVÁ, B. Alumina toughened zirconia made by room temperature extrusion of ceramic pastes. Ceramics Silikáty, v. 44, n. 2, pp. 41-47, 2000.

PALLONE, E. M. J. A.; TOMASI, R.; BOTTA Fo, W. J. Synthesis of $\mathrm{Al}_{2} \mathrm{O}_{3}-\mathrm{TiC}$ by reactive milling. Materials Science Forum, v. 346, pp. 393-398, 2000. 
PALLONE, E. M. J. A.; TROMBINI, V.; BOTTA Fo, W. J.; TOMASI, R. Synthesis of $\mathrm{Al}_{2} \mathrm{O}_{3}-\mathrm{NbC}$ by reactive milling and production of nanocomposite. Journal of Materials Processing Technology, v. 143, pp. 185,190, 2003.

PALLONE, E. M. J. A.; MARTIN, D. R.; TOMASI, R.; BOTTA Fo, W. J. $\mathrm{Al}_{2} \mathrm{O}_{3}-W C$ synthesis by high-energy reactive milling. Materials Science and Engineering A, v. 464, pp. 47-51, 2007.

PASARIBU, H. R.; SLOETJES, J. W.; SCHIPPER, D. J., The transition of mild to severe wear of ceramics, Wear, v. 256, pp. 585-591, 2004.

PĘDZICH, Z. Tungsten Carbide as an Reinforcement in Structural Oxide-Matrix Composites. In: LIU, K. (Ed.) Tungsten Carbide - Processing and Applications. Rijeka: InTech, 2012.

POORTEMAN, M.; DESCAMPS, P.; CAMBIER, F.; LERICHE, E.; THIERRY, B. Hot isostatic pressing of SiC-platelets/Y-TZP. Journal of the European Ceramic Society, v. 12, pp. 103-109, 1993.

PRASAD, D. H.; KIM, H. R.; PARK, J. S.; SON, J. W.; KIM, B. K.; LEE, H. W.; LEE, J. H. Superior sinterability of nano-crystalline gadolinium doped ceria powders synthesized by co-precipitation method. Journal of Alloys and Compounds, v. 495, pp. 238-241, 2010.

PRETTE, A. L. G.; COLOGNA, M.; SGLAVO, V.; RAJ, R. Flash sintering of $\mathrm{Co}_{2} \mathrm{MnO}_{4}$ spinel for solid oxide fuel cell applications. Journal of Power Sources, v. 196, pp. 2061-2065, 2011.

RAHAMAN, M. N. Ceramic Processing and Sintering. 2 ed. New York: Marcel Dekker, 2003.

RAHAMAN, M. N. Sintering of Ceramics. Taylor \& Francis: New York, 2007.

RAJ, R. Joule heating during flash-sintering. Journal of the European Ceramic Society, v. 32, pp. 2293-2301, 2012.

RAJ, R.; COLOGNA, M.; FRANCIS, J. S. C. Influence of externally imposed and internally generated electrical fields on grain growth, diffusional creep, sintering and related phebnomena in ceramics. Journal of the American Ceramic Society, v. 94, n. 7, pp. 1941-1965, 2011.

RAJ, R.; COLOGNA, M.; PRETTE, A. L. G. Methods of flash sintering. Aplicação de patente: US 13/562.040, 2013.

RAJENDRAN, S.; SWAIN, M. V.; ROSSELL, H. J. Mechanical properties and microstructures of co-precipitation derived tetragonal $\mathrm{Y}_{2} \mathrm{O}_{3}-\mathrm{ZrO}_{2}-\mathrm{Al}_{2} \mathrm{O}_{3}$ composites. Journal of Materials Science, v. 23, pp. 1805-1812, 1988. 
RIBEIRO, S.; GÊNOVA, L. A.; RIBEIRO, G. C.; OLIVEIRA, M. R.; BRESSIANI, A. H. A. Effect of temperature and heating rate on the sintering performance of $\mathrm{SiC}-\mathrm{Al}_{2} \mathrm{O}_{3}$ $\mathrm{Dy}_{2} \mathrm{O}_{3}$ and $\mathrm{SiC}-\mathrm{Al}_{2} \mathrm{O}_{3}-\mathrm{Yb}_{2} \mathrm{O}_{3}$ systems. Ceramics International, v. 43, n. 18, pp. 16048-16054, 2017.

ROTH, R.; NEGAS, T.; COOK, L. Phase diagrams for ceramists. Columbus: The American Ceramic Society, 1981, v. 4, p. 117.

RYU, S. S.; PARK, H. R.; KIM, H. T.; KIM, Y. D. On sinterability of Cu-coated W nanocomposite powder prepared by a hydrogen reduction of a high-energy ballmilled $\mathrm{WO}_{3}-\mathrm{CuO}$ mixture. Journal of Materials Science, v. 47, pp. 7099-7109, 2012.

SALEM, R. E. P.; MONTEIRO, F. R.; GUTIÉRREZ-GONZÁLEZ, C. F.; BORRELL, A.; SALVADOR, M. D.; CHINELATTO, A. S. A.; CHINELATTO, A. L.; FERREIRA, J. A.; PALLONE, E. M. J. A. Effect of $\mathrm{Al}_{2} \mathrm{O}_{3}-\mathrm{NbC}$ incorporation on the mechanical properties of $3 \mathrm{Y}-\mathrm{TZP} / \mathrm{Al}_{2} \mathrm{O}_{3}-\mathrm{NbC}$ nanocomposites obtained by conventional and spark plasma sintering. Ceramics International, v. 44, n. 2, pp. 2504-2509, 2018.

SÁNCHEZ-GONZÁLEZ, E.; MIRANDA, P.; GUIBERTEAU, F.; PAJARES, A. Effect of microstructure on the mechanical properties of liquid-phase-sintered silicon carbide at pre-creep temperatures. Journal of the European Ceramic Society, v. 31, pp. 1131-1139, 2011.

SANTOS, C.; MAEDA, L. D.; CAIRO, C. A. A.; ACCHAR, W. Mechanical properties of hot-pressed $\mathrm{ZrO}_{2}-\mathrm{NbC}$ ceramic composites. International Journal of Refractory Metals and Hard Materials, v. 26, pp. 14-18, 2008.

SASAKI, S. Tribochemistry in friction and wear of ceramics. Japanese Journal of Tribology, v. 36, pp. 699-707, 1991.

SCHAFFER, G. B.; McCORMICK, P. G. Displacement reactions during mechanical alloying. Metallurgical Transactions A, v. 21, pp. 2789-2794, 1990.

SCHERM, F.; VÖLKL, R.; NEUBRAND, A.; BOSBACH, F.; GLATZEL, U. Mechanical characterization of interpenetrating network metal-ceramic composites. Materials Science and Engineering A, v. 527, pp. 1260-1265, 2010.

SCHNEIDER, J.; BEGAND, S; KRIEGEL, R.; KAPS, C.; GLIEN, W.; OBERBACH, T. Low-temperature aging behavior of alumina-toughened zirconia. Journal of the American Ceramic Society, v. 91, pp. 3613-3618, 2008.

SCOTT, H. G. Phase relationships in the zirconia-yttria system. Journal of Materials Science, v. 10, n. 9, pp. 1527-1535, 2006.

SHACKELFORD, J. F.; DOREMUS, R. H. Ceramic and Glass Materials: Structure, Properties and Processing. New York: Springer, 2008.

SHEVCHENKO, A. S.; LYUTIKOV, R. A.; ANDRIEVSKII, R. A.; TEREHKOVA, V. A. Oxidation of zirconium and niobium carbides. Poroshkovaya Metallurgiya, v. 205, pp. 64-69, 1980. 
SHI, J. L.; GAO, J. H.; LIN, Z. X.; YAN, D. S. Effect of agglomerates in $\mathrm{ZrO}_{2}$ powder compacts on microstructural development. Journal of Materials Science, v. 28, n. 2, pp. 342-348, 1993.

SHIMADA, S. A kinetic and thermoanalytical study on oxidation of powder and single-crystal samples of niobium carbide. Oxidation of Metals, v. 42, pp. 357-373, 1994.

SHIMADA, S.; INAGAKI, M. A kinetic study on oxidation of niobium carbide. Solid State lonics, v. 63-65, pp. 312-317, 1993.

SILVA, J. G. P.; YAMCHELOU, A.N.; DEBRIS, A.; WIECK, C.; JELITTO, H.; ALQURESHI, H. A.; JANSSEN, R. Mechanical strength and defect distributions in flash sintered 3YSZ. Journal of the European Ceramic Society. v. 37, pp. 2901-2905, 2017.

STERNITZKE, M. Review: Structural ceramic nanocomposites. Journal of the European Ceramic Society, v. 17, pp. 1061-1082, 1997.

STOLOFF, N. S.; ALMAN, D. E. Processing and properties of MoSi2-Nb composites. Ceramics International, v. 21, pp. 289-292, 1995.

SŌMIYA, S.; YAMAMOTO, N.; YANAGIDA, H. Science and Technology of Zirconia III. Columbus: American Ceramic Society, 1988.

STACHOWIAK, G. W.; STACHOWIAK, G. B. Stachowiak. Unlubricated wear and friction of toughened zirconia ceramics at elevated temperatures. Wear, v. 143, pp. 277-295, 1991.

STACHOWIAK, G.; ANDREW, W.; BATCHELOR, W. Engineering Tribology. Oxford: Elsevier, 2001.

STEIL, M. C.; MARINHA, D.; AMAN, Y. GOMES, J. R. C.; KLEITZ, M. From conventional ac flash-sintering of YSZ to hyper-flash and double flash. Journal of the European Ceramic Society, v. 33, pp. 2093-2101, 2013.

SUMITOMO CHEMICALS. Product Databook (Excerpt: High Purity Alumina HPA). Disponível em: <http://www.sumitomo-chem.co.jp>. Acesso em: 20 ago 2015.

SURYANARAYANA, C. Mechanical alloying and milling. Progress in Materials Science, v. 46, pp. 1-184, 2001.

SUZUKI, H. Y.; SHINOZAKI, K.; KUROKI, H.; TASHIMA, S. Sintered microstructure and mechanical properties of high purity alumina ceramics made by high-speed centrifugal compaction process. Key Engineering Materials, v. 159-160, pp. 187192, 1999.

TAGUCHI, M. Application of high-technology ceramic in Japanesse automobiles. Advanced Ceramic Materials, v. 3, n. 4, 9p. 1759-1762, 1987. 
TAKACS, L. Reduction of magnetite by aluminum: a displacement reaction induced by mechanical alloying. Materials Letters, v. 13, pp. 119-124, 1992.

TAKACS, L. Nanocomposite formation and combustion induced by reaction milling. Materials Research Society - Symposium Proceedings, v. 286, pp. 413-418, 1993.

TEDESCO, N. R. Caracterização do comportamento de desgaste de cerâmicas de alumina densa: Efeitos de parâmetros de ensaio do tipo pino no disco. 2010, 231 f. Dissertação (Mestrado em Engenharia de Materiais) - Programa de Pós-Graduação em Ciência e Engenharia de Materiais, Universidade de Federal de São Carlos, São Carlos, 2010.

TEKELI, S. The solid solubility of $\mathrm{Al}_{2} \mathrm{O}_{3}$ and its effect on densification and microstructural evolution in cubic-zirconia used as an electrolyte for solid oxide fuel cell. Materials and Design, v. 28, pp. 713-716, 2007.

TERAUDS, K.; LEBRUN, J. M.; LEE, H. H.; JEON, T. Y.; LEE, S. H.; JE, J. H.; RAJ, $R$. Electroluminescence and the measurement of temperature during stage III of flash sintering experiments. Journal of the European Ceramic Society, v. 35, pp. 31953199, 2015.

THEUNISSEN, G. S. A. M.; WINNUBST, A. J. A.; BURGGRAAF, A. J. Sintering kinetics and microstructure development of nano scale Y-TZP ceramics. Journal of the European Ceramic Society, v. 11, n. 4, pp. 315-324, 1993.

THÜMMLER, F.; OBERACKER, R. Introduction to powder metallurgy. London: The Institute of Materials, 1993. pp. 305-306.

TODD, R. I.; ZAPATA-SOLVAS, E.; BONILLA, R. S.; SNEDDON, T.; WILSHAW, P. $R$. Electrical characteristics of flash sintering: thermal runaway of Joule heating. Journal of the European Ceramic Society, v. 35, pp. 1865-1877, 2015.

TODD, R. I. Flash sintering of ceramics: a short review. In: LEE, B.; GADOW, R.; MITIC, V. Proceedings of the IV Advanced Ceramic and Applications Conference. Paris: Atlantis Press, pp.1-12, 2017.

TOSOH. Advanced Materials: Zirconia Powders. Disponível em: <http://www.tosoh.com>. Acesso em: 20 ago 2015.

TROMBIN, F.; RAJ, R. Developing processing maps for implementing flash sintering into manufacture of whiteware ceramics. American Ceramic Society Bulletin, v. 93, pp. 32-35, 2014.

TROMBINI, V.; BRESSIANI, A. H. A.; PALLONE, E. M. J. A.; TOMASI, R. Otimização dos processos de moagem e secagem do pó de alumina/TiC obtido por moagem reativa. Cerâmica, v. 57, pp. 416-421, 2011.

TSE, A. W. C.; LAWSON, S.; GILL, C. Low amplitude oscillatory wear of Y-TZP in various environments. In: Proceedings of the $8^{\text {th }}$ CIMTEC, 1994. 
TSUKAMOTO, $\mathrm{H}$. Micromechanical modeling of transformation toughening in multiphase composites enriched with zirconia particles. Computational Materials Science, v. 48, pp. 724-729, 2010.

UEHARA, J. L. H. S. Estudo de materiais com gradiente funcional (MGF) à base de alumina $\left(\mathrm{Al}_{2} \mathrm{O}_{3}\right)$ e carbeto de nióbio $(\mathrm{NbC})$ obtidos por diferentes técnicas de sinterização. 2015, 124 f. Dissertação (Mestrado em Ciência e Engenharia de Materiais) - Programa de Pós-Graduação em Ciência e Engenharia de Materiais, Escola de Engenharia de São Carlos, Universidade de São Paulo, São Carlos, 2015.

VASYLKIV, O.; SAKKA, Y.; SKOROKHOD, V. V. Hardness and fracture toughness of alumina-doped tetragonal zirconia with different yttria contents. Materials Transactions, v. 44, n. 10, pp. 2235-2238, 2003.

VLEUGELS, J.; VAN DER BIEST, O. $\mathrm{ZrO}_{2}-\mathrm{TiX}$ composites. Key Engineering Materials, v. 132-136, pp. 2064-2067, 1997.

VLEUGELS, J.; YUAN, Z. X.; VAN DER BIEST, O. Mechanical properties of $\mathrm{Y}_{2} \mathrm{O}_{3} / \mathrm{Al}_{2} \mathrm{O}_{3}$-coated $\mathrm{Y}$-TZP ceramics. Journal of the European Ceramic Society, $v$. 22, pp. 873-881, 2002.

WAHI, R. P.; ILSCHNER, B. Fracture behavior of composites based on $\mathrm{Al}_{2} \mathrm{O}_{3}-\mathrm{TiC}$. Materials Science and Engineering, v. 15, pp. 875-885, 1980.

WANG, C. J.; HUANG, C. Y.; WU, Y. C. Two-step sintering of fine alumina-zirconia ceramics. Ceramics International, v. 35, n. 4, pp. 1467-1472, 2009.

WANG, D.; LI, J; MAO, Z. Study of abrasive wear resistance of transformation toughened ceramics, Wear, v. 165, pp. 159-167, 1993.

WANG, Z.; NAKAMURA, T. Simulations of crack propagation in elastic-plastic graded materials. Mechanics of Materials, v. 36, pp. 601-622, 2004.

WANG, J.; STEVENS, R. Zirconia-toughened alumina (ZTA) ceramics. Journal of Materials Science, v. 24, pp. 3421-3440, 1989.

WANG, Y. C.; FU, Z. Y. Study of temperature field in spark plasma sintering. Materials Science and Engineering B, v. 90, pp. 34-37, 2002.

WANG, S. W.; CHEN, L. D.; HIRAI, T.; KANG, Y. S. Microstructure inhomogeneity in $\mathrm{Al}_{2} \mathrm{O}_{3}$ sintered bodies formed during the plasma-activated sintering process. Journal of Materials Science Letters, v. 18, pp. 1119-1121, 1999.

WANG, Y., HSU, S. M., The effects of operating parameters and environment on the wear and wear transition of alumina, Wear, v. 195, pp. 90-99, 1996.

WEN, S.; YAN, D. Grain boundary in some nano-materials. Ceramics International, v. 21, pp. 301-303, 1995. 
WOYDT, M.; KLAFFKE, D.; HABIG, K.-H.; CZICHOS, H. Tribological transition phenomena of ceramic materials. Wear, v. 136, pp. 373-381, 1990

WOYDT, M.; KADOORI, J.; HABIG, K.-H.; HAUSNER, H. Unlubricated sliding behaviour of various zirconia based ceramics. Journal of the European Ceramic Society, v. 7, pp. 135-145, 1991.

YAMAMOTO, T.; KITAURA, H.; KODERA, Y.; ISHII, T.; OHYANAGI, M.; MUNIR, Z. A. Consolidation of nanostructured $\beta$-SiC by spark plasma sintering. Journal of the American Ceramic Society, v. 87, n. 8, pp. 1436-1441, 2004.

YU, M.; GRASSO, S.; McKINNON, R.; SAUNDERS, T.; REECE, M. J. Review of flash sintering: materials, mechanisms and modeling. Advances in Applied Ceramics, v. 116, pp. 1-37, 2017.

ZAPATA-SOLVAS, E.; BONILLA, S.; WILSHAW, P. R.; TODD, R. I. Preliminary investigation of flash sintering of $\mathrm{SiC}$. Journal of the European Ceramic Society, v. 33, pp. 2811-2816, 2013.

ZAPATA-SOLVAS, E.; GOMES-GARCÍA, D.; DOMINGUEZ-RODRIGUES, A.; TODD, R. I. Ultra-fast and energy efficient sintering of ceramics by electric current concentration. Scientific Reports, v. 5, artigo $\mathrm{n}^{\circ}$ 8513, 2015. DOI: 10.1038/srep08513.

ZENG, P.; ZAJAC, S.; CLAPP, P. C.; RIFKIN, J. A. Nanoparticle sintering simulations. Materials Science and Engineering A, v. 252, pp. 301-306, 1998.

ZHAN, G. D.; SHI, J. L.; ZHOU, Y.; ZHANG, Y. Z.; LAI, T. R.; YEN, T. S. Fabrication, characterization and mechanical properties of SiC-whisker-reinforced $\mathrm{Y}$-TZP composites. Journal of Materials Science, v. 31, pp. 3237-3243, 1996.

ZHANG, Y.; JUNG, J. I., LUO, J. Thermal runaway, flash sintering and asymmetrical microstructural development of $\mathrm{ZnO}$ and $\mathrm{ZnO}-\mathrm{Bi}_{2} \mathrm{O}_{3}$ under direct currents. Acta Materialia, v. 94, pp. 87-100, 2015.

ZHAO, C.; VLEUGELS, J.; BASU, B.; VAN DER BIEST, O. High toughness Ce-TZP by sintering in an inert atmosphere. Scripta Materialia, v. 43, pp. 1015-1020, 2000.

ZUM GAHR, K. H. Microstructure and Wear of Materials. Tribology Series, v. 10. Amsterdam: Elsevier, 1987.

ZUM GAHR, K.-H. Modelling of two-body abrasive wear. Wear, v. 124, pp. 87-103, 1988.

ZUM GAHR, K.-H. Sliding wear of ceramic-ceramic, ceramic-steel and steel-steel pairs in lubricated and unlubricated contact. Wear, v. 133, n. 1, pp. 1-22, 1989.

ZUM GAHR, K.-H., Wear by hard particles. Tribology International, v. 31, n. 10, pp. 587-596, 1998. 